\title{
REGION-TO-AREA SCREENING METHODOLOGY FOR THE CRYSTALLINE REPOSITORY PROJECT
}

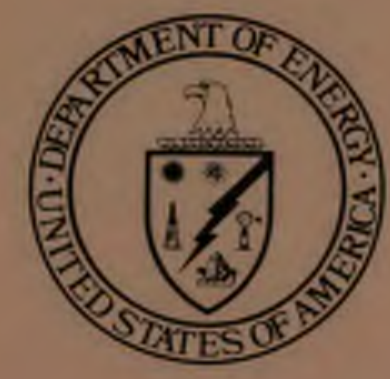

APRIL 1985

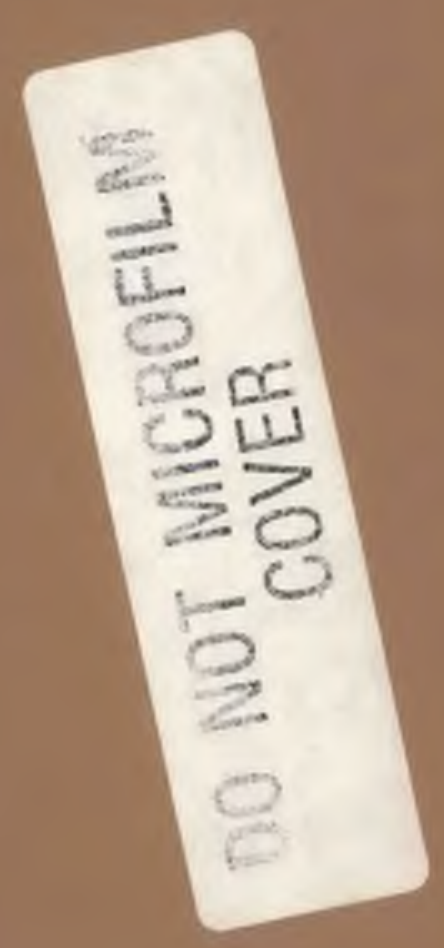

\section{U.S. DEPARTMENT OF ENERGY OFFICE OF CIVILIAN RADIOACTIVE WASTE MANAGEMENT CRYSTALLINE REPOSITORY PROJECT OFFICE}


U.S. Department of Energy, 1985. Region-to-Area Screening Methodology for the Crystalline Repository Project, DOE/CH-1, prepared for the Crystalline Repository Project Office by the Office of Crvstalline Repository Development, Battelle Project Management Division, Argonne, IL.

\section{NOTICE}

This report was prepared as an account of work sponsored by an agency of the United States Government. Neither the United States Government nor any agency thereof, nor any of their employees, makes any warranty, expressed or implied, or assumes any legal liability or responsibility for the accuracy, completeness, or usefulness of any information, apparatus, product, or process disclosed, or represents that its use would not infringe privately owned rights. Reference herein to any specific commercial product, process, or service by trade name, trademark, manufacturer, or otherwise, does not necessarily constitute or imply its endorsement, recommendation, or favoring by the United States Government or any agency thereof. The views and opinions of authors expressed herein do not necessarily state or reflect those of the United States Government or any agency thereof.

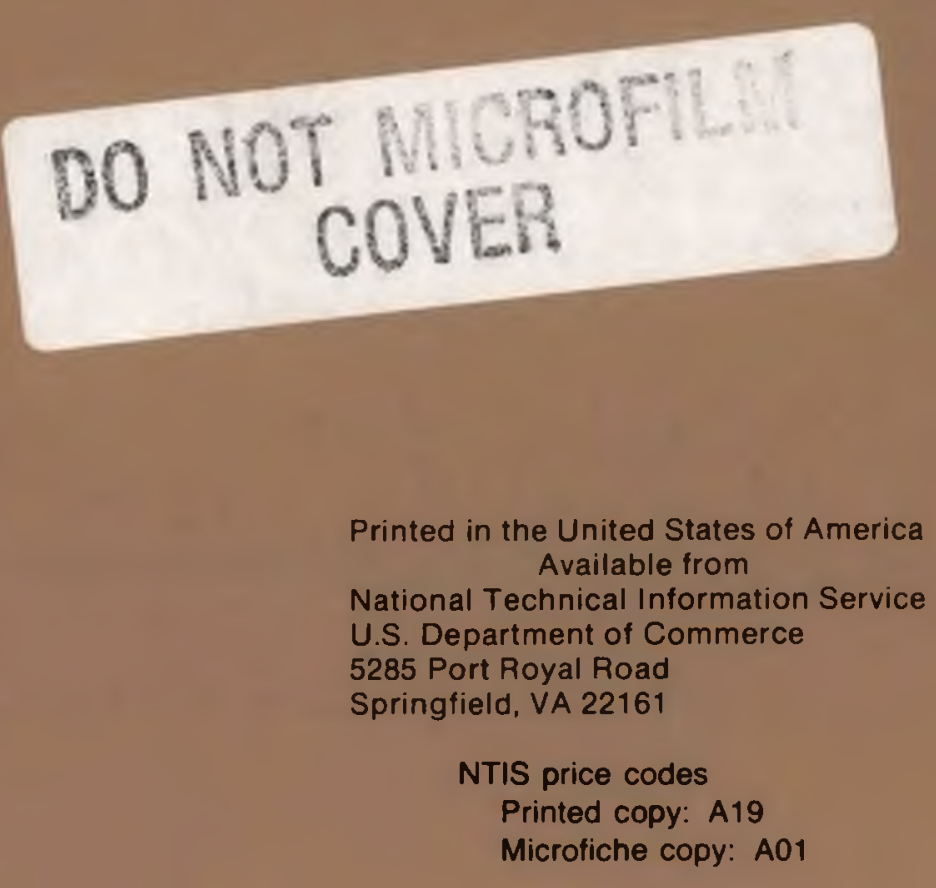




\section{DISCLAIMER}

This report was prepared as an account of work sponsored by an agency of the United States Government. Neither the United States Government nor any agency Thereof, nor any of their employees, makes any warranty, express or implied, or assumes any legal liability or responsibility for the accuracy, completeness, or usefulness of any information, apparatus, product, or process disclosed, or represents that its use would not infringe privately owned rights. Reference herein to any specific commercial product, process, or service by trade name, trademark, manufacturer, or otherwise does not necessarily constitute or imply its endorsement, recommendation, or favoring by the United States Government or any agency thereof. The views and opinions of authors expressed herein do not necessarily state or reflect those of the United States Government or any agency thereof. 


\section{DISCLAIMER}

Portions of this document may be illegible in electronic image products. Images are produced from the best available original document. 
The Crystalline Repository Project (CRP) of the Department of Energy's Civilian Radioactive Waste Management Program is responsible for identifying sites which could be considered by the Department for construction and operation of the second deep geologic repository for permanent disposal of high-level radioactive waste. The CRP is currently evaluating exposed and near surface crystalline rock bodies in three geographic regions in an effort to identify potentially suitable rock bodies for continued evaluations and eventual field investigations. The rock bodies being evaluated are located in the North Central Region, the Northeastern Region, and the Southeastern Region. This document describes the methodology that will be applied by the CRP in conducting the region-to-area screening of the crystalline rock bodies in these three geographic regions. This Region-to-Area Screening Methodology Document for the CRP is complementary to the Regional Geologic and Environmental Characterization Reports which are currently scheduled for release as final reports in the summer of 1985 and will contain the data to be used in the region-to-area screening.

This screening methodology description is a culmination of an approximately twenty-month effort involving extensive interaction between the CRP and representatives from the 17 involved states, and release of a draft document in September 1984. This interaction featured: (i) three workshops to obtain ideas and preferences from state representatives related to the selection and development of geologic and environmental disqualifying factors and screening variables, and to seek an understanding of state concerns regarding the region-to-area screening methodology; and ( $i \mathrm{i}$ ) an opportunity to review and comment on the proposed screening methodology by each of the 17 involved states. The DOE General Guidelines for the Recommendation of Sites for Nuclear Waste Repositories, concurred in by the Nuclear Regulatory Commission on June 22, 1984, and issued by DOE on December 6, 1984, provided the basis for establishing the disqualifying factors and favorable or potentially adverse conditions utilized in this region-to-area screening methodology.

Sections 1.0 through 6.0 of this document provide the basic description of the CRP region-to-area screening methodology. Changes between the draft and final Screening Methodology Document are highlighted in Section 1.2. Also contained within this document is the Department's response to state comment letters received on the draft version of this report (Appendix A). Finally, Appendix B provides the approach to be utilized by the CRP to classify state land type categories for application in the region-to-area screening. 
The region-to-area screening methodology documented in this report will be utilized as a major input to the DOE decision process to identify 15 to 20 candidate areas that will be evaluated and investigated in more detail during the area phase of the CRP.

An Area Recommendation Report (ARR) will document and fully explain the basis for the selection of those areas of exposed and near-surface crystalline rocks which are deemed suitable for area phase investigations. A draft of the ARR will be submitted to states and potentially affected Indian tribes for review and comment, prior to finalization of the selection in the final ARR.

On behalf of the CRP, I would like to extend our expression of appreciation to all of those state representatives who participated in the development of the screening methodology through workshop attendance, reviews of preliminary planning papers, construction of evaluative comments, review of the draft SMD, and discussions or suggestions on numerous aspects thereof.

$$
\text { Dale Q. Yoraum }
$$

Sally A. Mann, Manager

Crystalline Repository Project Office 


\title{
REGION-TO-AREA SCREENING METHODOLOGY FOR THE CRYSTALLINE REPOSITORY PROJECT
}

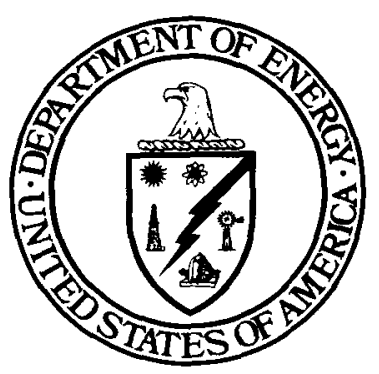

APRIL 1985

\section{DISCLAIMER}

\begin{abstract}
This report was prepared as an account of work sponsored by an agency of the United States Government. Neither the United States Government nor any agency thereof, nor any of their employees, makes any warranty, express or implied, or assumes any legal liability or responsibility for the accuracy, completeness, or usefulness of any information, apparatus, product, or process disclosed, or represents that its use would not infringe privately owned rights. Reference herein to any specific commercial product, process, or service by trade name, trademark, manufacturer, or otherwise does not necessarily constitute or imply its endorsement, recommendation, or favoring by the United States Government or any agency thereof. The views and opinions of authors expressed herein do not necessarily state or reflect those of the United States Government or any agency thereof.
\end{abstract}

\section{U.S. DEPARTMENT OF ENERGY \\ OFFICE OF CIVILIAN RADIOACTIVE WASTE MANAGEMENT CRYSTALLINE REPOSITORY PROJECT OFFICE}

This report was prepared by the Office of Crystalline Repository Development, Battelle Project Management Division, under Contract No. DE-AC02-83CH10139 with the U.S. Department of Energy. 
○ 


\section{FOREWORD}

High-level radioactive waste is produced by both national defense activities and commercial activities and includes spent fuel from nuclear power reactors and solidified waste from reprocessing of commercial reactor fuel. The National Waste Terminal Storage (NWTS) Program was established in 1976 by the Energy Research and Development Administration, the predecessor agency of the U.S. Department of Energy (DOE), to develop the technology and provide the facilities for the safe, environmentally acceptable, permanent disposal of commercial high-level radioactive waste. In 1983, the NWTS Program was retitled the Civilian Radioactive Waste Management (CRWM) Program to further indicate the DOE charge of managing commercial high-level radioactive waste.

Authority and responsibility for carrying out programs for management of high-level radioactive waste are derived from the following Federal laws:

- Atomic Energy Act of 1954, As Amended, 42 USC 2011 et seq.

- Energy Reorganization Act of 1974, 42 USC 5811 et seq.

- Department of Energy Organization Act of 1977, 42 USC 7101 et seq.

- Nuclear Waste Policy Act of 1982, 42 USC 10101 et seq. The Nuclear Waste Policy Act of 1982 (NWPA), enacted January 7, 1983 as Publ ic Law 97-425, confirmed the responsibility of the DOE for management of highlevel radioactive waste. The NWPA directed the DOE to provide safe facilities for isolation of high-level radioactive waste from the environment in federally owned and federally licensed repositories. Detailed policies, plans, and technical guidance for the CRWM Program have been presented in numerous other public documents. References to those documents which are most pertinent are made throughout this text, and lists of cited references and statutes and regulations are included.

The CRWM Program emphasizes deep underground disposal in excavated repositories which will be located in geologically stable bodies of rock. Rock types currently being considered include bedded salt deposits, salt domes, basalt, tuff, and crystalline rocks. These rock types are being analyzed at different localities within the conterminous United States under the following four distinct, but coordinated, projects: 
- The Salt Repository Project for bedded salt deposits and salt domes

- The Basalt Waste Isolation Project for basalt

- The Nevada Nuclear Waste Storage Investigations for tuff

- The Crystalline Repository Project for crystalline rocks.

Al though the four projects are distinct and focus on four different rock types, comparable technical activities are applied in each project for site evaluation, field and laboratory testing, technology development, and repository and waste package design. The process for siting the geologic repositories is defined in the NWPA, including a sequence of steps which forms the basis for the strategy to achieve operation of a safe and environmentally sound, licensed geologic repository by 1998.

The NWPA requires that the DOE recommend to the President, from at least five nominated sites, three candidate sites for characterization as possible locations for the first Federal repository. The rock types being considered as potential hosts for the first repository include salt, basalt, and tuff. This process is to be repeated for the second repository. Current DOE plans, as described in the Draft Mission Plan (DOE, 1984j) dated April 1984, provide that the President is to recommend the first repository site to Congress by June 1990.

The DOE's strategy for the second repository is to carry out the second repository siting process through acquisition of a construction authorization from the U.S. Nuclear Regulatory Commission. In addition to crystalline rocks, potential host rocks for the second repository include salt, tuff, and basalt, since the NWPA permits sites characterized for the first repository, but not selected as the repository site, to be nominated. The DOE will proceed with a plan to achieve the earliest date attainable for second repository operation consistent with requirements. However, the DOE will wait until the early 1990s to request Congressional approval for construction of the second repository. At that time, the DOE will use the best information available to match the requirements with the construction schedules in order to determine the best date for operational startup. Current estimates indicate that the second repository would begin operation about 6 years after the first repository if the DOE proceeds at the fastest pace possible, while at the same time accommodating all relevant safety issues. The two 
repositories, each with a planned 70,000-metric ton capacity, will accommodate all commercial wastes anticipated to be generated through 2020. In accordance with Section 8 of the NWPA, a decision is currently pending concerning whether the two repositories also will be used to dispose of defense wastes. 
- 


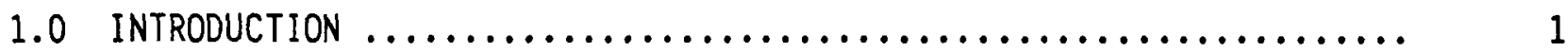

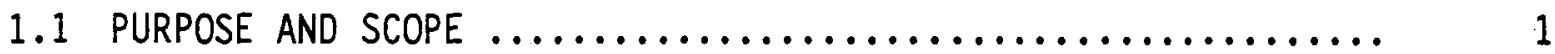

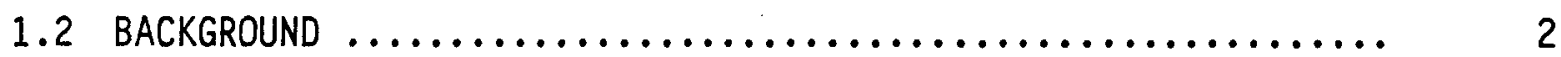

1.3 FEDERAL LAW AND REGULATORY CRITERIA ................... 4

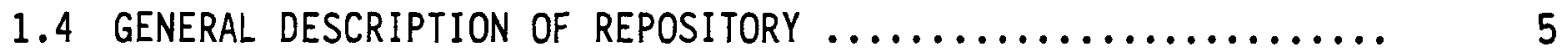

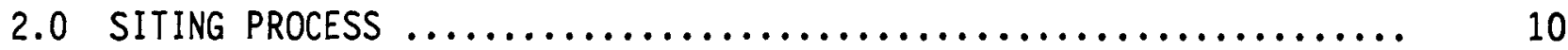

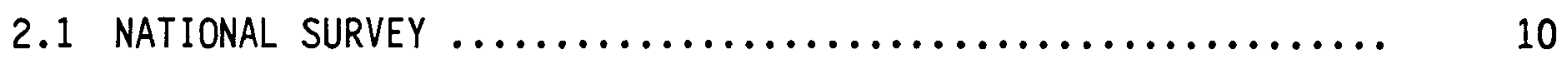

2.2 REGION-TO-AREA SCREENING PROCESS $\ldots \ldots \ldots \ldots \ldots \ldots \ldots \ldots \ldots \ldots . \ldots \ldots$

2.3 AREA SCREENING AND SITE NOMINATION AND

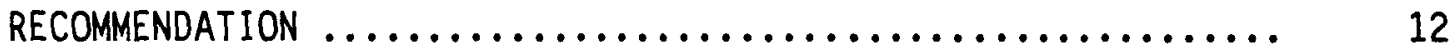

3.0 REGION-TO-AREA SCREENING PROCESS $\ldots \ldots \ldots \ldots \ldots \ldots \ldots \ldots \ldots \ldots \ldots \ldots \ldots \ldots \ldots \ldots$

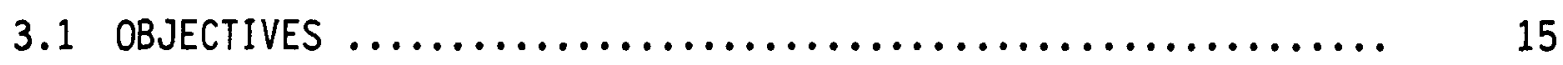

3.2 REGION-TO-AREA SCREENING METHODOLOGY .................... 17

3.2.1 Step 1 - The Disqualifying Factors' Screen ........... 17

3.2.2 Step 2 - The Scaled Regional Variables Screen ........ 19

3.2.3 Description and Role of the Weighting Process ........ 26

3.2.3.1 Selecting Workshop Participants .......... 36

3.2.3.2 The Weighting Process ................ 37

3.2.3.3 Preparation of Participant Orientation Material ................. 37

3.2.3.4 Conduct of the Weighting Workshops ......... 38

3.2.3.5 Documentation and Use of Weighting Workshop Results ..................... 43

3.2.4 Composite Map Development ..................... 44

3.2.5 Step 3 - Sensitivity Analyses .................. 45

3.2.5.1 Modifying Variable Scales .............. 45

3.2.5.2 Using Alternative Index of Aggregate Favorability................. 47

3.2.5.3 Evaluating Different Sets of Weights by Preparing Summary Composite Maps .......... 50 3.2.5.4 Incorporating Step 3 Variables ............ 51 
TABLE OF CONTENTS

(Continued)

3.3 SELECTING CANDIDATE AREAS AND IDENTIFYING

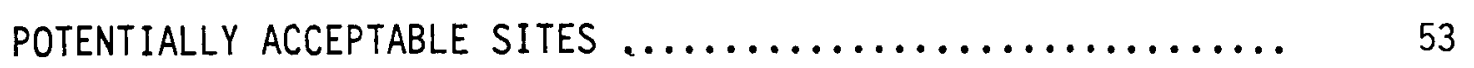

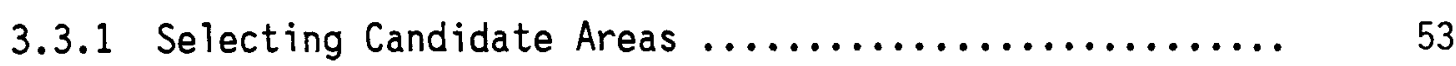

3.3.2 Identifying Potentially Acceptable Sites ........... 55 4.0 GUIDELINES USED IN REGION-TO-AREA SCREENING $\ldots \ldots \ldots \ldots \ldots \ldots \ldots \ldots \ldots$

4.1 DISQUALIFYING FACTORS FROM THE DOE

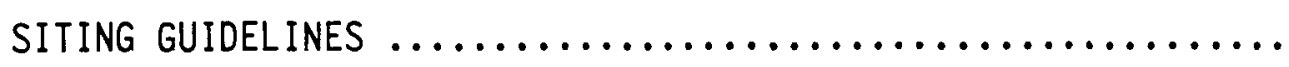

$\underline{\text { Page }}$ 3 55

4.2 IMPLEMENTATION GUIDELINES RELATED TO

REGION-TO-AREA SCREENING $\ldots \ldots \ldots \ldots \ldots \ldots \ldots \ldots \ldots \ldots \ldots$

4.3 POSTCLOSURE GUIDELINES RELATED TO

REGION-TO-AREA SCREENING $\ldots \ldots \ldots \ldots \ldots \ldots \ldots \ldots \ldots \ldots \ldots$

4.4 PRECLOSURE GUIDELINES RELATED TO

REGION-TO-AREA SCREENING

5.0 REGIONAL SCREENING FACTORS AND VARIABLES $\ldots \ldots \ldots \ldots \ldots \ldots \ldots \ldots \ldots$

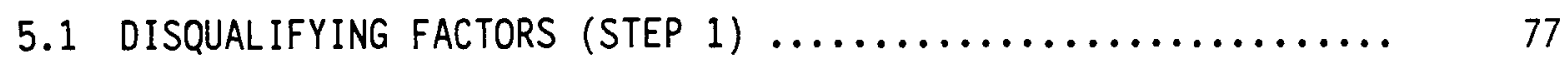

5.1 .1 Federal-Protected Lands ...................... 77

5.1 .2 Components of the National Forest Lands ........... 80

5.1.3 State-Protected Lands ........................ 82

5.1 .4 Population Density and Distribution .............. 84

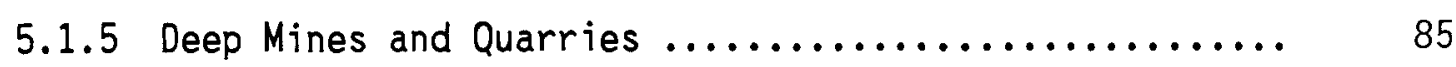

5.2 SCALED GEOLOGICAL VARIABLES (STEP 2) $\ldots \ldots \ldots \ldots \ldots \ldots \ldots \ldots \ldots \ldots \ldots \ldots \ldots \ldots \ldots \ldots \ldots$

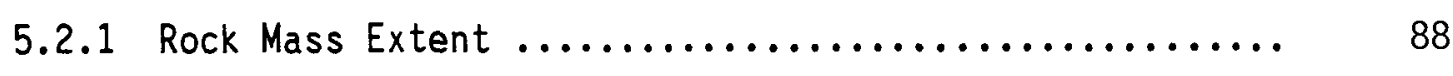

5.2 .2 Major Ground-Water Discharge Zones .............. 92

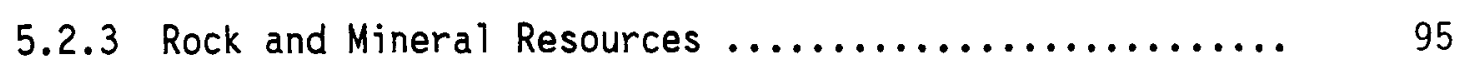

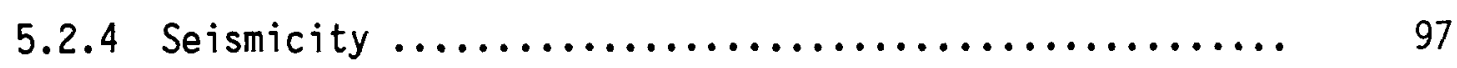

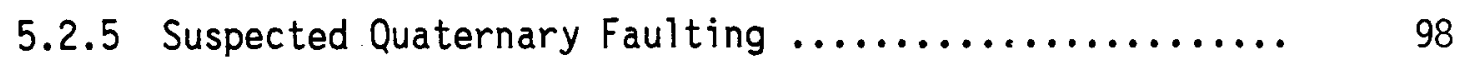

5.2 .6 Postemplacement Faulting $\ldots \ldots \ldots \ldots \ldots \ldots \ldots \ldots \ldots . \ldots \ldots$ 
TABLE OF CONTENTS

(Continued)

5.3 SCALED ENVIRONMENTAL VARIABLES (STEP 2) $\ldots \ldots \ldots \ldots \ldots \ldots \ldots . \ldots 100$

5.3.1 Proposed Federa1-Protected Lands .................. 101

5.3.2 Population Density ............................... 104

5.3.3 Proximity to Federal-Protected Lands ............... 106

5.3.4 Proximity to State-Protected Lands ................. 107

5.3.5 National Forest Lands ............................. 108

5.3.6 State Forest Lands ............................. 109

5.3.7 Designated Critical Habitat for

Threatened and Endangered Species ................ 110

5.3 .8 Wetlands .................................... 111

5.3.9 Surface Water Bodies ....................... 113

5.3.10 Proximity to Highly Populated Areas

or to 1-Mile-Square Areas with 1,000

or More Persons.............................. 116

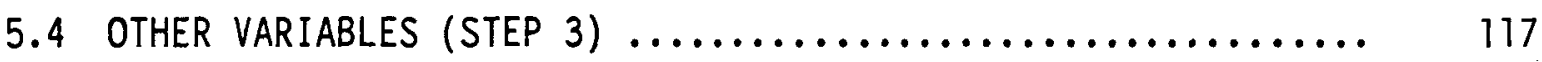

5.4.1 Thickness of Rock Mass ......................... 118

5.4 .2 Thickness of Overburden ........................ 119

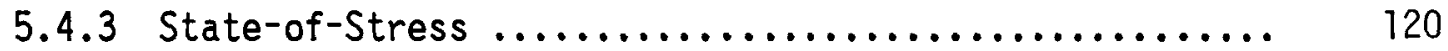

5.4 .4 Ground-Water Resources ....................... 122

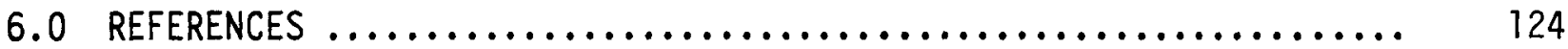

APPENDIX A State Comments on Draft Region-to-Area Screening

Methodology Document and CRP Responses ............... A-1

APPENDIX B Summaries of State-Protected Lands ................... B-1 
Figure 1. Schematic Layout of Areas at a Repository Site ........... 7

Figure 2. Artist's Concept of a Geologic Repository ................ 8

Figure 3. Crystalline Repository Project Report Schedule Leading to Initiation of Area Phase Field Work ........... 13

Figure 4. Examples of Hypothetical Disqualifying Factor Maps ....... 20

Figure 5. A Composite of Hypothetical Disqualifying Factor Maps Overlain on Hypnthetical Rock Bodies ............... 21

Figure 6. Example of Conversion of Polygonal to Gridded Data: Hypothetical Rock Bodies .......................... 23

Figure 7. Hypothetical Data Bases for a Subset of Geologic and Environmental Screening Variables .....................

Figure 8. Favorability Maps for Hypothetical Application of Environmental/Socioeconomic Step 2 Variables .............

Figure 9. Favorability Maps for Hypothetical Application of Geologic Step 2 Variables ............................

Figure 10. Favorability Maps for Hypothetical Application of Environmental/Socioeconomic Step 2 Variables ...........

Figure 11. Demonstration of the Composite Favorability

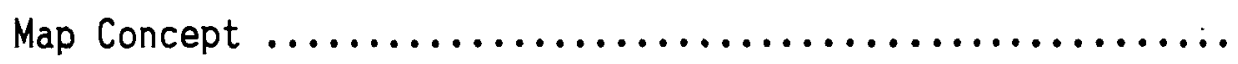

Figure 12. Summary Composite Favorability Greater Than 4.5 with Hypothetical Rock Bodies ...........................

Figure 13. Schematic Diagram of Drainage Basin, Showing the Major Stream (Ground-Water Discharge Zone) and Drainage Divide 


\section{LIST OF TABLES}

Page

Table 1. Example of the Point Allocation Approach to

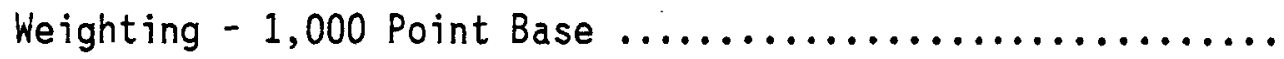

Table 2. Original and Modified Scales for Step 2 Variables:

Rock Mass Extent, Seismicity, and Proximity to

Highly Populated Areas or 1-Mile-Square Areas

with 1,000 or More Persons

Table 3. Summary of Disqualifying Conditions from the DOE

Siting Guidelines (10 CFR 960) and Applicability

in Region-to-Area Screening of Those

Conditions Requiring Findings 


\subsection{INTRODUCTION}

\subsection{PURPOSE AND SCOPE}

The purpose of this document is to describe the Crystalline Repository Project's (CRP) process for region-to-area screening of exposed and nearsurface crystalline rock bodies 1 in the three regions of the conterminous United States where crystalline rock is being evaluated as a potential host for the second nuclear waste repository (i.e., in the North Central, Northeastern, and Southeastern Regions). This document indicates how the U.S. Department of Energy's (DOE) "General Guidelines for the Recommendation of Sites for Nuclear Waste Repositories" (10 CFR 960) ${ }^{2}$ were used to select and apply factors ${ }^{3}$ and variables ${ }^{4}$ for the region-to-area screening, explains how these factors and variables are to be applied in the region-to-area screening, and indicates how this methodology relates to the decision process leading to the selection of candidate areas.

1The following definitions are used by the CRP for "exposed and near-surface" and "crystalline rocks":

"Exposed and near-surface" is defined as not being covered by pre-Quaternary rocks. Consequently, overlying alluvium, colluvium, glacial outwash, till, saprolite, regolith, or similar materials will not be cause for exclusion of rock bodies.

"Crystalline rocks" are defined as intrusive igneous and high-grade metamorphic rocks, rich in silicate minerals, with a grain size sufficiently coarse that individual minerals can be distinguished with the unaided eye. 2 The DOE "General Guidelines for the Recommendation of Sites for Nuclear Waste Repositories" (DOE, 1984a), will henceforth be referred to in this document as the DOE Siting Guidelines.

3The term "factor" or "disqualifying factor" is used throughout the text to refer to disqualifying conditions in the DOE Siting Guidelines.

"The term "variable" or "region-to-area screening variable" is used to refer to potentially adverse or favorable conditions in the DOE Siting Guidelines. 
A brief general discussion of the screening process from the national survey through area screening and site recommendation is presented in Chapter 2.0. This discussion sets the scene for detailed discussions which follow concerning the region-to-area screening process (Chapter 3.0), the guidance provided by the DOE Siting Guidelines for establishing disqualifying factors and variables for screening (Chapter 4.0), and application of the disqualifying factors and variables in the screening process (Chapter 5.0). This document is complementary to the regional geologic and environmental characterization reports to be issued in the summer of 1985 as final documents. These reports will contain the geologic and environmental data base that will be used in conjunction with the methodology to conduct region-to-area screening.

Appendix A summarizes the comments received from the states on the draft version of this document along with the CRP responses to each comment or to each cluster of related comments. Finally, Appendix B provides the approach to be utilized by the CRP to classify state-protected land type categories for application in the region-to-area screening.

\subsection{BACKGROUND}

The CRP will soon be conducting region-to-area screening, the methodology for which is discussed in detail in this document. Previous activities of the CRP conducted prior to the finalization of this document are discussed below.

The national survey of crystalline rocks resulted in a report (OCRD, 1983) which recommended that exposed and near-surface crystalline rocks in three regions of the conterminous United States be further explored for highlevel radioactive waste repository sites. These three regions, the North Central, Northeastern, and Southeastern Regions, comprise a total of 17 states, each of which contains areas which have exposed and near-surface crystalline rock bodies. These are the regions for which available geologic and environmental data were collected and presented in the draft regional geologic and environmental characterization reports (ANL, 1984a,b; ORNL, 1984a,b; PNL, 1984; WCC, 1984). State review of these draft reports resulted in the preparation of revised draft regional geologic and environmental characterization reports (DOE, 1984c-h) which were issued in December 1984 for 
state review and comment. These reports, when finalized, will document the data base for Steps 1 through 3 of region-to-area screening. Through state comments and cooperation, additional data were provided for incorporation into these reports. A comment response document (DOE, 1984b) was issued simultaneously with the issuance of the revised draft regional geologic and environmental characterization reports (DOE, $1984 \mathrm{c}-h$ ) to address state comments on the May 1983 draft characterization reports.

State workshops to discuss the region-to-area screening methodology including applicable factors and variables were conducted in June 1983, November 1983, and February 1984. These workshops provided an opportunity for representatives from the 17 crystalline states to comment on the region-toarea screening process and to present their ideas and preferences on screening factors and variables. In addition, drafts of this report (DOE, 1984i) were issued to the 17 states for review and comment. Many of their comments have been incorporated into this document, although it should be understood that consensus was not sought or attained through this consultation process.

Major changes reflected in this document occur in two primary areas: 1) modification to Step 1 disqualifying factors and to Steps 2 and 3 variables, and 2) modifications to aspects of the screening process. The geologic disqualifying factor, Hydrologically Significant Natural Resources, has been revised (and renamed) to include only deep mines and quarries. The environmental screening variable, State Wildlife Lands, has been eliminated and the State-Owned Wildlife Lands variable will be incorporated into the StateProtected Lands disqualifying factor. (Treatment of non-state-owned wildlife land has been deferred to subsequent phases.) The scales for four geologic variables have been changed (two Step 2 [Ground-Water Discharge Zones and Postemplacement Faulting] and two Step 3 [Thickness of Overburden and GroundWater Resources]).

As part of the Step 3 sensitivity analysis, scales of three variables (Rock Mass Extent, Seismicity, and Proximity to Highly Populated Areas or to 1-Mile-Square Areas with 1,000 or More Persons) were modified. The CRP plans to develop an equally weighted summary composite map for use in the screening process. Based on input from the states at a DOE-states meeting in October, 1984 in Atlanta, Georgia, the second workshop will be comprised of only representatives from the 17 crystalline states. Finally, additional text and 
descriptive information has been provided in Section 3.3 (Selecting Candidate Areas and Identifying Potentially Acceptable Sites).

Issuance of the DOE Siting Guidelines, as directed by the Nuclear Waste Policy Act of 1982 (NWPA), provided the basis for finalizing the region-toarea disqualifying factors and screening variables (favorable and potentially adverse conditions) presented in this document. The DOE Siting Guidelines based disqualifying factors, screening variables., and implementation guidelines applicable to region-to-area screening are incorporated into the region-to-area screening process as described in Chapters 4.0 and 5.0.

\subsection{FEDERAL LAW AND REGULATORY CRITERIA}

The NWPA provides for the development of repositories for the disposal of high-level radioactive waste and spent nuclear fuel, and establishes a program for research, development, and demonstration relating to this disposal. Section $112(a)$ of the NWPA requires that guidelines be developed by the DOE for use by the Secretary of Energy in evaluating the suitability of sites to be recommended as candidates for development of repositories. The DOE siting Guidelines were developed in accordance with the requirements set forth for their preparation in the NWPA and were issued by the Secretary of Energy after concurrence by the U.S. Nuclear Regulatory Commission (NRC), as 10 CFR 960. As previously stated, they provide the basis for CRP to select and apply those factors and variables to be used in region-to-area screening.

The DOE Siting Guidelines are consistent with the requirements defined in the licensing procedures for disposal of high-level radioactive waste in geologic repositories, issued by the NRC as 10 CFR 60 (NRC, 1981; 1982; 1983), and with the proposed environmental radiation protection standards for management and disposal of high-level radioactive waste, issued by the U.S. Environmental Protection Agency (EPA) as proposed 40 CFR 191 (EPA, 1982).

Section 112(a) of the NWPA allows for revisions to the DOE Siting Guidelines as required. Revisions to 10 CFR 60 by the NRC, or to proposed 40 CFR 191 by the EPA, will result in appropriate revisions to the DOE Siting Guidelines. All revisions to the DOE Siting Guidelines will require the concurrence of the NRC in accordance with 10 CFR 960.1. 


\subsection{GENERAL DESCRIPTION OF A REPOSITORY}

The overall purpose of the deep, mined geologic repository is to provide for the long-term containment and isolation of radioactive waste. The geologic and hydrologic characteristics of the sites serve as the primary safety features to prevent the release of radioactive waste to the environment. Additional protection to the environment is ensured by the design, construction, and operation of the facilities for waste receipt and handling, the waste package, facilities for underground emplacement of the packaged waste, and the provisions for backfilling the excavations and sealing off all entries. Design of a repository in crystalline rock will proceed from conceptual designs to preliminary and final designs. The designs will be based on overall performance constraints such as maximum waste temperature and maximum induced rock stresses that will ensure safe operation. The depth and general layout of the repository facilities are dependent upon the geology and hydrology of the site. While the conceptual design will be based on existing crystalline rock properties and field data obtained in the area phase, the preliminary and final designs will make full use of data obtained subsequently from in situ characterization activities at the recommended sites.

The waste types to be considered in the design process for receipt at the second repository are more fully described in the report "Generic Requirements for a Mined Geologic Disposal System," (DOE, 1984k). This document states that wastes to be received are spent fuel and, should the President so decidel, defense high-level waste. For early conceptual design purposes, the wastes are assumed to be brought to the facility by rail or truck in licensed, shielded shipping casks. At the repository, the wastes will be unloaded, inspected, sorted, and packaged in the surface facilities. Once the wastes have been packaged, they will be placed in transfer casks and transported underground for final disposal. Disposal operations cease when the disposal capacity (waste from about 70,000 metric tons of heavy metal) of the repository has been reached. The repository is to be designed so that any or all of the emplaced waste could be retrieved on a reasonable schedule starting at any

$1_{A}$ Presidential decision regarding comingling of commercial and defense highlevel waste in geologic repositories is pending as per NWPA, Section 8. 
time up to 50 years after emplacement operations are initiated, unless a different time period is approved or specified by the NRC. Following a decision to close the repository, backfilling of the underground workings with some relatively impermeable material will be completed and all shafts and boreholes will be sealed. During this process, all facilities will be decontaminated, dismantled, and decommissioned.

Figure 1 shows a schematic layout of areas at a repository site. Figure 2 shows an artist's concept of the surface facilities and underground disposal rooms. Conceptual designs for nuclear waste repositories in other rock types have shown that the surface facilities will occupy approximately 160 hectares ( 400 acres). Depending on the mode of underground emplacement of waste packages, the underground facility may occupy about 810 hectares $(2,000$ acres). The crystalline rock mass at the recommended site should have sufficient thickness and lateral extent to provide a zone of undisturbed rock surrounding the underground facility. Conditions that permit the emplacement of waste at a minimum depth of 300 meters ( 984 feet) from the ground surface are considered favorable siting conditions by both the NRC [10 CFR $60.122(b)(5)]$ and the DOE [10 CFR 960.4-2-5(b)(1)]. Favorable rock mass depth conditions can readily be met for the crystalline rocks being considered by the CRP because they are deep-seated masses that generally extend downward for thousands of meters.

It is anticipated that there will be restrictions on surface and subsurface activities in these facility areas for purposes of protecting individuals from exposure to radiation and radioactive materials. A controlled area, marked by suitable monuments, will extend horizontally no more than 10 kilometers ( 6 miles) in any direction from the outer boundary of the underground facility. However, the DOE Siting Guidelines and the NRC (10 CFR 60) allow for the designation of a smaller controlled area if the EPA standards for radioactive releases to the accessible environment can be met in a shorter distance (proposed 40 CFR 191, EPA, 1982). The size of the controlled area at a given site will ultimately depend on the rate of groundwater flow and other site characteristics and will be finalized on a sitespecific basis after completion of site characterization studies to ensure that releases to the accessible environment will not exceed those permitted by the EPA. Estimates of the size of the controlled area will be made earlier, 


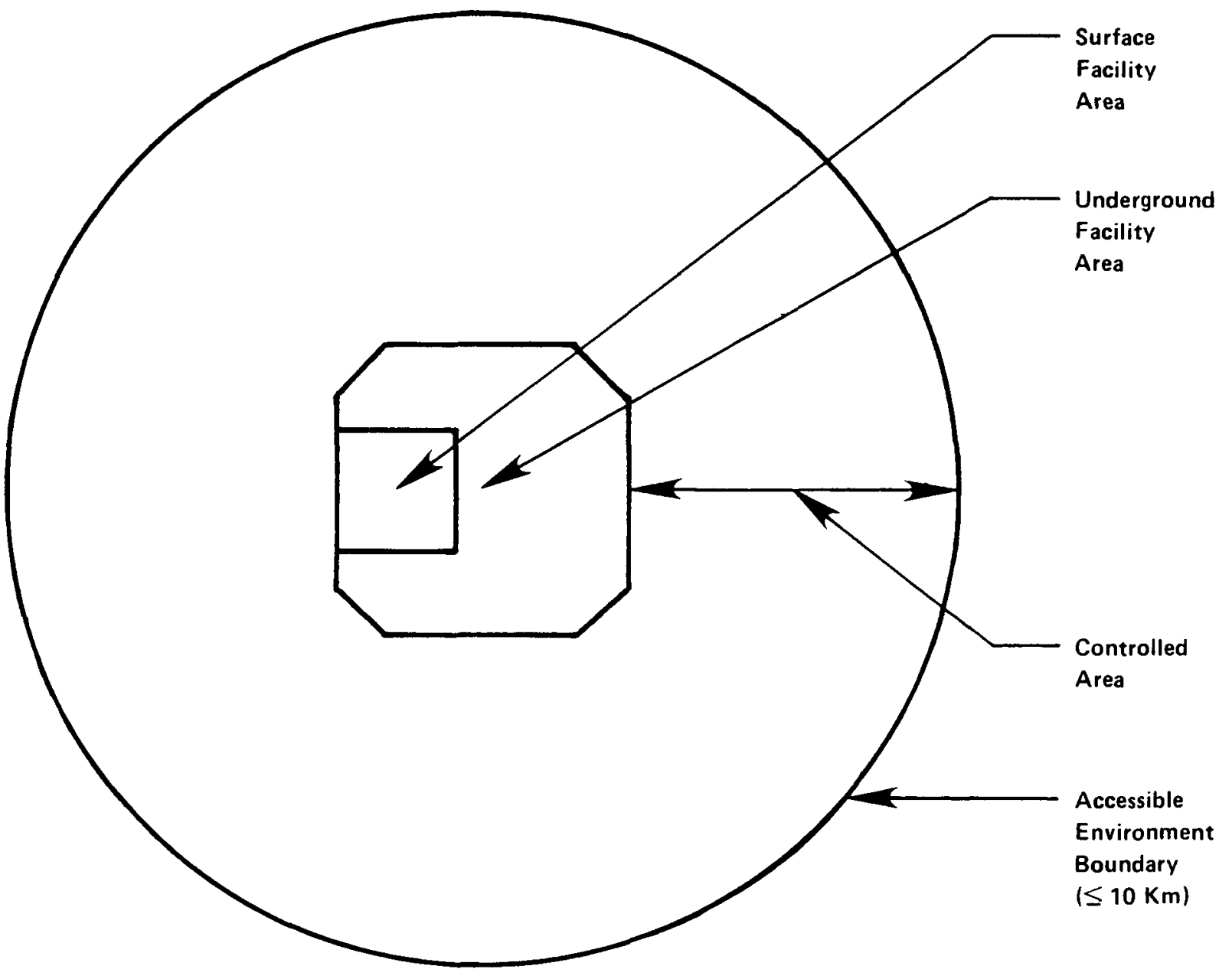

Figure 1 Schematic Layout of Areas at a Repository Site 


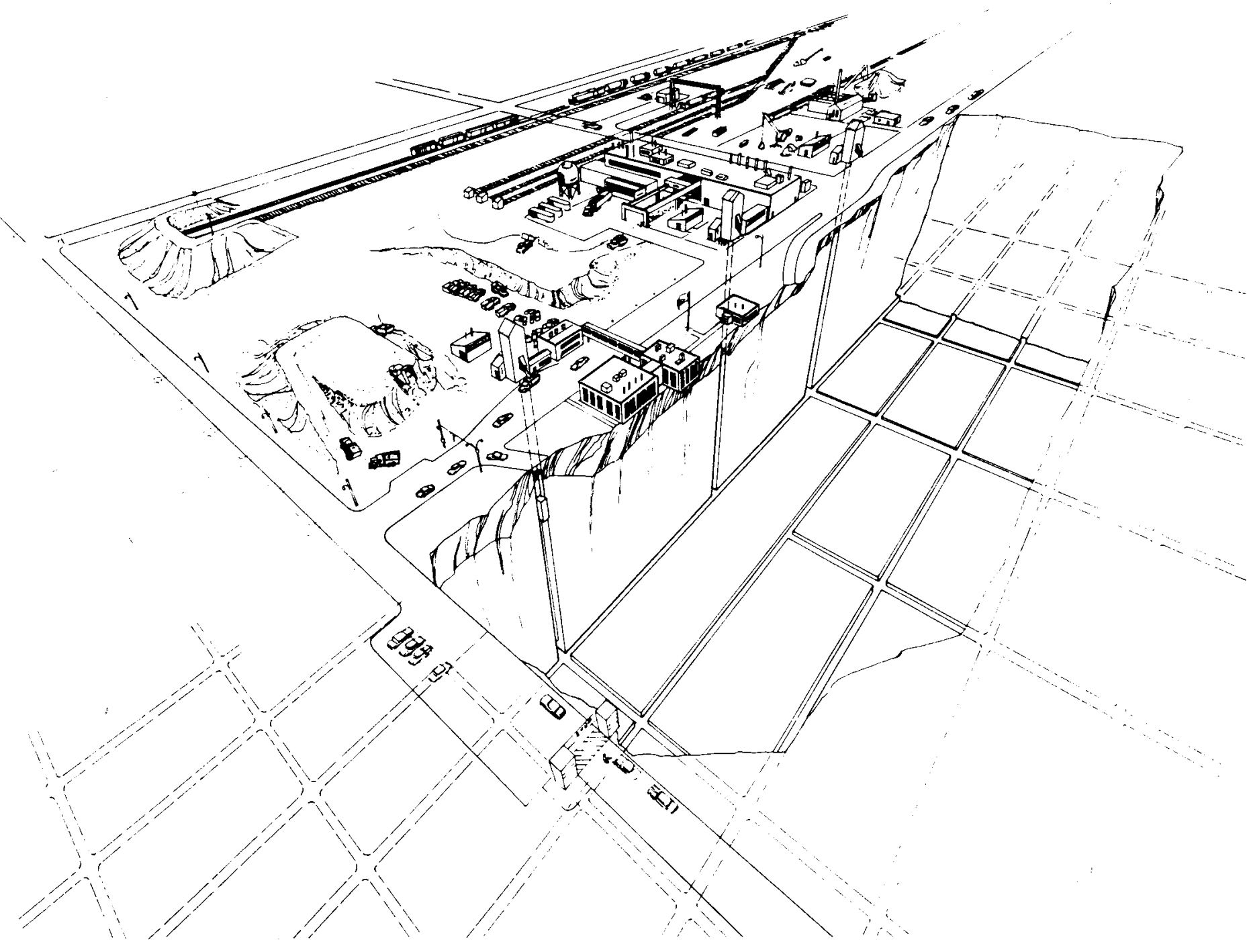

Figure 2 Artist's Concept of a Geologic Repository 
as part of area-phase investigations. Incompatible activities (e.g., deep mining) will be prohibited in the controlled area both before and after permanent closure of the repository. 


\subsection{SITING PROCESS}

\subsection{NATIONAL SURVEY}

Section 960.3-2-1 of the U.S. Department of Energy (DOE) Siting Guidelines (DOE, 1984a) directs that the screening process for determining potentially acceptable sites for the second repository should begin with screening activities on large land masses that contain suitable rock with features favorable for waste containment and isolation. The national survey of crystalline rocks, presented as report BMI/OCRD-1 by the Office of Crystalline Repository Development (OCRD, 1983), was conducted as a reconnaissance of available geologic literature on large regions of exposed and near-surface crystalline rocks in the conterminous United States. The requirement that only exposed or near-surface crystalline rocks would be considered was the initial criterion established by the Crystalline Repository Project (CRP) which determined where subsequent screening efforts would be concentrated. The survey evaluated the suitability of rocks in those regions as potential sites for repositories and recommended regions of exposed and near surface crystalline rocks for further evaluation for possible repository sites.

Other criteria used in the national survey were taken from draft regulations of the U.S. Nuclear Regulatory Commission (NRC) (NRC, 1981). These criteria included consideration of the following factors on a national scale:

- size of rock mass

- vertical movements

- faulting

- earthquakes

- seismically induced ground motion

- quaternary volcanic rocks

- mineral deposits

- high-temperature convective ground-water systems

- hydraulic gradients incorporating regional topographic variations

- erosion.

The national survey resulted in the recommendation that further studies be conducted to investigate exposed and near-surface crystalline rocks in the Lake Superior region (i.e., the North Central Region), the northern 
Appalachians and Adirondacks (i.e., the Northeastern Region), and the southern Appalachians (i.e., the Southeastern Region). Consequently, the national survey provided the basis for selection of the three regions in which region-toarea screening will be conducted to select areas for continued studies. Seventeen states with exposed and near-surface crystalline rock bodies are included in the three regions as stated below:

- North Central Region

Michigan, Minnesota, Wisconsin

- Northeastern Region

Connecticut, Maine, Massachusetts, New Hampshire, New Jersey, New York, Pennsylvania, Rhode Island, Vermont

- Southeastern Region

Georgia, Maryland, North Carolina, South Carolina, Virginia.

\subsection{REGION-TO-AREA SCREENING PROCESS}

Section 960.3-2-1 of the DOE Siting Guidelines requires that the process to determine potentially acceptable sites (PAS) shall be developed in consultation with the involved states and shall focus on smaller, more suitable land units by first using applicable disqualifying conditions from the guidelines, and then by using applicable favorable and potentially adverse conditions. 1 This consultation with the involved states over the development of the region-to-area screening methodology is described in Section 1.2 of this document. The intent of the region-to-area screening is to narrow the geographic focus of the CRP within the three study regions to approximately 15 to 20 candidate areas that will be investigated and evaluated in more detail during the area phase.

The data base to be used in Steps 1 through 3 of region-to-area screening to narrow the number of exposed and near-surface crystalline rock bodies currently under consideration will be presented in the final regional geologic and environmental characterization reports to be issued in the summer of 1985.

1For a discussion of the identification of PAS, see Sections 3.1 and 3.3. 
The data have been taken from existing literature and in some cases directly provided by the 17 crystalline states.

An area recommendation report (ARR) will document the selection of those areas of exposed and near-surface crystalline rocks which are deemed suitable for area-phase investigations. A draft of the ARR will be submitted to states and potentially affected Indian tribes for review and comment. The governors and legislators of those states which contain candidate areas and the tribal representative of any potentially affected Indian tribe will be notified by the DOE that these candidate areas have been selected for further investigation including field work in the area phase of the CRP.

\subsection{AREA SCREENING AND SITE NOMINATION AND RECOMMENDATION}

The focus of area-phase efforts will be the acquisition of new geologic, environmental, and socioeconomic data in the candidate areas that are identified as a result of region-to-area screening.

The area screening process also will use the DOE Siting Guidelines as the basic criteria for identifying candidate sites, although the approach will not be the same as that used in the region-to-area screening described in this document. The area characterization plan (ACP) will identify those conditions from the DOE Siting Guidelines which will be used to reduce the number and size of areas under consideration. Identification of these conditions will dictate the data collection and field work that will be conducted during the area phase. The major objective of the ACP will be to describe the plans for the acquisition of field data. The approach for area screening will be developed in consultation with the involved states and potentially affected Indian tribes, and a draft ACP will be issued for their review and comment. The final ACP will be issued prior to the initiation of area-phase field investigations. Figure 3 summarizes the CRP report schedule up to the beginning of area-phase field work.

Acquisition and evaluation of these data will make it possible to further evaluate crystalline rock areas and to nominate candidate sites in crystalline rock which are suitable to be included in the Secretary of Energy's recommendation to the President of sites which should undergo detailed site characterization as potential second repository sites. In accordance with 


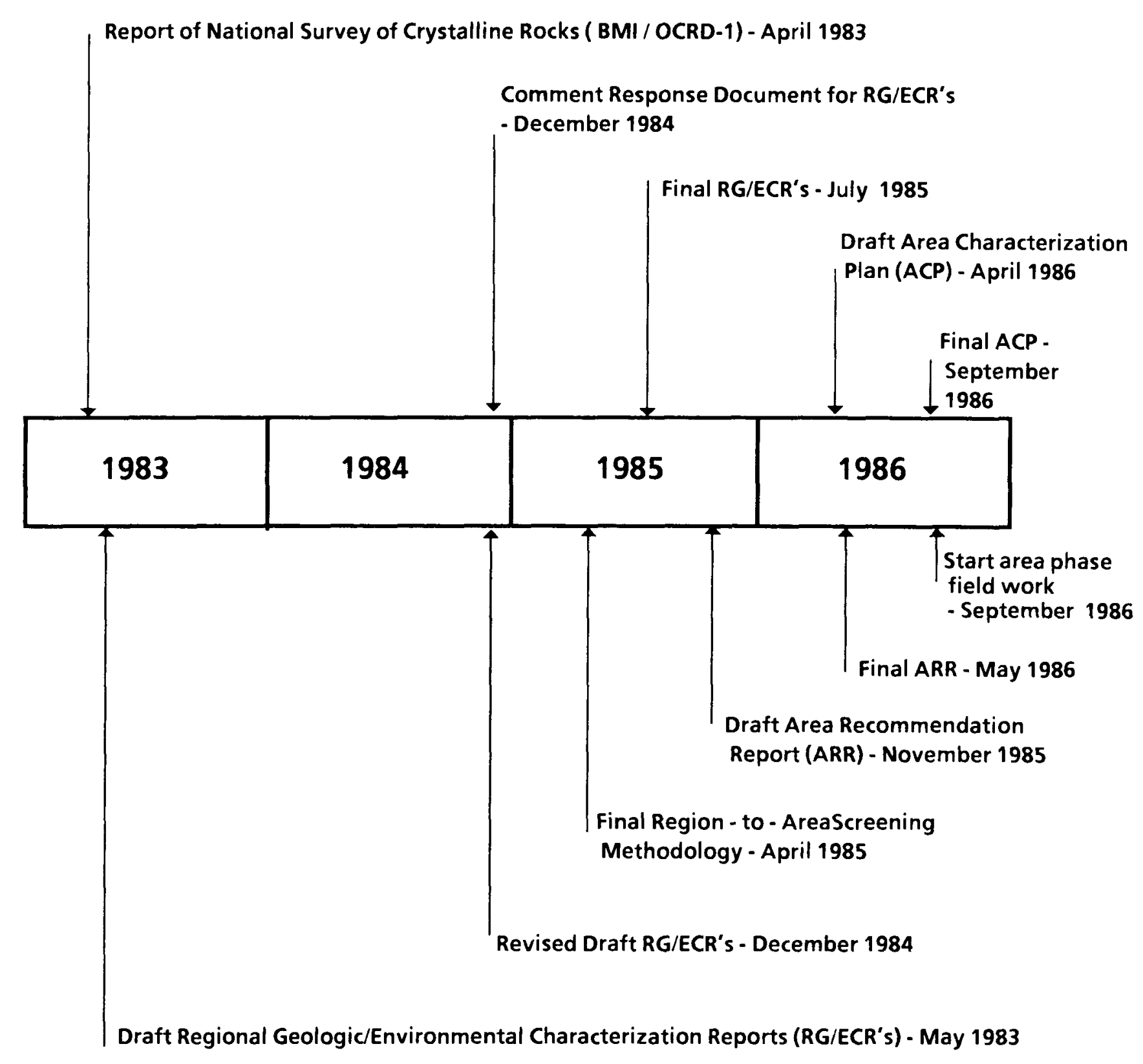

Figure 3 Crystalline Repository Project Report Schedule Leading to Initiation of Area-Phase Field Work 
current DOE planning, this recommendation to the President is scheduled to be made in 1991. Presidential approval of any of the crystalline rock sites as a potential second repository would result in more detailed site characterization work at the approved site or sites for approximately 4 to 6 years; be followed by the President's recommendation to Congress of a single ef for location of the second repository in 1997. 


\subsection{REGION-TO-AREA SCREENING PROCESS}

\subsection{OBJECTIVES}

The purpose of region-to-area screening is to narrow the number of exposed and near-surface crystalline rock bodies within the 17 crystalline states of the North Central, Northeastern, and Southeastern Regions to determine which areas will be investigated and evaluated in more detail during the area phase. In the event that DOE elects to identify potentially acceptable sites (PAS) at the beginning of the area phase, the region-to-area screening process has also been designed to allow the results to be utilized as the basis for such identification in accordance with 10 CFR 960.3-2-1. In the event that the Crystalline Repository Project (CRP) does not identify PAS in the area recommendation report (ARR), a separate decision-basis document would be developed during the area phase that describes the process and considerations that lead to the identification of all or any portion of candidate areas as PAS in accordance with the requirements of 10 CFR 960.3-2-1. The CRP will proceed into the area phase whether or not PAS are identified in the ARR.

The region-to-area screening process ${ }^{1}$ is designed to use regionally applicable data to identify areas with the highest likelihood of containing licensable sites. While subsequent field investigations will determine whether these areas actually contain sites which are potentially suitable for nomination, recommendation, and detailed site characterization, results of the region-to-area screening will indicate the most suitable areas for conducting these field investigations.

\footnotetext{
${ }^{1}$ As used in this document, the region-to-area screening process includes: Step 1, the disqualifying factors screen; Step 2, the scaled regional variables screen; Step 3, sensitivity analysis; and the selection of candidate areas in accordance with Subpart B - Implementation Guidelines of the DOE Siting Guidelines.
} 
The region-to-area screening methodology was developed to incorporate the following characteristics into the screening process:

- A systematic approach that has a logical progression of steps which indicate a trackable process and includes input from, and consultation with, state representatives and peer review groups.

- A consistent approach that includes equitable treatment of all 17 crystalline states in the screening process through the use of a reasonably consistent regional data base and sensitivity analyses. Sensitivity analyses improve the technical defensibility of the approach and the results.

- A comprehensive approach which uses regionally applicable disqualifying factors and screening variables in compliance with the DOE Siting Guidelines (DOE, 1984a) for selection of candidate areas and to serve as the basis for the identification of PAS in the event that DOE elects to identify PAS at the beginning of the area phase.

The approach used in the region-to-area screening methodology consists of a three-step process:

- Step 1 - This step directly uses the applicable disqualifying conditions called out by the DOE Siting Guidelines. This will eliminate certain rock bodies or portions of rock bodies from any further consideration.

- Step 2 - This step uses the applicable potentially adverse and favorable conditions called out by the DOE Siting Guidelines as scaled regional screening variables to identify the most suitable rock bodies (candidate areas) that warrant further analys is in subsequent screening phases. As described in Section 3.2.3, weighting workshops will be held to establish individual weights for Step 2 variables to indicate their relative importance. This weighting helps discriminate the most suitable rock bodies (candidate areas) from alternative points of view on the importance of the variables.

- Step 3 - This step (sensitivity analyses) is designed to accomplish four major objectives. The first is to explore the implications of modifying variable scales in the selection of rock bodies (candidate areas). The second is to evaluate the 
effects of using the geometric mean as an alternate index of aggregate favorability. The third is to evaluate the effects of utilizing different sets of weights for the variables by preparing and comparing summary composite maps. The fourth is to allow further differentiation by incorporating other geologic variables based upon available rock body-specific data.

The Step 1 disqualifying factors and Step 2 scaled variables selected for use in the region-to-area screening are part of the regional data base compiled for all 17 crystalline states from available data provided by the states and other sources. Step 3 variables will be used in the sensitivity analyses to assess the effects of incorporating data on geologic variables for which few data exist, but which still may aid in the selection of rock bodies (candidate areas) for further investigation.

Not all provisions prescribed by the DOE Siting Guidelines are applicable to the region-to-area screening either because the data to support the use of some disqualifying, potentially adverse, and favorable conditions will not be available until field data are collected in subsequent screening phases or because existing data in the literature are not appropriate for use on a regional scale. It is important to note that all provisions, including qualifying conditions, will be thoroughly and systematically applied in later screening or decision phases.

\subsection{REGION-TO-AREA SCREENING METHODOLOGY}

\subsubsection{Step 1 - The Disqual ifying Factors' Screen}

The first step in the region-to-area screening methodology is to directly apply the five DOE Siting Guidelines based disqualifying factors that have sufficient regional data in a form which permits their incorporation into Step 1, without evaluation/interpretation, in order to eliminate rock bodies, or portions of rock bodies from further consideration. The presence of a single disqualifying factor is sufficient to ensure permanent el imination during this phase or in subsequent phases. It should be noted, however, that the definitions, measures, scales, and assumptions utilized for region-to-area screening will not be identical to those utilized in later screening phases since the acquisition of more specific information will allow the CRP to 
further refine its application of these factors (disqualifying conditions). It should be further noted that, except for the disqualifying factor Deep Mines and Quarries, the disqualification of rock bodies, or portions thereof during Step 1 only precludes the location of ( $i$ ) the surface facility or (ii) the restricted area or repository support facilities, as appropriate within the boundaries of the disqualified areas.

Appendix III of the DOE Siting Guidelines specifies that 10 of these 17 disqualifying conditions must be applied to determine if a site is potentially acceptable. With respect to each of these 10 conditions, it must be determined whether or not the available evidence supports a finding of disqualification. Five of the 10 disqualifying conditions will be used by the CRP in Step 1. If a candidate area is to be identified as a PAS, a "finding" per Appendix III of the DOE Siting Guidelines that the evidence does not support disqualification must be made for each of these 10 disqualifying conditions. The results of Step 1 and additional evaluations (as described in Section 3.3) will provide the basis for the findings. The requisite findings will be documented in the ARR. The five disqualifiers not used in Step 1 of the region-to-area screening methodology do not have sufficient regional data in a form which allows their systematic application without evaluation/ interpretation. Chapter 4.0 of this document discusses the disqualifying conditions not used in Step 1 in more detail.

The disqualifying factors which can be used in Step 1 of the region-toarea screening are as follows:

- Geologic Disqualifying Factor

- Deep Mines and Quarries [10 CFR 960.4-2-8-1(d)(1)]

- Environmental-Socioeconomic Disqualifying Factors

- Federa 1-Protected Lands [10 CFR 960.5-2-5(d)(2)]

- State-Protected Lands [10 CFR 960.5-2-5(d)(3)]

- Population Density and Distribution [10 CFR 960.5-2-1(d)(1),(d)(2)]

- Components of the National Forest Lands [10 CFR 960.5-2-5(d)(3)].

The disqualifying factors screen will be accomplished by using data presented in the final regional characterization reports (RCR) to prepare maps that show the geographic distribution of the five disqualifiers in each of the 
17 crystalline states. A map will then be prepared for each of the three CRP regions which includes all regionally applicable disqualifiers. These maps will identify rock bodies or portions of rock bodies which will be eliminated from further consideration. Disqualified areas mapped during Step 1 of the methodology must be at least 130 hectares ( 320 acres) in size because of the scale at which regional-phase work is being conducted. If a feature is in excess of 130 hectares ( 320 acres) but, because of its orientation, it does not exceed 130 hectares ( 320 acres) in any single grid cell, the feature is assigned to the grid cell in which the centroid of the feature is located. Disqualifying features smaller than 130 hectares ( 320 acres) in size will also lead to disqualification within the boundaries of such features in subsequent phases and the location of such features will be evaluated to assess their impact on selection of candidate areas (see Section 3.3.1). The final RCR will contain lists of those features smaller than 130 hectares ( 320 acres) that have been identified.

Figures 4 and 5, which were adapted from the "Presentation of a Hypothetical Application of Crystalline Repository Project's Proposed Region-to-Area Screening Methodology", prepared for the third screening methodology workshop (February 1984), illustrate a simplified example of the Step 1 concept. Figure 5 is a composite map derived by overlaying the three maps in Figure 4 on each other to illustrate the total area disqualified by these factors. Figure 5 also includes the boundaries of the hypothetical rock bodies. The blacked-out portions of these hypothetical rock bodies would be eliminated in this example. It should be noted that new disqualifying factors, Components of the National Forest Lands and Deep Mines and Quarries, have been added since the hypothetical application was presented at the February 1984 methodology workshop. This was done in response to changes made in the final DOE Siting Guidelines.

\subsubsection{Step 2 - The Scaled Regional Variables Screen}

The objective of Step 2 of the region-to-area screening methodology is to further evaluate the rock bodies that remain after Step 1 in terms of the regionally applicable, potentially adverse, and favorable conditions outlined in the DOE Siting Guidelines. A given rock body that exhibits potentially 


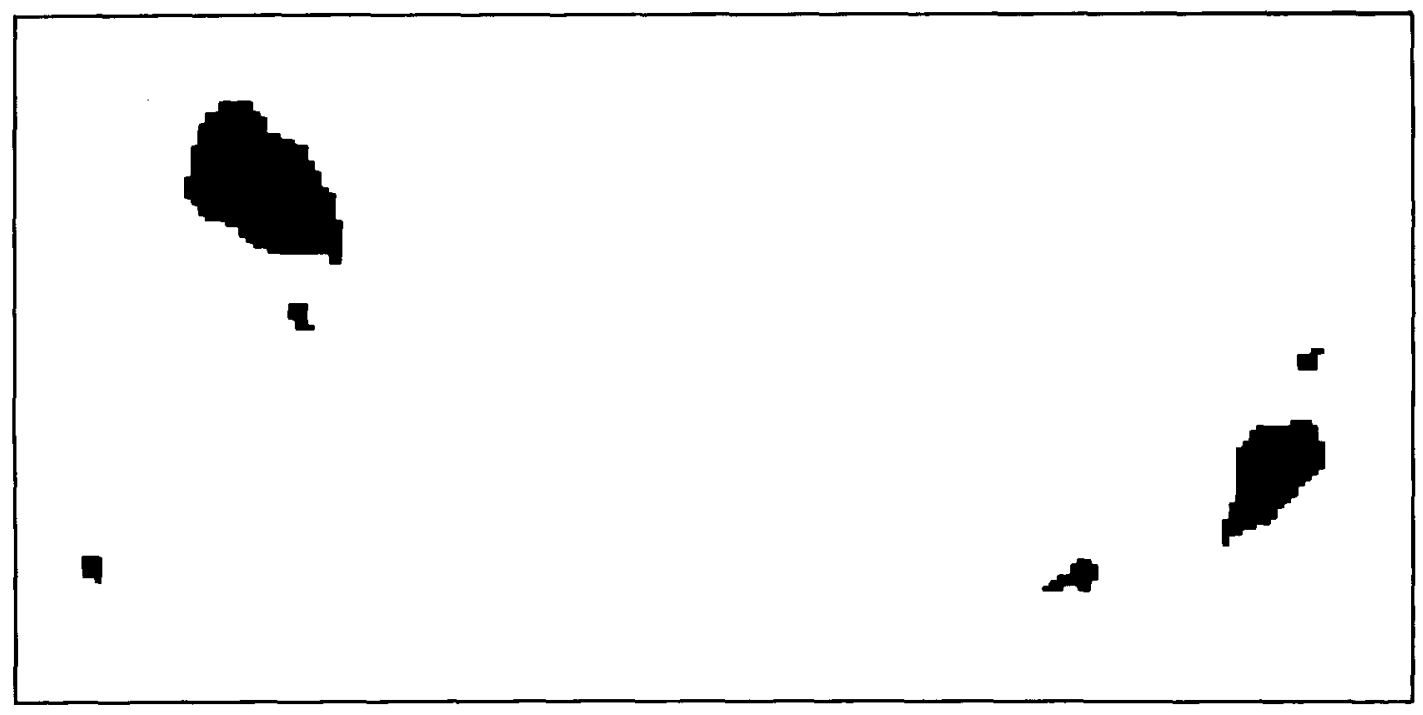

NATIONAL AND STATE PROTECTED LANDS

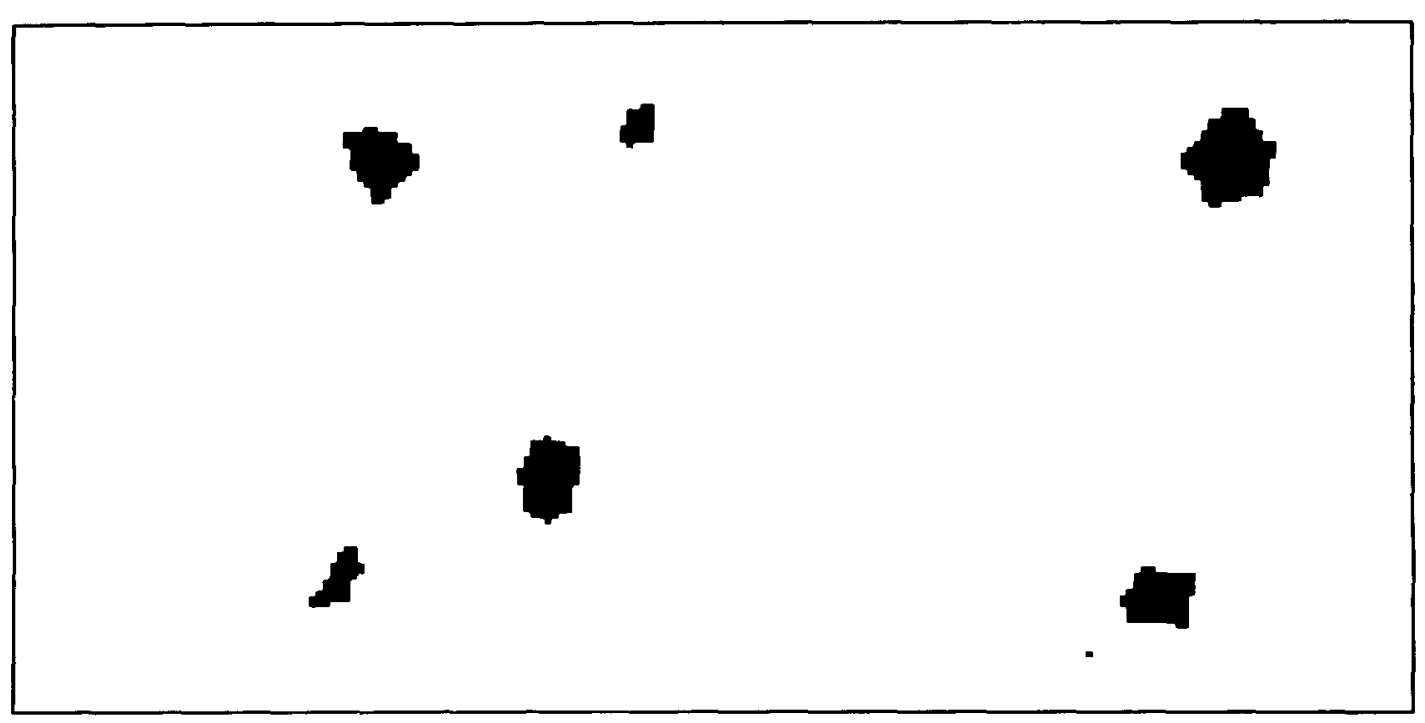

DEEP MINES AND QUARRIES

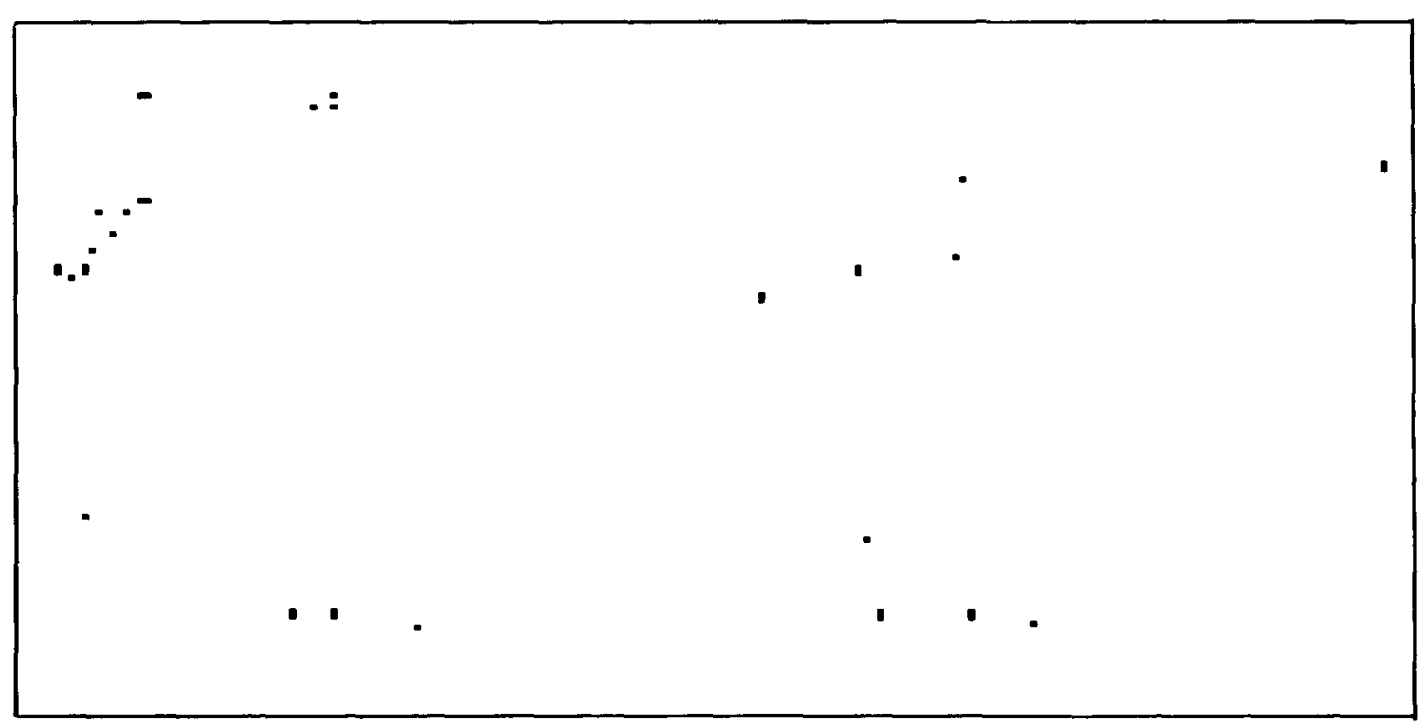

Figure 4 Examples of Hypothetical Disqualifying Factor Maps 


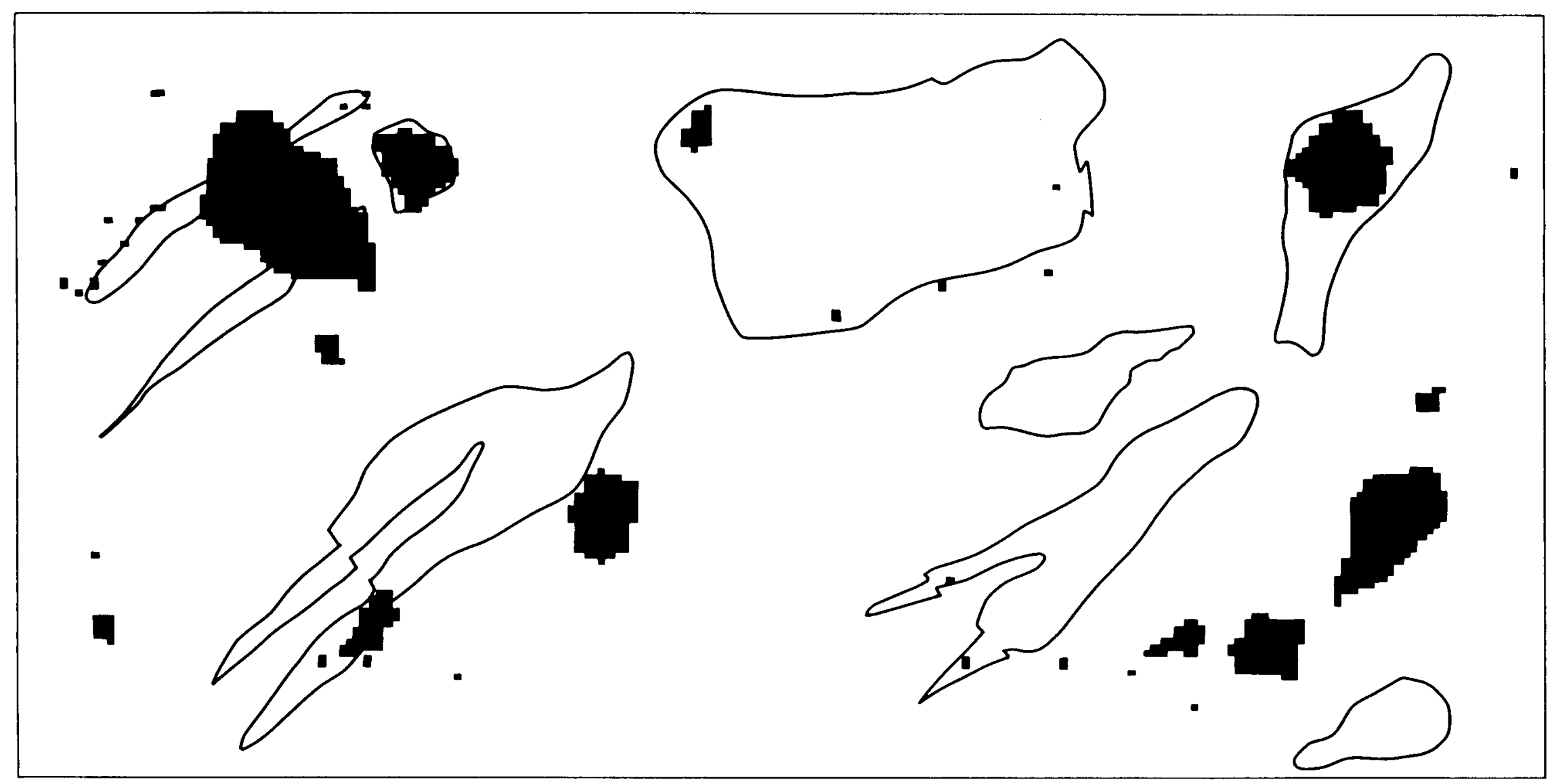

Figure 5 A Composite of Hypothetical Disqualitying Factor Maps Overlain on Hypothetical Rock Bodies 
adverse conditions will be penalized in Step 2. Conversely, a rock body that exhibits favorable conditions will be favored in the screening process. The degree to which a rock body is penalized or favored because of any single variable is determined by how the variable is scaled and on how heavily weighted that variable is vis-a-vis the other Step 2 variables. The product of Step 2 will be estimates of the composite or aggregate favorability of the portions of all the rock bodies not disqualified in Step 1. In order to illustrate the Step 2 process more clearly, the paragraphs and figures that follow describe a hypothetical application of Step 2.

Figure 6 depicts the actual boundaries of some hypothetical rock bodies in a hypothetical study area. The figure also illustrates the conversion of the rock body map into a gridded format. The decision rule for this conversion is that if one-half or more of a given grid cell is covered by a feature, then that whole grid cell is depicted as containing that feature. As previously noted, if a feature is in excess of 130 hectares (320 acres) but, because of its orientation, it does not exceed 130 hectares ( 320 acres) in any single grid cell, the feature will be assigned to the grid cell in which the centroid of the feature is located. As is evident from Figure 6 , the use of a 1-square-mile grid cell, at the regional scale, allows close approximation of the actual polygonal boundaries of the feature. Step 2 requires such a conversion of polygonal to gridded data because of the need for an accounting unit for the estimation of aggregate favorability using mathematical operations. A 1-square-mile grid cell size has been selected for this purpose. This size has been judged by the CRP to represent an appropriate balance between the regional scale and the need to discriminate degrees of favorability for each screening variable. There are approximately 500,000 square miles under study by the CRP. Consequently, there will be approximately 500,000 grid cells employed in Step 2, minus those grid cells disqualified in Step 1.

Figure 7 illustrates hypothetical data bases for a subset of both geologic and environmental Step 2 screening variables. This figure is presented to demonstrate how typical raw data, of the kind that appears in the RCR, will be used in Step 2. It should be noted that data collection is not just limited to the area within the boundaries of rock bodies. This is primarily because many of the variables relate to proximity considerations. For example, a park proximate to a rock body is a potentially adverse 


\section{HYPOTHETICAL ROCK BODIES}

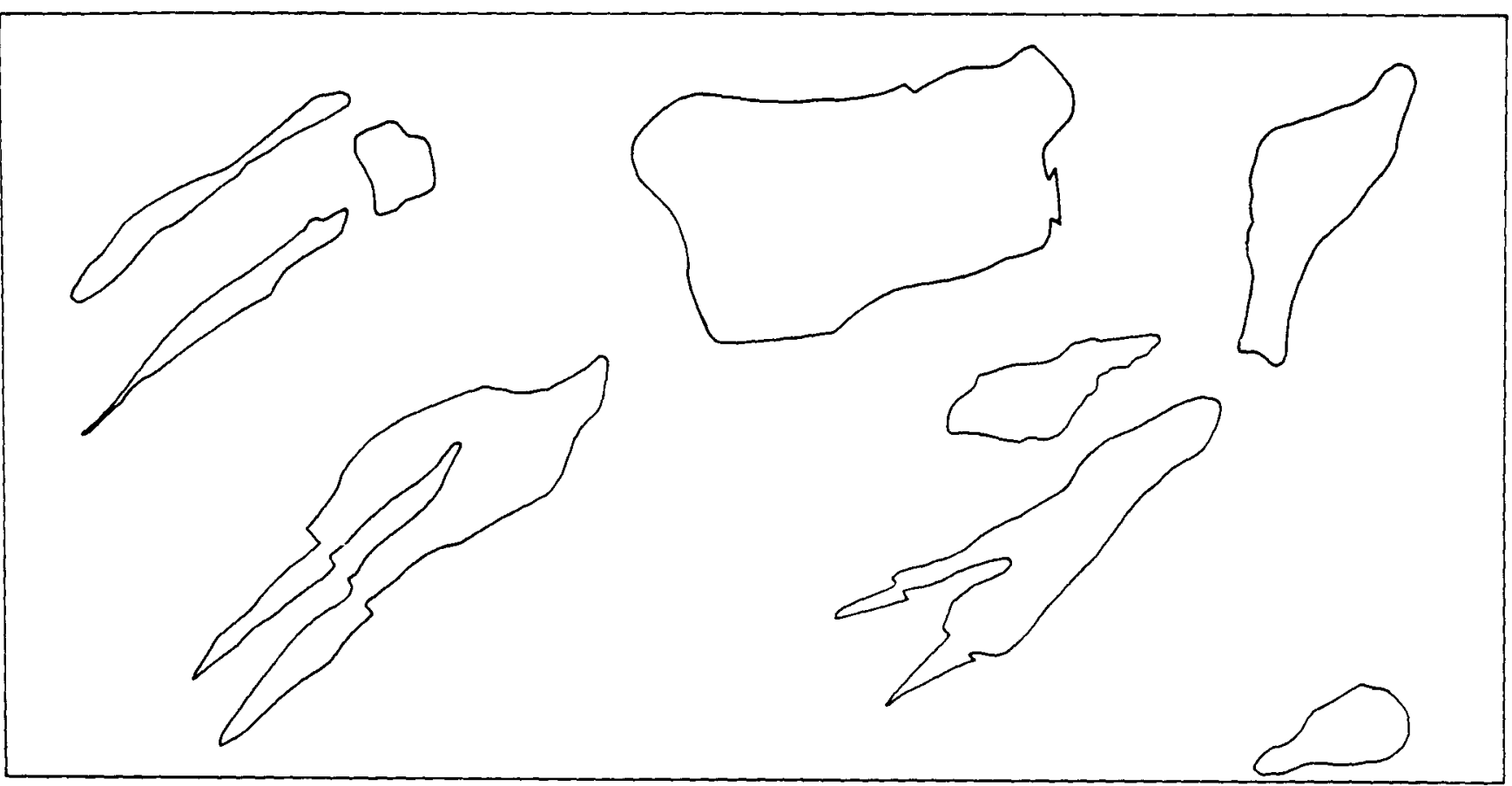

\section{HYPOTHETICAL ROCK BODIES - GRIDDED REPRESENTATION}
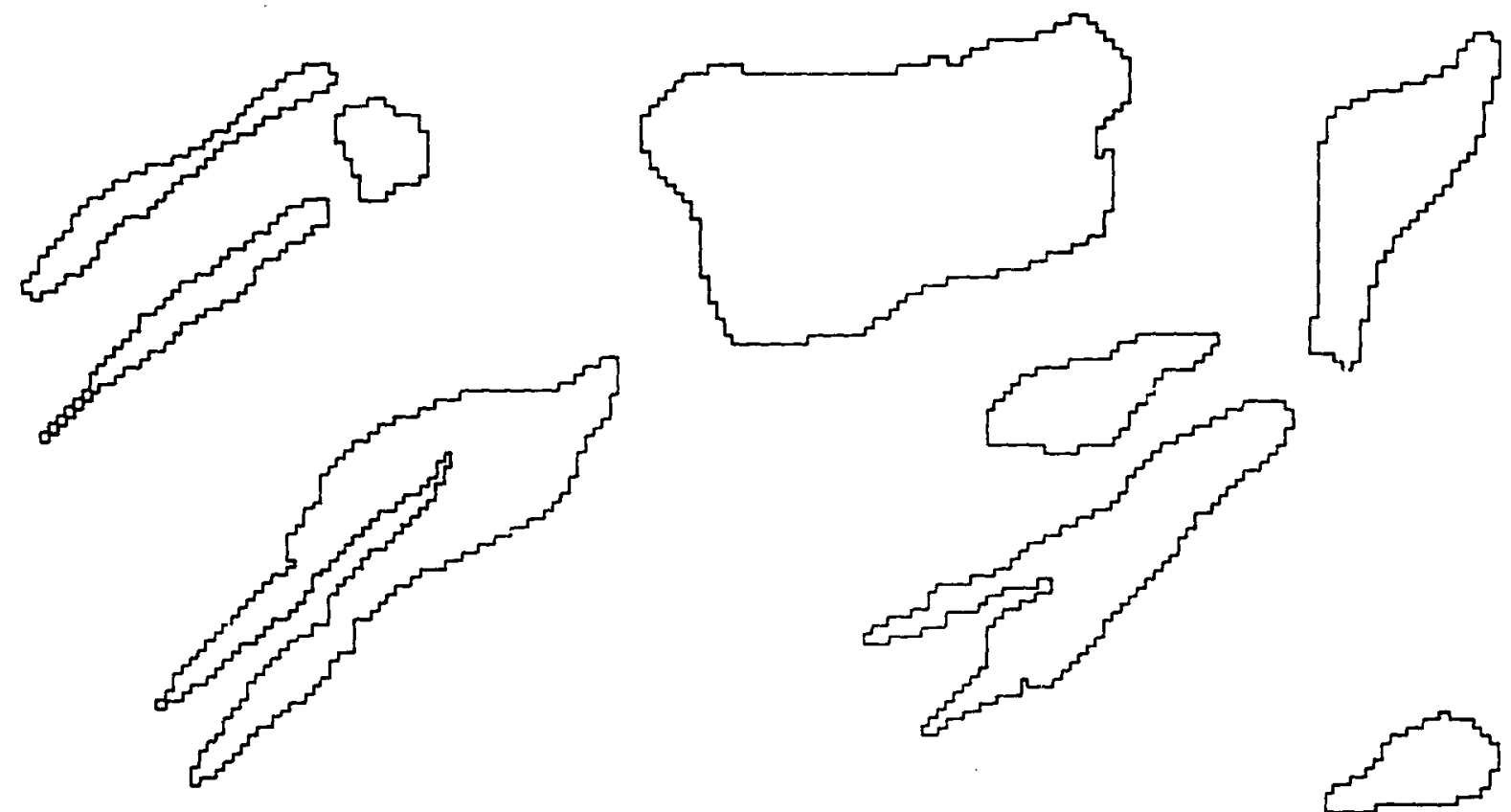

Figure 6 Example of Conversion of Polygonal to Gridded Data: Hypothetical Rock Bodies 
HYPOTHETICAL ENVIRONMENTAL DATA

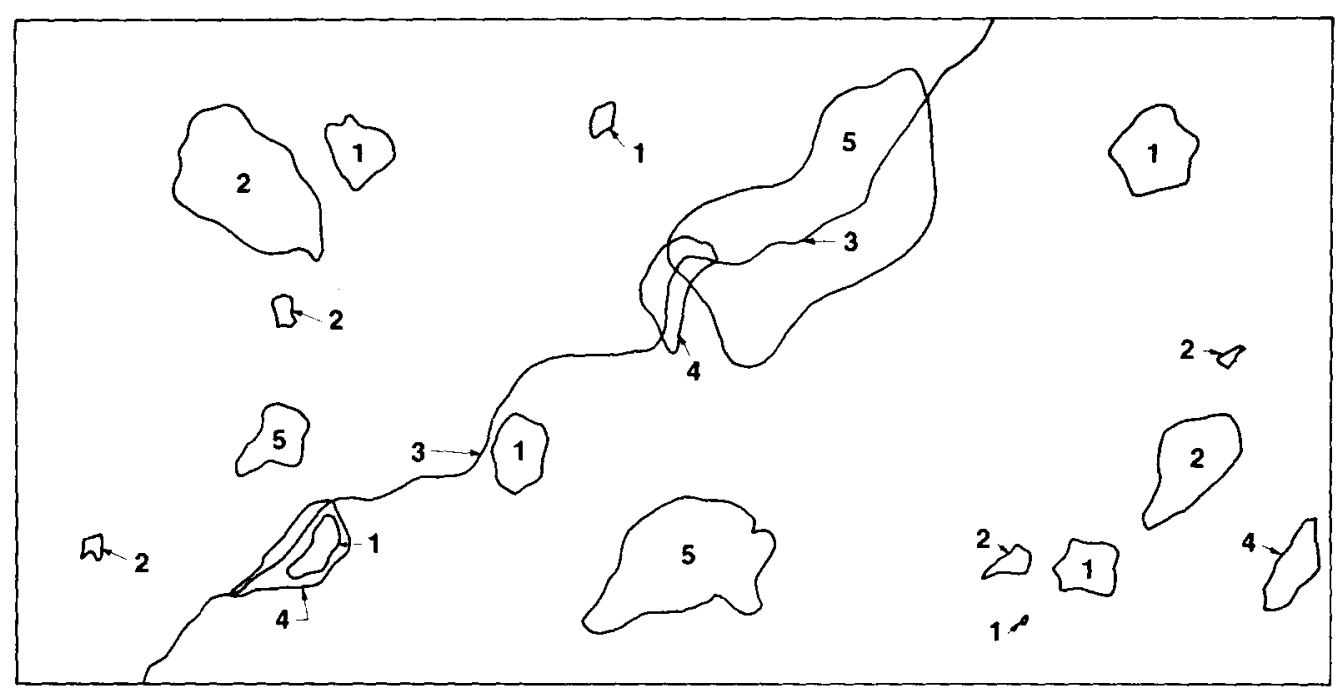

LEGEND:

1 Federal and State-Protected Lands

2 Population Density and Distribution

3 Surface Water Body - River

4 Wetlands

5 Federal and Sate Forest Lands

HYPOTHETICAL GEOLOGIC DATA

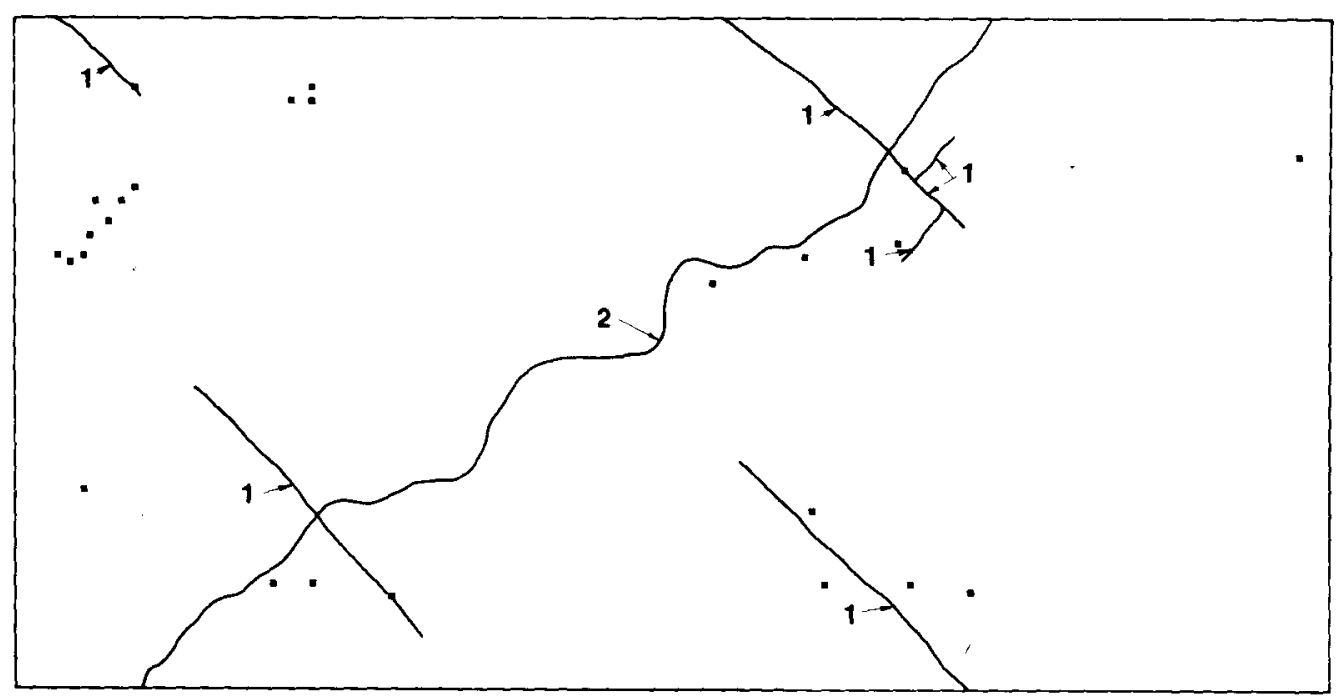

LEGEND:

1 Postemplacement Fault

2 River

Dock and Mineral Resources

Figure 7 Hypothetical Data Bases for a Subset of Geologic and Environmental Screening Variables 
condition that needs to be addressed. These raw data for Step 2 variables will be transformed into a gridded depiction of potentially adverse to favorable conditions using a process of scaling.

Scaling. Scaling is the process by which the CRP will translate physical conditions for each screening variable (potentially adverse or favorable) into a numerical value that can be used to evaluate the aggregate suitability of rock bodies. The scaling concepts discussed here are the result of substantial interaction with representatives from the 17 crystalline states at two workshops (November 1983 and February 1984) and comments received from the states subsequent to these workshops and after reviewing a draft of this report. A scale has been developed for each region-to-area screening variable that represents adversity and favorability on a standard 1 to 5 scale as follows:

Dark Gray

Light Gray

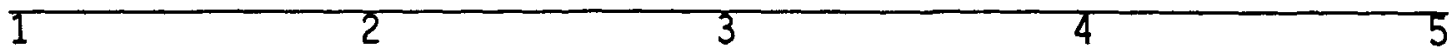

More Adverse

More Favorable

To the extent practicable, each variable discussed in Chapter 5.0 of this document has the same number of increments and numerical assignments assigned to a range of conditions for that variable. There are variables, however, where fewer than five increments are used in scaling. This is either because the available data do not allow the assignment of all five increments, or, in CRP's judgment, such an assignment cannot be technically justified. In such cases, the end points on the standard scale ( 1 and 5 ) are used along with one or more intermediate points $(e . g ., 3)^{1}$. This responds to the concern expressed by state representatives that, without such discipline in scaling, "internal weighting" would occur.

Other rules used to achieve consistency in the development of the scales outlined in Chapter 5.0 include:

I The only variable which does not have any intermediate increments is Suspected Quaternary Faulting. 
- The end points of the scale were determined by examining the range of conditions for each variable for the United States as a whole.

- The intermediate values were assigned on the basis of technical judgments (with state input) made about the affect of each variable on the potential difficulty of licensing a repository, including the ability to mitigate potentially adverse conditions.

- The scaling of variables reflects linear, exponential, or other nonlinear functions of physical conditions that represent the CRP's best technical judgment.

- Each numerical assignment depicts a physical condition translated into a degree of favorability.

Once the variable scales are established, favorability maps that geographically depict those numerical assignments as shades of gray are prepared. It should be noted that each number ( 1 through 5 ) is assigned as a standardized shade of gray for the favorability maps for all variables. The convention is that the darker the gray tone, the more adverse the condition that is being depicted. Figures 8,9 , and 10 provide examples of favorability maps derived for geologic, environmental, and socioeconomic Step 2 variables. It should be noted that these maps were derived by using the scales that are discussed in Chapter 5.0 of this document, some of which are revised from those previously presented and discussed at the last two methodology workshops or in the draft of this report. The black areas on each map represent those portions of the hypothetical study area that were disqualified in Step 1.

Before the first composite favorability maps can be prepared, alternative sets of variable weights must be developed. The sections that follow describe how weighting will be conducted for the region-to-area screening methodology for the CRP.

\subsubsection{Description and Role of the Weighting Process}

Weighting plays an important role in region-to-area screening. While scaling assesses the range of conditions for a single variable, weighting evaluates the relative importance of each variable vis-a-vis every other variable in region-to-area screening. The DOE will evaluate the implications of a broad range of views of the relative importance of individual regional 


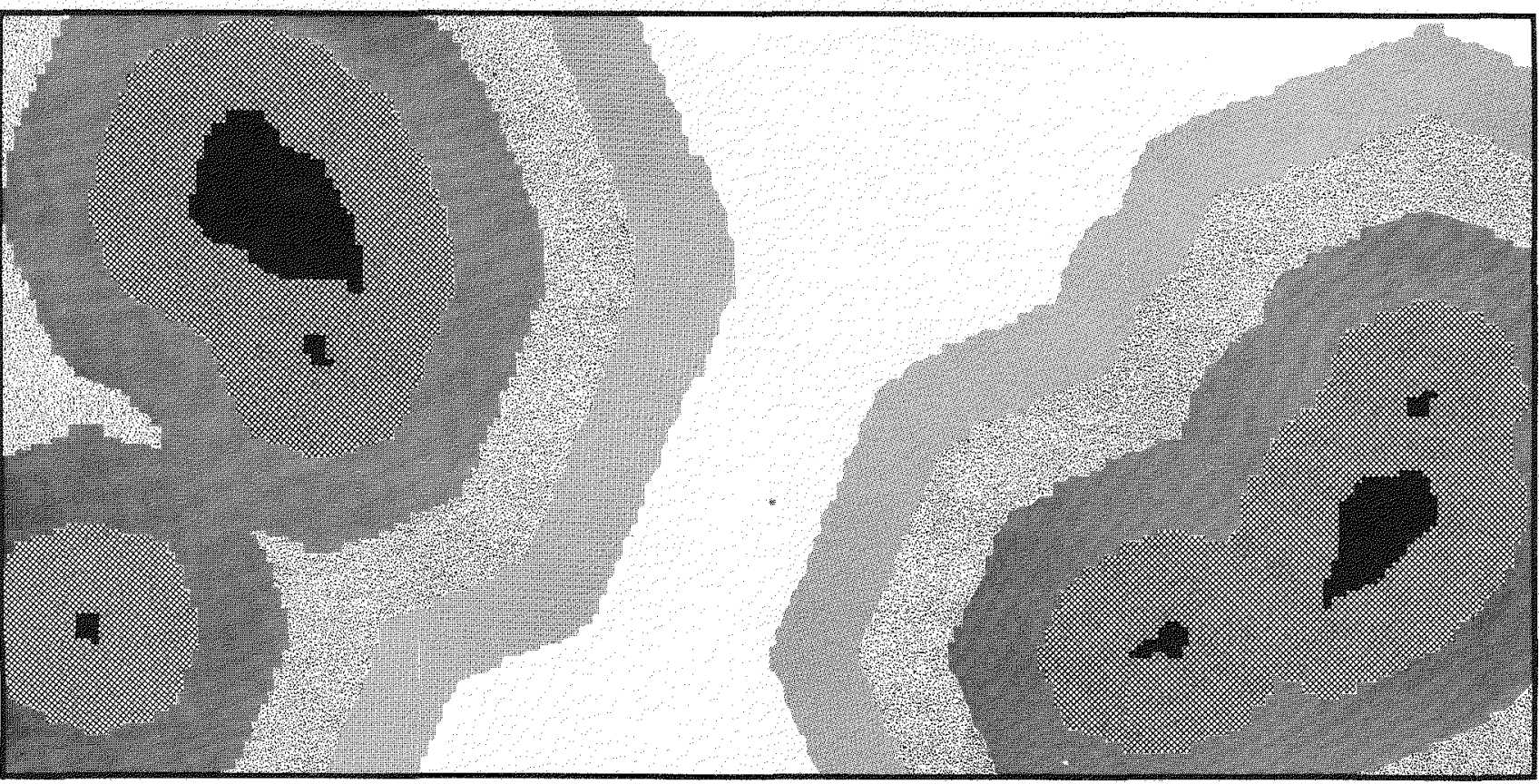

LEGEND (MILES):

Disqualified

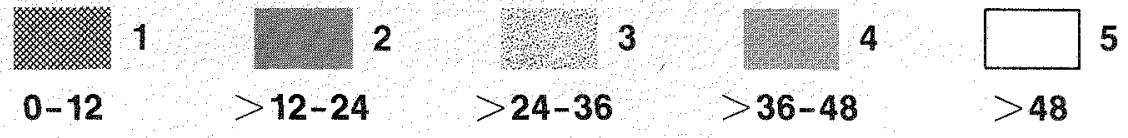

SCALED MAP - PROXIMITY TO

NATIONAL AND STATE PROTECTED LANDS

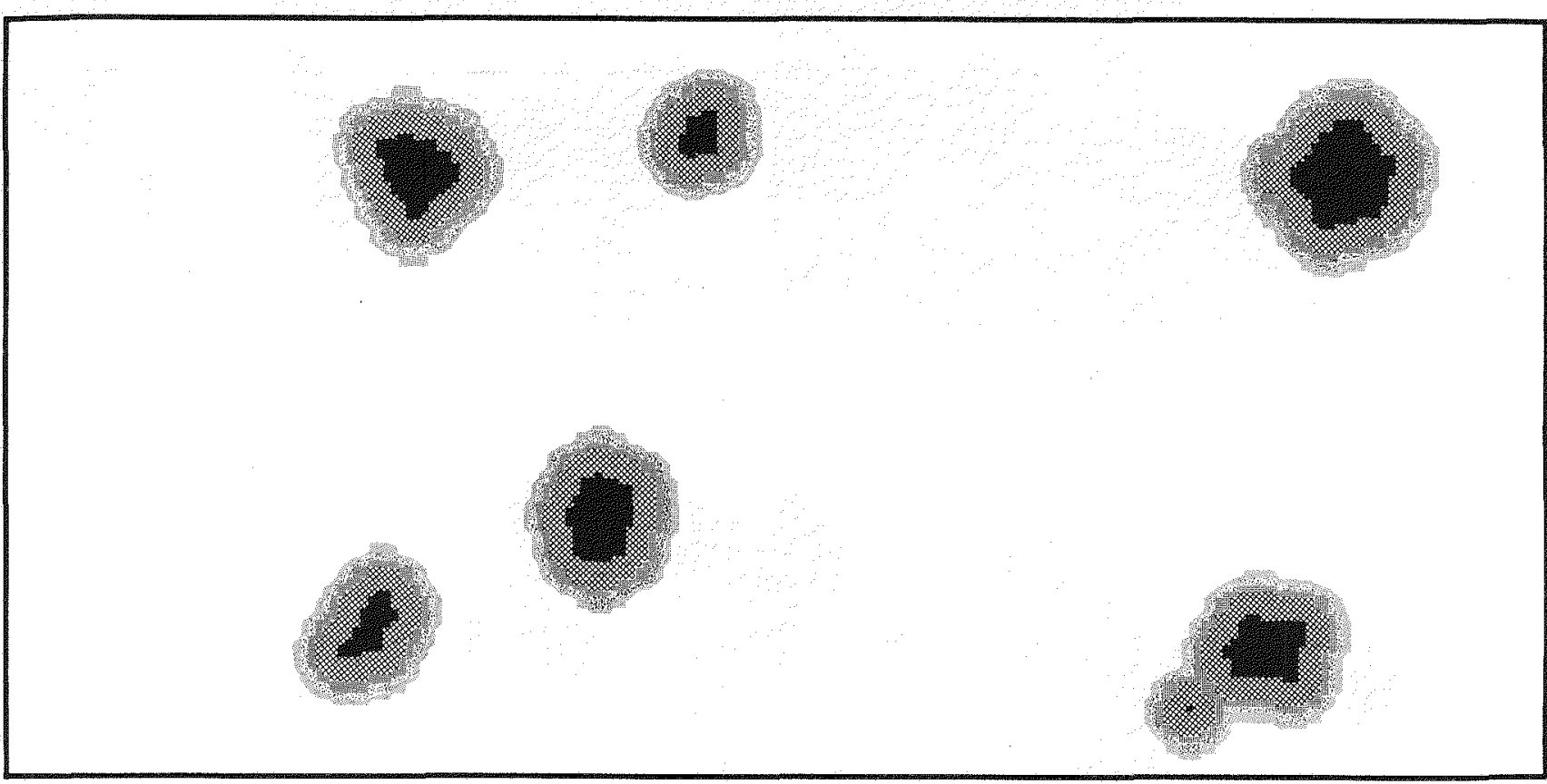

LEGEND (MILES):

Disqualified

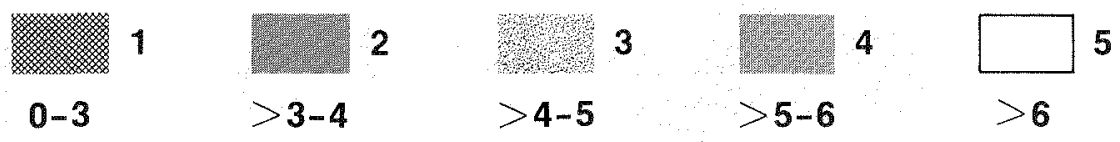

SCALED MAP - PROXIMITY TO NATIONAL

AND STATE FORESTS

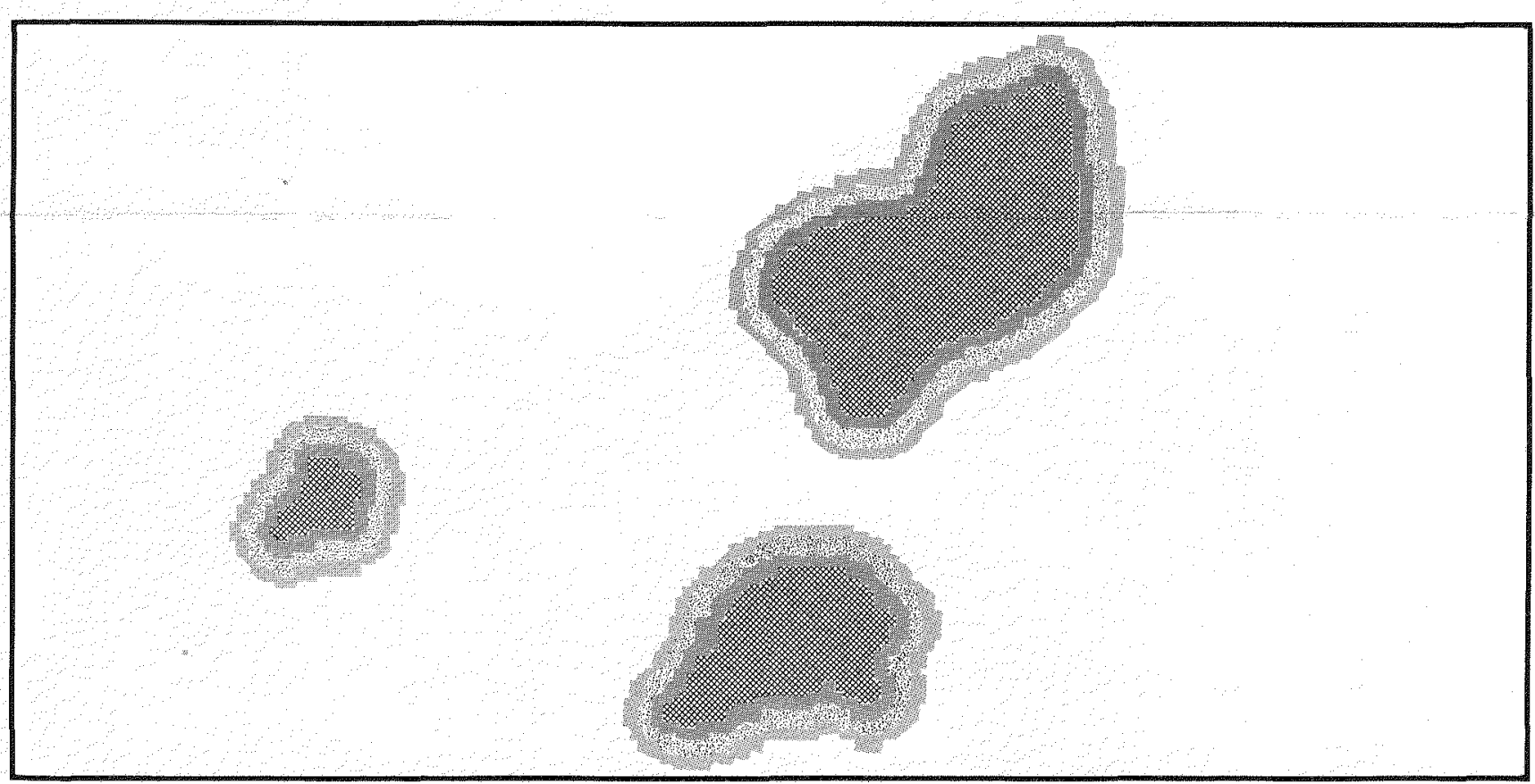

LEGEND (MILES):

$\begin{array}{lllll}1 & 2 & 3 & 4 & \\ \text { Inside } & \leq 2 & >2-4 & >4-6 & >6 \\ \text { Boundary } \\ \text { More Adverse }\end{array}$


$\bullet$

- 
SCALED MAP - MAJOR GROUND WATER DISCHARGE ZONES

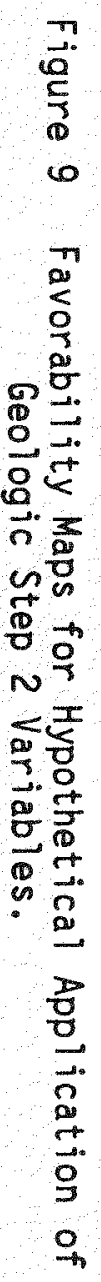

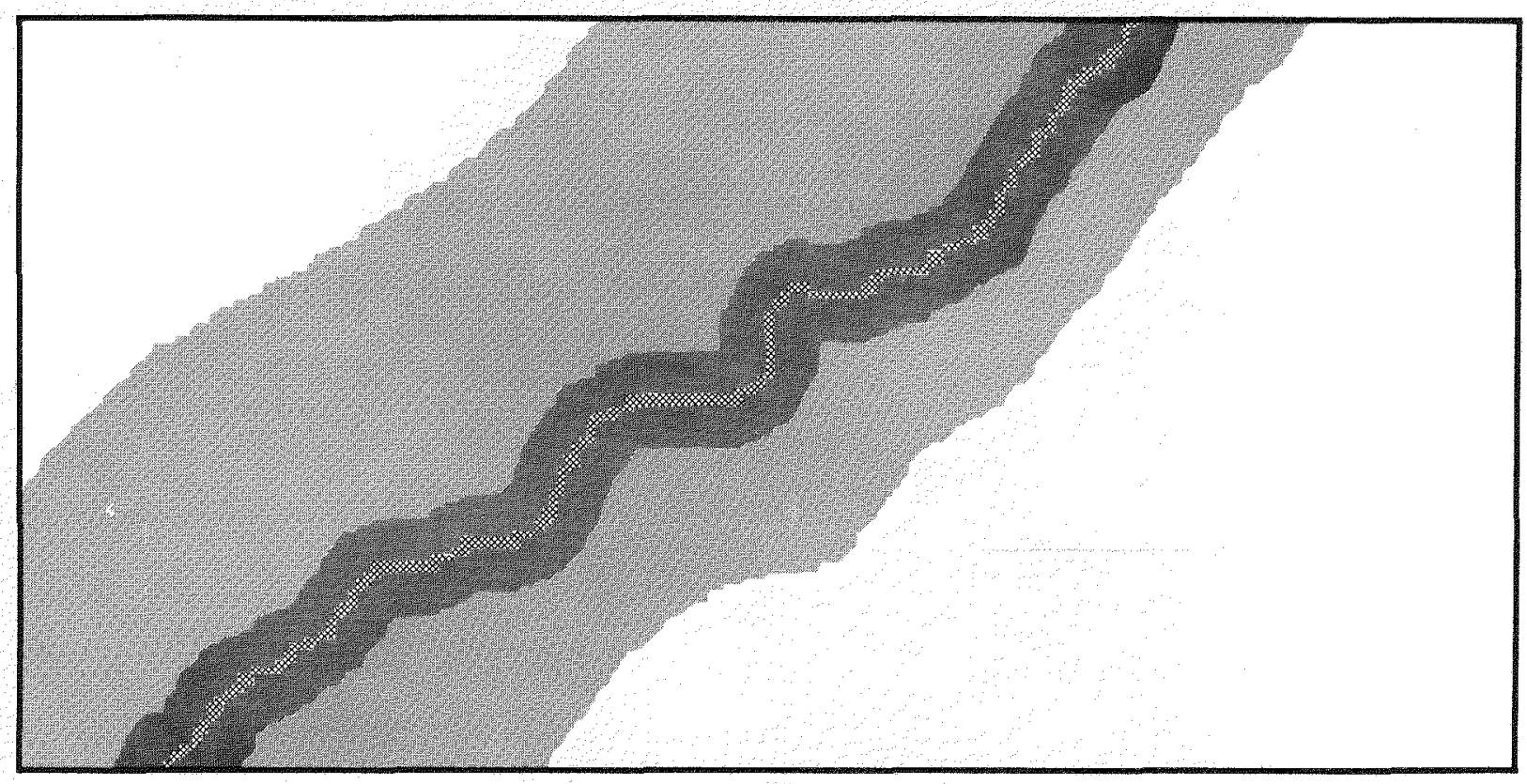

LEGEND (MILES):

$\begin{array}{lllll}2 & 2 & & \end{array}$

SCALED MAP - ROCK AND MINERAL RESOURCES

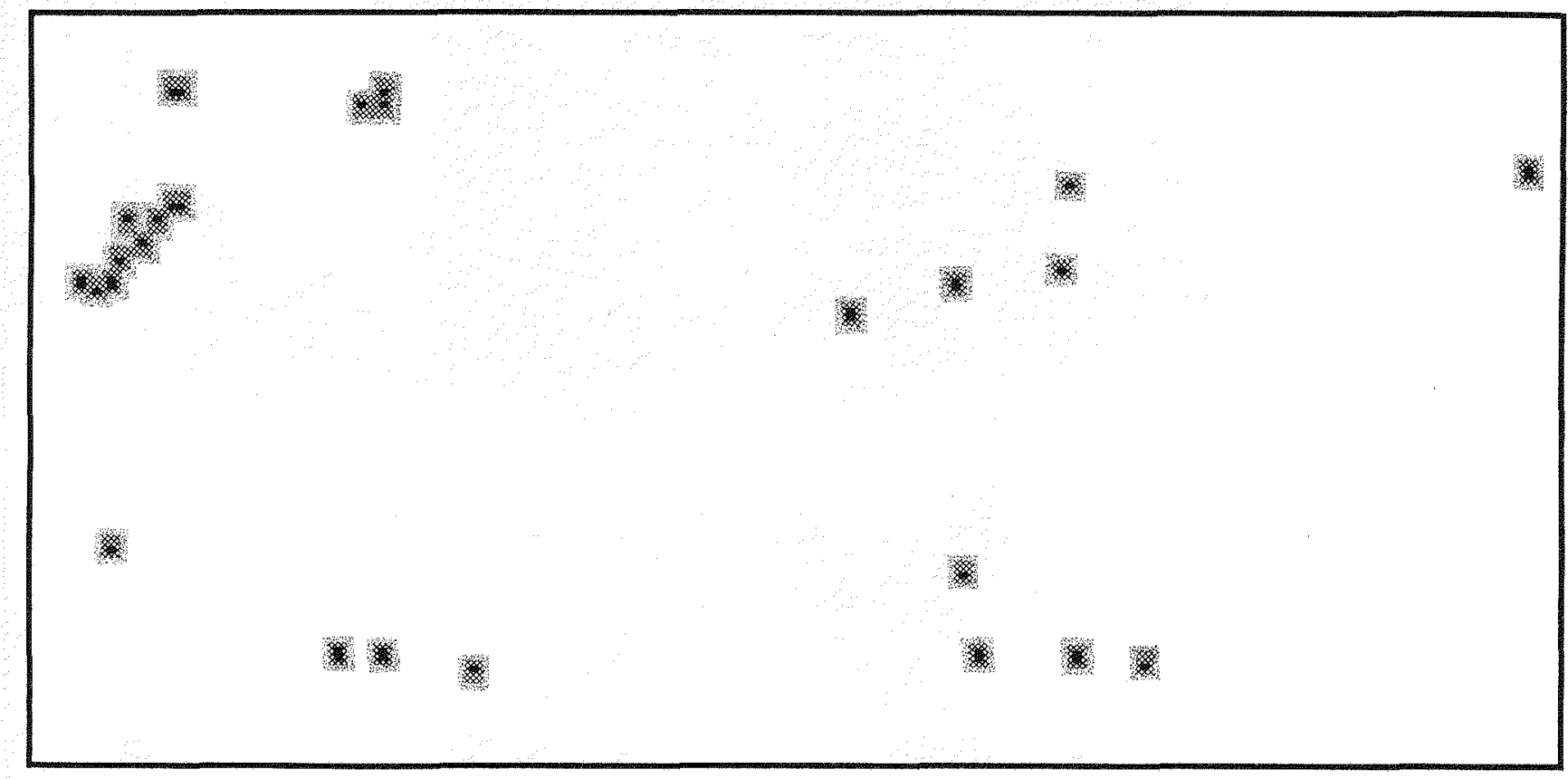

LEGEND (MILES):

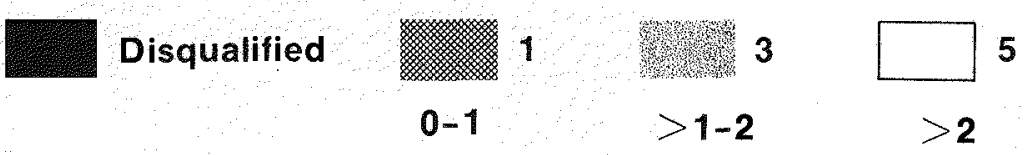

SCALED MAP - POSTEMPLACEMENT FAULTING

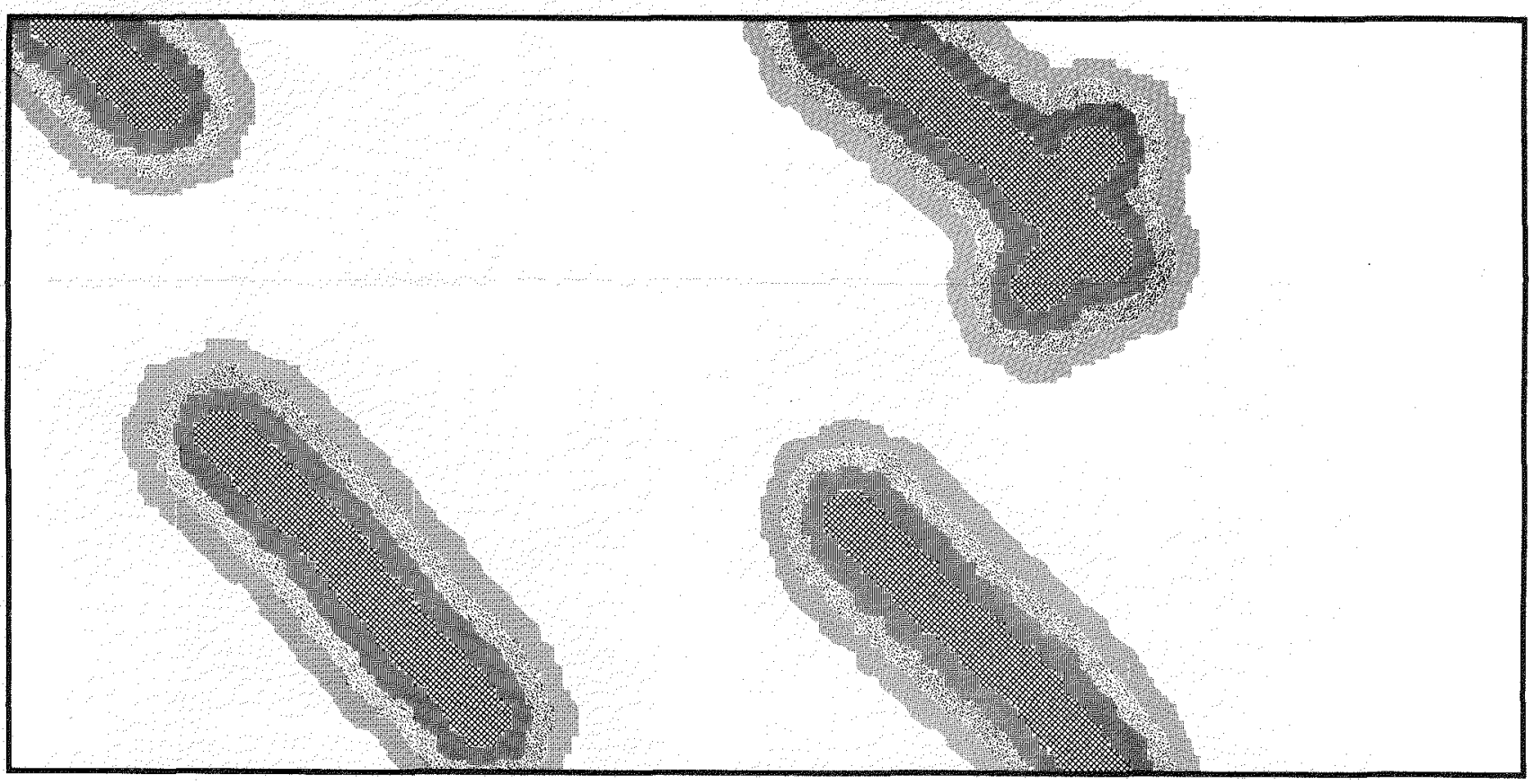

LEGEND (MILES):

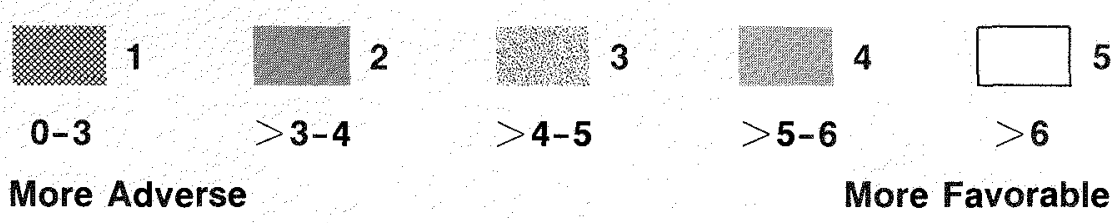


- 
SCALED MAP - WETLANDS

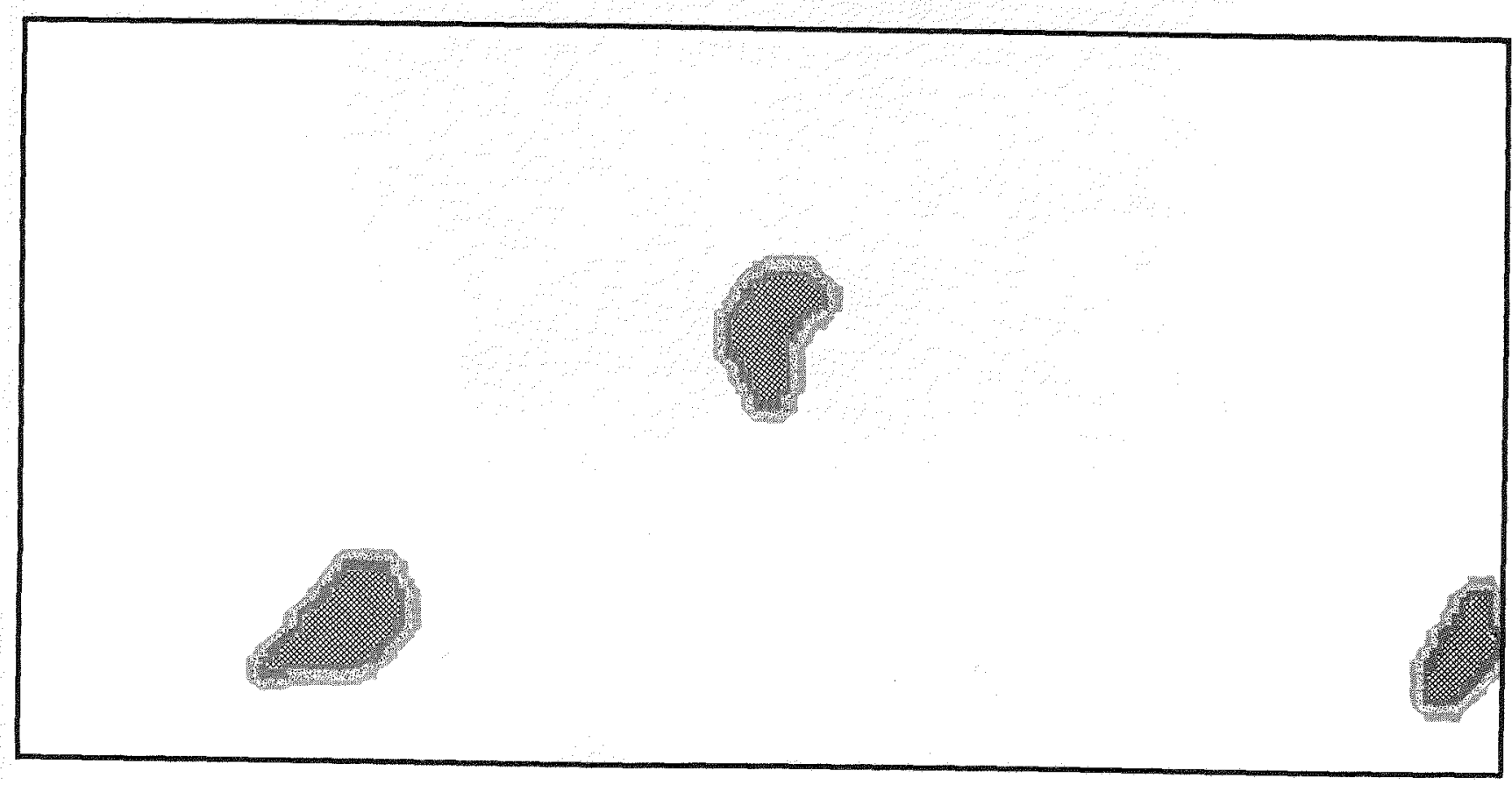

LEGEND (MILES):

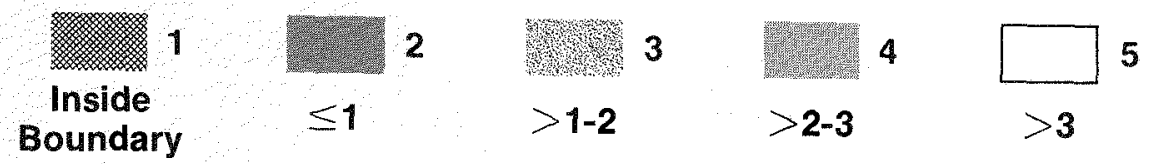

SCALED MAP - SURFACE WATER BODY

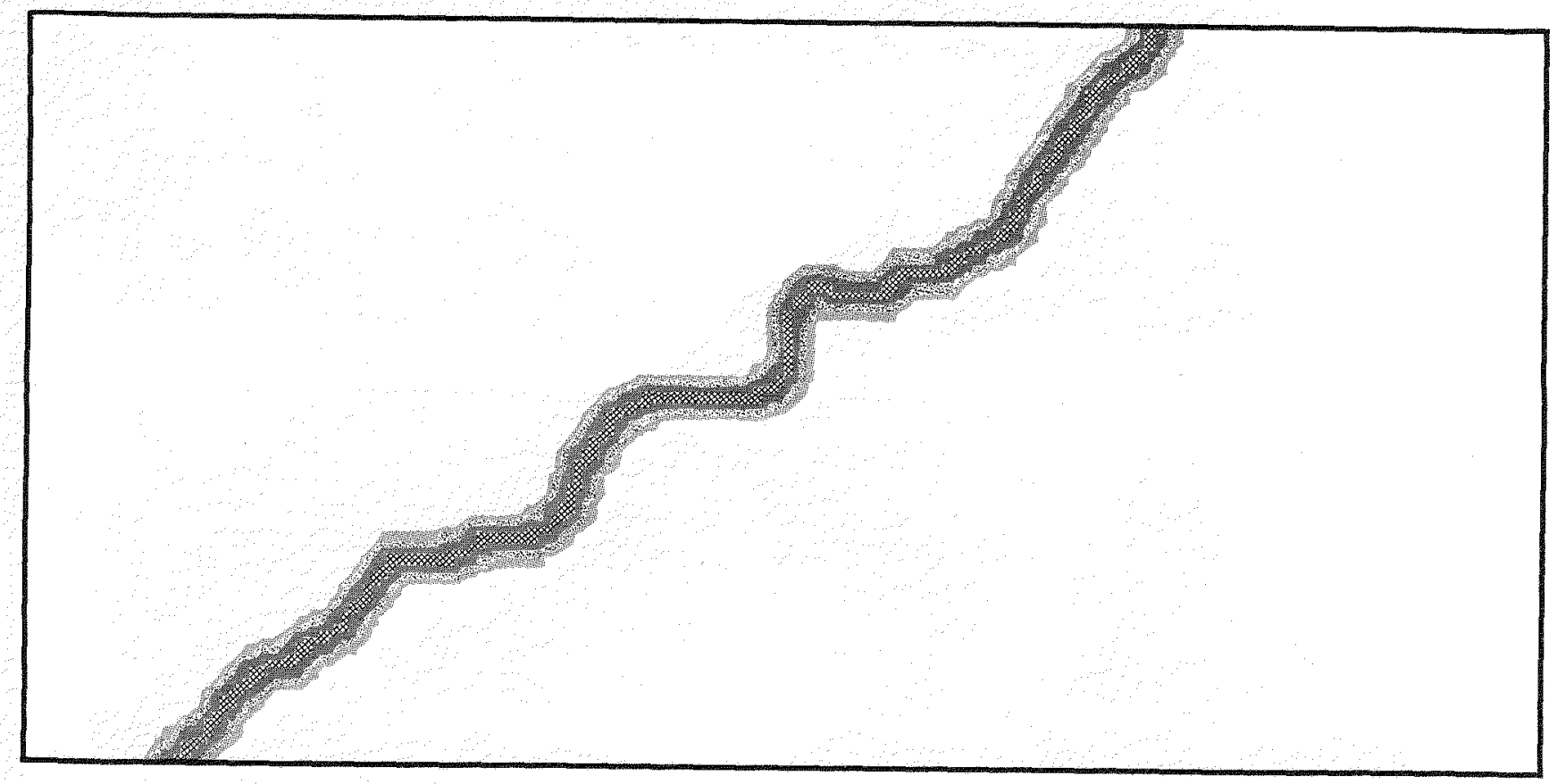

LEGEND (MILES):

\begin{tabular}{lllll}
\hline & 2 & 3 & 4 & $\square$ \\
\hline $\begin{array}{l}\text { Water body } \\
\text { Indicated } \\
\text { More Adverse }\end{array}$ & $>1$ & $>1-2$ & $>2-3$ & $>3$ \\
\end{tabular}


•

- 
screening variables for the selection of candidate areas for further study. To fulfill this commitment, a process has been devised to develop multiple sets of weights that are representative of a broad spectrum of technical views of the relative importance of the proposed regional screening variables. This process involves the development of two suites of weights 1 : one from the CRP weighting workshop 2 and a second from a similar workshop including only crystalline state representatives. Both workshops will be structured to include a cross section of technical representation to help ensure that the products of each workshop capture a wide range of views.

The objectives of the weighting process are to:

- Elicit two suites of weights that are representative of a broad spectrum of views of the relative importance of region-to-area screening variables to the selection of candidate areas.

- Afford the 17 crystalline states an opportunity to provide substantive input to the region-to-area screening process.

- Provide the DOE with useful information for selecting candidate areas of crystalline rocks that have the highest aggregate favorability as determined by groups of people with diverse interests and technical expertise.

The scope of the proposed weighting process, and this description of it, is bounded by the following considerations:

- This document describes how alternative suites of weights will be derived. It does not provide specific variable weights. The suites of weights will be the principal product of the workshop process.

- A CRP weighting workshop will be conducted first, using the same approach proposed for the second workshop that will involve state

\footnotetext{
1The term "suite of weights" is defined to be the multiple sets of weights derived at each workshop.

${ }^{2}$ The CRP weighting workshop was conducted in November 1984.
} 
participants. The multiple sets of weights resulting from the CRP workshop will be sent to the 17 crystalline states after the conclusion of the state workshop. 1

- Both weighting workshops will be based upon the final list of Step 2 and Step 3 variables, including their assigned scales, that appears in this document.

- In each workshop, weighting will be done four times ${ }^{2}$. The first iteration will involve only the Step 2 variables. The second will differentially weight the combined list of Step 2 and Step 3 variables. The third iteration will involve Step 2 variables with modified scales for certain Step 2 variables (see Section 3.2.5.1). The fourth iteration will involve Step 2 and Step 3 variables using the modified scales for the same Step 2 variables. The incorporation of Step 3 variables (iterations two and four) will be accommodated after weights are established for the Step 2 variables only in iterations one and three.

Iterations three and four have been incorporated into the process to ensure state participation in a portion of the sensitivity analysis.

- Crystalline state participation in weighting is judged by the DOE to enhance the region-to-area screening process, and every effort has been made in the development of the process to minimize constraints on state involvement. Accordingly, DOE will invite each

1As previously noted, the CRP weighting workshop was conducted in November 1984. Due to DOE's concern that release of the suite of weights developed at this workshop to the 17 crystalline states prior to their participation in the state workshop could influence the suite of weights to be developed, DOE has determined that its previous position to release the CRP weights in advance of the state workshop for information purposes was inappropriate. This revised position was encouraged by a majority of the 17 crystalline states.

2 The results of the four iterations for each subgroup is considered to be a set of weights. 
of the 17 crystalline states to participate in the weighting workshop, although it is recognized that some crystalline states may choose not to participate.

- While categorization of screening variables (e.g., postclosure and preclosure) is useful to the establishment of weights, DOE will not specify categories for use by participants. Furthermore, in accordance with 10 CFR 960.3-1-5, state representatives are not required to place primary significance on the postclosure guidelines and secondary significance on the preclosure conditions. Accordingly, individual respondents will be given complete latitude in developing categories of their own in the individual weighting exercise. This approach was also utilized in the CRP weighting workshop.

- Participants in the state weighting workshop may represent their individual views or the views of some constituency (e.g., a state advisory group). In any event, the positions of individual participants will not be readily identifiable in the documentation of the exercise. The product of the workshop will be sets of weights that are representative of the subgroups' views.

- DOE will select broadly representative sets of weights (from the two suites of weights) to be used in the development of alternate composite favorability maps. Consequently, not every set of weights developed will be used in the recommendation of candidate areas. This is because it is quite possible that there will be significant similarity between the two suites of weights, the CRP suite and the state suite. The DOE is committed in the selection of weights to capturing and using a broad range of representative weights, from the two workshops including extremes and intermediate views. Where sets of weights from the two suites are similar, the DOE's preference is to use the set that is the product of the state workshop. In addition, in response to state comments, DOE will also develop an equally weighted case. 


\subsubsection{Selecting Workshop Participants}

The DOE will seek to compose groups of approximately equal size ( 45 to 50 individuals) to participate in the separate weighting workshops. Each group will be composed of individuals representing geologic, engineering, waste isolation, environmental, and socioeconomic disciplines.

The CRP group was selected from the following sources:

- DOE's Crystalline Repository Project Office

- DOE's Office of Civilian Radioactive Waste Management

- Battelle's Office of Crystalline Repository Development (OCRD)

- OCRD's subcontractors

- geologic project managers

- environmental project managers

- licensing project manager

- U.S. Geological Survey.

The CRP participants have been involved in the day-to-day execution of the project. Key technical personnel from each major discipline were represented in the group. Even so, it was necessary to fully orient each participant regarding the entire technical scope of the region-to-area screening methodology because the entire list of variables was comparatively evaluated in the weighting exercise. This gave CRP staff the opportunity to evaluate the effectiveness of background materials and briefings used to support the CRP weighting workshop, and it is anticipated that this will lead to improvements in the materials to be sent to state representatives in advance of their workshop, and in the briefing at the state workshop.

The CRP will solicit participation from the 17 crystalline states, and hopefully their representatives will constitute, as a group, a cross section of technical expertise in accordance with the general specifications previously noted.

The composition of the state weighting workshop group will be developed as follows. Each involved state will be requested to send three representatives, preferably one representative with geologic or relevant waste isolation expertise, a second with expertise in the environmental or socioeconomic disciplines, and a third with a relevant policy background. It is also desirable that these representatives be participants from previous methodology 
workshops. However, despite these preferences, the DOE will accept any three individuals proposed by each state.

\subsubsection{The Weighting Process}

This section describes the process for the development and selection of broadly representative sets of weights in region-to-area screening. The following topics are discussed:

- Preparation of materials to support the weighting process and to orient participants.

- Conduct of the weighting workshop.

- Documentation and use of weighting workshop results.

The material outlined below is applicable to both the CRP weighting workshop and to the state workshop. It should be recognized that the state weighting process may be refined based upon experience from the CRP workshop already held.

\subsubsection{Preparation of Participant Orientation Material}

In order to help ensure informed participation in weighting, all participants in both workshops must be fully oriented regarding substantive and procedural considerations. Orientation will be required to ensure comprehension of the weighting process, and the definition and significance of each screening variable. Each participant will be asked to comparatively evaluate all the Step 2 and Step 3 screening variables. To do so requires knowledge of each variable, even though a given individual may have depth of expertise with respect to only a subset of the total variable list.

Some participants may not have been exposed to CRP activities at all prior to the weighting workshop. These individuals must be given background regarding the scope and objectives of the CRP, the region-to-area screening methodology, the limitations involved in regional-phase activities, the specific definitions and related information on the screening variables, and the details of the weighting process.

In order to properly orient the participants on weighting, several activities will be undertaken. The first involves the preparation of written materials that cover the necessary procedural and substantive topics. This 
document will be used to help complete this task. Topics to be covered in these background materials will, at a minimum, include the following:

- Outline of the scope and objectives of the CRP.

- Review of the region-to-area screening methodology.

- Summary of the role of weighting in the screening methodology.

- Definition of the screening variables and associated scales.

- Detailed description of and instructions for participation in both individual and subgroup weighting exercises (including a list of participants and their affiliation).

These materials will be mailed to each participant in advance of the actual workshop.

In addition to the above descriptive material, a list of CRP experts by topics and their telephone numbers will be provided. These individuals will be available as resource people to answer technical questions and to respond to inquiries from participants. This will assist individuals in preparing for the weighting exercises. The first event at each weighting workshop will be devoted to group discussion of the process and the variables, and to answer any additional questions prior to the exercises.

These orientation activities should provide each participant with the required background to participate effectively in the weighting workshops.

\subsubsection{Conduct of the Weighting Workshops}

The weighting workshops will be largely the same procedurally and will involve both individual and subgroup exercises. It is expected that the specifics of the second weighting workshop (the state workshop) will be refined and improved as a result of the experience of the CRP workshop.

The first activity involved in each of the two weighting workshops (CRP and state) will be the review and group discussion of any and all procedural and substantive questions raised by the participants. Following this orientation session and discussion, each participant will be asked to complete an individual weighting exercise. The detailed instructions for completing the individual exercise will have been mailed, in advance, to each participant as part of the orientation package. The CRP technical experts will be made available to answer questions from individual participants as they perform their individual weighting exercise. 
A point allocation approach has been selected for the weighting process. This approach is designed to systematically allocate a standard number of "weighting points", specifically 1,000 points, among the region-to-area screening variables. The steps in the individual exercise are as follows: Step A: The complete list of Step 2 screening variables will be categorized in a manner selected by the individual participant. Participants may use preclosure versus postclosure categories, environmental versus geology, or any other categorization scheme preferred by that individual as an aid in the allocation of points. The use of categorization is judged to be important to the weighting process because of the large number of variables to be considered. Categorization helps maintain a reasonable span for the comparative analysis that takes place in weighting. It provides a systematic and simplified approach to ultimately deriving weights for individual screening variables.

Step B: Each participant will allocate the 1,000 weighting points to the Step 2 variable categories in accordance with their views of the relative importance of the categories in the selection of candidate areas for further study.

Step C: The variables within each category will be ordered from that variable the individual feels should be the most heavily weighted to the one they believe should be the least heavily weighted. The result should be a rank order from most important to least important variables for each category.

Step D: The total points assigned to each category of variables are al located to individual variables in accordance with the results of Step $C$ and with the participant's comparative evaluation of the variables and their relative importance to the selection of candidate areas. Each participant may assign zero weight to one or more variables in the event they believe that variable is either unimportant to the selection of candidate areas, or is judged to be poorly measured within the constraints of a regional investigation. Each participant may also determine that a single variable should be placed in more than one category. Points would then be assigned to that variable as it relates to each category, and the sum of the 
points for that variable from all of the categories would be that variable's weight. It should also be recognized that individual variables in a category judged to be least important may still be assigned more weight than one or more variables in the most important category. An example in Table 1 is that Variable $A$ in Category 2 is judged to be more important to the recommendation of candidate areas than Variables $\mathrm{H}$ and $\mathrm{J}$ in Category 1 . The final point allocations, by variable, will be used as the weights in subsequent estimations of aggregate favorability.

After each participant has completed the individual exercise, the results will undergo statistical analysis. It will be these analytical results that are used to assist in the formation of subgroups for the balance of the weighting workshop. The objective of subgroup formation will be to identify individuals with similar views of the relative importance of the screening variables as demonstrated by the individual weighting exercises. These subgroups will be no more than 10 to 12 persons each in size, so it is expected that five or six subgroups will be formed for both the CRP and the state weighting workshops. In fact, five subgroups were formed for the CRP workshop. It will be the interaction within each of these subgroups that will yield the alternative sets of weights that will constitute the product of the two workshops.

The statistical analyses will be initiated at the end of the first day of each of the two workshops, and subgroup formation will have been accomplished prior to the start of the second day. The statistical approach selected for subgroup formation at the CRP workshop was cluster analysis (SPSS, Inc., 1984). Given the success of this approach at the first workshop, and the desirability of parallelism between workshops, cluster analysis will also be used at the state weighting workshop. The subgroups will be formed so as to be representative of the entire spectrum of views held by the entire group of participants at each workshop.

Once the subgroups have been identified, the mean weights for each variable for that subgroup will be determined as a point of departure for discussions within each subgroup on the second day. Visual displays of each subgroup's mean weights will be prepared to facilitate that discussion. In addition, each participant will be provided with a summary of the mean weights for each of the five or six subgroups. Participants in weighting will be allowed 
Table 1. Example of the Point Allocation Approach to Weighting - 1,000 Point Base

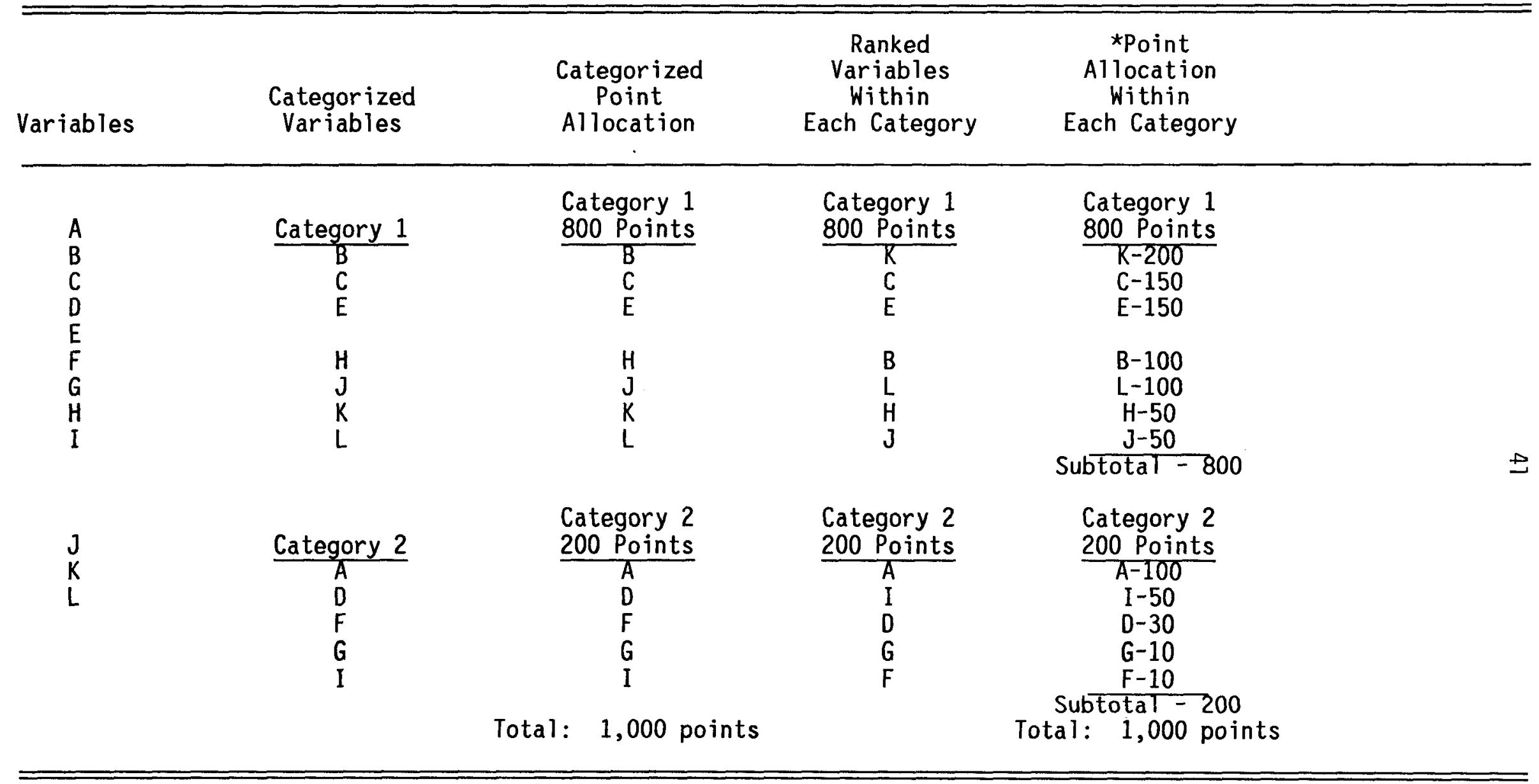

*Weights used to multiply by scale values for each variable to yield the weighted average for each square mile grid cell. 
to move to another subgroup only once, after the conclusion of the first weighting exercise using the Step 2 variables list.

The second day of each workshop will begin by acquainting all participants with their particular subgroup assignments, along with a review of the complete results of the statistical analysis done on the results of the individual exercises from the first day. This will include a summary of each participant's set of weights from the first day, organized by subgroup, but not identified by name. The balance of the second day will be devoted to parallel subgroup sessions to discuss and revise the mean weights for each of the subgroups.

A skilled individual (non-CRP) will be retained to facilitate the discussion of each subgroup. The initial activity in each subgroup will be a structured discussion of the mean weights for that subgroup. In this discussion, each individual will be given an opportunity to compare the mean weights with his or her individual weights from the previous day. Individuals will be asked to explain their own rationale for their positions without interruption from any other subgroup member. After each participant has had that opportunity, the discussion of variable weights will be opened up to all participants with assistance from the facilitator.

After the subgroup discussion, each individual will be asked to reconsider his or her original weights by completing another individual exercise. With the revised individual weights as input, revised mean weights for the variables will be calculated and recorded. The facilitator will be provided with a full range of descriptive statistics for this exercise; thus assisting with the identification of where there is basic agreement and where the subgroup is polarized on variable weights. Using this information, the facilitator repeats the process described above, this time focusing subgroup attention on where there is significant disagreement. This iterative process continues until there is no significant change in mean weights from one iteration to the next. At that point, while a range of individual opinions on weights still exists, each subgroup participant has solidified his or her views to the point that subgroup interaction is not leading to further change in the mean weights. The final set of mean weights is then taken to be representative of the views of that particular subgroup regarding the relative importance of the region-to-area screening variables. Consequently, each workshop will yield 
five or six sets of weights derived from the parallel conduct of subgroup iterations. It should also be noted that the original subgroup iterations will involve only the Step 2 variables. After those iterations are complete, the weighting process will be sequentially repeated with the inclusion of (a) the Step 3 variables, (b) Step 2 variables with modified scales, and (c) Step 2 variables with modified scales and Step 3 variables.

Because of the structured, interactive nature of the process described, each weighting workshop will be limited to participants, facilitators, and CRP technical resource staff (on an as-needed basis). Each subgroup will determine if, and when, CRP technical resource staff should be requested.

\subsubsection{Documentation and Use of Weighting Workshop Results}

The third day of each of the two workshops will be devoted to completing the weighting process (if required), and to reporting the results to the entire group of participants. Each participant will receive a copy of the weights developed by each of the subgroups. An opportunity will then be provided for participants to discuss the weights, and the extent to which they are representative of a range of views of the relative importance of the screening variables. At the end of the CRP workshop, process improvements were discussed to maximize the efficiency of deriving weights from the state workshop to follow.

The weights derived from the two workshops will be documented and forwarded to each crystalline state. Based on the results of the CRP workshop, it is expected that a total of 10 to 12 sets of weights will be derived from both workshops. As previous $1 y$ noted, the weights derived from the CRP workshop will be provided to each crystalline state after the conclusion of the state workshop. The complete documentation of the weighting process, including a description of the selection of participants and of the steps in weighting, will be provided in the ARR documentation. This documentation will report the results of subgroup iterations, not the weights of individual participants. While the individual weights used to form the initial subgroups will be reported, they will not be reported by participant name. This will help minimize undue pressure on individual participants from various constituencies. 
After both suites of weights have been developed, they will be compared and contrasted prior to the selection by the DOE of the sets to be used in screening. As mentioned earlier, the DOE is committed to selecting and using a broad range of weights. It is recognized that there may be significant similarity between the two suites of weights. Where such similarity exists, the DOE will select sets of weights with a preference given to those developed in the state workshop. The most extreme, as well as intermediate, sets of weights will be used to estimate aggregate favorability of crystalline rocks in support of the selection of candidate areas. The selection of weight sets will be documented in the ARR.

\subsubsection{Composite Map Development}

Once the Step 2 variables have been scaled, gridded favorability maps for each variable have been prepared, and representative sets of weights have been selected, composite favorability maps will be prepared. Because of the large number of grid cells and data processing involved, a computer-assisted approach will be employed to prepare these maps.

As mentioned earlier, the 1-square-mile grid cells will be the accounting unit for this analysis. Each grid cell will have a numerical entry for each Step 2 variable which depicts an appropriate level of a favorable or potentially adverse condition. Composite or aggregate favorability maps will be prepared by calculating the weighted (arithmetic) average of all numerical entries in each grid cell as an index or estimate of composite favorability. 1 Consequently, one composite favorability map will be prepared using each selected set of weights and the same set of variable scales.

1The weighted (arithmetic) average is defined as the sum, over all variables, of the product of the scale value for a variable multiplied by the weight for that variable, divided by the sum of the weights (or 1,000 points). The same result can be achieved by treating the weight point allocations as decimals that sum to 1.0. This approach will be utilized in the actual computer calculations of weighted averages. 
The composite favorability maps will indicate where the most favorable rock bodies or portions of rock bodies are located as determined by that specific set of variable weights. Figure 11 provides a simplified example of what these composite maps may look like. It is simplified because it was derived as part of the hypothetical application of the methodology using a smaller number of variables than will actually be used in Step 2 of region-toarea screening. Again, the darker the zone on the composite maps, the less favorable that zone is based on that set of weights and scales.

Several composite favorability maps will be prepared to support the candidate area selection process. Each map will provide a graphic depiction of those rock bodies, or portions of rock bodies, which are the most favorable with respect to the specific weighting and scaling assumptions used in their preparation. These maps will be the key inputs to the Step 3 sensitivity analyses.

\subsubsection{Step 3 - Sensitivity Analyses}

The third step in the region-to-area screening methodology is the conduct of sensitivity analyses on the results of Step 2. Four types of sensitivity analyses may be conducted in this step, including:

- Modifying the scales of Step 2 variables.

- Evaluating the effects of using the geometric mean as an alternate index of aggregate favorability in deriving composite maps.

- Preparing and comparing summary composite maps.

- Incorporating other geologic variables based upon available rock body-specific data.

\subsubsection{Modifying Variable Scales}

The variable scales outlined in Chapter 5.0 were prepared after considerable state interaction at two methodology development workshops and DOE evaluation of state comments following these workshops, along with state comments on the draft version of this document. While there was substantial agreement, there was not total accord. It is recognized that scaling judgments are 


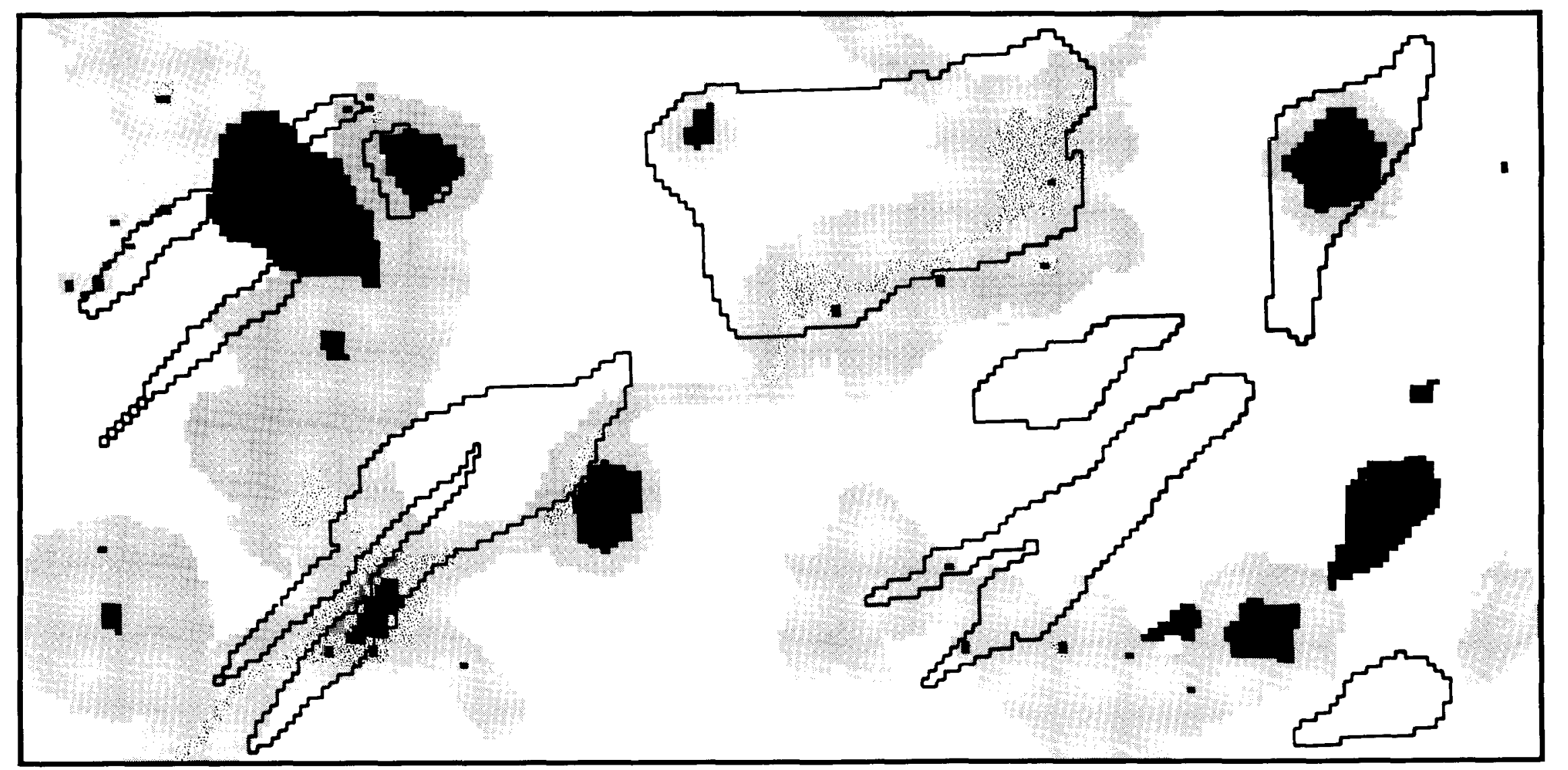

\section{LEGEND:}

$\begin{array}{llll}\text { Disqualified } & 1.00-2.00 & 3.00-4.00 \\ 0-1.00 & 2.00-3.00 & \square .00-5.00\end{array}$


subjective. In an effort to explore the effects of modifying variable scales, the CRP technical staff will selectively modify the scales. The actual selection by DOE of which scales to modify will be based on feedback from the prior methodology development workshops, on formal comments on the scales contained in the draft version of this methodology document, and on CRP staff views of the variable scales. In addition, DOE has determined that three Step 2 variable scales should be modified as part of the sensitivity analysis; these are Rock Mass Extent (Section 5.2.1), Seismicity (Section 5.2.4) and Proximity to Highly Populated Areas or to 1-Mile-Square Areas with 1,000 or More Persons (Section 5.3.10). Table 2 contains both the original scales and the modified scales for these three Step 2 variables. One or more sets of scale changes will be used along with alternative sets of weights to generate additional composite favorability maps. These maps will be compared with the composites that result from Step 2 to determine the extent to which scaling differences affect the identification of the most favorable candidate areas (rock bodies). These comparisons, including maps as appropriate, will be documented in the ARR.

\subsubsection{Using Alternative Index of Aggregate Favorability}

Step 2 uses the weighted average as an index of aggregate favorability in the development of composite maps. While the CRP believes the weighted average is a defensible index, it is recognized that other indices could also be used. Consequently, provision has been made in Step 3 sensitivity analysis to test one other index. This index is the geometric mean. 1 This is because the geometric mean has been applied effectively in contexts similar to that of the CRP's regional phase and because the use of this alternative index may also aid in discriminating the most favorable rock bodies for further investigation.

The geometric mean is calculated as the $n$th root of the product of $n$ numbers. In Step 3 sensitivity analysis, the $n$ numbers are $W_{1} S_{1}, W_{2} S_{2}, \ldots W_{n} S_{n}$, where $W_{i}=$ weighting coefficient for variable $i$

$S_{j}=$ scale value for variable $i$

$\mathrm{n}=$ number of variables. 
Table 2. Original and Modified Scales for Step 2 Variables: Rock Mass Extent, Seismicity, and Proximity to Highly Populated Areas or 1-MileSquare Areas with 1,000 or More Persons

1) Rock Mass Extent

Original Scale

Diameter of Maximum Circle That Will Fit in Rock Body (Miles)

$\leq 2 \quad>2-8 \quad>8-14 \quad>14-20 \quad>20$

\begin{tabular}{lllll}
\hline 1 & 2 & 3 & 4 & 5
\end{tabular}

Modified Scale

Diameter of Maximum Circle That Will Fit in Rock Body (Miles)

$\leq 2 \quad>2-8 \quad>8-14 \quad>14$

\begin{tabular}{lllll}
\hline 1 & 2 & 3 & 4 & 5
\end{tabular}

2) Seismicity

Original Scale

Maximum Probable Ground Acceleration (\% g)

$>70>50-70 \quad>30-50 \quad>10-30 \quad \leq 10$

$\begin{array}{lllll}1 & 2 & 3 & 4 & 5\end{array}$

Seismicity

Modified Scale

Maximum Probable Ground Acceleration (\% g)

\begin{tabular}{llccc}
$>40$ & $>30-40$ & $>20-30$ & $>10-20$ & $\leq 10$ \\
\hline 1 & 2 & 3 & 4 & 5
\end{tabular}


Table 2. (Continued)

3) Proximity to Highly Populated Areas or to 1-Mile-Square Areas with 1,000 or More Persons

Original Scale

Distance from Highly Populated Areas (Miles)

\begin{tabular}{lcccc}
$0-12$ & $>12-24$ & $>24-36$ & $>36-48$ & $>48$ \\
\hline 1 & 2 & 3 & 4 & 5
\end{tabular}

Modified Scale

Distance from Highly Populated Areas (Miles)

\begin{tabular}{lcccc}
$0-5$ & $>5-10$ & $>10-15$ & $>15-20$ & $>20$ \\
\hline 1 & 2 & 3 & 4 & 5
\end{tabular}


The testing will be done on one or more sets of scales and weights used in Step 2. The results will be compared with the composites generated through the use of the weighted average to determine whether the use of the alternative index significantly changes the selection of the most favorable rock bodies. If the differences are judged to be significant, the alternative index will be more broadly applied to other sets of weights and scales. Statistical differences will be evaluated, and implications for selection of candidate areas will be assessed. Such assessments will be documented in the ARR.

\subsubsection{Evaluating Different Sets of Weights by Preparing and Comparing Summary Composite Maps}

Step 2 and the sensitivity analyses described previously will lead to the development of numerous composite favorability maps. A large number of these maps will make it difficult for identification of candidate areas for further study unless they are processed further into a form that facilitates decisionmaking. This form has been termed the "summary composite map".

The summary composite map is used to identify similarity or overlapping areas of the most favorable candidate areas (rock bodies) on a related series of composites. For example, the CRP may want to identify which candidate areas (rock bodies) show up with a weighted average greater than 4.5 (out of 5) on all four composite maps derived using four sets of state-derived weights. A summary composite map which identifies the most highly rated candidate areas (rock bodies) on all four composites could be prepared, on three of the four composites, etc. Figure 12 illustrates such a summary composite map. The lighter areas indicate the highest coincidence of grid cells with a weighted average greater than 4.5 on the four composite maps.

The use of summary composites allows the examination of which candidate areas (rock bodies) are highly rated, as defined by the Step 2 variables, under a range of scaling and weighting scenarios. The precise groups of composites from which summary composites will be prepared cannot be determined at this time. Logical series of composites that are candidates for such analys is include:

- A summary composite derived from all Step 2 composites (includes composites derived from CRP and state sets of weights). 


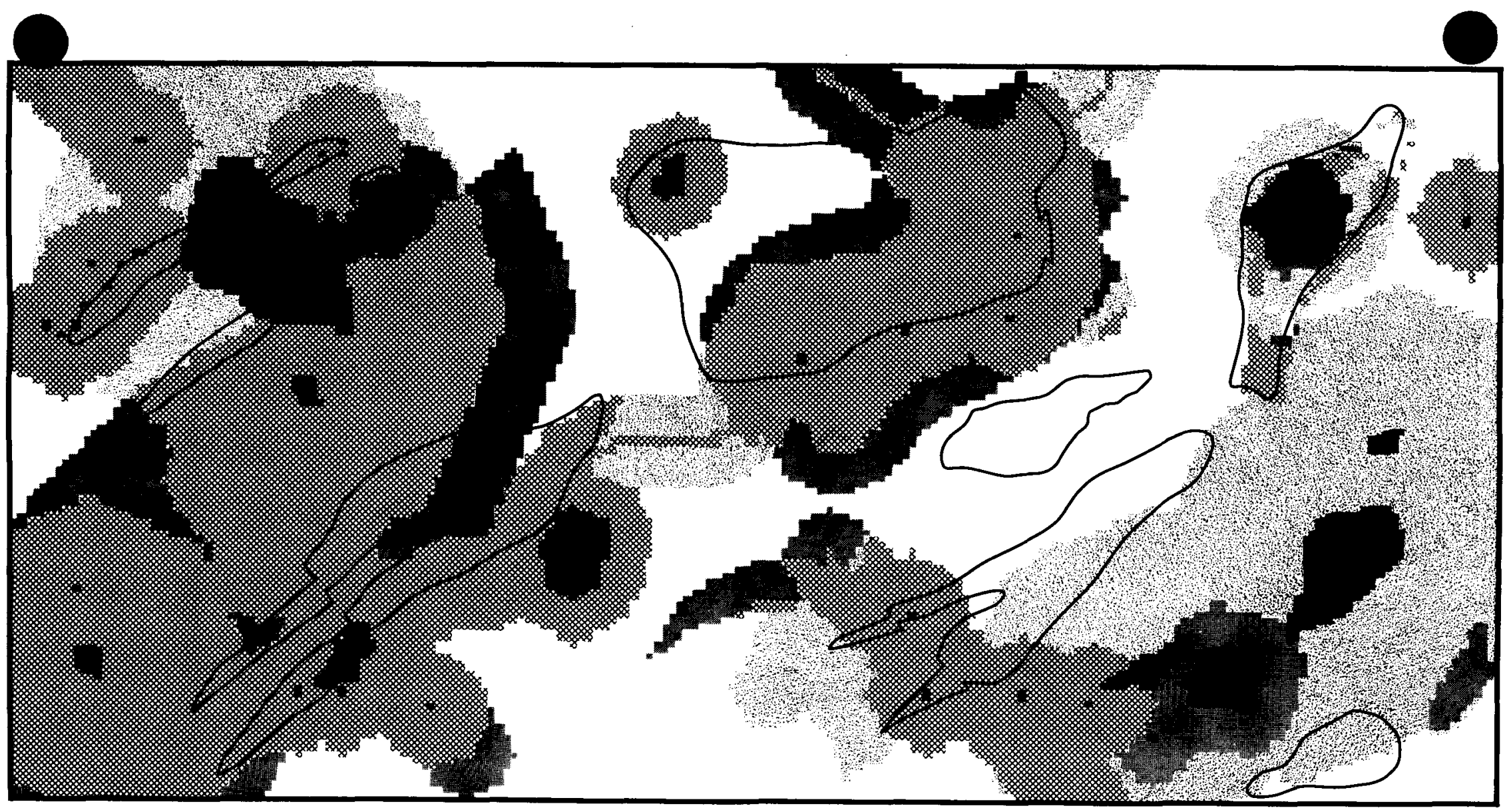

\section{LEGEND: Coincidence of}

4 Maps, Composite Favorability $>4.5$

3 Maps, Comp. Fav. $>4.5$

2 Maps, Comp. Fav. $>4.5$
One Map, Comp. Fav. $>4.5$

No Maps, Comp. Fav. $>4.5$

Disqualified

Figure 12 Summary Composite Favorability Greater than 4.5 with Hypothetical Rock Bodies 
- A summary composite derived from Step 2 composites prepared using state sets of weights.

- A summary composite derived from Step 2 composites prepared using the CRP sets of weights.

- Various summary composites derived from combinations of Step 2 and Step 3 composites related to modified scales and/or to the use of the alternative index of aggregate favorability.

The summary composites developed in this step will be key inputs to decision making. They will be developed to summarize the relatively complex information in a logical, highly graphic, and understandable format. The summary composites will be presented in the ARR.

\subsubsection{Incorporating Step 3 Variables}

The Step 2 region-to-area screening variables described in Chapter 5.0 were selected on the basis that a reasonably consistent data base could be developed for all 17 crystalline states. In response to state requests to use other rock body-specific data, the CRP developed the concept of Step 3 variables.

The Step 3 variables to be used in this process are also described in Chapter 5.0. These variables have only scattered data available across the 17 crystalline states (e.g., State-of-Stress), or the data collection effort to achieve a consistent data base for use in Step 2 would have been prohibitively costly given the expected benefits in discriminating between rocks (e.g., Ground-Water Resources).

Once the most favorable candidate areas (rock bodies) have been identified from the analysis of summary composites, the CRP data base will be examined to identify Step 3 variable data on any of these candidate areas (rock bodies). This is done to ensure that other readily available rock bodyspecific data are incorporated into the analysis before making area recommendations. This will be accomplished by generating new composites and summary composites based upon the addition of new variable(s) to affected grid cells. This will identify whether the addition of such data affects the aggregate favorability of these rocks significantly enough to displace them from the list of top-rated candidate areas. 
It should be noted that the weighted averages calculated in this process will be derived using a larger number of variables depending upon how many Step 3 variables influence a given grid cell. For those grid cells without Step 3 variable data, nothing will be assumed about the adversity or favorability of those grid cells for the Step 3 variables.

\subsection{SELECTING CANDIDATE AREAS AND IDENTIFYING POTENTIALLY ACCEPTABLE SITES}

As stated previously, the purpose of region-to-area screening is to narrow the number of exposed and near-surface crystalline rock bodies with in the 17 crystall ine states of the North Central, Northeastern, and Southeastern Regions to determine which areas will be investigated and evaluated in more detail during the area phase. In the event that DOE elects to identify PAS at the beginning of the area phase, the region-to-area screening process has also been designed to allow these results to be utilized as the basis for such identification in accordance with 10 CFR 960.3-2-1. If DOE so elects, the actual identification of PAS is dependent upon whether "the evidence does not support a finding that the site is disqualified" for each of the disqualifying conditions that must be addressed in accordance with the application requirements of Appendix III of the DOE Siting Guidelines. Furthermore, such evidence shall support the decision by DOE to proceed with the continued investigation of the site on the basis of the favorable and potentially adverse conditions identified to date. In the event that DOE does not identify PAS in the ARR, a separate decision-basis document would be developed during the area phase that describes the process and considerations that lead to the subsequent identification of all or any portion of a candidate area as a PAS in accordance with the requirements of 10 CFR 960.3-2-1. The CRP will proceed into the area phase whether or not PAS are identified in the ARR.

\subsubsection{Selecting Candidate Areas}

The results of Steps 1 through 3 will serve as the basis for the selection of candidate areas. This selection will be done in accordance with Subpart B - Implementation Guidelines of the DOE Siting Guidelines. More 
specifically, prior to the final selection of candidate areas, the following will be undertaken:

- A complete review of the results of the region-to-area screening methodology described herein to ensure its accuracy and technical defensibility.

- A review of qualitative/descriptive literature to help ensure that there is reasonable expectation, within the constraints of a regional study, that the candidate areas warrant further examination in the area phase. The purpose of this review is intended to ensure that there are no data in the CRP data base, as reflected in the final RCR or in the existing literature, that indicates an anomaly in the results of region-to-area screening. For example, CRP will evaluate the impact of Step 1 disqualifying features which are less than 130 hectares (320 acres) in size on the candidate areas. In addition, CRP will be attempting to determine if there is any evidence (i.e., types of information specified in Appendix IV of the DOE Siting Guidelines) that either a disqualifying condition or a potentially adverse condition not utilized in Steps 2 or 3 of the methodology actually exists within the candidate area. For example, the CRP will assess whether the candidate area is impacted by the Coastal Barrier Resources Act (P.L. 97-348). If there is evidence that supports a finding that a disqualifying condition exists, the grid cells affected will be disqualified and an assessment will be made to determine if the remaining area should continue to be considered a candidate area. If a new potentially adverse condition is encountered, DOE will assess its impact on the candidate area. It should be noted, however, that the presence of such a condition will not necessarily result in a change in the candidate areas. Furthermore, if such a potentially adverse condition is encountered, DOE will also assess whether there is evidence of an offsetting favorable condition not utilized in Steps 2 or 3. For example, CRP plans to review for non-riskrelated considerations existing highway networks (interstate, state, and local) and rail networks to evaluate the favorable and potentially adverse conditions of 
10 CFR 960.5-2-7. In the event that these reviews result in any proposed change to the list of candidate areas, the proposed change (including the rationale for it) will be documented in the draft ARR. Any data relied on but not included in the final RCR that are used in making these evaluations will be documented.

- A review and application, as appropriate, of the Implementation Guidelines (Subpart B of DOE's Siting Guidelines; see also Section 4.2 .1 of the document) including:

- Diversity of geohydrologic settings (10 CFR 960.3-1-1)

- Diversity of rock types (10 CFR 960.3-1-2)

- Regionality (10 CFR 960.3-1-3)

- Site identification as potentially acceptable

(10 CFR 960.3-1-4-1)

- Basis for site evaluations (10 CFR 960.3-1-5)

- Site screening for potentially acceptable sites

(10 CFR 960.3-2-1)

- Consultation (10 CFR 960.3-3).

It should be noted that the region-to-area screening process described herein is designed to provide DOE decisionmakers with the appropriate information for the selection of candidate areas that warrant further study in the area phase.

The area recommendation decisions will be made in accordance with the inputs described above. A draft of the ARR will be subject to review and comment by the 17 crystalline states and potentially affected Indian tribes prior to its issuance as a final document.

\subsubsection{Identifying Potentially Acceptable Sites}

In the event that DOE elects to identify PAS at the beginning of the area phase, each candidate area selected in accordance with Section 3.3 will be further analyzed to determine if DOE can identify each such area as a PAS in accordance with 10 CFR 960.3-2-1. In order for DOE to identify a PAS, the "evidence shall support a finding that the site is not disqualified in accordance with the application requirements set forth in Appendix III of this part [10 CFR 960] and shall support the decision by DOE to proceed with the 
continued investigation of the site on the basis of the favorable and potentially adverse conditions identified to date". Accordingly, for the identification of a PAS, DOE must apply the 10 disqualifying conditions specified in Appendix III and assess whether the available evidence does or does not support a finding that a site is disqualified. The evidence for the identification of a PAS shall be the types of information specified in Appendix IV of the DOE Siting Guidelines although such evidence will be relatively general and less detailed than that required for the nomination of a site as suitable for characterization (see 10 CFR 960.3-1-4-1). As previously stated, actual identification of an area as a PAS will be dependent on DOE's ability to make a finding that "the evidence does not support a finding that the site is disqualified" for each of the 10 disqualifying conditions that must be addressed in accordance with the application requirements of Appendix III of the DOE Siting Guidelines. The evidence to support the decision to proceed with the continued investigation of the site on the basis of the favorable and potentially adverse conditions identified to date will be the evaluations described as part of the qualitative/descriptive literature review in Section 3.3.1.

Because 5 of the 10 disqualifying conditions will be directly applied in Step 1 of the screening methodology [i.e., 10 CFR 960.4-2-8-1(d)(1), 10 CFR 960.5-2-1(d)(1) and (d)(2), 10 CFR 960.5-2-5(d)(2) and (d)(3)], DOE expects that it will have the evidence to support a finding that a site is not disqualified for these disqualifying conditions. Of the remaining five disqualifying conditions, the rate of dissolution [10 CFR 960.4-2-6(d)] in crystalline rocks is so small as to not affect crystalline rocks in the context of this guideline. Consequently, dissolution is not a concern for the types of rock bodies being investigated in the CRP and, in accordance with Appendix IV of the DOE Siting Guidelines, such information would not be required for any crystalline site. Accordingly, DOE expects to be able to support a finding that the evidence does not disqualify a site for this disqualifying condition. With respect to the other four disqualifying conditions, [10 CFR 960.4-2-5(d), 10 CFR 960.4-2-7(d), 10 CFR 960.5-2-4(d), and 10 CFR 960.5-2-11(d)], DOE expects that it will be able to make a finding that the evidence does not disqualify the site for each of these four disqualifying conditions based on a review of the literature as described in 
Section 3.3.1. (For a more detailed discussion of these 10 disqualifying conditions, see Section 4.1)

Accordingly, DOE expects that it will have the evidence to make formal findings for all 10 disqualifying conditions. 


\subsection{GUIDELINES USED IN REGION-TO-AREA SCREENING}

The U.S. Department of Energy (DOE) Siting Guidelines (DOE, 1984a), developed in accordance with requirements of the Nuclear Waste Policy Act of 1982 (NWPA) for use by the Secretary of Energy in evaluating the suitability of sites for repository development, served as the source for the factors and variables applied in region-to-area screening. Detailed discussion of how the regionally applicable factors and variables from the DOE Siting Guidelines are used in this region-to-area screening methodology is presented in Chapter 5.0.

The factors and variables to be used in region-to-area screening were determined based on which characteristics could be adequately evaluated across the three regions. Qual ifying, disqualifying, favorable, and potentially adverse conditions presented in the DOE Siting Guidelines which are not used in region-to-area screening will be applied in later screening phases when data to support their use are available.

\subsection{DISQUALIFYING FACTORS FROM THE DOE SITING GUIDELINES}

The DOE Siting Guidelines contains a total of 17 disqualifying conditions. Appendix III of the DOE Siting Guidelines explains how the guidelines are to be used during the siting process and specifies 10 of the 17 disqualifying conditions that must be applied to determine if a site is potentially acceptable. The determination of potential acceptability is accomplished by evaluating the types of information available for these 10 disqualifying conditions and assessing whether the available evidence does or does not support a finding that a site is disqualified. Table 3 summarizes the 17 disqualifying conditions from the DOE Siting Guidelines and identifies the 10 for which a finding is required by Appendix III to determine if a site is potentially acceptable.

Table 3 a? :0 indicates 5 of the 10 disqualifying conditions for which findings are required that have sufficient regional data in a form which permits their incorporation into Step 1 without evaluation/interpretation. These five conditions are summarized in Sections 4.3 and 4.4 of this document and are outlined in the following paragraphs. Detailed discussion of the Step 1 disqualifying factors is presented in Section 5.1 . 
Table 3 Summary of Disqualifying Conditions From the DOE Siting

Guidelines 1 (10 CFR 960) and Applicability in Region-to-

Area Screening of Those Conditions Requiring Findings

\begin{tabular}{|c|c|c|c|c|}
\hline $\begin{array}{l}10 \text { CFR } 960 \\
\text { Section No. }\end{array}$ & Summary of Disqualifying Condition & $\begin{array}{c}\text { Finding } \\
\text { Required per } \\
\text { Appendix III } \\
\text { of } \\
10 \mathrm{CFR} 960\end{array}$ & $\begin{array}{l}\text { Regional Data } \\
\text { Available and } \\
\text { Used in } \\
\text { Step } 1\end{array}$ & $\begin{array}{l}\text { Data Requires } \\
\text { Evaluation } \\
\text { Condition Not } \\
\text { Used in } \\
\text { Step 1 }\end{array}$ \\
\hline
\end{tabular}

\begin{tabular}{|c|c|c|c|c|}
\hline & Postclosure & & & \\
\hline $4-2-1(d)$ & $\begin{array}{l}\text { Pre-waste emplacement ground-water travel time from the disturbed zone to } \\
\text { the accessible environment is expected to be less than } 1,000 \text { years }\end{array}$ & & & \\
\hline $4-2-5(d)$ & $\begin{array}{l}\text { The underground facility cannot be located at least } 200 \text { meters ( } 656 \text { feet) } \\
\text { below the overlying ground surface }\end{array}$ & $x$ & & $x$ \\
\hline $4-2-6(d)$ & $\begin{array}{l}\text { During the first } 10,000 \text { years after closure active dissolution would result in } \\
\text { loss of waste isolation }\end{array}$ & $x$ & & $x^{2}$ \\
\hline $4-2 \cdot 7(d)$ & $\begin{array}{l}\text { Nature and rates of fault movement or other ground motion would likely } \\
\text { cause loss of waste isolation }\end{array}$ & $\dddot{2}$ & & $x$ \\
\hline $4-2 \cdot 8-1(d)(1)$ & $\begin{array}{l}\text { Previous activities at the site related to extraction, mining, or exploration } \\
\text { for resources of commercial importance have created significant pathways } \\
\text { to the accessible environment }\end{array}$ & $x$ & $x$ & \\
\hline \multirow[t]{2}{*}{$4-2-8-1(d)(2)$} & $\begin{array}{l}\text { Ongoing or future activities to recover presently valuable natural mineral } \\
\text { resources outside the controlled area would be expected to lead to loss of } \\
\text { waste isolation }\end{array}$ & & & \\
\hline & Preclosure & & & \\
\hline $5-2-1(d)(1)$ & Surface facility located in a highly populated area & $x$ & $x$ & \\
\hline $5-2-1(d)(2)$ & $\begin{array}{l}\text { Surface facility located adjacent to } 1 \text {-mile-square-area with a population } \\
\text { greater than } 1,000\end{array}$ & $x$ & $x$ & \\
\hline $5-2-1(d)(3)$ & $\begin{array}{l}\text { DOE could not develop an emergency preparedness program which meets } \\
\text { requirements in DOE Order } 5500.3 \text { or } 10 \text { CFR } 60 \text {, Subpart I }\end{array}$ & & & \\
\hline $5-2-4(d)$ & $\begin{array}{l}\text { Atomic energy defense activities in proximity to the site are expected to } \\
\text { irreconcilably conflict with repository siting, construction, operation, } \\
\text { closure, or decommissioning }\end{array}$ & $x$ & & $x$ \\
\hline $5-2-5(d)(1)$ & $\begin{array}{l}\text { Repository siting, construction, operation, closure, or decommissioning } \\
\text { create unacceptable adverse impacts that cannot be mitigated }\end{array}$ & & & \\
\hline $5-2-5(d)(2)$ & $\begin{array}{l}\text { The restricted area or repository support facilities would be located within } \\
\text { the boundaries of a component of the National Park System, National Wild- } \\
\text { life Refuge System, National Wilderness Preservation System, or National } \\
\text { Wild and Scenic Rivers System }\end{array}$ & $x$ & $x$ & \\
\hline $5-2-5(d)(3)$ & $\begin{array}{l}\text { The presence of the restricted area or repository support facilities would } \\
\text { irreconcilably conflict with the previously designated resource preservation } \\
\text { use of a component of the National Park System, National Wildlife Refuge } \\
\text { System, National Wilderness Preservation System, National Wild and Scenic } \\
\text { Rivers System, National Forest Lands, or any comparably significant state } \\
\text { protected resource }\end{array}$ & $x$ & $x$ & \\
\hline $5-2-6(d)$ & $\begin{array}{l}\text { Repository construction, operation, or closure would significantly reduce } \\
\text { quality or quantity of water from major offsite sources }\end{array}$ & & & \\
\hline $5-2-9(d)$ & $\begin{array}{l}\text { Rock characteristics are predicted to cause a significant risk to health and } \\
\text { safety of personnel during repository construction, operation, or closure }\end{array}$ & & & \\
\hline $5-2-10(d)$ & $\begin{array}{l}\text { Expected ground-water conditions would likely require engineering measures } \\
\text { that are beyond reasonably available technology for the exploratory shaft } \\
\text { construction or for repository construction, operation, or closure }\end{array}$ & & & \\
\hline $5-2-11(d)$ & $\begin{array}{l}\text { Expected nature and rates of fault movernent or other ground motion would } \\
\text { likely require engineering measures that are beyond reasonably available } \\
\text { technology for exploratory shaft construction or for repository construc- } \\
\text { tion, operation, or closure }\end{array}$ & $x$ & & $x$ \\
\hline
\end{tabular}

For complete statements of the disqualifying conditions, refer to the DOE General Guidelines for Recommendation of Sites for Nuclear Waste Repositories (10 CFR 960) in Federal Register v. 49, no. 236, pgs 47714-47770 dated December 6, 1984.

2 The rate of dissolution in crystalline rocks is so small so as to not affect crystalline rocks in the context of 10 CFR 960.4-26(d). Consequently. dissolution is not a concern for the types of rock bodies being investigated in the CRP, (cf, p. 49). 


\section{Postclosure}

1. Previous activities at the site related to extraction, mining, or exploration for resources of commercial importance have created significant pathways to the accessible environment

[10 CFR 960.4-2-8-1(d)(1)].

- This postclosure disqualifying condition is incorporated into the Deep Mines and Quarries disqualifying factor, which is discussed in Section 5.1 .5 of this document.

Preclosure

2. Surface facility is located in a highly populated area [10 CFR 960.5-2-1(d)(1)].

3. Surface facility is located adjacent to a 1-mile-square area with 1,000 or more persons [10 CFR 960.5-2-1(d)(2)].

- These preclosure disqualifying conditions are incorporated into the Population Density and Distribution disqualifying factor, which is discussed in Section 5.1.4 of this document.

4. The restricted area or repository support facilities are located within the boundaries of a component of the National Park System, National Wildlife Refuge System, National Wilderness Preservation System, or National Wild and Scenic Rivers System [10 CFR $960.5-2-5(d)(2)]$.

- This preclosure disqualifying condition is incorporated into the Federal-Protected Lands disqualifying factor, which is discussed in Section 5.1.1 of this document.

5. The presence of the restricted area or repository support facilities would irreconcilably conflict with the previously designated resource preservation use of a component of the National Park System, National Wildlife Refuge System, National Wilderness Preservation System, National Wild and Scenic Rivers System, National Forest Lands, or any comparably significant state-protected resource [10 CFR 960.5-2-5(d)(3)]. It should be noted that to disqualify Federal- or comparably significant state-protected lands with this provision of the DOE Siting Guidelines in the regional phase, the Crystalline Repository Project (CRP) has determined that it must be 
able to categorically identify lands that constitute an irreconcilable conflict of use. The CRP's judgment is that this can only be applied within the boundaries of three components of the National Forest Lands (i.e. primitive areas, research natural areas, and national recreation areas) and certain categories of state-protected lands (e.g., parks, wild and scenic rivers, stateowned wildlife lands, wilderness and natural areas), and that area or site-specific analysis is required to determine if an irreconcilable conflict exists if a repository would be sited proximate to other lands in the scope of this disqualifier. Such analyses will be conducted in subsequent siting phases.

- This preclosure disqualifying condition is incorporated into two disqualifying factors: Components of the National Forest Lands, discussed in Section 5.1.2, and State-Protected Lands, discussed in Section 5.1.3.

The remaining five disqualifying conditions in Table 3 for which findings are required to determine if a site is potentially acceptable but which are not being used as Step 1 disqualifying factors, also require discussion. In general, the disqualifying conditions not used in Step 1 of the region-to-area screening methodology do not have sufficient regional data in a form which allows their systematic application without evaluation/interpretation. If a candidate area is to be identified as a potentially acceptable site (PAS), data pertinent to these five disqualifying conditions will be drawn from the regional characterization reports $(R C R)$ and from other information in the existing literature. Unless this review of the literature concerning the identified candidate areas (rock bodies) (see Section 3.3.1) results in evidence supporting a finding of disqualification of the candidate area (rock body) or portions thereof, DOE expects that it will have the evidence to make a finding in the area recommendation report (ARR) that the available evidence does not support a finding of disqualification for the five disqualifying conditions discussed below.

The following discussion specifically addresses each of the five disqualifying conditions not used in Step 1 of region-to-area screening.

1. The underground facility cannot be located at least 200 meters (656 feet) below the directly overlying ground surface [10 CFR $960.4-2-5(d)]$. 
- This postclosure disqualifying condition is related to the concern that the underground facility be situated at a depth which would prevent surficial erosional processes from affecting the facility and inducing unacceptable radionuclide releases. It should be noted that a depth limitation for the underground facility of at least 300 meters ( 984 feet) below the overlying ground surface is used as a Step 3 variable in region-to-area screening, where this minimum depth is treated as a favorable condition for siting under the Thickness of Rock Mass variable in Section 5.4.1 of this document. This variable incorporates the favorable condition for erosion from the DOE Siting Guidelines [10 CFR 960.4-2-5(b)(1)], which states that site conditions permitting emplacement of waste at a depth of at least 300 meters (984 feet) below the overlying ground surface area are considered favorable. Because most crystalline rocks extend to depths of many thousands of feet, the scale used for this Step 3 variable was given a broad range. The main thrust for doing so was to avoid rock bodies that would have relatively shallow floors and favor those that have greater vertical extent. Rock bodies having shallow floors are indicative of potential complex modeling for repository performance.

2. It is likely that, during the first 10,000 years after closure, active dissolution as predicted on the geologic record would result in loss of waste isolation [10 CFR 960.4-2-6(d)].

- This postclosure disqualifying condition is related to the concern about subsurface rock dissolution leading to unacceptable radionuclide releases. The rate of dissolution in crystalline rocks is so small as to not affect crystalline rocks in the context of this guideline. Consequently, dissolution is not a concern for the rock bodies being investigated in the CRP. Accordingly, it is expected that no finding supporting disqualification of the site will result from this condition at any stage of the siting process.

3. The nature and rates of fault movement or other ground motion would likely cause loss of waste isolation [10 CFR 960.4-2-7(d)]. 
- This postclosure disqualifying condition is related to the concern that future tectonic events and processes could lead to unacceptable radionuclide releases. It should be noted that tectonism is addressed as a Step 2 variable in region-to-area screening by treatment of Seismicity, Suspected Quaternary Faulting, and Postemplacement Faulting variables in Sections 5.2.4, 5.2.5, and 5.2.6 of this document. These three variables incorporate the favorable condition for tectonics from the DOE Siting Guide] ines [10 CFR 960.4-2-7(b)], which states that it is considered favorable if the nature and rates of tectonic processes operating during the Quaternary Period would, if continued, have less than one chance in 10,000 of leading to release of radionuclides to the accessible environment, over the first 10,000 years after closure. The three variables also consider potentially adverse conditions for tectonics from the DOE Siting Guidelines [10 CFR 960.4-2-7(c)] by evaluating horizontal ground accelerations due to earthquakes, potential Quaternary faulting, and brittle deformation of any age.

4. Atomic energy defense activities in proximity to the site are expected to irreconcilably conflict with repository siting, construction, operation, closure, or decommissioning [10 CFR 960.5-2-4(d)].

- Application of this preclosure disqualifying condition requires the determination of irreconcilable conflict. The degree to which this potential exists depends on the type and location of atomic energy defense activities, specific environmental conditions, the provisions of emergency response plans, and cumulative dose calculations. These parameters are highly site- and facility-specific.

5. Expected nature and rates of faulting movement or other ground motion would likely require engineering measures that are beyond reasonably available technology for exploratory shaft construction or for repository construction, operation, or closure [10 CFR 960.5-2-11(d)].

- This preclosure disqualifying condition is related to the concern that the projected effects of expected tectonic events could 
require engineering measures beyond reasonably available technology for exploratory shaft construction or for repository construction, operation, or closure. As previously noted, tectonism is addressed as a Step 2 variable in region-to-area screening by treatment of the Seismicity variable in Section 5.2.4 of this document. By evaluating horizontal ground accelerations due to earthquakes, this variable incorporates the favorable condition for tectonics from the DOE Siting Guidelines [10 CFR 960.5-2-11(b)] which states that it is considered favorable if the nature and rates of faulting within the geologic setting are such that the magnitude and intensity of the associated seismicity are significantly less than generally allowable for construction and operation of nuclear facilities. The Seismicity variable (see Section 5.2.4) also considers potentially adverse conditions for tectonics from the DOE Siting Guidelines [10 CFR 960.5-2-11(c)] when evaluating horizontal ground motions.

\subsection{IMPLEMENTATION GUIDELINES RELATED TO REGION-TO-AREA SCREENING}

The implementation guidelines establish the procedure and basis for applying the postclosure and the preclosure guidelines to evaluate the suitability of sites for the development of repositories. There are no implementation guidelines specifically used as variables or factors in region-to-area screening. However, the implementation guidelines establish the procedure and basis for applying the postclosure and preclosure guidelines. Further, since it is known that sites found acceptable through the regional screening process must subsequently meet the criteria specified in the DOE Siting Guidelines, it was deemed both prudent and practical to establish as early as possible a parallelism between the regional screening logic and the guidelines. Therefore, those implementation guidelines which show some relation to regionto-area screening are summarized below.

Diversity of Geohydrologic Settings (10 CFR 960.3-1-1). This criterion is met through the DOE having a national radioactive waste isolation program 
which encompasses crystalline rocks, salt, tuff, basalt, and subseabed. This variety of rock types located in different areas ensures a variety of geohydrologic settings. The CRP, having three regions of the conterminous United States under active consideration (i.e., North Central, Northeastern, and Southeastern Regions), also has the ability to consider sites in a variety of geohydrologic settings other than those under consideration in salt, basalt, and tuff.

Diversity of Rock Types (10 CFR 960.3-1-2). This criterion is met through the DOE having a national Civilian Radioactive Waste Management (CRWM) Program comprising crystalline rocks, salt, tuff, basalt, and the subseabed for disposal of waste. The CRP has a large range of rock types to choose from, including gabbro and granite, as well as various high-grade metamorphic rocks, which may provide some additional diversity considerations in the selection of candidate areas.

Regionality (10 CFR 960.3-1-3). The DOE Siting Guidelines state that regionality should be considered in the selection of a second repository site after the first repository site is identified. The first repository will be selected from sites located in the states of Louisiana, Mississippi, Nevada, Texas, Utah, and Washington. The sites recommended for characterization but not selected as the first repository site may be considered for the second repository along with sites in crystalline rocks that are recommended for characterization. Distribution of candidate areas in the crystalline regions may provide additional flexibility in the future consideration of this guideline.

Site Identification as Potentially Acceptable (10 CFR 960.3-1-4-1). The DOE plans to comply with this implementation guideline, which calls for use of the types of information specified in Appendix IV of the DOE Siting Guidelines, through the qualitative/descriptive literature review described in Section 3.3.1. To date, the information that has been collected for use in the region-to-area screening process consists of documents available in the public domain. 
Basis for Site Evaluations (10 CRF 960.3-1-5). Although this implementation guideline is primarily applicable to the nomination, recommendation, and site selection stages of repository siting, certain provisions have been incorporated into the region-to-area screening process. As noted in this guideline, evaluations made during the screening process should be (and are being) based on postclosure and preclosure guidelines. This implementation guideline also states that when comparisons cannot be made on the basis of system guidelines, technical guidelines are to be used. The disqualifying, potentially adverse, and favorable conditions (of the technical guidelines) are used as the basis for the region-to-area screening process.

Site Screening for Potentially Acceptable Sites (10 CFR 960.3-2-1). This implementation guideline is followed in the CRP region-to-area screening. This screening is accomplished by first applying disqualifying conditions, followed by application of favorable and potentially adverse conditions. The CRP screening process is applied to large land units, and will result in the selection of smaller candidate areas. Subsequent screening activities will focus on successively smaller and increasingly more suitable land units.

Consultation (10 CFR 960.3-3). The DOE has maintained consultation and cooperation relationships throughout the CRWM Program. Further, the CRP has had three workshops to discuss the screening methodology presented in this document; has provided the 17 crystalline states with an opportunity to review a draft of this document; has responded to comments regarding the CRP methodology as well as general comments and questions regarding the CRP; and has held numerous briefings to discuss the DOE Siting Guidelines.

Implementation guidelines from the DOE Siting Guidelines not included in this summary are:

- Environmental Assessment (10 CFR 960.3-2-2-4)

- Formal Site Nomination (10 CFR 960,3-2-2-5)

- Recommendation of Site for Characterization (10 CFR 960.3-2-3)

- Recommendation of Sites for the Development of Repositories (10 CFR 960.3-2-4)

- Environmental Impacts (10 CFR 960.3-4). 
These guidelines are not related sufficiently to the region-to-area screening to warrant discussion in this document.

\subsection{POSTCLOSURE GUIDELINES REALTED TO REGION-TO-AREA SCREENING}

The postclosure guidelines specify the factors to be considered in evaluating and comparing sites on the basis of expected repository performance after closure. The postclosure guidelines are separated into a system guideline and eight technical guidelines. The system guideline establishes waste containment and isolation requirements that are based on U.S. Nuclear Regulatory Commission (NRC) and IJ.S Environmental Protection Agency (EPA) regulations. These requirements must be met by the natural and engineered barriers of the repository system. The engineered barriers will be designed to complement the natural barriers present at the site, the latter of which provide the primary means for waste isolation. The postclosure guidelines related to region-to-area screening are summarized below.

Downward or Horizontal Hydraul ic Gradient [10 CFR 960.4-2-1(b)(4)(ii)]. This favorable condition guideline is addressed through the Major Ground-Water Discharge Zones variable, which is discussed in Section 5.2.2 of this document. Areas of major water bodies and major through-flowing streams are potential locations of deep ground-water discharge. The major discharge areas will be less favorable as possible repository sites. Greater preference will be assigned, in increments, to areas further away from discharge areas and closer to the recharge area where ground-water gradients are predominately downward or horizontal.

Presence of Ground-Water Sources Between Host Rock and Accessible Environment [10 CFR $960.4-2-1(c)(2)]$. This potentially adverse condition guideline is addressed in the Ground-Water Resources variable, which is discussed in Section 5.4.4. Data on ground-water yield and developed resource potential will be used as a screening factor to judge whether ground-water sources are present along flow paths from the host rock to the accessible environment. Potential, long-term, average ground-water yield of wells in overlying rock bodies will be considered. Thus, areas which exhibit 
significant ground-water resource potential will be considered more unfavorable.

Sufficiently Thick and Extensive Host Rock [10 CFR 960.4-2-3(b)(1)]. This favorable condition guideline is addressed by the two variables, Rock Mass Extent and Thickness of Rock Mass, which are discussed in Sections 5.2.1 and 5.4.1, respectively. Any rock body selected for further characterization should be large enough to accommodate the subsurface space required for construction and to mitigate any construction-induced effects that might compromise repository performance. In calculating a minimum acceptable area, consideration must be given to the requirement for modeling repository performance out to the accessible environment and ground-water flow patterns. The confidence in selecting a suitable site can be increased by requiring that the minimum area be a circle 13 kilometers ( 8 miles) in diameter. Thus, rock bodies of greater extent than this area are more favorable, allowing more flexibility of moving within the same rock body to optimize siting conditions. Likewise, rock mass thickness is a consideration in the flexibility of the repository location within the rock mass. Thus, greater thickness of the rock mass is more favorable.

Emplacement of Waste at Depth Greater than 300 Meters [10 CFR 960.4-2-5(b)(1)]. This favorable condition guideline is also addressed in the Thickness of Rock Mass variable of Section 5.4.1. Therefore, again, greater thickness of the rock mass is more favorable.

Very Low Probability of Igneous Activity and Tectonic Processes for 10,000 Years After Closure [10 CFR 960.4-2-7(b)]. This favorable condition guideline is addressed in the Seismicity, Suspected Quaternary Faulting, and Postemplacement Faulting variables, which are discussed in Sections 5.2.4, 5.2.5, and 5.2.6, respectively. The presence of igneous activity or tectonic processes such as uplift, subsidence, faulting, or folding could compromise the integrity of the repository system, leading to escape of radionuclides to the accessible environment. Therefore, any geologic evidence that the probability of such events happening is very unlikely would be considered a favorable condition. The above variables are an attempt to assess this likelihood. 
Evidence of Active Tectonic Processes or Igneous Activity During the Quaternary Period [10 CFR 960.4-2-7(c)(1)]; Historic Earthquakes of Significant Magnitude and Intensity [10 CFR 960.4-2-7(c)(2)]; Indications That Frequency of Occurrence or Magnitude of Earthquakes May Increase [10 CFR 960.4-2-7(c)(3)]; More Frequent Occurrences or Higher Magnitude of Earthquakes Than Are Representative of the Region [10 CFR 960.4-2-7(c)(4)]; Potential for Natural Phenomena That Could Create Large-Scale Surface Water Impoundments [10 CFR 960.4-2-7(c)(5)]; and Potential for Tectonic Deformation That Could Adversely Affect Regional Ground-Water Flow [10 CFR 960.4-2-7(c)(6)]. The above potentially adverse condition guidelines are addressed in the Seismicity, Suspected Quaternary Faulting, and Postemplacement Faulting variables of Sections 5.2.4, 5.2.5, and 5.2.6, respectively. Again, the presence of any natural phenomena that could compromise waste isolation, such as those listed above from the guidelines, would be considered potentially adverse conditions.

No Known Natural Resources That May Have Commercial Value in the Foreseeable Future [10 CFR 960.4-2-8-1(b)(1)]. This favorable condition guideline is addressed in the Rock and Mineral Resources variable, which is discussed in Section 5.2.3. Siting the repository near a known strategic or unique mineral resource poses a potential concern in that the repository may actually preempt future use of the resource. The greater the distance from a resource, the more favorable the situation.

Indications That the Site Contains Naturally Occurring Materials of Commercial Value [10 CFR 960.4-2-8-1(c)(1)]; Evidence of Subsurface Mining [10 CFR 960.4-2-8-1(c)(2)(c)(3)]; Evidence of Significant Concentration of Unique Resources [10 CFR 960.4-2-8-1(c)(4)]; and Potential for Foreseeable Human Activities That Could Change the Ground-Water Flow [10 CFR 960.4-2-8-1]. The above potentially adverse condition guidelines are also addressed by the Rock and Mineral Resources variable of Section 5.2.3.

If Previous Activities at the Site Related to Mining, Exploration or Extraction of Resources of Commercial Importance Have Created Significant Pathways to the Accessible Environment [10 CFR 960.4-2-8-1(d)(1)]. The 
postclosure disqualifying guideline is addressed in the Deep Mines and Quarries disqualifying factor, which is discussed in Section 5.1.5. One of the hazards associated with siting near a known resource arises from the fact that exploration or extraction might have altered the hydrologic conditions of the repository. Therefore, as previously stated, the greater the distance from a resource, the more favorable the situation.

\subsection{PRECLOSURE GUIDELINES RELATED TO REGION-TO-AREA SCREENING}

The preclosure guidelines specify the factors to be considered in evaluating and comparing sites on the basis of expected repository performance before closure. The preclosure guidelines are separated into three system guidelines and eleven technical guidelines. These requirements must be met by the repository system, which includes the site and the affected surroundings, the engineered components of the repository, and the repository performance during repository siting, construction, operation, closure, and decommissioning. The preclosure guidelines related to region-to-area screening are summarized below.

Low Population Density Around Site [10 CFR 960.5-2-1(b)(1)]. This favorable condition is addressed in the Population Density variable and is discussed in Section 5.3.2 of this document. Locating a repository in the vicinity of lower population densities would minimize risks to the public health and safety and disruption to the public. Lower population densities are scaled more favorably, while higher population densitites are scaled less favorably.

Remoteness of Site from Highly Populated Areas [10 CFR 960.5-2-1(b)(2)]. This favorable condition guideline is addressed in the Population Density variable, which is discussed in Section 5.3.2 of this document and in the Proximity to Highly Populated Areas or to 1-Mile-Square Areas with 1,000 or More Persons variable, which is discussed in Section 5.3.10 of this document. Locating a repository away from population concentrations would minimize risk to the public health and safety and disruption to the public. Greater distances from highly populated areas or to areas with populations greater 
than 1,000 people per square mile are scaled more favorably, while lesser increments of distance are scaled less favorably.

Proximity of the Site to Highly Populated Areas or to 1-Mile-Square Areas With 1,000 or More Persons [10 CFR 960.5-2-1(c)(2)]. This potentially adverse condition guideline is addressed in the Population Density variable discussed in Section 5.3.2 of this document and in the Proximity to Highly Populated Areas or to 1-Mile-Square Areas with 1,000 or More Persons variable discussed in Section 5.3 .10 of this document.

Surface Facility Located in a Highly Populated Area [10 CFR 960.5-2-1(d)(1)] and Surface Facility Located Adjacent to 1-MileSquare Area With a Population of 1,000 or More Persons [10 CFR 960.5-2-1(d)(2)]. For purposes of the region-to-area screening, the CRP will be disqualifying highly populated areas and areas within the boundaries of minor civil divisions (MCD) or census county divisions (CCD) having population densities greater than 1,000 persons per square mile under 10 CFR 960.5-2-1(d)(2). The CRP's conservative assumption for the region-toarea screening is that a repository surface facility sited any place within a MCD or CCD of 1,000 or more persons per square mile would be adjacent to an area 1 mile by 1 mile having a population of not less than 1,000 individuals. These two disqualifying condition guidelines are addressed in the Population Density and Distribution disqualifying factor, which is discussed in Section 5.1.4. In using this disqualifying factor, highly populated areas and areas of 1,000 or more persons per square mile will be mapped and disqualified from further consideration as the location of the surface facility.

\section{Projected Major Conflicts With Governmental Environmental Requirements}

[10 CFR 960.5-2-5(c)(1)]. The use of a Wetlands variable, discussed in Section 5.3.8, addresses this potentially adverse condition guideline. Of major Federal environmental concern is the protection of wetlands. To minimize conflicts with the interests and intents of these environmental concerns, the boundaries of these designated areas will be identified and penalized in screening. Thus, it is more favorable to be a greater distance from these boundaries. 
Projected Significant Adverse Environmental Impacts That Cannot Be Avoided or Mitigated [10 CFR 960.5-2-5(c)(2)]. This potentially adverse condition guideline is addressed in the Wetlands and Surface Water Bodies variables discussed in Sections 5.3.8 and 5.3.9, respectively. Application and significance regarding Wetlands are as stated for 10 CFR 960.5-2-5(c)(1). Development of a repository in a flood plain could present major conflicts with environmental requirements and/or could result in significant environmental impacts that cannot be avoided or mitigated. Thus, the presence of a flood plain represents a potentially adverse condition for repository siting.

Proximity to and Projected Significant Adverse Environmental Impacts on the National Park System, National Wildlife Refuge System, National Wild and Scenic Rivers System, National Wilderness Preservation System, or National Forest Land [10 CFR 960.5-2-5(c)(3)]. This potentially adverse condition guideline is addressed in the Proximity to Federal-Protected Lands and National Forest Lands variables, which are discussed in Sections 5.3.3 and 5.3.5, respectively. The potential use of adjacent lands for repository surface facility development could have direct and indirect adverse affects on the function and management of these lands. A significant measure of public importance and sensitivity has been attached to these lands by virtue of public use and ownership and their role in environmental protection and resource development. Therefore, boundaries of these lands will be determined and distance to the boundaries will be scaled to determine degrees of potentially adverse conditions.

This guideline is also addressed in the Proposed Federal-Protected Lands variable, which is discussed in Section 5.3.1. Proposed Federal-protected lands will be treated as indicating potentially adverse conditions. The administrative boundaries of proposed Federal-protected lands will be identified and areas within these boundaries will be assigned the least favorable scale value. More favorable designations will be assigned with increasing distance from the boundaries.

Proximity to and Projected Significant Adverse Environmental Impacts on State- or Regional-Protected Resource Areas [10 CFR 960.5-2-5(c)(4)]. This potentially adverse condition guideline is addressed in the Proximity to 
State-Protected Lands and State Forest Lands variables, which are discussed in Section 5.3.4 and 5.3.6. Treatment of this guideline by these variables is identical to the previous guideline to the extent that state-protected lands, rather than Federal, are under consideration.

Presence of Critical Habitats for Threatened or Endangered Species [10 CFR 960.5-2-5(c)(6)]. This potentially adverse condition guideline is addressed in the Designated Critical Habitat for Threatened or Endangered Species variable, which is discussed in Section 5.3.7. The treatment of this guideline by this variable is as stated for 10 CFR $960.5-2-5(c)(1)$.

Location Within the Boundaries of a Component of the National Park System, National Wildlife Refuge System, National Wilderness Preservation System, or National Wi]d and Scenic Rivers System [10 CFR 960.5-2-5(d)(2)] and Irreconcilable Conflict With the Previously Designated Use of a Component of the National Park System, National Wildlife Refuge System, National Wilderness Preservation System, National Wild and Scenic Rivers System, National Forest Lands, or Any Comparably Significant State-Protected Resource [10 CFR $960.5-2-5(d)(3)]$. The above two disqualifying condition guidelines are addressed in the Federal-Protected Lands, Components of the National Forest Lands, and State-Protected Lands disqualifying factors, which are discussed in Sections 5.1.1, 5.1.2 and 5.1.3, respectively. Federal- and state-protected lands will be identified as disqualifiers in the region-toarea screening methodology to protect and provide for public enjoyment of important Federal and state resources. The existing administrative boundaries of the applicable Federal- and state-protected lands will be determined and these areas will be disqualified from further consideration.

Ability of an Affected Area to Absorb Project-Related Population Changes Without Significant Disruptions of Community Services and Without Significant Impacts on Housing Supply and Demand [10 CFR 960.5-2-6(b)(1)]; Availability of Adequate Labor Force [10 CFR 960.5-2-6(b)(2)]; No Projected Substantial Disruption of Primary Sectors of the Economy [10 CFR 960.5-2-6(b)(4)]; Potential for Significant Repository-Related Impacts on Community Services, lousing Supply and Demand, and the Finances of State and Local Government 
Agencies [10 CFR 960.5-2-6(c)(1)]; Lack of Adequate Labor Force [10 CFR 960.5-2-6(c)(2)]; and Potential for Major Disruptions of Primary Sectors of the Economy [10 CFR 960.5-2-6(c)(4)]. These favorable and potentially adverse conditions are addressed in the Proximity to Highly Populated Areas or to 1-Mile-Square Areas with 1,000 or More Persons variable which is discussed in Section 5.3.10 of this document. The intent of this variable, with respect to the above DOE Siting Guidelines provisions, is to minimize disruption to the public caused by construction and industrial-type activity.

Surface Characteristics That Could Lead to Flooding of Repository Facilities [10 CFR 960.5-2-8(c)]. This potentially adverse condition guideline is addressed in the Surface Water Bodies variable, which is discussed in Section 5.3.9. The occurrence of water bodies is of primary concern in the region-toarea screening as a surface characteristic that could impede surface facility development or lead to the flooding of the repository. Therefore, favorable conditions would occur in the absence of surface water bodies that could cause flooding of the repository.

A Host Rock That is Sufficiently Thick and Laterally Extensive to Allow Flexibility [10 CFR 960.5-2-9(b)(1)]. This favorable condition guideline is addressed in the Thickness of Rock Mass and Rock Mass Extent variables, which are discussed in Sections 5.4.1 and 5.2.1, respectively. This use of these two variables is identical in application to that for 10 CFR 960.4-2-3(b)(1).

Host Rock Characteristics Requiring Minimal or No Artificial Support for Underground Openings [10 CFR 960.5-2-9(b)(2)]. This favorable condition guideline is addressed in the State-of-Stress variable, which is discussed in Section 5.4.3. Knowledge of the state-of-stress will provide a measure of rock characteristics as related to engineering and construction of the underground repository. "If it is assumed that, at depth, rocks.... are subjected in geological time to some form of stress relaxation, then it is a valid assumption that... the stresses can be described as ... lithostatic and $\sigma_{x}^{\prime}=\sigma_{y}^{\prime}=\sigma_{z}^{\prime}$, "where $\sigma_{x}^{\prime}$ and $\sigma_{y}^{\prime}$ are the principal horizontal stress components and $\sigma_{z}^{\prime}$ is the vertical stress component (Farmer, 1983). A high or low 
horizontal-to-vertical stress ratio may require engineering measures beyond the state-of-the-art in design and construction of the underground facility. Therefore, areas of rock expected to have a large difference between the maximum and minimum principal stresses at the repository horizon will be considered more adverse whereas a small difference will be considered more favorable.

Thin or Laterally Restricted Host Rock Allows Little Flexibility [10 CFR 960.5-2-9(c)(1)]. This potentially adverse condition guideline is addressed in the Thickness of Rock Mass and Rock Mass Extent variables, as discussed for 10 CFR 960.4-2-3(b)(1). These two variables are discussed in Sections 5.4 .1 and 5.2 .1 , respectively.

In Situ Characteristics Requiring Engineering Measures Beyond Reasonably Available Technology [10 CFR 960.5-2-9(c)(2)] and Geomechanical Properties Necessitating Extensive Maintenance of Underground Openings

[10 CFR 960.5-2-9(c)(3)]. The above two potentially adverse condition guidelines are addressed in the State-of-Stress variable, as explained for 10 CFR $960.5-2-9(b)(2)$. This variable is discussed in Section 5.4.3. The first of the above two guidelines is also addressed in the Thickness of Overburden variable discussed in Section 5.4.2.

Stratigraphic or Structural Features That Could Endanger Repository Personnel [10 CFR 960.5-2-9(c)(5)]. This potentially adverse condition guideline is addressed in the Postemplacement Faulting variable, as explained for 10 CFR $960.5-2-5(c)(3)$. This variable is discussed in Section 5.2.6.

Absence of Aquifer Between Host Rock and Land Surface

[10 CFR 960.5-2-10(b)(1)] and Absence of Surface-Water System

[10 CFR 960.5-2-10(b)(2)]. The first of the above two favorable condition guidelines is addressed in the Thickness of Overburden variable, which is discussed in Section 5.4.2, and is also addressed in the Ground-Water Resources variable which is discussed in Section 5.4.4. The second favorable condition is addressed in the Surface Water Bodies variable, as previously described for 10 CFR $960.5-2-8(c)$, which is discussed in Section 5.3.9. 
Construction of shafts in crystalline rock is complicated by the presence of surficial deposits, especially where these deposits are saturated with ground water. Because most of the rock bodies being studied have some surface exposure, areas with thick overburden should be avoided where possible. Thus, the greater the thickness of overburden, the more adverse the condition.

Ground-water Conditions That Could Require Complex Engineering Measures That Are Beyond Reasonably Available Technology for Repository Construction, Operation, and Closure [10 CFR 960.5-2-10(c)]. This potentially adverse condition guideline is addressed in the Thickness of Overburden variable which is discussed in Section 5.4.2.

Magnitude and Intensity of Seismicity Significantly Less Than Those Al lowable for Nuclear Facilities [10 CFR 960.5-2-11(b)]; Evidence of Active Faulting [10 CFR 960.5-2-11(c)(1)]; and Seismicity That Could Exceed Design Limits [10 CFR 960.5-2-11(c)(2)]. The above favorable and two potentially adverse condition guidelines are addressed in the Seismicity variable, as previously described for 10 CFR 960.4-2-7(b), which is discussed in Section 5.2.4. The second of the above three guidelines is also addressed in the Suspected Quaternary Faulting variable which is discussed in Section 5.2.5. 


\subsection{REGIONAL SCREENING FACTORS AND VARIABLES}

This chapter presents more detailed information on the factors and variables judged by the Crystalline Repository Project (CRP) to be applicable for region-to-area screening. It is organized to proceed sequentially through the Step 1, Step 2, and Step 3 screening factors and variables. For each factor or variable, a definition is provided; its significance to siting is discussed; how it is measured is reviewed; the data sources being used are discussed; general explanatory comments are provided; and for the Step 2 and Step 3 variables, the CRP scales are presented.

\subsection{DISQUALIFYING FACTORS (STEP 1 )}

The disqualifying factors included here are consistent with and selected from the U.S. Department of Energy (DOE) Siting Guidelines as described in Chapter 4.0. The following listing cross references the proposed disqualifying factors to the appropriate section of the DOE Siting Guidelines (DOE, 1984a).

\section{Disqualifying Factor}

Federal-Protected Lands

Components of the National Forest Lands

State-Protected Lands

Population Density and Distribution

Deep Mines and Quarries
DOE Siting Guidelines Section

$960.5-2-5(d)(2)$

$960.5-2-5$ (d) (3)

$960.5-2-5$ (d) (3)

$960.5-2-1(d)(1),(2)$

$960.4-2-8-1(d)(1)$

\subsubsection{Federal-Protected Lands}

Definition. Lands within the administrative boundaries of components of the National Park System, National Wild and Scenic River System, National Wilderness Preservation System, and National Wildlife Refuge System were identified based on a review of appropriate U.S. Code Sections, Federal Regulations, and applicable publications of the National Park Service, the Forest Service, and the Fish and Wildlife Service. Specific features within each of these systems are as follows: 
National Park System (16 USC 1 et seq.)

National Parks

National Monuments

National Preserves

National Lakeshores

National Seashores

National Historic Sites

National Military Parks
National Battlefield Parks

National Battlefield Sites

National Battlefields

National Historical Parks

National Memorials

National Recreation Areas

National Parkways

National Wildlife Refuge System (16 USC 668 dd)

National Wildlife Refuges

Waterfowl Production Areas

Wildlife Management Areas

Wildlife Ranges

Other Protection and Conservation Areas 1

Protection for Species

Threatened with

Extinction

National Wilderness Preservation System (16 USC 1131 et seq.)

National Wilderness Areas

National Wild and Scenic Rivers System (16 USC 1271 et seq.)

Wild rivers

Scenic rivers

Recreational rivers

1The CRP has determined that administrative sites, research stations, fish hatcheries, and fishery research stations are not specifically listed as components and are categorized as other lands not included in National Wildlife Refuge System Lands pursuant to 50 CFR \$29.21, "Land Use Management: Rights-of-Way General Regulations", Definitions, Paragraph (g). 
Significance. The DOE Siting Guidelines indicate that a site shall be disqualified if any part of the restricted area or the repository support facilities would be located within the boundaries of a component of the National Park System, the National Wildlife Refuge System, the National Wilderness Preservation System, or the National Wild and Scenic Rivers System. The CRP, in defining its region-to-area screening methodology, plans to implement the guidelines by disqualifying the above-listed Federal-protected lands as noted below.

Measure. The existing administrative boundaries of the listed Federal-protected lands greater than 130 hectares ( 320 acres) in size will be mapped and these areas disqualified from further consideration as a location for the restricted area and repository support facilities.

Data Sources. Sources of identification, location, and boundary information for the various Federal-protected land categories are as follows:

- National Park System - Publications of the National Park Service.

- National Wild and Scenic River System - Publications of the National Park Service, the Forest Service, and/or the Department of the Interior, as applicable.

- National Wilderness Preservation System - Publications of the Forest Service and the U.S. Department of Interior.

- National Wildlife Refuge System - Publications of the Fish and Wildlife Service.

Comments. Lands within the administrative boundaries of these systems that are owned by the Federal government will be disqualified. In addition, the use of administrative boundaries will lead to disqualification of lands within these boundaries that are not owned by the Federal government. . This is considered reasonable for the CRP as a conservative screening assumption given the likely difficulties of licensing a repository located on private or stateowned lands within the boundaries of a recognized Federal-protected land.

The boundaries of the national parks and many of the other Federalprotected lands defined as disqualifying factors coincide with the boundaries of Class I Areas regulated under the Clean Air Act (42 USC 1857 et seq., 
1977). Disqualifying such lands effectively eliminates the Class I Areas in the 17 crystalline states. Consequently, a separate screening factor for Class I Areas is not proposed to avoid unnecessary duplication. Air quality considerations will be examined in detail in subsequent phases of repository siting.

\subsubsection{Components of the National Forest Lands}

Definition. National Forest Lands are defined in Federal regulations to comprise the following components: (1) forests (16 USC \$581a), (2) forest experiment stations ( 36 CFR $\$ 251.23$ ), (3) research natura? areas (36 CFR \$251.23), (4) national forest wilderness or primitive areas (36 CFR \$293, 16 USC \$529), (5) special areas (36 CFR \$294), and (6) national recreation areas 1 . All six components were evaluated to determine whether they could meet the tests of irreconcilable conflict-of-use and designation for resource preservation. Three components of the National Forest Lands are consequently judged by the CRP to warrant categorical disqualification under the provisions of 10 CFR $960.5-2-5(d)(3)$ which state: "The presence of the restricted area or the repository support facilities would conflict irreconcilably with the previously designated resource-preservation use of a component of the National Park System, the National Wildlife Refuge System, the National Wilderness Preservation System, the National Wild and Scenic Rivers System, or National Forest Lands." The three components that categorically meet this test for region-to-area screening are (1) research natural areas, (2) primitive areas, and (3) national recreation areas (see Appendix B).

Significance. The above three components of National Forest Lands are typically dedicated to single-purpose use and are oriented to scientific

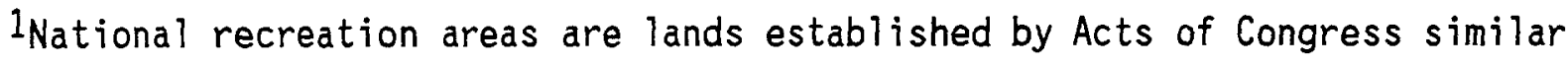
in purpose to national recreation areas under the National Park System. However, national recreation areas located in national forests are administered by the Forest Service.
} 
value, public recreation, and environmental preservation. Research natural areas have special or unique characteristics of scientific interest and importance (36 CFR \$251.23). Primitive areas are administered to meet the public purposes of recreational, scenic, scientific, educational, conservation, and historical uses, and in a manner to preserve and protect its wilderness charters ( 36 CFR 293, 16 USC \$529). National recreation areas are established by Congress for public recreational use and protection of related resource values. The sensitivity of these lands to disruption associated with repository development has led to their categorization as a disqualifying condition. There are, however, no primitive areas in the 17 crystalline states.

Measure. The existing boundaries of these three components of National Forest Lands will be identified and mapped. Lands within these boundaries will be disqualified from further consideration as a location for the restricted area or repository support facilities.

Data Sources. The boundaries of these components are indicated on forest maps published by the Forest Service.

Comments. The remaining components of National Forest Lands are judged to be categorically less sensitive to repository development than research natural areas, primitive areas, and national recreation areas. This is not to say that other components of National Forest Lands will not be disqualified in subsequent phases of study based upon site-specific determinations of irreconcilable conflict-of-use. The other components of National Forest Lands, however, do not defensibly lend themselves to categorical treatment as disqualifying conditions which is appropriate in the regional phase. To disqualify these components requires a case-by-case evaluation which is beyond the scope of region-to-area screening. Examples include a variety of wildlife areas and what are termed "special areas or special management areas". National forests in the CRP regions include units labelled as game refuges, wildlife management areas, and waterfowl production areas. These units possess some attributes similar to those of components of the National Wildlife Refuge System and state wildlife lands, but they vary considerably in their purpose, management prescription, and administrative responsibility. 
The degree of resource protection is significantly different among units, for example, and some units are managed cooperatively with state agencies. Consequently, the variability of the wildlife areas precludes their categorical treatment in the regional phase. Special areas within National Forest Lands can be designated administratively (under 36 CFR \$251.23 and \$294) to serve scenic, geologic, archaeological, historical, botanical, recreational, or other interests. A number of these special management areas have been designated in the CRP regions, most of them for recreational purposes. While many of these special areas may merit disqualification, to do so requires a case-by-case analysis which is considered to be beyond the scope of regionalphase studies. Such analysis will be the subject of area-phase studies.

It should be noted that National Forest Lands also contain lands that are formally designated as wilderness areas, wild and scenic rivers, etc. Consequently, such lands included in the National Forest Lands will be disqualified under Federal-Protected Lands [10 CFR 960.5-2-5(d)(2)].

The remaining portions of National Forest Lands will be treated as potentially adverse conditions, with a Step 2 variable defined to achieve that purpose.

\subsubsection{State-Protected Lands}

Definition. The guidelines also provide for the disqualification in 10 CFR 960.5-2-5(d)(3) of any site where the presence of the restricted area or the repository support facilities would conflict irreconcilably with the previously designated resource preservation use of a component of the National Park System, the National Wildlife Refuge System, the National Wilderness Preservation System, the National Wild and Scenic Rivers System, or National Forest Lands, or any comparably significant state-protected resource that was dedicated to resource preservation at the time of the enactment of the NWPA. The CRP has worked, with extensive state involvement, to apply this guideline in the region-to-area phase. The evaluation of "comparably significant" has been based on a thorough study of the statutory authority for each category of lands that the states and the CRP staff suggested could warrant disqualifier status. Based upon the language in these statutes or regulations and on the existence of a reasonable analog with the Federal-protected lands components, 
including ownership of state wildlife areas, the CRP has categorized the diverse and complex array of state-protected lands into disqualified status, potentially adverse status, or lands without status under these provisions of the guidelines. Because of the length and complexity of the results of this effort, they are not reported here but may be found in their entirety, by state, in Appendix B. In general, however, state parks, state wild and scenic rivers, state wilderness areas, state natural areas, and certain types of state wildlife areas will be disqualified.

Significance. The significance of these lands is parallel to the significance of the Federal-protected lands. These lands are recognized by their respective states as having value worthy of preserving and protecting for future generations. Hence, the irreconcilable conflict-of-use is established with the prospect of the construction, operation, closure, or decommissioning of a repository.

Measure. The existing administrative boundaries of the state-protected lands judged to be disqualifiers will be mapped and the area within those administrative boundaries disqualified from further consideration as a location for the restricted area or the repository support facilities.

Data Sources. Sources of the identification, location, and status of state-protected lands have included relevant state agencies in all 17 crystalline states.

Comments. The same conservative assumption in using administrative boundaries has been used for state-protected lands as was described previously for Federal-protected lands. Consequently, the disqualification of inholdings that are not state-owned will be the result.

It should also be recognized that state-protected lands to be disqualified will be identified by their functional use, as described in authorizing statutes, and such uses are analogous to Federal-protected lands. Because of diversity of use and variability in statutory authority, stateprotected lands will not be solely defined by title. 
Those state-protected lands not determined to warrant disqualified status but which merit treatment in the regional phase under the DOE Siting Guidelines, are identified and mapped as potentially adverse conditions in Step 2. These lands are also identified by state in Appendix B.

\subsubsection{Population Density and Distribution}

Definition. Highly populated areas and areas of 1,000 or more persons per square mile. "Highly populated area", as defined in the DOE Siting Guidelines, means any incorporated place (recognized by the decennial reports of the Bureau of the Census) of 2,500 or more persons, or any census-designated place (as defined and delineated by the Bureau) of 2,500 or more persons, unless it can be demonstrated that any such place has a lower population density than the mean value for the continental United States (64 persons per square mile in 1980). Counties or county equivalents, whether incorporated or not, are specifically excluded from the definition of place.

Significance. It is the intent of the Nuclear Waste Poljcy Act of 1982 (NWPA) and the DOE Siting Guidelines to locate a repository outside of highly populated areas. The disqualifying factor of Population Density and Distribution reflects the coincidence and adjacency conditions of Section 112(a) in the NWPA and 10 CFR 960.5-2-1(d)(1),(2): A site shall be disqualified if (1) any surface facility of a repository would be located in a highly populated area (coincidence), or (2) any surface facility would be located adjacent to a 1-mile by 1-mile area having a population of not less than 1,000 individuals (adjacency).

Measure. Highly populated areas, as well as minor civil divisions (MCD) and census county divisions (CCD) with 1,000 or more persons per square mile, will be mapped and those areas eliminated from further consideration as a repository site.

Data Sources. Highly populated areas will be identified on the basis of the 1980 census reports Series PC80-1-A (DOC, 1982) of characteristics of the population. Boundaries for these places will be taken from official 
Bureau of the Census maps of counties, county subdivisions, and places. The data used to calculate population densities on a MCD or CCD basis are part of a commercially available data base from Rand McNally Corporation. These data include MCD and CCD boundaries in digital tape form that, with the 1980 population data, greatly facilitated the calculations required to utilize this variable in the region-to-area phase.

Comments. There is a high degree of correlation between highly populated areas and areas in excess of 1,000 persons per square mile. Outside highly populated areas, density is calculated for $M C D / C C D$. The population density assigned each 1-mile by 1 -mile grid cell is the mean density per square mile for the entire $M C D / C C D$, even though some 1 -mile squares might contain fewer than 1,000 persons. The CRP's conservative assumption for the region-to-area screening is that a repository surface facility sited any place within an $M C D / C C D$ of 1,000 or more persons per square mile would be adjacent to an area 1 mile by 1 mile having a population of not less than 1,000 individuals. Use of this conservative assumption, i.e., that the fence of the surface facility would share a boundary with a 1-mile by 1 -mile area having not less than 1,000 persons, actually underestimates the potential of a site to meet the guideline. Any densely populated areas in excess of 1,000 persons per square mile but smaller than an $M C D / C C D$ will be evaluated during future phases of the siting process.

\subsubsection{Deep Mines and Quarries}

Definition. This includes active or inactive mines or quarries, either underground or open pits that are greater than 100 meters (328 feet) in depth. Singular or multiple boreholes for exploration of mineral resources and water wells are not included for the purpose of region-to-area screening.

Significance. The DOE Siting Guidelines (10 CFR 960.4-2-4-8-1(d)(1)) state that a "site shall be disqualified if previous exploration, mining, or extraction for resources of commercial importance at the site have created significant pathways between the projected underground facility and the accessible environment." 
One of the hazards associated with siting near a mined resource in crystalline rock arises from the high probability that the mine workings intercept fractures and thus create significant hydrologic pathways from the repository horizon to the accessible environment. For the purpose of utilizing this disqualifier at the regional screening level, mines and quarries deeper than 100 meters (328 feet) are disqualified. This disqualification is based on the assumption that mines and quarries deeper than 100 meters (328 feet) would tend to intercept ground water in the regional flow regime and thereby create hydrologic pathways to the accessible environment.

Measure. Depth of mine or quarry. Disruption of the regional groundwater flow regime due to resource extraction can be avoided by selecting repository sites well away from mines or quarries deeper than 100 meters (328 feet). An area of 23 square kilometers ( 9 square miles) centered on the onesquare-mile-grid cell that contains the deep mine or quarry will be disqualified. This disqualified area will include the grid cell containing the mine or quarry and all immediately adjacent grid cells. Due to the lack of specific information concerning the extent and direction of workings in the regional data base, it is prudent to disqualify the additional grid cells adjacent to the cell which contains the deep mine or quarry. This disqualified area is intended to encompass the mine or quarry workings. Workings in crystalline rocks or rock formations immediately adjacent to crystalline rocks in the eastern United States commonly extend 1.6 kilometers ( 1 mile) or less with a few exceptions. One exception is the Mt. Hope mine in New Jersey which has workings 3,656 meters $(12,000$ feet) from the main shaft. Where known workings extend beyond the disqualified area, additional grid cells encompassing those workings will also be disqualified.

The depth measure for deep mines and quarries was chosen to allow for potential effects on the regional ground-water flow system. Studies of regional and local ground-water systems in fractured rock indicate that local systems are relatively shallow and have unique circulation patterns controlled by topography, fracture permeabilities, and depth and density of saturated fractures. Local systems usually have limited area extent. Under water-table conditions, these local circulation zones give way at depth to regional or subregional flow systems (Freeze and Witherspoon, 1967). DOE's evaluation of 
data from the eastern United States supports the assumption that with the exception of regional discharge areas, regional ground-water flow regimes in crystalline rock bodies tend to occur at depths greater than 100 meters ( 328 feet). Adopting an exclusionary depth of 100 meters ( 328 feet) is therefore a conservative approach in disqualifying mines and quarries which intercept ground water in the regional flow regime and thereby create hydrologic pathways to the accessible environment.

A few examples of mines which intercept the regional ground-water flow system are: a 366-meter (1,200-foot) shaft in fractured marlstone (which has similar flow characteristics to those found in crystalline rock) in the Piceance Basin of Colorado caused a decline in the regional water table of about ( 30 meters (100 feet) at a distance of ( 10 kilometers ( 6 miles) from the mine (Weeks et a1, 1974); mine adits in fractured granite at the Quartz Hill molybdenum prospect in southern Alaska approximately 610 meters (250 feet) and (200 meters (700 feet) below the ground surface and laterally separated by about $0.4 \mathrm{kilometer}(0.25 \mathrm{mile})$ produced drawdown effects approximately 610 meters (2,000 feet) away (Forest Service, 1984); and in Sweden, the Stripa mine which is about 430 meters $(1,410$ feet) deep caused an increase in the measured hydraulic gradient at a depth of 100 meters ( 328 feet) while producing gradients that resulted in upward flow at a depth of 418 meters (1,370 feet) (Gale et al, 1982). These observations influenced selection of 100 meters ( 328 feet) as the depth below which a mine or quarry is assumed to have created significant hydrologic pathways.

The lateral area of influence of a deep mine or quarry is indeterminate at this stage of the siting process. Site specific data collection and analysis would be necessary to determine the extent to which hydrologically significant pathways have been created.

Data Sources. Maps and records of Federal and state agencies.

Comments. Exploratory drill holes for mineral resources are not considered as significant hydrologic pathways for the purpose of region-toarea screening. In addition, this disqualifying factor does not include ground-water resources since the DOE judged that the effort necessary for inclusion of these resources would be unwarranted. Ground-water resources are included as a Step 3 variable, and DOE will evaluate the existing literature 
as part of its qualitative/descriptive literature review of identified candidate areas (see Section 3.3.1).

\subsection{SCALED GEOLOGICAL VARIABLES (STEP 2)}

All of the variables included here are consistent with and selected from the DOE Siting Guidelines as described in Chapter 4.0. The following listing cross references the geologic regional screening variables to the appropriate section of the DOE Siting Guidelines document.

Regional Screening Variable

Rock Mass Extent

Major Ground-Water Discharge Zones

Rock and Mineral Resources

Seismicity

Suspected Quaternary Faulting

Postemplacement Faulting
DOE Siting Guidelines Section

$960.4-2-3(b)(1)$,

$960.5-2-9(b)(1),(c)(1)$

$960.4-2-1$ (b) (4) ( $i$ i)

$960.4-2-8-1(b)(1),(c)(1)-(4)$

$960.4-2-7(b),(c)$

960.4-2-7(b), (c),

$960.5-2-11$ (c) (1)

$960.4-2-7(\mathrm{~b}),(\mathrm{c})$,

$960.5-2-9(c)(5)$

\subsubsection{Rock Mass Extent}

Definition. Areal extent of host rock body.

Significance. Any rock body selected for further characterization should be large enough to accommodate the subsurface space required for construction of the repository. This minimum size is equal to the area of a circle approximately 3 kilometers ( 2 miles) in diameter. It should also be large enough that construction-induced effects in the rock will not unduly compromise repository performance. The shape of the underground workings is assumed to be round, but the actual configuration will be site-dependent.

Repository performance will have to be modeled out to the accessible environment (generally accepted as being no more than 10 kilometers ( 6 miles) from the repositoryl in as rigorous a way as possible and it is desirable to

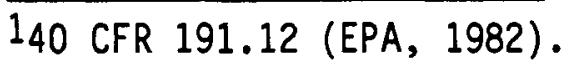


have the area to be modeled within the limits of the host rock body. For sites where the ground-water flow patterns can be inferred fairly confidently, this area will generally include a wedge-shaped area extending $10 \mathrm{kilometers}$ ( 6 miles) downgradient from the repository. This shape will accommodate any of the flow patterns that may occur.

Where the inferred direction of ground-water flow is less certain, the confidence in selecting a suitable site can be increased by having the minimum area be a circle about 13 kilometers ( $8 \mathrm{miles}$ ) in diameter. In this manner, the repository surface facilities could be placed at any point tangent to the circumference of the circle and the downgradient area to be modeled would still lie within the boundaries of the rock body.

Where no information is available on the ground-water flow regime, it would be prudent to select a rock body which is at least 23 kilometers (14 miles) in diameter. This would provide flexibility to move within the same rock body to optimize both performance-based and environmental siting conditions. Additional flexibility to avoid unfavorable conditions would be provided if the rock body could contain a larger circle.

Measure. The diameter of a circle that can be wholly contained within the boundaries of the rock body would be calculated after the application of the Deep Mines and Quarries disqualifying condition.

Data Sources. State geologic maps, or the best available information. For the North Central Region, Plate 1 of the December 1984 revised draft regional geologic characterization report (DOE, 1984c) as a principal data source, as well as the state geologic maps.

Comments. Decision rules adopted by the CRP for inclusion of rock bodies to be considered in the region-to-area screening are as follows:

- Included rocks are to be limited to "crystalline" rocks, as defined by Office of Crystalline Repository Development (OCRD) (1983).

- Included rocks must have a horizontal areal extent of at least 100 square kilometers ( 38 square miles), as shown on a bedrock map, irrespective of shape. 
- Included rocks are to be "exposed or near-surface" as shown on a bedrock map, as opposed to "buried", following the philosophy of OCRD (1983).

- Rock bodies are not to be subdivided internally unless there is a major compositional or structural change (i.e., felsic to mafic composition; massive equigranular to gneissic texture).

- In general, external boundaries (contacts between different, adjacent crystalline rock units) should conform to those shown on small-scale published state maps or the best available published or unpublished information according to the state surveys. Such contacts should represent a significant change in composition, texture, or age (i.e., contacts between rocks of different "systems").

The definition of crystalline rock (OCRD, 1983) is central to the decision rules for delineation of crystalline rock bodies. Within the stated definition, professional judgment is required as to the precise meaning of "high-grade metamorphic rocks ..." for there to be a consistent application of the decision rules during preparation of the crystalline rock body maps. Judgment is necessary for two issues, namely, at what stage a metamorphosed rock becomes high-grade, and whether all high-grade metamorphic rocks actually satisfy the intent of the DOE Siting Guidelines (10 CFR 960). Therefore, the following criteria for metamorphic rocks were developed to supplement previous decision rules. Metamorphic rocks are included in crystalline rock bodies if they can be characterized as:

1. Having been metamorphosed to at least upper amphibolite facies (sillimanite plus potassium feldspar)

2. Exhibiting chiefly granoblastic texture (nonschistose)

3. (For a cartographic unit consisting of mixed lithologies) having less than 50 percent marble, calc-silicate, and pelitic schist or schist with amphibolite.

In support of these criteria, reference was made to the DOE Siting Guidelines [10 CFR 960.4-2-1(b)(3)] which state that favorable hydrogeologic conditions with respect to repository performance include "stratigraphic, structural, and hydrologic features such that the hydrogeologic system can be readily characterized and modeled with reasonable certainty". The CRP applied 
(2) and (3) above to certain metamorphic complexes even though (1) might be satisfied. For this reason, certain major "basement" gneisses have been el iminated, including the Berkshire Massif (Massachusetts), the Barnard Gneiss (Vermont), and the Plainfield Formation (Connecticut).

The decision rules for inclusion of rock bodies state that external boundaries (especially the ones between contiguous rock units) should "represent a significant change in composition, texture, or age (i.e., contacts between rocks of different 'systems')". Internal subdivisions are to be included only if "there is a major compositional or structural change (i.e., felsic to mafic composition; massive equigranular to gneissic texture, change in foliation ...)". Because there is no way to determine a priori what the physical character and significance of various contacts depicted on state geologic maps might be insofar as repository performance is concerned, the CRP used a criterion of similar geologic age, areal extent, and the definition of crystalline rock to delineate external limits of rock bodies. This approach also provided a certain amount of consistency in using the state geologic maps which vary greatly in terms of the delineation and explanation of internal contacts. Consequently, CRP rock body map boundaries depict crystalline rock bodies with "internal" contacts irrespective of whether the contact origins are intrusive, replacement, fault-related, or some combination of these. It should be noted that the CRP will also use a modified scale for this variable (see Section 3.2.5.1 and Table 2) during Step 3 sensitivity analysis.

Scaling. The scale adopted is based on the size of the reference repository and increments of the maximum distance to the accessible environment.

Diameter of Maximum Circle That Will Fit in Rock Body (miles)

\begin{tabular}{ccccc}
$\leq 2$ & $>2-8$ & $>8-14$ & $>14-20$ & $>20$ \\
\hline 1 & 2 & 3 & 4 & 5
\end{tabular}

More Adverse

Scale Value

More Favorable 


\subsubsection{Major Ground-Water Discharge Zones}

Definition. Distance to streams, the ocean, or large lakes to which deep (repository depth) ground water is discharged. Eligible streams include that part of the principal (trunk) stream of a "hydrologic subregion" (as defined in hydrologic unit maps published by U.S. Geological Survey (USGS), which is downstream of the point at which the named principal stream is the dominant surface water hydrologic element of the subregion watershed. An eligible lake is one that is the primary surface water discharge point of a "hydrologic subregion" as defined in hydrologic unit maps published by the USGS. The ocean includes the ocean and its embayments that contain salt water. The upstream "limit", or cut-off point, of the discharge zone (stream) is taken as the point where there are only three tributaries entering the major stream (including the tributary at the cut-off point), as shown on the described maps and illustrated in Figure 13. In the North Central Region, where ground water (piezometric surface) maps exist, ground-water discharge zones are those zones in which ground-water contours (plotted at 34-meter [100-foot] intervals) indicate convergence of ground-water flow, typical of discharge areas.

Significance. Areas of major water bodies and major through-flowing streams are potential locations of deep ground-water discharge. In these areas, the primary direction of ground-water flow is toward the surface and ground water may have a relatively higher velocity. The distance and travel time to the accessible environment is thus at a minimum. These areas are generally considered unfavorable with respect to siting a high-level nuclear waste repository. This factor is cited in 10 CFR $60.122(c)(i i)$ and the 10 CFR $960.4-2-1$ for consideration in repository siting.

Measure. The position of an area relative to the major ground-water discharge (as determined by the location of major water bodies) will be used as a measure for this variable. The least desirable location for a repository is under the discharge zone. The next least desirable location is within 10 kilometers ( 6 miles) of a discharge point, since 10 kilometers (6 miles) is the approximate maximum limit of the controlled zone (10 CFR 60). For this reason, a 10-kilometer (6-mile) distance from ground-water discharge has been incorporated into the scale. 


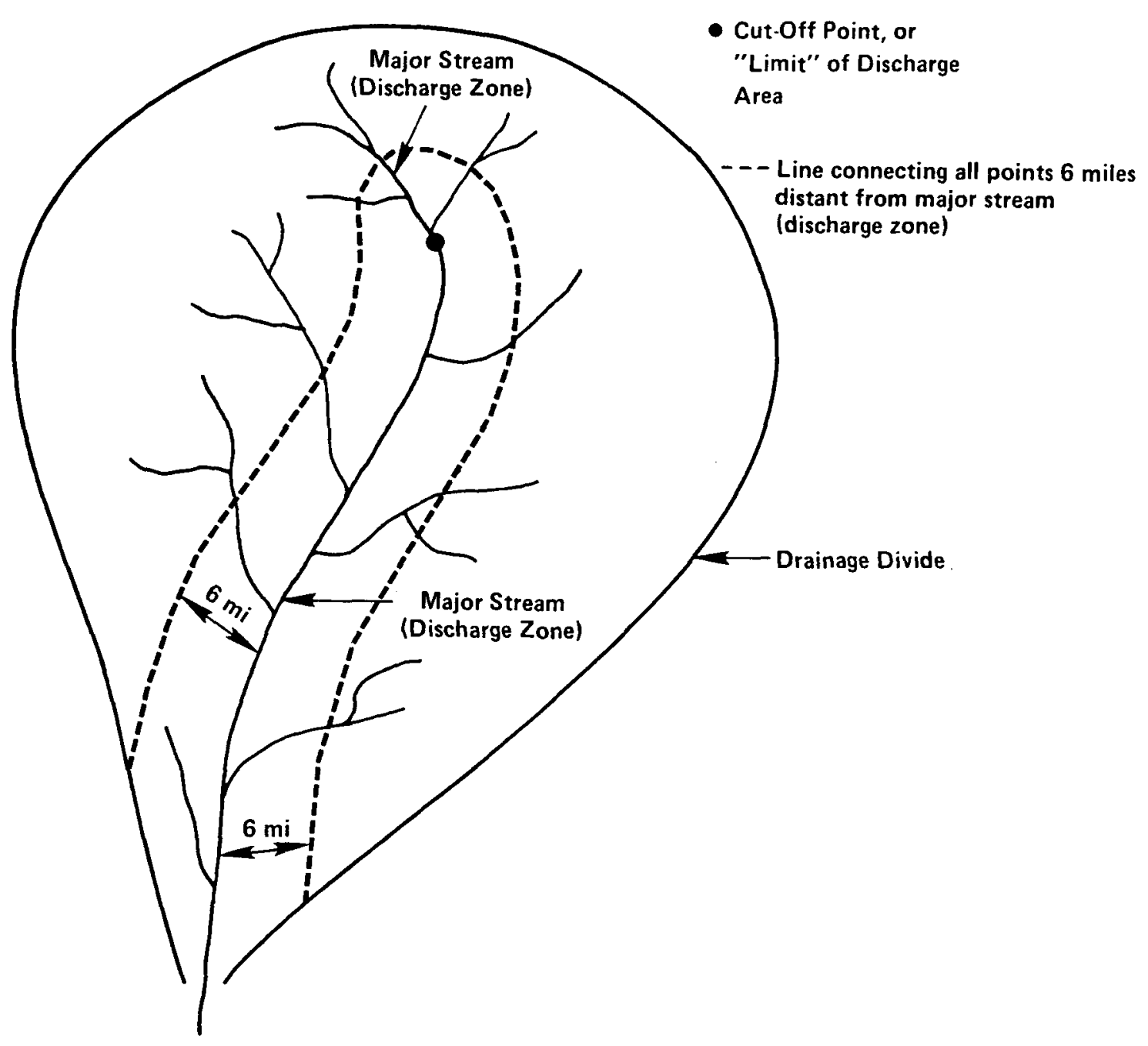

Figure 13 Schematic Diagram of Drainage Basin, Showing the Major Stream (Ground-Water Discharge Zone) and Drainage Divide 
In the locales where actual ground-water potentiometric data are available, that information will be used rather than topography to define recharge areas and discharge zones.

Data Sources. Hydrologic unit maps and small-scale topographic maps published by the USGS will serve as data sources for this variable.

Comments. Ground-water flow in crystalline rocks can be very complex. Factors including structure and topography will exert major influences on the flow systems. Generally, crystalline rocks have low permeability, and any ground-water flow takes place predominantly along the more permeable zones associated with geologic structures, including faults, fractures, foliations, and postemplacement dikes. The specific characteristics of the flow systems are impossible to determine from the available regional-scale data. However, it is possible to determine potential areas of deep ground-water discharge based upon topography and/or shallow water table contours. The distance from these potential discharge zones will be used as a region-to-area screening variable. Specifically, the following areas will be delineated as potential ground-water discharge areas: (1) that part of the major (trunk) stream of a "hydrologic subregion" (as defined in hydrologic unit maps published by the USGS) which is downstream from the point at which the major stream is the dominant surface water hydrologic element in the subregion watershed; surface water bodies along the major stream; and (3) the Great Lakes, and the ocean, including its embayments. In addition, known thermal springs and 
mineral springs, as described in the available literature, will be identified as potential regional ground-water discharge areas.

Scaling. The adopted scale is based on the relative position of an area with respect to the discharge zone. This scale has been changed from that in the draft document at the suggestion of several states. The previous scale was determined to be too complex. The only increment values used are 1,2 , and 5 .

\section{Distance to Discharge Point (Major Water Body)}

\begin{tabular}{|c|c|c|c|c|}
\hline $\begin{array}{l}\text { Underneath } \\
\text { Major Stream } \\
\text { (Discharge } \\
\text { Zone) }\end{array}$ & $\begin{array}{c}0-6 \text { miles from } \\
\text { Discharge Zone or } \\
\text { to Drainage Basin } \\
\text { Divide if }<6 \text { miles }\end{array}$ & & & $\begin{array}{l}\text { from } \\
\text { Zone to } \\
\text { Divide }\end{array}$ \\
\hline 1 & 2 & 3 & 4 & 5 \\
\hline
\end{tabular}

\subsubsection{Rock and Mineral Resources}

Definition. Strategic and unique mineral resources at a depth less than 100 meters ( 328 feet). Active or inactive mines or quarries and proven but undeveloped resources would be included. Strategic resources are those defined as such by the U.S. Bureau of Mines in their determination of worldwide engineering and economic availability for the Minerals Availability System. Unique resources are those which do not have an alternate source within a comparable distance from the market for that resource. Examples of resources and commodities which may be included are cobalt, copper, aluminum, titanium, iron, platinum, nickel, tungsten, mercury, molybdenum, and any other mineral important to strategic defense; metallurgical crushed stone (limestone, silica sand, etc.); unique dimension stone; unique aggregate deposits, and unique mineral fuels (i.e., uranium, thorium, etc.). 
Significance. Siting the repository near a known strategic or unique mineral resource poses a potential concern in that the repository may actually preempt future use of the resource. Since shallow mining which does not affect the ground-water hydrology of the site could be allowed inside the controlled area, it may be possible to make a change in the actual repository location to avoid a strategic or unique resource.

Measure. Distance from the resource location.

Data Sources. Maps and records of the state geologic surveys, other state agencies, and Federal agencies.

Comments. This variable is meant to prevent denial of access to resources. It does not address any hydrologic impacts. Hydrologic impacts resulting from the presence of deep mines or quarries is addressed by a disqualifying factor specifically developed for this purpose (see Section 5.1.5).

Scaling. The application of this variable differs from that of most other variables in that the scale has fewer increments. Distance beyond 3 kilometers ( 2 miles) is not a consideration since it is possible for shallow resource operations to be carried out anywhere beyond the boundary of the restricted area of a repository site and not affect repository performance. The underground workings of a repository will nominally occupy 810 hectares (2,000 acres).

Distance From Resource Deposit (miles)

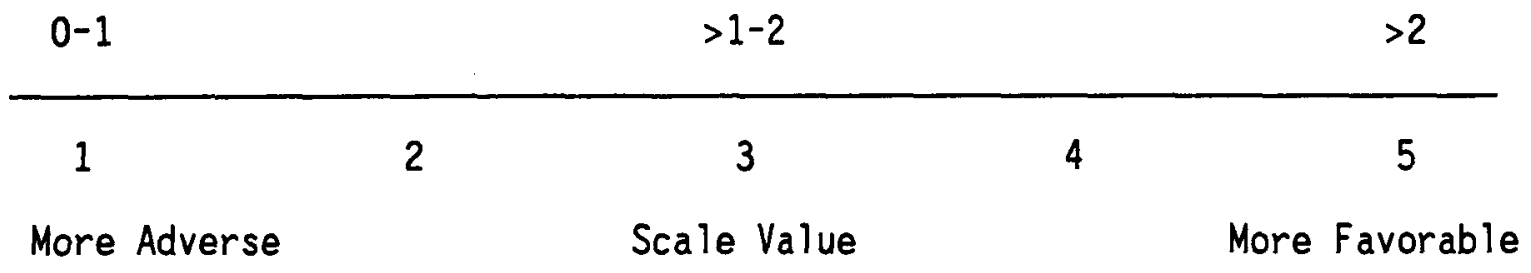




\subsubsection{Seismicity}

Definition. Predicted horizontal ground acceleration due to earthquakes.

Significance. Ground motion due to earthquakes is defined as a potentially adverse condition by the U.S. Nuclear Regulatory Commission (NRC) (10 CFR 60.12) and DOE (10 CFR 960.4-2-7). Data on seismicity may be used as a screening variable because they can be related to known or suspected seismic source zones and can be expressed as probabilistic occurrences of maximum ground acceleration which can be used to define areas of relative seismic hazard. Such probabilities may indicate possible damage to surface and subsurface facilities as well as the possible reactivation of faults that are favorably oriented in the present-day stress field and which would need to be assessed as possible ground-water flow paths. Thus, locales should be avoided where seismic hazards have the potential to compromise the overall integrity of a site (including both surface and subsurface facilities). The fact that ground shaking at depth is generally considerably less than that at or near the surface makes this variable more important with regard to the surface facilities than to the subsurface facilities.

Two reports (Pratt et al, 1978, DP-1513; and Wahi et al, 1980, DP-1579) document past seismic damage to underground engineered structures and examine the conditions under which seismic waves might cause instability in an underground repository.

Measure. The predicted maximum horizontal ground acceleration -- 70 percent, 50 percent, 30 percent, and 10 percent $g$ contours with a 90 percent probability of these values not being exceeded in 250 years, as given by Algermissen et al (1982).

Data Sources. Historically and instrumentally recorded data on seismicity are available in various regional and national earthquake catalogues. Analyses of ground-motion attenuation and location, size, and frequency of earthquakes, as they relate to proposed seismic source zones, have been used by Algermissen et al (1982) to determine probabilistic values of maximum ground acceleration. Germane to this discussion is the map in the Algermissen 
et al (1982) report showing horizontal acceleration (in percent of $g$ ) with a 90 percent probability of not being exceeded in 250 years. The Algermissen et al (1982) report will be utilized unless other published records indicate that it is not reasonably conservative for specific locations.

Comments. The CRP will also use a modified scale for this variable (see Section 3.2.5.1 and Table 2) during Step 3 sensitivity analysis.

Scaling.

Maximum Probable Ground Acceleration (\% g)

\begin{tabular}{ccccc}
$>70$ & $>50-70$ & $>30-50$ & $>10-30$ & $<10$ \\
\hline 1 & 2 & 3 & 4 & 5 \\
More Adverse & & Scale Value & & More Favorable
\end{tabular}

\subsubsection{Suspected Quaternary Faulting}

Definition. Faulting in bedrock which is suspected of having movement since the start of the Quaternary period (approximately 2 million years ago).

Significance. Quaternary faulting is defined as a potentially adverse condition by the NRC (10 CFR 60.122) and the DOE (10 CFR 960.4-2-7). The potential for adverse effects of faulting or fault movement (ground motion, or opening of faults or fractures) that could compromise the integrity of a repository system and impair its ability to isolate waste by changing the ground-water flow system is a prime consideration in siting. Land units where Quaternary faulting or fault movement have been noted should be avoided to enhance confidence in the performance of the repository system over time.

Measure. The distance from known and suspected zones of Quaternary faulting will be measured. Therefore, locales farther than 8 kilometers ( 5 miles) from suspected Quaternary faulting would be considered more favorable than those within 8 kilometers ( 5 miles). 
Data Sources. Available records and maps of the state geological surveys will be used to supplement USGS Miscellaneous Field Studies Map MF-916, Preliminary Map of Young Faults in the United States as a Guide to Possible Fault Activity (Howard et al, 1978).

Comments. There are very few faults in the three regions of interest suspected of having Quaternary movement.

Scaling.

Distance From Fault (miles)

$\begin{array}{ccccc}\leq 5 & & & >5 \\ 1 & 2 & 3 & 4 & 5 \\ \text { More Adverse } & & \text { Scale Value } & & \text { More Favorable }\end{array}$

\subsubsection{Postemplacement Faulting}

Definition. All faults, shear zones, and zones of brittle deformation of any age, having a length of greater than about 24 kilometers ( 15 miles) or that are shown on smal1-scale bedrock maps considered accurate by the state geological surveys.

Significance. This factor is significant since a major fault may be a potential ground-water flow path which could compromise the ability of the repository system to isolate waste. Locales where major faults exist should be avoided to enhance the performance over time of a repository site. It is assumed that all crystalline rock bodies are faulted to some extent. Small, individual faults will occur in all areas. The intent of this variable is to avoid the very large faults and zones of brittle deformation that are likely to represent an adverse condition.

Measure. Distance from faults as shown on bedrock maps. 
Data Sources. State geologic maps and other small-scale maps (generally $1: 250,000$ or smaller) are considered to most accurately represent the structural geology. For the North Central Region, Plate 1 of the December 1984 regional geologic characterization report (DOE, 1984c) will serve as a data source, as well as the state geologic maps.

\section{Comments. None.}

Scaling. The scale adopted is based on the anticipated repository size and increasing distance from a fault. The scale was changed from that in the draft document in order to have a linear scale and one more consistent with scales for other variables.

$$
\text { Distance From Fault (miles) }
$$

\begin{tabular}{ccccc}
$0-3$ & $>3-4$ & $>4-5$ & $>5-6$ & $>6$ \\
\hline 1 & 2 & 3 & 4 & 5 \\
More Adverse & & Scale Value & & More Favorable
\end{tabular}

\subsection{SCALED ENVIRONMENTAL VARIABLES (STEP 2)}

All of the variables included here are consistent with and selected from the DOE Siting Guidelines as described in Chapter 4.0. The following listing cross references the environmental region-to-area screening variables to the appropriate section of the DOE Siting Guidelines.

Regional Screening Variable

Proposed Federal-Protected Lands

Population Density

Proximity to Federal-Protected Lands

Proximity to State-Protected lands

National Forest Lands

State Forest Lands

Designated Critical Habitat For Threatened and Endangered Species Wetlands

Surface Water Bodies
DOE Siting Guidelines Section

960.5-2-5(c)(3)

$960.5-2-1$ (b) (1), (c) (2)

960.5-2-5(c)(3)

$960.5-2-5(c)(4)$

$960.5-2-5(c)(3)$

$960.5-2-5(c)(4)$

$960.5-2-5(c)(2),(6)$

$960.5-2-5(c)(1),(2)$

$960.5-2-5$ (c) (2), $960.5-2-8(c)$ $960.5-2-10(b)(2)$ 
Proximity to Highly Populated Areas or to 1-Mile-Square Areas with 1,000 or More Persons

\author{
$960.5-2-1(b)(2),(c)(2)$ \\ $960.5-2-6(b)(1)-(4)$, \\ (c) (1), (2), (4)
}

\subsubsection{Proposed Federal-Protected Lands}

Definition. All lands which are, at any time, proposed to receive one of the designations included in the list of Federal-protected lands to be disqualified for further consideration. Generally, the term "proposed" will be defined to mean that some official Federal government action has been taken to consider designation of lands within the specific categories of Federal protection. More specific definitions for each subfactor are given below.

1. Components of National Park System. Official Federal actions taken that meet minimum sufficient conditions to constitute a proposal are: introduction of legislation in Congress to create such a unit; inclusion in a National Park Service master plan; or inclusion of acquisition funds for a specific area in an existing National Park Service budget program. Components of the National Park System consist of national parks, national monuments, national preserves, national lakeshores, national seashores, national historic sites, national military parks, national battlefield parks, national battlefield sites, national battlefields, national historical parks, national memorials, national recreation areas, and national parkways.

2. Components of National Wild and Scenic Rivers System. Proposed national wild and scenic rivers will be defined by a specific proposal for designation submitted by the President to Congress in accordance with the Wild and Scenic Rivers Act of 1968, or status as a congressionally mandated study river in accordance with Section 5(a) of the Wild and Scenic Rivers Act except where such studies have been completed and a recommendation of nondesignation or state-level protection was made. Components include wild rivers, scenic rivers, and recreational rivers.

3. Components of National Wilderness Preservation System. Proposed national wilderness areas will consist of those national forest roadless areas studied in the second roadless area review and evaluation (RARE II), as identified by the Forest Service (1979), which have been recommended by the Forest Service for wilderness designation, or those lands delineated in wilderness bills submitted to Congress. Potential wilderness areas within the units of the National Park System and National Wildlife Refuge System need not be considered independently, due to their inclusion within the Federal- 
Protected Lands disqualifying factor. Components consist of national wilderness areas.

4. Components of National Wildlife Refuge System. The minimum action required to constitute a proposal for dedication will consist of a Fish and Wildlife Service recommendation for a specific refuge, approved by the Secretary of the Interior. Components consist of national wildlife refuges, waterfowl production areas, wildlife management areas, wildlife ranges, and other protection and conservation areas (protection of species threatened with extinction).

5. Components of National Forest Lands. A proposal for a new protection component of National Forest Lands will consist of an official recommendation for designation by a completed forest plan, by the Chief of the Forest Service to the Secretary of Agriculture, or by the respective Forest Supervisor in the case of areas that can be designated at the forest level. Components include research natural areas, primitive areas, and national recreation areas to be administered by the Forest Service.

Significance. Proposed Federal-Protected Lands will be treated as a regional screening variable indicating potentially adverse conditions. As defined, these lands exhibit potential for inclusion in specific categories of Federal-protected lands. That is, they may become designated protected lands at some future date. The region-to-area screening process will penalize these areas, but because they currently do not enjoy the full measure of Federal protection, treatment as a disqualifying factor is not warranted. The significance of each subfactor is addressed below:

1. Components of the National Park System. The National Park Service Act of 1916 (16 USC 1) requires that national parks and monuments be managed to conserve resources for the enjoyment of present and future generations. Although management of certain units of the National Park System places greater emphasis on public use, the overall management orientation of the system is toward conservation/preservation. The future designation of such areas would be in conflict with their potential use for repository surface facility development.

2. Components of National Wild and Scenic Rivers System. The Wild and Scenic Rivers Act of 1968 (16 USC 1271) was enacted to preserve the resource values of streams that are completely or largely undeveloped. The future designation of such rivers as part of this protected system would be in conflict with the potential use of such areas for repository surface facility development. 
3. Components of National Wilderness Preservation System. The Wilderness Act of 1964 (16 USC 1131) requires that lands with in the National Wilderness Preservation System be managed to preserve their wilderness character, without evidence of human habitation or landscape alteration. Court decisions and Federal land management agency directives also stipulate that the wilderness values of lands eligible for wilderness designation be protected until the completion of formal, legally sufficient studies of their suitability for dedication as wilderness. The future designation of roadless lands as wilderness would be in conflict with the potential use of such areas for repository surface facility development.

4. Components of National Wildlife Refuge System. Refuge system lands are managed primarily for the conservation and protection of fish and wildlife. The future dedication of such may be in conflict with their potential use for repository surface facility development.

5. Components of National Forest Lands. Protected components of National Forest Lands (primitive areas, research natural areas, and national recreation areas) are managed to preserve scientific, natural, and recreational values. The future dedication of such areas may be in conflict with their potential use for the repository surface facility development.

Measure. Administrative boundaries of proposed Federal-protected lands previously listed will be identified and mapped. Areas within these boundaries will be assigned the least favorable scale value for repository siting. Distance from proposed administrative boundaries will be used as a rough measure of potential impacts from a repository sited near these proposed areas. More favorable designations will be assigned with increasing distance from proposed Federal-protected area boundaries.

Data Sources. Data sources for proposed components of the National Park System, National Wild and Scenic Rivers System, and National Wildlife Refuge System will be the corresponding managing agencies and records of congressional proposals. Data sources for proposed components of the National Wilderness Preservation System will consist of the final Forest Service (1979) RARE II recommendations and maps, forest maps, and supplemental information obtained from the supervisor's office of each national forest in the CRP regions, and logs of wilderness bills formally introduced in Congress. National forest component proposals will be determined from completed forest plans and current planning activities, and from documented action recommendalions at the forest, region, or service level. 
Comments. Two important observations regarding the development of this regional screening variable should be noted.

1. The Federal-Protected Lands disqualifying factor will be measured using administrative boundaries rather than fee-ownership boundaries. Since many proposals for additions to these Federalprotected land types simply consist of consolidation of public land ownership within the present administrative boundaries, the CRP will be taking a conservative approach in treating proposed Federalprotected lands. Many proposed Federal-protected lands will have been disqualified during application of the Federal-protected lands disqualifier (Section 5.1.1) and by use of the administrative boundary measure. Thus, the use of Proposed Federal-Protected Lands as a regional screening variable will apply solely to completely new land units.

2. The development of the proposed national wilderness areas definition has been difficult because of the current administration's decision to abandon the RARE II Program. Future administrative recommendations for wilderness designation will be made through the National Forest Planning Process. Draft forest plans issued by the Forest Service would constitute proposals. In the absence of such plans, the CRP has included lands pending Congressional authorization as wilderness, or, in the absence of such bills, lands previously recommended for wilderness designation by the Forest Service under the RARE II Program, as a conservative surrogate. Lands included in currently pending wilderness bills do not necessarily correspond with the Forest Service (1979) recommendations resulting from RARE II.

Scaling.

Distance From Proposed Federal-Protected Lands (miles)

Inside

Boundary $\leq$

$\begin{array}{lcccc}1 & 2 & 3 & 4 & 5 \\ \text { More Adverse } & & \text { Scale Value } & & \text { More Favorable }\end{array}$

\subsubsection{Population Density}

Definition. Areas of specified population density per square mile, where densities are less than the 1,000 persons per square mile disqualifying level. 
Significance. It is the intent of the NWPA and the DOE Siting Guidelines to locate a repository outside of highly populated areas. The use of population densities of less than 1,000 persons per square mile in the region-toarea screening provides a conservative surrogate for the more detailed studies required at later phases to accurately assess both the health and safety and other impacts which may result from the siting, construction, and operation of a repository.

Measure. The estimated number of permanent residents per square mile by MCD or CCD. The lower the estimated density, the higher the favorability for repository siting. The scale for this variable reflects equal increments of density below the 1,000-person-per-square-mile disqualifying threshold, based upon the general, regional-scale assumption that population density-related impacts of a repository are a linear function of distance.

Data Sources. Population densities will be calculated from the same data base and through the same process as that employed in determining areas of 1,000 or more persons per square mile (see Population Density and Distribution disqualifying factor, Section 5.1.4).

Comments. Subsequent screening phases will perform more detailed studies of population projections, seasonal population fluctuations, and socioeconomic impacts or effects. Such studies will be performed during the area and site characterization phases.

Scaling.

Population Density (persons per square mile)

$\begin{array}{llll}800-999 & 600-799 & 400-599 & 200-399\end{array}$

$\begin{array}{lcccc}1 & 2 & 3 & 4 & 5 \\ \text { More Adverse } & & \text { Scale Value } & & \text { More Favorable }\end{array}$




\subsubsection{Proximity to Federal-Protected Lands}

Definition. Straight-line distance from those lands identified in the Federal-Protected Lands and Components of the National Forest Lands disqualifiers (see Sections 5.1.1 and 5.1.2).

Significance. Proximity to Federal-Protected Lands will be treated as a region-to-area screening variable indicating potentially adverse conditions. Federal-protected lands identified as disqualifiers in the region-to-area screening methodology have been established to protect and provide for public enjoyment of important national resources. The potential use of adjacent lands for repository surface facility development could, therefore, have direct and indirect adverse effects on these lands.

Measure. Areas within specified distances of existing Federal-protected lands will be mapped. Uniform distance zones will be established on the basis of estimated size of the repository restricted area and the extent of potential impacts on protected lands. Degrees of potentially adverse conditions are then assigned to these distance zones.

Data Sources. Data sources for Federal-protected lands from which distances will be computed are identical to those for the corresponding lands described under the Federal-Protected Lands and Components of the National Forest Lands disqualifiers (see Sections 5.1.1 and 5.1.2).

Comments. It is assumed for this and other "proximity to" variables that there is a reasonable relationship between proximity and degree of direct and indirect impacts on the protected resource. It is recognized that there are numerous circumstances that may contradict this assumption in specific cases, but such an assumption is reasonable as applied to the regional-scale studies. The first scale increment is the largest ( 5 kilometers [ 3 miles]) to conservatively estimate a zone around each protected land that would be most vulnerable to significant potentially adverse direct and indirect environmental impacts. 
Scaling.

\begin{tabular}{ccccc}
\multicolumn{5}{c}{ Distance From Boundary (miles) } \\
$0-3$ & $>3-4$ & $>4-5$ & $>5-6$ & $>6$ \\
\hline 1 & 2 & 3 & 4 & 5 \\
More Adverse & & Scale Value & & More Favorable
\end{tabular}

\subsubsection{Proximity to State-Protected Lands}

Definition. Straight-line distance from those lands identified in the State-Protected Lands disqualifier (see Sections 5.1.3 and Appendix B).

Significance. Proximity to state-protected lands which are identified as disqualiers will be treated as a region-to-area screening variable indicating potentially adverse conditions. State-protected lands having disqualified status in the region-to-area screening methodology have been established to protect and provide for public enjoyment of resources comparably significant to those protected at the Federal level. The potential use of adjacent lands for repository surface facility development could, therefore, have direct and indirect adverse effects on these resources, and could present a potential irreconcilable conflict-of-use.

Measure. The administrative boundaries of state-protected resources will be mapped. Uniform distance zones will be established based on the estimated size of the repository restricted area and the estimated extent of potential effects on protected lands. Degrees of potentially adverse conditions are then assigned to these distance zones.

Data Sources. Sources for data on state-protected lands will be publications from each state within the CRP. Specific identification of publications will vary from state to state, according to the treatment of land categories in state statutes and regulations, and to the administrative agencies responsible for land management. 
Comments. This variable continues the parallel treatment of Federal- and state-protected lands in the region-to-area screening. The first scale increment is the largest ( $5 \mathrm{kilometers} \mathrm{[} 3$ miles]) to conservatively estimate a zone around each protected land that would be most vulnerable to adverse direct and indirect environmental impacts.

Scaling.

Distance From Boundary (miles)

\begin{tabular}{ccccc}
$0-3$ & $>3-4$ & $>4-5$ & $>5-6$ & $>6$ \\
\hline 1 & 2 & 3 & 4 & 5 \\
More Adverse & & Scale Value & & More Favorable
\end{tabular}

\subsubsection{National Forest Lands}

Definition. All lands within the administrative boundaries of national forests that are not classified as research natural areas, primitive areas, national recreation areas, wilderness areas, wild and scenic rivers, or any other disqualifying condition. These forest lands are generally designated as multiple-use lands.

Significance. The National Forest Lands defined above will be treated as a region-to-area screening variable indicating potentially adverse conditions. A significant measure of public importance and sensitivity has been attached to these lands by virtue of public use, ownership, and their role in environmental protection and resource development. Repository development might impose single-use status on such lands.

Measure. The existing administrative boundaries of such national forest units will be identified and mapped. Distances from these boundaries will be used to determine degrees of potentially adverse conditions.

Data Sources. National forest administrative boundaries are indicated on the forest maps published for each national forest. 
Comments. Substantial areas of private lands are contained within the administrative boundaries of national forests. The use of administrative boundaries, rather than fee-ownership, is a conservative treatment of these national forest lands as a potentially adverse condition.

Scaling.

$$
\text { Distance From National Forests (miles) }
$$

Inside

\begin{tabular}{ccccc} 
Boundary & $\leq 2$ & $>2-4$ & $>4-6$ & $>6$ \\
\hline 1 & 2 & 3 & 4 & 5
\end{tabular}

More Adverse

Scale Value

More Favorable

\subsubsection{State Forest Lands}

Definition. State forests, that by virtue of an analysis of relevant statutory authority and regulations, are analogous in purpose and management objectives to the national forest lands that are not disqualified. Generally, these lands are devoted to multiple uses.

Significance. The state forest lands defined above will be treated as potentially adverse conditions in region-to-area screening. A significant measure of public importance and sensitivity has been attached to these lands by virtue of public benefits derived from their role in environmental protection and resource development. Repository development might impose single-use status on such lands. Appendix $B$ summarizes the classification and treatment of state forest lands for the region-to-area screening, by state. This appendix also summarizes the rationale for the treatment of such lands, by state.

Measure. Existing administrative boundaries for state forests will be identified and mapped. Distances from the administrative boundaries will be used to determine degrees of potentially adverse conditions, which are assumed 0 decrease in adversity with distance. 
Data Sources. State forest administrative boundaries are indicated on forest maps provided to the CRP by each of the 17 crystalline states.

Comments. None

Scaling.

Distance From State Forests (miles)

\begin{tabular}{ccccc}
$\begin{array}{c}\text { Inside } \\
\text { Boundary }\end{array}$ & $\leq 2$ & $>2-4$ & $>4-6$ & $>6$ \\
\hline 1 & 2 & 3 & 4 & 5 \\
More Adverse & & Scale Value & & More Favorable
\end{tabular}

\subsubsection{Designated Critical Habitat for Threatened and Endangered Species}

Definition. Threatened and endangered species habitats formally designated by the U.S. Department of the Interior pursuant to the Endangered Species Act of 1973 (16 USC 1531).

Significance. The presence and extent of designated critical habitat for threatened and endangered species will be treated as a regional screening variable indicating potentially adverse conditions. The Endangered Species Act enables the U.S. Department of the Interior to designate as critical habitat areas that are essential to the preservation of a given species and that may require special management considerations or protection. These management considerations are established on a case-by-case basis.

Measure. Existing boundaries of areas designated as critical habitat for federally listed threatened and endangered species will be identified and mapped. Distances from these boundaries will be used to determine degrees of potentially adverse conditions, with estimated degree of adverse conditions decreasing with distance. 
Data Sources. Notices are published periodically in the Federal Register which announce areas identified by the U.S. Fish and Wildlife Service as designated critical habitat for threatened or endangered species. These notices will be the source of information for identification and mapping of data for this variable.

Comments. The Endangered Species Act was amended on November 10, 1978. One principal feature of the amended Act, as expressed in Section $7(\mathrm{~h})$, was the provision of an extensive review process for the purpose of providing exemptions of the Act's provisions concerning development within a designated critical habitat. To qualify for an exemption, a proposed action must meet three criteria.

1. There are no reasonable and prudent alternatives to the action.

2. The benefits of the action clearly outweigh the benefits of alternative courses of action, and the action is in the public interest.

3. The action is of regional or national significance.

Mitigation measures must also be established. It is conceivable that repository surface facility development could meet these criteria.

It should be noted that state-designated critical habitats will not be treated as potentially adverse conditions in the region-to-area phase. The criteria used by the states for such designation vary widely. Thus, use of state-designated habitats would build inequities of treatment into the screening process. In addition, designated species habitat may be threatened or endangered in that state but not when viewed in a national context.

Scaling.

Distance From Boundary (miles)

Inside

Boundary

$\leq 2 \quad>2-4 \quad>4-6 \quad>6$

1

More Adverse
2

3

Scale Value
4 More Favorable 


\subsubsection{Wetlands}

Definition. Areas that are inundated with a frequency adequate to support vegetative and/or aquatic life that requires periodically saturated soil for growth and reproduction. Features classified as wetlands include swamps, marshes, bogs, and similar features such as sloughs, potholes, wet meadows, river overflows, mud flats, and natural ponds.

Significance. The importance of preserving wetlands has been officially recognized and made part of national policy in Executive Order 11990, Protection of Wetlands, and is implemented by the DOE in 10 CFR 1022. Development of a repository in or near a wetland feature could represent major conflicts with environmental requirements and/or could result in significant environmental impacts that cannot be avoided or mitigated. The key potential impacts are construction-related direct impacts. The presence of wetlands in the vicinity of a repository site may represent a potentially adverse condition as defined in the DOE Siting Guidelines.

Measure. A 1-square-mile grid will be registered over the data source maps. If wetlands occupy more than one-half of any individual grid cell, that cell will be designated as a wetland. This technique effectively depicts the boundaries of large wetlands in the 17 crystalline states, as well as those subregions with a high density of small wetlands.

Data Sources. There are three data sources that best characterize wetlands in the three regions for the region-to-area phase. The data sources, listed in order of their usage are: USGS land use data analys is (LUDA) maps, State government sources, and USGS 1:250,000 scale series quadrangle maps.

Comments. Treatment of this variable is complex given the large number of wetlands in the regions, the widely varying data sources, and dense areas of small wetlands (especially in the North Central states). The sampling technique described above will closely approximate actual wetland boundaries and serve as an indication of the presence of densely packed small wetlands. 
The distance limit for wetlands is designated as 5 kilometers ( 3 miles) instead of the 10-kilometer (6-mile) limit used for previous variables. This is because wetlands-related direct and indirect adverse impacts are generally not likely to be as extensive in geographic scope as are the impacts associated with the previously described land features. More specifically, the potential surface hydrology, water quality, ecological, and noise-related impacts of repository construction and operation are judged by the CRP to be unlikely, in most instances, to extend beyond a 5-kilometer (3-mile) limit around a given wetland.

Scaling.

$$
\text { Distance From Wetlands (miles) }
$$

Inside

Boundary

$\leq 1$

3

Scale Value

5

More Adverse

Scale Value

More Favorable

\subsubsection{Surface Water Bodies}

Definition. Water bodies are herein defined as major rivers, perennial lakes, reservoirs, oceans, bays, and estuaries. Lakes are nonflowing, naturally enclosed bodies of water including regulated lakes. Reservoirs are artificial impoundments typically serving multiple purposes. Major rivers are included in this category as a surrogate, though not very accurate, measure of flood potential. The lakes, reservoirs, oceans, bays, and estuaries are included in the definition for constructability and water quality considerations.

Significance. The occurrence of water bodies is of primary concern in the regional phase as a surface characteristic that could prohibit surface facility development or lead to the flooding of surface facilities; a potentially adverse condition [10 CFR 960.5-2-8(c)]. Favorable conditions could pccur in the absence of surface water bodies that could cause flooding of the repository [10 CFR 960.5-2-10(b)(2)]. 
Executive Order 11988, Floodplain Management, implemented by the DOE in 10 CFR 1022, directs Federal agencies to evaluate the potential effects of any actions they may take in a flood plain "in order to avoid, to the extent possible, the long and short-term adverse impacts associated with the occupancy and modification of flood plains and to avoid direct or indirect support of flood plain development wherever there is a practicable alternative." Development of a repository in a flood plain could present major conflicts with environmental requirements and/or could result in significant environmental impacts that cannot be avoided or mitigated. Thus, again, the presence of a flood plain represents a potentially adverse condition for repository siting as set forth in the guidelines [10 CFR $960.5-2-5(c)(2)]$.

Measure. The regional environmental characterization reports will illustrate the location of those surface water bodies to be addressed in the regional phase in the 17 crystalline states. The rivers will be presented as linear features, and the lakes, reservoirs, oceans, bays, and estuaries as gridded features derived by implementing the sampling approach described below. For screening purposes, all surface water data will be converted to the gridded format.

Practical application of this sampling procedure in screening will address lakes, reservoirs, oceans, bays, estuaries, and wide river channels large enough to include at least one-half of a grid cell. In addition to these surface water bodies of significant areal extent, the channels of major rivers will be identified and mapped as linear features. After converting mapped polygonal data to a grid cell form for applying the regional screening variables, these river course data will appear as connected strings of 1-square-mile grid cells, each of which will be designated as a surface water body.

In summary, for screening, grid cells will be characterized as surface water bodies if:

1. More than 50 percent of the grid cell is characterized as a surface water body on the data sources listed below.

2. A major river course traverses the grid cell. 
Data Sources. There are four data sources which appear to best characterize extensive surface water bodies in the three regions. The data sources, listed in order of their proposed usage, are: USGS LUDA maps, state government sources, and USGS 1:250,000-scale series quadrangle maps. Additional major rivers included in the surface water body variable will be identified from USGS Map 3-A, A Base Map of the United States at a 1:3,168,000 scale (USGS, 1965).

Comments. Treatment of this variable is complex given the large number of water bodies in the regions, the widely varying data sources, and dense areas of small water bodies (especially in the North Central states). The sampling technique described above for screening will closely approximate actual large water body boundaries (greater than 130 hectares [320 acres]) and will ensure that within a grid cell the aggregate area of small surface water bodies exceeding 130 hectares ( 320 acres) will receive screening status. Inclusion of major rivers will provide a rough measure of additional areas with higher potential for flooding as well as potential impacts on important surface water resources.

The rationale for the 5-kilometer (3-mile) limit for water bodies is the same as that described previously for wetlands. This is the generalized estimate of the distance from surface water within which direct and indirect impacts are likely to occur.

Scaling. Scaling for the Surface Water Bodies variable will be as follows:

Distance From Water Body (miles)

\begin{tabular}{ccccc}
$\begin{array}{c}\text { Water Body } \\
\text { Indicated }\end{array}$ & $\leq 1$ & $>1-2$ & $>2-3$ & $>3$ \\
\hline 1 & 2 & 3 & 4 & 5 \\
More Adverse & & Scale Value & & More Favorable
\end{tabular}




\subsubsection{Proximity to Highly Populated Areas or to 1-Square-Mile} Areas with 1,000 or More Persons

Definition. Distance from highly populated areas and areas of 1,000 or more persons per square mile contained in an MCD or CCD. (See disqualifying factor, Population Density and Distribution - Section 5.1.4.)

Significance. It is the intent of the NWPA and the DOE Siting Guidelines to locate a repository away from population concentrations. This would minimize risk to the public health and safety and would minimize disruption to the public caused by construction and industrial-type activity [10 CFR 960.5-2-1(b)(2),(c)(2) and 960.5-2-6(b)(1)-(4),(c)(1),(2),(4)]. The CRP recognizes that detailed data collection is necessary to accurately assess both health and safety impacts, as well as socioeconomic impacts, and such studies will be conducted during a later phase. However, the CRP proposes to utilize a conservative approach for these studies in its region-to-area screening, and apply straight-line distance as a measure of favorability. This variable will help provide assurance that the population density and distribution guideline is met.

Measure. Greater distances from highly populated areas and from MCD or CCD with 1,000 or more persons per square mile are scaled more favorably, while lesser increments of distance from these population concentrations are scaled less favorably.

Data Sources. Data sources will be the same as for the Population Density and Distribution disqualifying factor (see Section 5.1.4).

Comments. Remoteness of a site from highly populated areas is a favorable condition in the DOE Siting Guidelines (10 CFR 960.5-2-1(b)(2)). The scale of distance with intervals up to and beyond 77 kilometers ( 48 miles), as was discussed with the representatives of the states at the February 1984 screening workshop in Atlanta, will tend to drive the siting focus to the more remote and less populated areas of the CRP regions. This will meet the widely accepted intent to locate a repository away from 
population concentrations. The CRP will also use a modified scale for this variable (see Section 3.2.5.1 and Table 2) during the step 3 sensitivity analysis.

Scaling.

Proximity to Highly Populated Areas or to 1-Mile Square Areas With 1,000 or More Persons (miles)

\begin{tabular}{ccccc}
$0-12$ & $>12-24$ & $>24-36$ & $>36-48$ & $>48$ \\
\hline 1 & 2 & 3 & 4 & 5 \\
More Adverse & & Scale Value & & More Favorable
\end{tabular}

\subsection{OTHER VARIABLES (STEP 3)}

A1l of the variables included here are consistent with and selected from the DOE Siting Guidelines. The following listing cross references the proposed Step 3 variables to the appropriate section of the DOE Siting Guidelines. Data relative to these variables are not uniformly available over all of the three regions. These variables are deemed to be of sufficient importance that they will be used in the Step 3 sensitivity analysis to the extent that any data are available.

Step 3 Regional Screening Variable DOE Siting Guidelines

Thickness of Rock Mass

$$
\begin{aligned}
& 960.4-2-3(b)(1), 960.4-2-5(b)(1) \\
& 960.5-2-9(b)(1),(c)(1) \\
& 960.5-2-9(c)(2), 960.5-2-10(b)(1),(c) \\
& 960.5-2-9(b)(2),(c)(2),(c)(3) \\
& 960.4-2-1(c)(2), \\
& 960.5-2-10(b)(1)
\end{aligned}
$$

Thickness of Overburden

State-of-Stress

Ground-Water Resources

One variable, that of Ground-Water Salinity, has been deleted since issuance of the draft document. It was determined that most of the data points represented sea-water intrusion, and the variable, therefore, was not a measure of what was originally intended. 


\subsubsection{Thickness of Rock Mass}

Definition. The minimum vertical dimension of the crystalline rock mass limited by its natural bottom, its structural bottom (as in the case of a lowangle thrust fault), or its petrologic bottom (as in the case of contacts between multiple injections).

Significance. It is least complex to characterize a hydrologic regime occurring within a single homogeneous rock mass. Therefore, the most favorable condition is to be able to maintain deep flow paths in a single medium and avoid major discontinuities at depth.

Measure. The thickness of the rock body, as measured in feet from the ground surface.

Data Sources. Existing information from drill holes or geophysical surveys. The Cocorp Seismic Reflection Traverse Across the Southern Appalachians (Cook et al, 1983) will be utilized where those data are in the vicinity of crystalline rock bodies.

Comments. Favorable siting conditions are those that permit emplacement of the waste at a depth of at least 300 meters ( 984 feet) below the directly overlying ground surface (10 CFR 960.4-2-5). An additional 50 meters (164 feet) of rock could be required in which to place the repository workings and contain the mechanically disturbed zone.

Because most crystalline rocks extend to depths of many thousands of feet, the scale used for this Step 3 variable was given a broad range. The main thrust for doing so was to avoid rock bodies that would have relatively shallow floors and favor those that have greater vertical extent. Rock bodies having shallow floors are indicative of potential complex modeling for repository performance. The favorable 300-meter (984-foot) depth guideline is relatively close to the 457 meters (1,500 feet) generally given as the reference repository depth and, therefore, leaves little margin for discrimination and provides a low level of conservatism. The expanded scale established by the CRP provides for more discrimination and a higher level of 
conservatism. This and other scales developed for use in the screening methodology described herein are not intended to be equated with or strictly tied to the potentially adverse or favorable conditions defined in the DOE Siting Guidelines but were derived to provide reasonable discrimination for purposes of region-to-area screening.

Scaling. The first increment of the scale is based on a multiple of twice the depth of a reference repository.

\begin{tabular}{ccccc}
\multicolumn{5}{c}{ Distance to Bottom of Rock Body (feèt) } \\
$0-3,000$ & $>3,000-4,500$ & $>4,500-6,000$ & $>6,000-7,500$ & $>7,500$ \\
\hline 1 & 2 & 3 & 4 & 5 \\
More Adverse & Scale Value & & More Favorable
\end{tabular}

\subsubsection{Thickness of Overburden}

Definition. Depth of materials (sediments, glacial debris, saprolite, etc.) overlying competent crystalline rock.

Significance. Construction of shafts in crystalline rock is complicated by surficial deposits including soils, glacial drift, and saprolites, especially where these deposits are saturated with ground water. Sinking shafts through these deposits may require greater water and ground control measures (e.g., grouting or ground freezing) than sinking a shaft through hard rock. Potable water aquifers must be cased off to prevent communication with nonpotable ground water and with repository excavations. Thick overburden will also require more extensive shaft collaring and headframe foundations.

Measure. The thickness of material overlying, or depth to, competent crystalline rock.

Data Sources. Compilations and maps previously prepared by state agencies, principally the state geological surveys. 
Comments. Data on this variable exist in only a few states. Additionally, in many locales where data do not exist, it is suspected that thickness of overburden varies greatly over short distances; so it would be difficult, if not impossible, to estimate or extrapolate from isolated data points. This variable will therefore be used only where reliable information has been previously compiled and contoured into a usable form. Where isolated data points exist but have not been previously contoured, the data will be compiled for future use but not used in the region-to-area screening. Where "indications" of depth exist (e.g., well-casing depth), the data will be obtained for future use but not compiled. To actually use data in either of the last two mentioned instances would require considerable interpretation.

Scaling. The scale adopted is based on the thickness of overburden of concern for engineering purposes and the data available. This scale represents a change from that shown in the draft document. The scale adopted is the one that fits the most abundant data and is within the range of values significant to this issue.

Thickness of Overburden (feet)

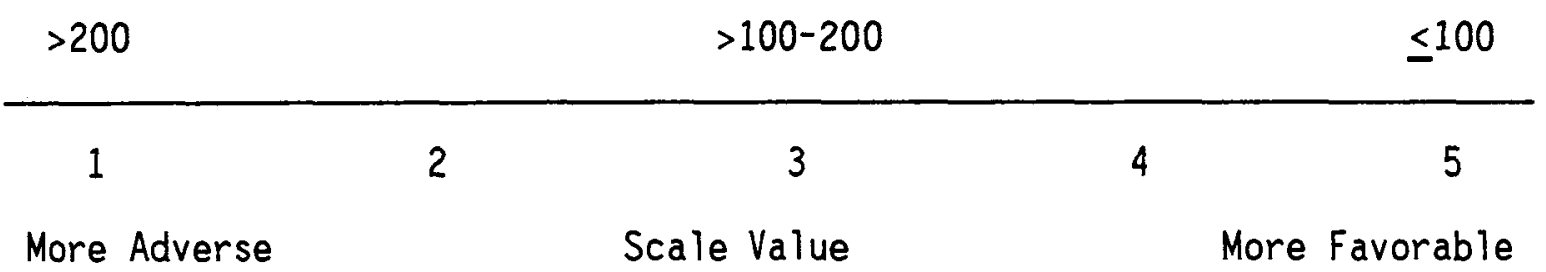

\subsubsection{State-of-Stress}

Definition. The magnitude of the preconstruction principal stresses in the overall rock mass at depth of the area under consideration.

Significance. An evaluation of the in situ stress at the potential repository site, as it pertains to excavation stability, should ensure that the repository construction, operation, and closure will not cause undue hazard to personnel. The DOE defines a favorable condition under 
10 CFR $960.5-2-9(a)$ as a host rock with characteristics that would require minimal or no artificial support for underground openings to ensure safe repository construction, operation, and closure. Knowledge of the stress state of the rock mass is an important characteristic to engineering and construction of the underground repository. Exceptionally high differences between principal stress values (termed the shear stress) would be detrimental to pillar stability, could possibly induce rock burst (the sudden separation of a portion of the rock mass into the excavation), and would prove detrimental to rock characterization activities due to core discing. 1

Measure. The magnitude of the difference between the maximum and minimum principal stresses expected at the repository horizon.

Data Sources. Any previously existing stress measurements that are publicly available.

Comments. Only a few stress measurements have been made in the three regions of interest, and even fewer in crystalline rocks. The distance that any measurement can be extrapolated depends on topography, continuity of rock structure, and continuity of rock mineralogy and texture. For this process, it is proposed that stress measurement values be arbitrarily applied to a circular area of 16-kilometer (10-mile) radius around the point of measurement in lieu of more accurate information. The stress difference at the measurement depth will be considered to be equal to the stress difference at the expected repository depth; measurements at shallow depths, i.e., less than 34 meters ( 100 feet), will be excluded from consideration due to near-surface stress relief and possible stress concentrations from topographic features. Also, normal stresses in the horizontal and vertical planes will be assumed to

1 The phenomenon of discing occurs during core drilling with a diamond crown. When drilling into highly stressed hard rock, it is common for the core to emerge as regular discs, perhaps as thin as a fifth of the core diameter and quite unrelated to the structure of the rock. The phenomenon is best observed when drilling parallel to the bedding in hard, homogeneous rock. The hickness of the discs diminishes with increasing stress. 
be principal stresses and that the vertical stress is equal to the weight of the overlying rock units. Accurate evaluation of stress conditions will require site-specific measurements at a later phase of the project.

Scaling. The scale adopted is based on (1) the range of stress conditions actually found in nature, (2) the range of conditions of concern in constructing an underground facility, and (3) the uniaxial strength of crystalline rock units.

\begin{tabular}{|c|c|c|c|c|}
\hline \multicolumn{5}{|c|}{ Maximum Stress Difference $(\mathrm{MPa})^{1}$} \\
\hline$>30$ & $23-30$ & $17-23$ & $10-16$ & $<10$ \\
\hline 1 & 2 & 3 & 4 & 5 \\
\hline
\end{tabular}

\subsubsection{Ground-Water Resources}

Definition. High-yield aquifers that are or can be designated as significant potable ground-water resources suitable for development as water supplies. In crystalline rock, significant ground-water resources may occur in major fracture or shear zones of the crystalline rock body or in surficial areas of saprolite or sand and gravel deposits. Major fractures or shear zones that can produce significant quantities of ground water may be major ground-water discharge zones.

Significance. Hydrologic data on ground-water yield and developedresource potential will be used as a screening variable to judge whether ground-water sources are present along flow paths from the host rock body to the accessible environment. Also, construction of surface facilities and the shaft could affect ground-water resources, or the water-producing zones could potentially flood subsurface facilities prior to closure of the facility.

Ine MPa (megapascal) equals 145 pounds per square inch. 
Measure. Potential (long-term, average) ground-water yields of wells in and overlying crystalline rock bodies will be considered.

Because it is the range of an industrial capacity water well, 1,900 liters (500 gallons) per minute is taken as the more adverse condition and 76 liters (20 gallons) per minute is taken as the more favorable condition.

Data Sources. Water well yield maps, tabulations, and other records of appropriate state and Federal agencies will serve as data sources for this variable.

Comments. Availability, reliability, and utility of data on this factor vary widely between and within the states. In some states, all wells are recorded and reported on a form which requests information on gallons per minute pumped and drawdown, thus giving information on specific capacity. More commonly, however, data are not available for areas remote from population centers, are not uniform in quality and quantity, and of ten exist as hundreds or thousands of records that are inconsistent in quality and never have been evaluated by professional hydrogeologists familiar with local ground-water resources. The reasons for the lack of consistent quality of information and its nonuniform geographic distribution are, in part, historical. Only in the recent past has there been recognition of concern for water supply problems in some sections of the country.

Scaling. The scale adopted represents a change from that shown in the draft document and is based on the range of ground-water yield that can be anticipated and the most abundant data available.

Average Ground-Water Yield (gpm)

\begin{tabular}{ccccc}
$>500$ & $>100-500$ & & $>20-100$ & $\leq 20$ \\
\hline 1 & 2 & 3 & 4 & 5 \\
More Adverse & & Scale Value & & More Favorable
\end{tabular}




\subsection{REFERENCES}

Algermissen, S. T., D. M. Perkins, P. C. Thenhaus, S. L. Hanson, and B. L. Bender, 1982. Probabilistic Estimates of Maximum Acceleration and Velocity in Rock in the Contiguous United States, U.S. Geological Survey Open-File Report 82-1033, U.S. Department of the Interior, Washington, DC.

ANL, see Argonne National Laboratory.

Argonne National Laboratory, 1984a. North Central Regional Environmental Characterization Report, BMI/OCRD-10 (Review Draft), prepared for Office of Crystalline Repository Development, Battelle Memorial Institutes, Columbus, $\mathrm{OH}$.

Argonne National Laboratory, 1984b. North Central Regional Geologic Characterization Report, BMI/OCRD-11 (Review Draft), prepared for Office of Crystalline Repository Development, Battelle Memorial Institute, Columbus, $\mathrm{OH}$.

Cook, F., et al, 1983. "AAPG Studies in Geology", No. 134, American Association of Petroleum Geologists.

DOC, see U.S. Department of Commerce.

DOE, see U.S. Department of Energy.

EPA, see U.S. Environmental Protection Agency.

Farmer, I., 1983. Engineering Behaviour of Rocks, 2nd ed., Chapman and Hall, New York, NY, p. 51.

Forest Service, 1979. Roadless Area Review and Review and Evaluation, Final Environmental Statement, FS-325, U.S. Department of Agriculture, Washington, DC. 
Forest Service, 1984. Draft Environmental Impact Statement, Quartz Hill Molybedenum Project Mine Development, FS-133, U.S. Department of Agriculture, Washington, DC.

Freeze, R. D., and P. A. Witherspoon, 1967. "Theoretical Analys is of Regional Groundwater Flow - 2, Effect of Water-Table Configuration and Subsurface Permeability Variation", Water Resources Research, Vol. 3, No. 2, American Geophysical Union, Washington, DC.

Gale, J. E., A. Rouleau, P. A. Witherspoon, and C. R. Wilson, 1982. Progress in the Hydrogeological Characterization of the Stripa Site, LBL-14878, SAC-49, prepared for Swedish Nuclear Power Utility Industry and U.S. Department of Energy by Memorial University of Newfoundland, Canada, and Lawrence Berkeley Laboratory, University of California, Berkeley, CA.

Howard, K. H., et al, 1978. Preliminary Map of Young Faults in the U.S. as a Guide to Possible Fault Activity, U.S. Geological Survey Miscellaneous Field Studies Map MF-916, U.S. Department of the Interior, Washington, DC.

NRC, see U.S. Nuclear Regulatory Commission.

Oak Ridge National Laboratory, 1984a. Southeastern Regional Environmental Characterization Report, BMI/OCRD-5 (Review Draft), prepared for Office of Crystalline Repository Development, Battelle Memorial Institute, Columbus, $\mathrm{OH}$.

Oak Ridge National Laboratory, 1984b. Southeastern Regional Geologic Characterization Report, BMI/OCRD-14, (Review Draft) prepared for Office of Crystalline Repository Development, Battelle Memorial Institute, Columbus, $\mathrm{OH}$.

OCRD, see Office of Crystalline Repository Development.

Office of Crystalline Repository Development, 1983. A National Survey of Crystalline Rock and Recommendations of Regions to be Explored for High-Level Radioactive Waste Repository Sites, BMI/OCRD-1, Battelle Memorial Institute, Columbus, $\mathrm{OH}$. 
ORNL, see Oak Ridge National Laboratory.

Pacific Northwest Laboratory, 1984. Northeastern Regional Environmental Characterization Report, BMI/OCRD-6 (Review Draft), prepared for Office of Crystalline Repository Development, Battelle Memorial Institute, Columbus, $\mathrm{OH}$.

PNL, see Pacific Northwest Laboratory.

Pratt, H. R., W. A. Hustrulid, and D. E. Stephenson, 1978. Earthquake Damage to Underground Facilities, DP-1513, prepared for U.S. Department of Energy by E. I. du Pont de Nemours and Company, Savannah River Laboratory, Aiken, SC. SPSS, Inc., 1984. Statistical Package for the Social Sciences, Statistical Analysis System for the IBM PC/XT, Version 1, Chicago, IL.

U.S. Department of Commerce, 1982. "1980 Census of Population," Bureau of the Census, Series PC80-1-A, Washington, DC.

U.S. Department of Energy, 1984a. "General Guidelines for Recommendation of Sites for Nuclear Waste Repositories", Federal Register, Vol. 49, No. 236, pp. 47714-47770, Washington, DC.

U.S. Department of Energy, 1984b. Response to State Comments on the Draft Regional Characterization Reports for the Crystalline Repository Project, DOE/CH-2, prepared for the Crystalline Repository Project Office by the Office of Crystalline Repository Development, Battelle Project Management Division, Argonne, 11:

U.S. Department of Energy, 1984c. Revised Draft North Central Regional Geologic Characterization Report, Vols. 1 and 2, DOE/CH-8, prepared for the Crystalline Repository Project Office by the Office of Crystalline Repository Development, Battelle Project Management Division, Argonne, II.

U.S. Department of Energy, 1984d. Revised Draft Northeastern Regional Geologic Characterization Report, Vols. 1 and 2, DOE/CH-7, prepared for the 
Crystalline Repository Project Office by the Office of Crystalline Repository Development, Battelle Project Management Division, Argonne, Il.

U.S. Department of Energy, 1984e. Revised Draft Southeastern Regional Geologic Characterization Report, Vols. 1 and 2, DOE/CH-6, prepared for the Crystalline Repository Project Office by the Office of Crystalline Repository Development, Battelle Project Management Division, Argonne, Il.

U.S. Department of Energy, 1984f. Revised Draft North Central Regional Environmental Characterization Report, Vols. 1 and 2, DOE/CH-5, prepared for the Crystalline Repository Project Office by the Office of Crystalline Repository Development, Battelle Project Management Division, Argonne, Il.

U.S. Department of Energy, 1984g. Revised Draft Northeastern Regional Environmental Characterization Report, Vols. 1 and 2, DOE/CH-4, prepared for the Crystalline Repository Project Office by the Office of Crystalline Repository Development, Battelle Project Management Division, Argonne, Il.

U.S. Department of Energy, 1984h. Revised Draft Southeastern Regional Environmental Characterization Report, Vols. 1 and 2, DOE/CH-3, prepared for the Crystalline Repository Project Office by the Office of Crystalline Repository Development, Battelle Project Management Division, Argonne, I1.

U.S. Department of Energy, 1984i. Region-to-Area Screening Methodology for the Crystalline Repository Project, DOE/CH/10139-1 (Draft), prepared for the Crystalline Repository Project Office by the Office of Crystalline Repository Development, Battelle Project Management Division, Argonne, IL.

U.S. Department of Energy, 1984j. "Mission Plan for the Civilian Radioactive Waste Management Program", Vol. I, Overview and Current Program Plans, DOE/RW-0005 Draft, prepared for Office of Civilian Radioactive Waste Management, Washington, $D C$.

U.S. Department of Energy, 1984k. Generic Requirements for a Mined Geologic isposal System, DOE/NE/44301-1, prepared for Office of Civilian Radioactive Waste Management by Roy F. Weston Inc., Washington, DC. 
U.S. Environmental Protection Agency, 1982. "Environmental Standards for the Management and Disposal of Spent Nuclear Fuel, High-Level and Transuranic Radioactive Wastes" (Proposed Rule) (40 CFR 191), Federal Register, V01. 47, No. 250, pp. 58196-58206, December.

U.S. Geological Survey, 1965. A Base Map of the United States, Map 3-A.

USGS, see U.S. Geological Survey.

U.S. Nuclear Regulatory Commission, 1981. "Disposal of High-Level Radioactive Wastes in Geologic Repositories: Licensing Procedures Procedural Rule" 10 CFR 60, Federal Register, J. 46, No. 37, pp. 13971-13987 (Feb. 25, 1981), Washington, DC.

U.S. Nuclear Regulatory Commission, 1982. "Disposal of High-Level Radioactive Wastes in Geologic Repositories, Proposed Technical Criteria", 10 CFR 60, Federal Register, SECY-82-288, Enclosure B (July 7, 1982), Washington, DC.

U.S. Nuclear Regulatory Commission, 1983. Disposal of High-Level Radioactive Wastes in Geologic Repositories: Licensing Procedures Technical Rule, 10 CFR 60 , Title 10, Ch. 1, Code of Federal Regulations, pp. 60-1-60-17, June 30, 1983, Washington, DC.

Wahi, K. K., B. C. Trent, D. E. Maxwe 11, R. M. Pyke, C. Young, and D. M. RossBrown, 1980. Numerical Simulations of Earthquake Effects on tunnels for Generic Nuclear Waste Repositories, DP-1579, prepared for U.S. Department of Energy by Science Applications, Inc. for E. I. du Pont de Nemours and Company, Savannah River Laboratory, Aiken, SC.

WCC, see Woodward-Clyde Consultants.

Weeks, J. B., et al, 1974. Simulated Effects of Oil Shale Development on the Hydrology of Piceance Basin, Colorado, USGS Professional Paper 908, prepared in cooperation with Colorado Department of Natural Resources, U.S. Department of the Interior, Reston, VA. 
Woodward-Clyde Consultants, 1984. Northeastern Regional Geologic Characterization Report, BMI/OCRD-13 (Review Draft), prepared for Office of Crystalline Repository Development, Battelle Memorial Institute, Columbus, $\mathrm{OH}$. 
APPENDIX A

STATE COMMENTS ON DRAFT REGION-TO-AREA SCREENING METHODOLOGY DOCUMENT AND CRP RESPONSES 


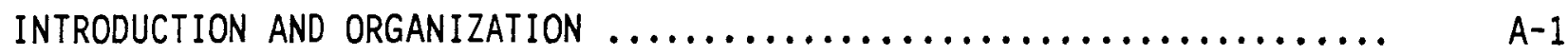

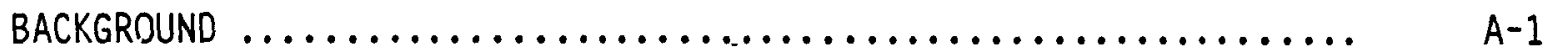

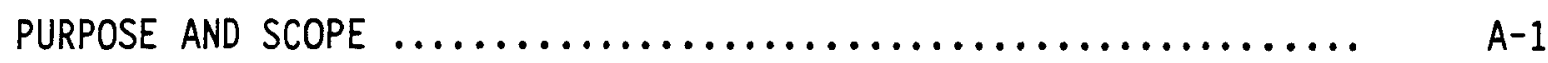

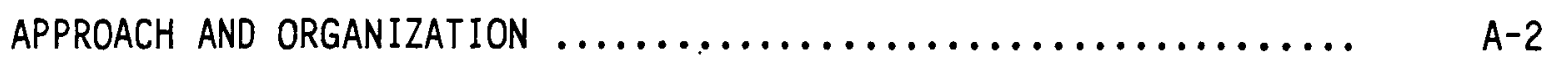

STATE COMMENTS ON DRAFT SMD AND CRP RESPONSES $\ldots \ldots \ldots \ldots \ldots \ldots \ldots \ldots$ A-11

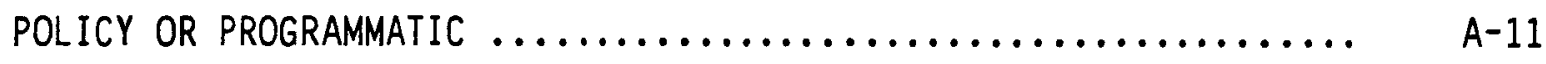

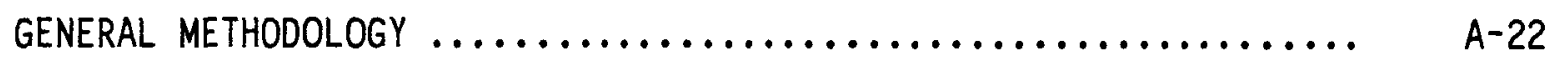

SECTION AND TOPIC SPECIFIC

1.4 General Description of Repository ............. A-42

2.1 National Survey $\ldots \ldots \ldots \ldots \ldots \ldots \ldots \ldots \ldots \ldots \ldots \ldots, A-46$

2.2 Region-to-Area Screening ................... A-47

2.3 Area Screening and Site Recommendation ........... A-50

3.0 Regional Screening Methodology ................ A-52

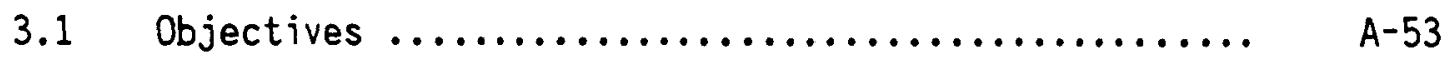

3.2.1 Step 1 - The Disqualifying Factors Screen ......... A-57

3.2.2 Step 2 - The Scaled Regional Variables Screen ....... A-66

3.2.3 Description and Role of the Weighting Process ....... A-69

3.2.4 Composite Map Development .................... A-92

3.2.5 Step 3 - Sensitivity Analysis ................ A-97

3.2.6 Selecting Candidate Areas .................... A-107

4.1 Disqualifying Factors from the General Siting Guidelines ........................ A-113

4.2 Implementation Guidelines ................... A-120

1The organization of this Table of Contents, beginning with Chapter 1.0, basically conforms to the format of the draft SMD. Comments on Appendix $A$ of the draft SMD are located under the section (or under the topical area) of this Appendix $A$ to which the comment refers. 


\section{TABLE OF CONTENTS}

(Continued)

4.3 Postclosure Guidelines

$A-123$

4.4 Preclosure Guidelines

A-124

5.1.1 Federal-Protected Lands

A-125

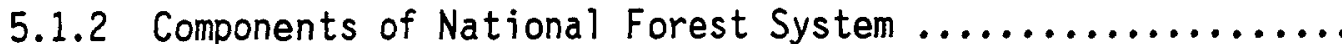

A-126

5.1.3 State-Protected Lands

$A-128$

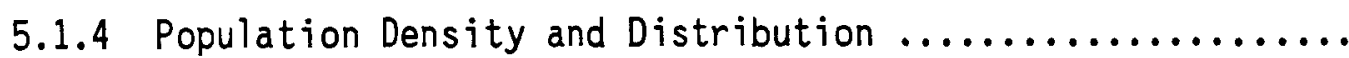

$A-130$

5.1.5 Hydrologically Significant Natural Resources 1 .........

A-133

Other Disqualifying Factors

A-137

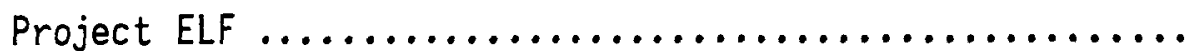

$A-137$

Ground-Water Travel Time

$A-138$

Areas Designated by Federal Statute...............

$A-139$

Proposed State-Protected Lands

$A-140$

Significant Protected Private Lands

A-142

5.2 Scaled Geologic Variables (Step 2)

A-143

5.2.1 Rock Mass Extent

A-144

5.2.2 Major Ground-Water Discharge Zones ................. A-153

5.2.3 Rock and Mineral Resources ....................... A-162

5.2 .4 Seismicity .................................. A-165

5.2 .5 Suspected Quaternary Faulting .................... A-169

5.2.6 Postemplacement Faulting ....................... A-172

Other Geologic Variables ............................. A-177

Uplift and Subsidences .......................... A-177

Climate Change ................................ A-179

Enhanced Natural Radiation ........................ A-180

Peat Lands ..................................... A-181

1This section has been retitled "Deep Mines and Quarries", Section 5.1.5, in the final SMD. 
Table of Contents

(Continued)

Page

5.3.1 Proposed Federal-Protected Lands ............... A-182

5.3 .2 Population Density .......................... A-185

5.3.3 Proximity to Federal-Protected Lands ............. A-188

5.3.4 Proximity to State-Protected Lands ............... A-192

5.3.5 National Forest Lands ....................... A-195

5.3.7 State Wildlife Lands ${ }^{1} \ldots \ldots \ldots \ldots \ldots \ldots \ldots \ldots \ldots$ A-197

5.3.8 Designated Critical Habitat for Threatened and Endangered Species ........................ A-200

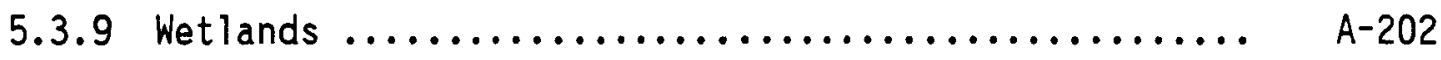

5.3.10 Surface Water Bodies ...................... A-205

5.3.11 Proximity to Highly Populated Areas ............. A-215

Other Environmental Variables ...................... A-218

Proposed State-Protected Lands ............... A-218

Transportation .......................... A-220

Prime Agricultural Land ................... A-224

Defense Facilities ....................... A-225

Hazardous Facilities .................... A-226

Nuclear Facilities ....................... A-227

Appalachian Trail ......................... A-229

Seasonal Population and Population

Projections ............................. A-231

Green Acres Land ........................ A-233

Meteorology ............................. A-234

Socioeconomic Factors ...................... A-235

Cultural, Archaeological, and

Historic Resources ....................... A-236

Native American Resources .................... A-237

This section has been incorporated into State-Protected Lands, Section 5.1.3, in the final SMD. 
Table of Contents

(Continued)

5.4 Other Factors (Step 3) $\ldots \ldots \ldots \ldots \ldots \ldots \ldots \ldots \ldots \ldots$ A-238

5.4 .1 Thickness of Rock Mass ..................... A-239

5.4 .2 Thickness of Overburden .................... A-242

5.4 .3 State of Stress ........................ A-244

5.4 .4 Ground-Water Salinity .................... A-245

5.4 .5 Ground-Water Resources .................... A-247

Other Step 3 Variables ......................... A-252

Host Rock Thermal Properties ................. A-252

7.0 Statutes and Regulations .................. A-253

Appendix B: Summaries of State-Protected Lands .......... A-254 
INTRODUCTION AND ORGANIZATION

BACKGROUND

The draft Region-to-Area Screening Methodology for the Crystalline Repository Project screening methodology document (SMD), (DOE, 1984a), was released for state review and comment on September 6, 1984. The Crystalline Repository Project Office (CPO) requested that all comments on the draft SMD be transmitted to CPO by October 12, 1984. However, during the course of a U.S. Department of Energy (DOE)-states meeting in Atlanta, Georgia, on October $3-4,1984$, the 17 involved states 1 asked for additional time to complete their review of the draft SMD and the comment period was extended 2 weeks. As a result of this state review, 23 letters were received from 15 states and one letter was received from a Federal agency.

The draft SMD, as well as comments on the document, were based on the July 5, 1984 version of the DOE Siting Guidelines (10 CFR 960 [DOE, 1984b]), which were concurred in by the U.S. Nuclear Regulatory Commission (NRC) on June 22, 1984. The DOE Siting Guidelines were codified in the Federal Register December 6, 1984. Because of this situation, the CPO invited any additional state comments on the draft SMD, as a result of their review of the final DOE Siting Guidelines, (10 CFR 960 [DOE, 1984C]), to be transmitted by January 7, 1985. Three letters from three states were received. These 27 letters form the basis for this appendix and a detailed listing of these letters is provided.

PURPOSE AND SCOPE

The purpose of this appendix is to present the comments on the draft SMD contained in the 27 letters and, in the responses, indicate how or to what extent the suggestions or comments received have been considered in modifying

1The crystalline states categorized by region include: Northeastern Region (Connecticut, Maine, Massachusetts, New Hampshire, New Jersey, New York, Pennsylvania, Rhode Island, and Vermont), Southeastern Region (Georgia, Maryland, North Carolina, South Carolina, and Virginia), and North Central Region (Michigan, Minnesota, and Wisconsin). 
the draft SMD. Comments related to the content, structure, approach, or mechanics of the region-to-area screening process or comments on specific passages of the draft SMD are addressed. Therefore, this appendix responds only to State comments on the draft SMD. Appendix A of the draft SMD responded to State comments received following the three methodology workshops.

APPROACH AND ORGANIZATION

Comments specific to the region-to-area screening process have been transcribed verbatim, to the extent practical, from the letters and entered directly into the appendix. In those instances where, due to the length of the comment, the transcription of an entire passage was not practical, three periods have been used to denote that a word(s) or phrase(s) has been excluded in transcription.

The presentation of comments and responses has been organized to parallel the sections of the draft SMD to which the comments refer. There are, in addition, other topics related to the region-to-area screening process that are included. The overall structure of the appendix is shown in the Table of Contents. A response is provided to each individual comment or, whenever appropriate, to a "cluster of comments". A cluster of comments occurs when several letters raise virtually the same issue or recommendation, regardless of viewpoint (i.e., parallel or conflicting), that can be answered by a singular response.

The format used to present comments and responses is shown in Exhibit A-1 for a single comment response, and Exhibit A-2 for a clustered comment response. The "Comment Letter Reference" entry provides the reader with a key to the origin of the comment and assists internally in tracking comments from the letters to the appendix. The entry denotes the author (i.e., state), and the particular comment number within the letter. In many instances, the reference entry has a letter associated with it (e.g., MN-B-7). This is an indication that a particular state provided more than one comment letter on the draft SMD. To provide the reader with an example of how the "Comment Letter Reference" entry is constructed, the state letter from which Exhibit $A-1$ is developed is shown following the exhibit. State comments appear in bold type, and CRP responses are in regular type. 
A-3

A listing of the comment letters and comment letter references received on the draft SMD is provided on pages A-7 through A-10. 
SECTION/TOPIC AREA: Other Disqualifying Factors (Project ELF)

COMMENT LETTER REFERENCE: MI-B-1

Comment:

It is our belief that the presence of this system (U.S. Navy's extra low frequency communications system - Project ELF) renders the rock body designated \#9 on the map provided by your office unsuitable for further consideration as a potential host for a high-level radioactive waste repository. We believe that it would be virtually impossible to assess the environmental, geologic, and socioeconomic effects or the strategic and tactical implications of establishing and operating a repository in close proximity to ELF Communication System. We urge you to consider this matter carefully and delete rock body \#9 from the list of areas to be considered in selecting potentially acceptable sites.

\section{Response:}

An evaluation of the potential interactive effects between the ELF Communication System and a geologic repository will not be undertaken at the regional phase. This is because the relevant provisions of the DOE Siting Guidelines (10 CFR 960.5-2-4) require site-specific information, of not only the offsite installation but the geologic repository as well, in order to make the determinations required in 10 CFR $960.5-2-4(a)(1),(c)(1)$. It is CRP's position that if any of the candidate areas are coincident with or proximate to an atomic energy defense activity, a nuclear facility, or a potentially hazardous facility, then an assessment of potential interactive effects would occur as a part of subsequent investigations. 
EXAMPLE OF "COMMENT LETTER REFERENCE" ENTRY

Sally A. Mann, Ph.D., Manager

Crystalline Repository Project Office

U.S. Department of Energy

Chicago Operations Office

9800 South Cass Avenue

Argonne, Illinois 60439

Dear Doctor Mann:

As the enclosed map indicates, one of the rock bodies in Michigan's Upper Peninsula presently under consideration as a repository site underlies the U.S. Navy's extra-low frequency communications system (Project ELF), which is currently under construction. It is our belief that the presence of this system renders the rock body destgnated \#9 on the map provided by your office unsuitable for further consideration as a potential host for a high-level radioactive waste repository. We believe that it would be virtually impossible to assiss the environmental, geologic, and , socioeconomic effects or the strategic and tactical implications of establishing and operating a repository in close proximity to the ELF communications system. We urge you to examine this matter carefully, and to delete rock body \#9 from the list of areas to be considered in selecting potentially acceptable sites.] You may wish to contact:

Captain Ronald Koontz

Naval Electronic Sys tems Command

PME 110-E

Washington, D.C. 20363

(202) 692-8871

for further information in this regard.

Very truly yours,

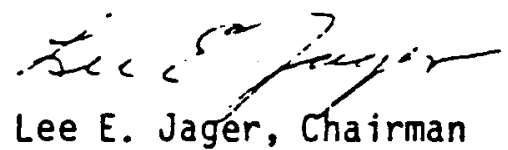

Governor's Task Force on

High-Level Radioactive Waste 
SECTION/TOPIC AREA: e.g., Policy or Programmatic

COMMENT LETTER REFERENCE: e.g., NH-10, NC-B-2, NC-B-3, and SC-A-1 (This line item includes a chain listing for clustered comments.)

\section{Comments:}

(This line item includes a verbatim text of the several comments.)

Response: (This line item includes an integrated response to comments cited above.)

\section{Exhibit A-2}

Clustered Comment Response Format 
North Central Region

Michigan Department of Public Health-

L. Jager, Chairman, Governor's Task

Force on High-Level Radioactive Waste

to S. Mann, CPO. October 30, 1984

Michigan Department of Public Health-

L. Jager, Chairman, Governor's Task

Force on High-Level Radioactive Waste

to S. Mann, CPO. November 6, 1984

Minnesota Department of Natural Resources-

J. Alexander, Commissioner to S. Mann, CPO.

September 26, 1984

Minnesota Department of Agriculture-

J. Nichols, Commissioner to S. Mann, CPO.

September 27, 1984

Minnesota Environmental Quality Board-

T. Kalitowski, Chairman, Governor's Task

Force on High-Level Radioactive Waste

to S. Mann, CPO. October 31, 1984

Minnesota Environmental Quality Board-

T. Kalitowski, Chairman, Governor's Task

Force on High-Level Radioactive Waste

to S. Mann, CPO. December 28, 1984

Wiscons in Department of Natural Resources-

D. Gebken, Chairman, Technical Advisory

Council to S. Mann, CPO. November 2, 1984 
Northeastern Region

Maine Department of Conservation-

W. Anderson, State Geologist to

S. Mann, CPO. October 24, 1984

Massachusetts Department of Public Health-

R. Hallisey, Director, Radiation Control

Program to S. Mann, CPO. October 29, 1984

New Hampshire Office of State Planning-

D. Scott, Acting Director to S. Mann, CPO. October 24, 1984

New Jersey Department of Environmental Protection-

C. Gordon, Project Manager to S. Mann, CPO.

November 15, 1984

New York Energy Research and Development Authority-

T. DeBoer, Director, West Valley/Radioactive

Waste Management Program to S. Mann, CPO.

October 29, 1984

New York State Department of Conservation-

C. Burt, Senior Environmental Scientist to

S. Mann, CPO. February 22, 1985

Rhode Is land Governor's Energy Office-

B. Vild, Coordinator, Crystalline Rock

Project Review Team to S. Mann, CPO.

November 5, 1984

Vermont Agency of Environmental Conservation-

C. Ratté, State Geologist to S. Mann, CPO.

October 24, 1984 
Southeastern Region

Georgia Department of Natural Resources-

J. Ledbetter, Commissioner to S. Mann, CPO.

October 19, 1984

Georgia Department of Natural Resources-

W. McLemore, State Geologist to M. Bender, CPO.

December 10, 1984

Maryland Office of Environmental Programs-

W. Eichbaum, Assistant Secretary for

Environmental Programs to S. Mann, CPO.

November 5, 1984

North Carolina Department of Cultural Resources-

D. Brook, Deputy State Historic Presentation

Officer to S. Mann, CPO. October 9, 1984

North Carolina Department of Natural Resources and

Community Development- S. Conrad, Director of Land

Resources to S. Mann, CPO. October 26, 1984

South Carolina Office of the Governor-

W. Marshal1, Technical Coordinator, Office of

Executive Policy and Programs to P. Kearns, CPO.

October 25, 1984 
South Carolina Office of the Governor-

S. Rhodes, Nuclear Waste Project

Administrator to S. Mann, CPO.

October 30, 1984

South Carolina Office of the Governor-

S. Rhodes, Nuclear Waste Project

Administrator to S. Mann, CPO.

January 4, 1985

Virginia Solid Waste Commission-

B. Wrenn, Executive Director to

S. Mann CPO. October 25, 1984

Virginia Department of Health-

W. Gilley, Director, Division of Solid

and Hazardous Waste Management to S. Mann,

CPO. October 26, 1984

Virginia Council on the Government-

K. Buttleman, Administrator to S. Mann, CPO.

October 30, 1984.

\section{Federal Agency}

U.S. Department of Interior, Fish and Wildlife

Service- H. Nelson to S. Mann, CPO.

November 27, 1984 
POLICY OR PROGRAMMATIC

COMMENT LETTER REFERENCE: VA-A-1 and VA-B-2

Comments:

... the schedule established over the next 12 months is inadequate for substantial review of the forthcoming reports. Specifically, additional time should be allowed for review of the draft RCR to ascertain the inclusion of the most effective screening elements. (VA-A-1)

The review of the methodology by states should be further delayed pending release of the Draft Regional Characterization Reports. The RCR draft should be considered by states for applicability to the proposed screening methodology. (VA-B-2)

\section{Response:}

As a result of prior input from the states, the schedule for release of the SMD and the regional characterization reports (RCR) was resequenced such that the draft SMD was released prior to the draft RCR (approximately 3 months) and the draft RCR were released for review prior to the close of the comment period on the SMD. The Crystalline Repository Project (CRP) schedule provides approximately 90 days for state review and comment on the revised draft RCR. The RCR were issued for comment on December 11, 1984, and the comment period terminated on March 15, 1985. Two distinct review periods were scheduled for the draft SMD; one between September 6 and 0ctober 26, 1984, and a second between December 6, 1984, and January 7, 1985. The second review period on the draft SMD allowed the states to review the document and provide comments based on the final DOE Siting Guidelines and afforded the states the opportunity to consider the data base in the revised draft RCR which will be used in region-to-area-screening. Three letters were received during this cond review period, one from Minnesota, one from South Carolina, and one rrom New York. 
COMMENT LETTER REFERENCE: MI-A-1, MN-C-2, WI-1, WI-2, ME-4, ME-5, NY-A-8, RI-7, VT-1, GA-A-9, NC-B-1, SC-B-1, VA-B-1, VA-C-1, and $\mathrm{VA}-\mathrm{C}-2$

\section{Comments:}

It is impossible to perform a meaningful comprehensive review of the proposed screening methodology until the Siting Guidelines (10 CFR 960) have been finalized. The Screening Methodology Document should not be finalized until final Siting Guidelines are published and the states have ample opportunity ( 30 days minimum) to review a DOE redraft of the Screening Methodology Document. (MI-A-1)

As we pointed out at the October, 1984 Atlanta meeting, the site selection process must be logical and sequential. Requiring conments on the Screening Methodology prior to the final issuance of the Siting Guidelines violates that principle. Submittal of our comments constitutes a draft response to the Screening Methodology. We reserve the option of modifying our comments based on the final Siting Guidelines. (MN-C-2)

There is no legal basis for the finalization of the screening methodology prior to final adoption of the Siting Guidelines. (WI-1)

The Screening Methodology should be part of the Siting Guidelines. ... Analysis will be required to determine how comingling will effect repository operations and performance standards, and how such effect should be addressed in the siting guidelines and in the screening methodology. (WI-2)

... Finalization of the Screening Guidelines is premature. (ME-4)

... We reserve the right to review the draft Screening Methodology when the final Guidelines are published, and ... to provide additional comments to DOE. (ME-5) 
It appears obvious that the Siting Guidelines should be finalized prior to issuance of a Screening Methodology. (NY-A-8)

Another, more general problem the Project Review Team has with the Draft Methodology is one shared by other States at the Atlanta meeting: the sequencing of the Siting Guidelines and the Methodology. (RI-7)

Our comments are preliminary in nature due to the Guidelines having not yet been released. We are willing to forward preliminary comments to you at this time with the clear understanding that we reserve the right to submit additional comments up to thirty days after the Guidelines are finalized. (VT-1)

In the event that the final Preamble and Siting Guidelines (which we understand will not be issued until mid to late November) contain significant changes, we reserve the option to modify our comments to the Methodology Document as appropriate. (GA-A-9)

The sequencing of the many activities related to the siting process continues to be a major concern. In this case, the Siting Guidelines have yet to be finalized, so the Screening Methodology should not be forced to completion. Once the Siting Guidelines are official, there should be a reasonable period of time provided for further review and comparison between the Guidelines and Methodology before the Methodology is institutionalized. (NC-B-1)

South Carolina will file formal comments on the Screening Methodology document after the Final Siting Guidelines, including the Preamble, are released by the Department of Energy. (SC-B-1)

My concern in submitting these comments is that they seem to be premature considering the pending release of the draft Regional Characterization Report and the final publication of the Siting Guidelines. Without these documents, the comments submitted are not complete. (VA-B-1) 
We agree with Mr. Gilley's view that the timing sequence--publication of the Screening Methodology prior to publication of the Repository Siting Guidelines on which it depends--is inappropriate. (VA-C-1)

The DOE should ensure that, to some extent at least, its Repository Siting Guidelines are made consistent with the already-reviewed methodology, and that opportunity to evaluate that consistency is provided. (VA-C-2)

Response:

The SMD was not finalized until after the final DOE Siting Guidelines were codified in the Federal Register December 6, 1984, and became effective January 6, 1985 (10 CFR 960 [DOE, 1984C]). The CRP provided unt il January 7, 1985, 30 days after Federal Register publication of the final DOE Siting Guidelines, for states to submit additional comments on the draft SMD. This enabled the states to reexamine their original comments based on the contents of the final DOE Siting Guidelines. Three states, Minnesota, South Carolina, and New York provided additional comments during this second comment period.

The CRP does not agree that considerations of comingling need to be addressed in the region-to-area screening process, and therefore, this subject is not considered in the final SMD.

Regarding that portion of VA-B-1 pertaining to the RCR, see CRP'S immediately preceding response to $V A-A-1$ and $V A-B-2$.

COMMENT LETTER REFERENCE: MI-A-65 and MN-C-29

\section{Comments:}

Appendix A ... is an inappropriate inclusion in the report... Several states, including Michigan, undoubtedly would have consolidated verbal comments presented during the workshops had DOE explained that subsequent written comments ... and the corresponding DOE responses were to be presented as part of the Screening Methodology Document. (MI-A-65) 
During the recent meeting of the crystalline states in Atlanta, on October 3 and 4, the states expressed their dismay over the format of the comment response portion of the Screening Methodology. The deletions, paraphrasing, and lack of proper context frequently resulted in distortion and incorrectly emphasized state positions. We recommend that the state comments, in their entirety, be provided in a separate document and be specifically referred to, when appropriate, in the CRP responses. This is a standard format for many comment response documents and is one that avoids the problems of CRP interpretation that are evident in Appendix A. (MN-C-29)

\section{Response:}

The CRP believed that publishing state comments received subsequent to each of the workshops and the associated responses would provide an indication as to how state views were used in developing the draft SMD. Appendix $A$ of the draft SMD is replaced with this appendix (which is based on state comments on the draft SMD and CRP responses) using a format similar to that in Appendix $A$ of the draft SMD. However, in preparation of this appendix, the CRP has attempted to provide the proper context for each comment and has not paraphrased any comments. All the state letters in their entirety were transmitted to each state on February 13, 1985.

\section{COMMENT LETTER REFERENCE: MI-A-4 and MI-A-5}

\section{Comments:}

With regard to the Siting Guidelines,

(a) Have any factors, besides "hydrologically significant rock and mineral resources", been proposed for incorporation in the Guidelines?

(b) If so, are they applicable at the regional screening phase? (MI-A-4)

(c) Have the implementation guidelines been altered in a manner affecting the region-to-area screening process? (MI-A-5) 
Response:

No other disqualifying factors have been incorporated into the final DOE Siting Guidelines beyond those presented in the July 3, 1984, version of the Siting Guidelines that was concurred in by the NRC. The implementation guidelines have not changed from the July 3, 1984, version of the DOE Siting Guidelines. In addition, the states had an opportunity to review the draft SMD after the DOE Siting Guidelines were published in the Federal Register.

COMMENT LETTER REFERENCE: NH-10, NC-B-2, NC-B-3, and SC-A-1

Comments:

During the meeting in Atlanta in early 0ctober it was noted that several States subsequently had rock masses added to their maps. This situation should not be allowed to occur at this stage of the process. (NH-10)

It is strongly felt that no additional rock bodies should be added to the study after the release of the 1984 maps. If the DOE insists on adding rock bodies after that date, then extra grant funds must be released to allow states to retrofit their participation and accelerate the rock bodies inclusion in the affected states' participation process at the earliest possible date. (NC-B-2)

Furthermore, if rock types other than siliceous metamorphic or granite rocks are added in North Carolina, then we would insist that similar rock types in the other crystalline rock states also be reevaluated. (NC-B-3)

In the interest of fairness and a technically defensible process, we insist upon a more rigorous definition by DOE of crystalline rocks and such a definition should be documented. In addition DOE should publish a formal technical definition for crystalline rocks and a formal set of technical criteria by which various lithologies and facies are included or excluded. The definition and criteria should be distributed to the states for comment 
prior to the acceptance of any proposed new rock bodies and prior to the release of the final RCR's. (SC-A-1)

\section{Response:}

Additional rock bodies have been identified in all three regions since the winter of 1983-1984. The rock bodies more recently added in the Southeastern Region include mafic rock types that have previously been evaluated and included in the North Central and Northeastern Regions but not previously included in the Southeastern Region. Thus, similar rock types have now been evaluated and included in all three regions. No additional rock bodies are expected to be included beyond those currently identified in the revised draft regional geologic characterization reports (RGCR). The currently-identified rock bodies represent DOE's final list unless state review of the revised draft RGCR results in identification of additional rock bodies. It is believed that the grant funding provided to date to each requesting crystalline state provides the requisite level of financing for state overview of the CRP.

The formalized definition of crystalline rock appearing in the national survey (OCRD, 1983) and clarified in the draft SMD (DOE, 1984a, page 74) and the main body of this document, Section 5.2.1) is considered sufficiently rigorous to carry out the regional screening phase. Area-phase field investigations will provide more detail on specific rock composition and other physical properties but are not expected to necessitate revising the current definition.

\section{COMMENT LETTER REFERENCE: NJ-5}

\section{Comment:}

The 10,000 years mentioned in this (favorable) condition (10 CFR 960.4-2-1(b)) is not consistent with the 1,000 years used in the disqualifying condition. What is the significance of the difference in the ground-water 


\section{Response:}

The DOE approach to preparation of the hydrogeology favorable condition was one of conservatism. The 1,000-year travel time in the disqualifying statement is consistent with the NRC criterion in 10 CFR 60.113 (NRC, 1983a) and is a sufficient period for most of the fission products to decay to generally safe levels. Any travel time greater than 1,000 years is acceptable. However, in view of the uncertainties involved in travel time calculations, the DOE selected the conservative period of 10,000 years for a favorable condition. Any site having a travel time between 1,000 and 9,999 years would not rank as high as sites having 10,000-year or greater travel time.

\section{COMMENT LETTER REFERENCE: NJ-6}

\section{Comment:}

As with the rates referred to in (10 CFR 960.4-2-5, Erosion) the ability of a repository to isolate waste is 10,000 years. Yet in this condition and in (10 CFR 960.4-2-2(b)(1)) the time span is 100,000 years. The DOE needs to define a consistent time frame for waste isolation and the effects of geologic processes.

\section{Response:}

Consistent time frames are not always practical for application to a wide range of geologic processes that are controlled by a variety of conditions operating at vastly different rates for different periods of time. The time frames referred to in 10 CFR 960.4-2-2(b)(1) and 10 CFR 960.4-2-5(c)(2) are related to favorable and potentially adverse conditions, respectively. Thus, they cannot and should not be considered to require equity in time frame. Generally, potentially adverse conditions are considered over a shorter time scale to be conservative. On the other hand, favorable conditions are expressed in terms of longer time spans, again to be conservative. That is, it is preferable to be in a place where potentially disruptive events occur 
every 100,000 years rather than where they occur every 10,000 years and further to disqualify places where occurrences are possible in 1,000 years or less. Considering the above rationale, it is reasonable that a variety of time periods are needed to place potentially disruptive events and processes in perspective relative to favorable and potentially adverse conditions. Accordingly, the use of different time periods is not inconsistent.

\section{COMMENT LETTER REFERENCE: $\mathrm{NJ}-7$}

\section{Comment:}

The downward gradient in (10 CFR 960.4-2-1(b)(4)(ii)) appears to conf1ict with the low gradient requirement in ( $i i i)$ with the host rock. This still needs to be clarified. How will this downward gradient be calculated?

\section{Response:}

The downward gradient (10 CFR 960.4-2-1(b)(4)(ii)) is not inconsistent with low gradient (10 CFR 960.4-2-1(b)(4)( $i i j)$ ) when viewed from the perspective that potential migration from the waste should be away from the human environment (downward), and that the rate of movement should be low (e.g., low gradient).

Gradients will be measured with piezometers in zones where enough permeability exists so that equilibrium can be reached in a relatively short period of time (several weeks to several months), and the piezometric heads will be extrapolated between the two points. For example, in salt or unfractured crystalline rock, head measurements cannot be made; in the case of salt, measurements are made above and below the salt unit, and for crystalline rocks, measurements would be made in fractured areas. Then heads are estimated in the salt or unfractured crystalline by straight line interpolation, which is a conservative approach. 
Comment:

Both external and internal workshops will be based on the final list of Step 2 and Step 3 variables that appear in the final region-to-area screening methodology document. Therefore, states should have sufficient time between the issuance of the final document and the workshop to familiarize themselves with the document.

\section{Response:}

The CRP agrees with this comment and currently plans to hold the States' weighting workshop approximately 1 month after transmittal of the final SMD to the states.

COMMENT LETTER REFERENCE: SC-C-1

Comment:

Extending the SMD review for the two weeks available in December has not allowed for the review process provided in the Nuclear Waste Policy Act of 1982... The critical problem is that the Screening Methodology Document (SMD) review process has been carried out in a hurried and confused fashion, particularly during the two week period which followed the release of the Final Siting Guidelines.

\section{Response:}

The CRP believes that the crystalline states have been afforded significant opportunity to provide input into the region-to-area scresning methodology (through the workshop and document review process) and this is reflected by the fact that the methodology has been modified and finalized based on state input and involvement. At state request, the original review period for 
the draft SMD was extended from 36 to 50 days. In addition, a 1-month period was allowed for review of the draft SMD (December 6, 1984 - January 7, 1985) following codification of the final DOE Siting Guidelines. 
GENERAL METHODOLOGY

COMMENT LETTER REFERENCE: MI-A-6

Comment:

We strongly object to the implication that the region-to-area screening will be used to compare crystalline rock sites to sites in other media. We pointed out that region-to-area screening is being conducted only for crystalline rock sites and find no justification for the approach in the Nuclear Waste Policy Act or in the "...need for the region-to-area Screening Methodology to be viewed as consistent with overall Office of Civilian Radioactive Waste Management (OCRWM) program objectives and to maintain a national perspective".

\section{Response:}

The region-to-area screening process will be applied only to the CRP. However, the Nuclear Waste Policy Act sets up a process by which there is provision for those sites recommended for characterization but not selected as the nation's first repository to be considered for the second repository, along with nominated second repository (crystalline) sites. Accordingly, it has been deemed appropriate to take a national perspective in the siting process for the CRP.

This decision has an effect on the development of scales for only a couple of screening variables (e.g., seismicity). Step 3 sensitivity analys is will selectively be utilized to evaluate the effects of alternative scales on the identification of candidate areas. This sensitivity analysis will be used to evaluate a regionally oriented scale for seismicity (in this case, using a maximum ground acceleration of $40 \% \mathrm{~g}$ ). 


\section{COMMENT LETTER REFERENCE: MI-A-7}

Comment:

We suggest that many of the variables were amenable to scaling on a continuum, increasing the discriminatory power of the methodology, and eliminating such technically unjustifiable distinctions as those proposed, for example, between ground-water yields of $250 \mathrm{gpm}$ (scaled 2) and $251 \mathrm{gpm}$ (scaled 3). A simple equation would account for many of the variables where distance is used as a proxy for impact. The DOE and their contractors agreed to consider this suggestion, but no proposal for scaling any of the variables on a continuum has been forthcoming. In view of the apparent willingness of the participating states to agree with Minnesota's incremental 1 to 5 scaling, we are not surprised at this, but we caution the DOE that an insensitive screening methodology, one that succeeds in eliminating only the most grossly inadequate areas, may not be sufficient to defend selection of potentially acceptable sites against challenges from affected states or Indian tribes.

Response:

Continuous scales have been evaluated and judged not to be practical to implement in the region-to-area screening methodology. It is recognized that scaling in increments represents a simplification of the variables being measured. However, the primary objective of the regional phase is effectively met with the screening methodology. Specifically, this objective is to identify candidate areas that warrant further investigation for a second repository given an aggregate assessment using variables supported by literature-based data. This approach provides sufficient discriminatory power and sensitivity at the regional scale to accomplish this objective. In addition, the 17 states have been directly involved in the development of variable scales to help assure that those scaies represent reasonable and acceptable approximations of the phenomena being evaluated for region-to-area screening. 
COMMENT LETTER REFERENCE: MN-C-11, WI-4, ME-7, ME-8, MA-2, NJ-47, NY-A-6, NC-B-6, SC-A-2, SC-A-3, SC-B-2, SC-C-2, SC-B-3, and $\mathrm{SC}-\mathrm{C}-3$

\section{Comments:}

With regard to the weighting procedure in general, we argue, again, that weighting may prove unnecessary if CRP first maps the unweighted grid cells to determine whether or not 15-20 potentially acceptable rock bodies can be discerned. If CRP can identify a sufficient number of potentially acceptable sites without weighting the variables, then weighting will add nothing to the analysis. This approach is referred to as the Base Case scenario, and CRP committed to further consider it at the October 3-4 Atlanta meeting. If CRP opts to begin the Region-to-Area screen with the Base Case analysis, then an approach to the remainder of the screening process must be developed in the event that weighting is unnecessary. (MN-C-11)

The OCRD's proposed process for assigning weights to screening variables is unacceptable. Weights may not be necessary to identify those areas which deserve further study in the area stage. Base case maps should be developed which have equally weighted variables before making any decisions on the need for further weighting. (WI-4)

... the base aggregate favorability map prepared at the end of step 2 should have all variables equally weighted. This would indicate whether there are areas where all the step 2 variables are in the "most favorable" class. The identification of these areas as "most favorable" will not change with weighting, and if sufficient areas are identified at the end of step 2 the weighting process may not be necessary. (ME-7)

In addition, an equally weighted base case is a convenient reference point against which to judge the effects of weighting the step 2 variables. (ME-8) 
The second major concern we have is the elimination of the concept of a base case set of weights. We feel this would be a good way to illustrate the process and how it will be applied to a representative region. It is not clear who is going to make the final weighting decisions. It would be useful to Massachusetts to have a base case set of weights prior to participation in the weighting workshop.

Thus far throughout the screening process we have sought to apply the best scientific and most objective methodology for site selection. We must make sure that this continues to be the case. It is possible that the assignment of weights to the variables at this stage could result in the ultimate selection of areas based on something other than scientific data, that is on weighting judgments. For this reason we would like to see a base case screening done with an unweighted application of variables as well as with a weighted set of variables. (MA-2)

New Jersey objects to the elimination of a set of base case maps due to the claim they "may not be representative of the view of the technical community"... This is inconsistent with the weighting process which will produce several sets of weights based on the representation of various opinions of the technical community. The base case maps simply provide another set of weights, a starting point for the weighting process, and a set of maps should be completed. (NJ-47)

... A base case favorability map with all variables equally weighted would be appropriate background information for the weighting process.

It may be beneficial to prepare an initial screening of all sites using the three-phase selection criteria but without weights. This would yield an example of the process and indicate a general number of areas that will require further detailed study. (NY-A-6)

The DOE should prepare a base case with equally weighted variables. It is possible that this exercise will eliminate the need for weighting workshops by identifying a satisfactory number of sites for further consideration, with no unfavorable points. If weighting workshops must be held, then two are recommended--one for states only and one for nonstate interests. (NC-B-6) 
During the October CRP meeting the States expressed the need for regionto-area screening and composite map development to include a base case/equally weighted sumary composite map for evaluation. Plans for the development and evaluation of this form of composite mapping have not been included in the Draft Screening Methodology Document. South Carolina believes that they must be included. (SC-A-2)

Some states have carried this issue as far as to say that the base-case summary composites may provide DOE with all the answers they need and that weighting may be a superfluous exercise which would only complicate the process. This is contrary to the most recent version of the Siting Guidelines, where in postclosure variables are deemed more important than preclosure variables. South Carolina supports the application of weighted variables in the screening process and strongly objects to the notion of withdrawing weighting from the Screening Methodology. However, due to the many questions raised recently regarding the weighting process, we suggest that the issue remain open for more discussion between DOE and the states. (SC-A-3)

We suggest that the weighting process remain open for more discussion between DOE and the states in order to address these and other weighting issues brought up during the October meeting in Atlanta. (SC-B-2 and SC-C-2)

During the 0ctober CRP meeting, the states expressed the need for composite map development to include a base-case/equally weighted summary composite map. Plans for the development and evaluation of this form of composite mapping have not been included in the Draft Screening Methodology Document. South Carolina believes that they must be included. (SC-B-3 and SC-C-3)

\section{Response:}

The CRP has decided to include the equally weighted base case as an input to the candidate-area selection process. This case will be run and evaluated early in the region-to-area screening process in order to provide an initial view of the most favorable rock bodies without differential weighting. 
It should be noted, however, that this base case does not provide a depiction of the most favorable rock bodies taking either a strong postclosure or preclosure view of the selection decision. (Note: It is likely much closer to the preclosure view if all Step 2 variables are weighted the same, as there are more preclosure [environmental] variables included in Step 2.) Differential weighting of the variables does capture these and intermediate views of the relative importance of the screening variables. In doing so, it provides an important discriminating input into the decision process. Consequently, representative unequally weighted cases also will be utilized to develop summary composite maps in support of the selection of candidate areas. Thus, it is the CRP's intent to hold weighting workshops to derive these representative sets of weights.

The CRP's position regarding distribution of equally weighted composite maps is that they will not be released prior to conducting the states' workshop but will be documented in the draft ARR. In striving for consistency between the workshops, access to and analysis of equally weighted composite maps would represent a significant difference between the weighting workshops because such equally weighted composite maps were not available for the CRP weighting workshop. At this time, the CRP has not determined what an equally weighted case means. For example, it could mean that each variable is equal in weight to every other variable, that the sum of all geologic variables equals the sum of all environmental variables, etc. As discussed with representatives of the crystalline states in Alburquerque, New Mexico (February, 1985), the CRP will seek state input on this issue.

Section 960.3-1-5 of the DOE Siting Guidelines specifically provides that postclosure guidelines need not be weighted more heavily than preclosure variables during region-to-area screening.

\section{COMMENT LETTER REFERENCE: ME-12}

\section{Comment:}

Specifically no discussion of quality assurance of the data used in either step 1, step 2, or step 3 is included in the draft methodology. This 
is critical and we have to assume that the DOE is relying on the States to assure that the data used in the screening is current and adequate.

\section{Response:}

The CRP has implemented a rigorous quality assurance program for both its internal and subcontractor activities. This program is in compliance with the applicable provisions of 10 CFR 50, Appendix B, as implemented by ANSI/ASME NQA-1 (1983), Quality Assurance Program Requirements for Nuclear Facilities. The quality assurance effort involves internal checks and cross-checks as we 11 as interactions with the states to verify that the data being used are not only accurate but current. This has been an on-going process involving many telephone conversations and visits by CRP staff to the states. The states' review of the revised draft regional geologic and environmental characterization reports is the primary mechanism for verifying that information to be used in application of the disqualifying factors and screening variables is correct.

In addition, an extensive quality assurance program is in place to ensure that geologic and environmental information is accurately portrayed on the data maps as shown in the revised draft regional geologic and environmental characterization reports and that this information is correctly translated in the development of favorability maps, composite maps, and summary composite maps. This program includes mandated reviews and periodic audits.

COMMENT LETTER REFERENCE: MA-3, NY-A-26, and RI-4

\section{Comments:}

Another generic concern is that of utilizing local geological reports and maps. There are many such maps which have been developed at the State and local level. Certainly they should be looked at when evaluating crystalline rock areas. The quality of these papers varies greatly however, and care must be taken in the amount of weight these papers carry. (MA-3) 
P. 73 - State geologic maps are referred to as the source of data for many conditions. There must be some qualification as to what is considered a "State Map". Are these maps only those published? Does the age of the map play any part in the weighting of the validity of the information it contained? Is the scale at which the map was compiled or published considered? (NY-A-26)

Similarly, some concern has been raised that the Department's decision to base so much of the geological information used in this stage on State geology maps may allow truly unfavorable rock bodies to slip through the screen. Rhode Island's geology map, for example, was derived primarily from limited outcrop data compiled in the 1950s and may not be of sufficient detail to be useful in screening or may be inaccurate. That may or may not be the situation with the geology maps of other States. Rhode Island is presently developing its own set of maps to incorporate gravity, magnetics, radar imagery and Landsat data. We would certainly recommend that DOE supplement its Rhode Island information with these maps as they become available. Our point, however, is that DOE must recognize that the data base derived from the State geology maps is anything but consistent from State to State, and at least in Rhode Island, may be inadequate for screening. The Department's reliance on that data base forces us (as in the case of the environmental features slipping through the one-square-mile grid) to defer a body of information of which we are well aware at present, but which does not show up in DOE's methods. (RI-4)

\section{Response:}

Regarding the age and quality of geological maps at the state and local levels, the use of these maps is explained and qualified in Appendix $A$ of the revised draft RGCR. Only published and open-file maps were used. Also the most up-to-date information was used and obsolete data discarded. The data summaries of crystalline rock bodies (CRB) in Appendix A of the RGCR are believed to reflect concisely and accurately the principal geologic characteristics of the CRB. The CRB outlines are portrayed based on the most recent published or open-file geological maps of the respective states. 
Quadrangle-scale compilation of parts of the crystalline rock bodies was beyond the scope of data compilation for the region-to-area screening.

As noted in another response, features in excess of 130 hectares (320 acres) but split among several grid cells are assigned to the grid cell containing the centroid of the feature. Appendix $A$ of the revised draft RECR lists Federal-protected lands less than 130 hectares (320 acres) and Appendix $B$ of the revised draft RECR lists state-protected lands less than 130 hectares ( 320 acres).

\section{COMMENT LETTER REFERENCE: MA-4}

\section{Comment:}

In terms of site selection in crystalline rock bodies, it is unclear if decisions will be made by DOE on the need for diversity among the selected rock bodies. Is there an intent to have a diversity of geological and geohydrologic settings and originality (sic, regionality) among the selected crystalline rock bodies?

\section{Response:}

Steps 1 through 3 of the region-to-area screening methodology will identify the most favorable 15 to 20 areas in support of the selection of candidate areas. This selection process, in accordance with DOE's Siting Guidelines, will take into consideration provisions of the implementation guidelines in recommending areas for further investigation. If it is determined that the intent of the DOE Siting Guidelines could be better met by considering regionality, diversity of rock type, and geohydrologic settings, then the CRP would reexamine these areas to determine the trade-offs involved in substituing new areas. 
COMMENT LETTER REFERENCE: NH-4, NJ-37, NJ-39, NJ-43, RI-5, RI-6, GA-A-1, GA-A-5, NC-B-5, SC-B-5, and SC-C-5

Comments:

Several scales are non-linear. (NH-4)

New Jersey supports a standard 1 to 5 scale which has the same number of increments and numerical assignments for each variable. (NJ-37)

Also for consistency in scaling it is also important that each scale have 5 categories or 5 clear ranges from which to judge favorability or potential adversity. (NJ-39)

It is also important to maintain consistency by applying the same type of 1 to 5 scale in step 3 variables. These scales must be uniformed and consistent with scales in step 2. (NJ-43)

The Draft Methodology states on p. 22 that "the scaling of variables reflects linear, exponential, or other nonlinear functions of physical conditions..." The scale on p. 84, for example, is nonlinear, with increments of one mile or two, depending on the scale value. The use of such nonlinear scales is not defended well in the Draft Methodology, and therefore does not avoid the appearance of being highly subjective, or arbitrary. (RI-5)

The scales also contain built in weights, in spite of the Department's move to make all the scale values consistent, i.e., from 1 to 5 . (RI-6)

I am concerned that a number of the screening variables identified in the Methodology Document remain nonlinear/illogical and thus appear arbitrary. (GA-A-1)

The situation becomes more complex when the scale values are multiplied by weighting factors. If the scales are inappropriately skewed, then the final weighted scale values will also be inappropriately skewed. The end 
result could be that mere proximity to public lands would more than offset safety related issues. We are quite concerned that DOE might disqualify a number of high-quality rock bodies for so-called "environmental" reasons and end up siting a repository in a possibly unsafe crystalline body. (GA-A-5)

While the scaling proposal offered in the draft Screening Methodology document is a vast improvement over earlier versions, there is still room for improvement. Several scales are still nonlinear or internally inconsistent and this should be corrected in the final document. (NC-B-5)

We are concerned about the nature of many of the scales within Chapter 5. In several instances the scaling increments are inconsistent and can be construed to be illogical.

We have discussed in detail the scaling problems cited by the State of Georgia and are in general agreement with their comments and concerns regarding the inappropriate skewing of scale values.

DOE should reexamine the rationale and technical basis for these scales before publishing a final Document. (SC-B-5 and SC-C-5)

\section{Response:}

The CRP has attempted to scale each Step 2 and Step 3 variable in a consistent manner. Wherever possible, the scales have numerical assignments for each of 5 scale increments. There are a couple of instances, however, where this was not possible because the data source being utilized did not have the original data broken into 5 increments, and to do so would not have been technically defensible. The scale for each variable has the same assigned end-point values, and all but one scale (Suspected Quaternary Faulting) have intermediate increments, each of which has been assigned a value.

With respect to the linearity of the scales, most of the scales are linear in nature. Scales that are not linear are chosen for one of two reasons. Either it was judged to be technically the most defensible scale, or deviating from linearity for the first scale increment is a conservative approach to screening (e.g., the most adverse increment for postemplacement 
faulting is 5 kilometers ( 3 miles) wide while the remaining increments are 1.6 kilometers ( 1 mile) wide. This is viewed by the CRP as a reasonable approach to apply in the regional-phase investigation, which is intended to significantly reduce the number of crystalline rock bodies under investigation and to identify candidate areas for further study which have the highest aggregate favorability.

The final scales listed in this document incorporate, to the extent practicable, state concerns about consistency and linearity. What some states have viewed as "internal weighting" in the scales has been minimized within the constraints outlined above. Incorporation of variable scales and workshop weights do not disqualify rock bodies but are used as a basis for determining those rock bodies that are the most favorable in the aggregate. The application of the methodology will yield internally consistent results for the comparison of candidate areas to be considered for subsequent area-phase investigations.

COMMENT LETTER REFERENCE: $\mathrm{NH}-18$ and NH-19

\section{Comments:}

A report by the U.S. Geological Survey entitled "Review of Buried Crystalline Rocks of Eastern United States in Selected Hydrogeologic Environments Potentially Suitable for Isolating High-Level Radioactive Wastes" released in the Summer of 1984 suggests hydrogeologic concepts which are not consistent with those which provide the basis for this Screening Methodology. (NH-18)

Is it DOE's thinking that this report by the U.S. Geological Survey and other similar or related reports would have an impact upon the repository siting process? Is it in DOE's current thinking that this type of report could alter the siting methodology? (NH-19)

\section{Response:}

The hydrologic concepts used by the U.S. Geological Survey (USGS) in evaluating buried plutons are totally different from those being applied to 
the screening of exposed and near-surface crystalline rock bodies using this methodology. The USGS report and other reports promoting use of hydrologic characteristics as a means of isolation from the accessible environment are purely conceptual at this time and have no influence on the region-to-area screening methodology detailed in this report.

COMMENT LETTER REFERENCE: NJ-48

Comment:

While the Presentation of a Hypothetical Application of the Crystalline Repository Program's Proposed Region-to-Area Screening Methodology, February, 1984 helped considerably in understanding the development of composite or aggregate favorability maps, these maps remain visually and conceptually difficult to understand. When using a single variable the maps are quite useful and readable, however when the variables are composited and summary composite maps are developed with Step 2 and Step 3 variables these maps become hard to read.

It is important that the use of single variable maps and overlays is retained so that the composite maps are completely understood. Overlays allow the map reader the option of removing and adding certain variables to check for overlap. This also allows the reader the option of examining each variable individually as well as together.

\section{Response:}

As part of development of the draft ARR, CRP will be developing individual favorability maps for each regional screening variable. Although transparent overlays will not be provided, each favorability map will depict the geographic application of the given scale to the three regions. After incorporation of variable weights and integration of the favorability maps, composite maps will be developed. The CRP expects to include favorability maps as part of the draft ARR documentation. 
Comments:

The definition included of "exposed and near surface rock" as those not covered by pre-Quaternary rocks is insufficient. A more complete definition would include some indication of depth from the surface. (NY-A-20)

The definition of "exposed and near surface" crystalline rocks is still not satisfactory. Rocks covered with overlying materials should not be considered "exposed", regardless of the age. A rock covered with glacial outwash or till is just as covered as a rock covered by pre-Quaternary sediments. (MN-C-1)

\section{Response:}

"Covered" rock is a programmatic definition used by the CRP (as well as the USGS) to refer to crystalline rock underlying consolidated sedimentary rock that constrains the flow systems. Rocks covered by Quaternary materials are not considered "exposed" but "near-surface", as they generally reveal some measure of outcrop. Outcrops of crystalline rock under pre-Quaternary sediments are rare. Thickness of Overburden is included in region-to-area screening as a Step 3 variable.

COMMENT LETTER REFERENCE: NY-A-32 and NY-A-33

\section{Comments:}

What method will be used to establish the equivalency of different variables? (NY-A-32)

For example: Does a rating of 3 describing the relation of a site to a population center carry the same weight as a rating of 3 for distance to a fault? (NY-A-33) 
Response:

The weighting workshop process described in Section 3.2.3 will be implemented to derive representative views of the relative importance of the screening variables in the selection of candidate areas.

The scaling process has been designed to respond to state concerns about consistency, with the exception of instances where the original data base, technical defensibility, or conservatism considerations dictated otherwise. The results of scaling and weighting processes, when utilized in the proposed methodology, will yield an equitable comparison of the relative merits of the candidate areas under consideration.

COMMENT LETTER REFERENCE: GA-A-7 and GA-A-8

\section{Comments:}

We also have serious reservations concerning the statistical validity of the proposed weighting methodology. A preliminary analysis of the methodology shows the existence of a number of statistical anomalies (such as the invariance of certain composite favorability scores relative to weighting, a direct relationship between composite favorability scores and expected variation of those scores, and the de facto equal weighting of variables that is a consequence of the construction of Summary Composite Favorability Maps). These problems strongly suggest that the results from the use of this methodology do not justify the time and effort involved. A simpler, statistically more robust approach, that still incorporates State input, would be more defensible. (GA-A-7).

Because of the complexity of the issues and the fact that the Region-toArea Screening Methodology document is not clear on this matter, we cannot appropriately respond in writing at this time. In this regard, I am requesting that DOE or its subcontractors visit with Dr. McLemore of the Georgia Geologic Survey so that a mutual understanding can be achieved on this issue. An appropriate written response can then be submitted, if such a response is then deemed necessary. (GA-A-8) 


\section{Response:}

The region-to-area screening methodology has been developed through extensive CRP-state interaction over the past 2 years. It is believed that a majority of the states support the rigorous nature of the methodology. Comments from some states suggest additional activities to those associated with the methodology. It is recognized that in development of scales, assignment of weights, and preparation of composite and summary composite maps, certain "statistical anomalies" may occur. However, CRP believes that, on balance, the current methodology provides a systematic, replicable, and documentable approach to regional-phase screening and provides the DOE decisionmakers with the necessary information upon which to base informed judgments.

CRP staff have discussed this issue with Dr. McLemore.

\section{COMMENT LETTER REFERENCE: GA-B-2}

\section{Comment:}

Another somewhat related problem with the draft Methodology is the failure to handle interactions among variables. The proposed Methodology can only measure main effects whereby it would seem, intuitively, that interaction would be important here. Probably, if some of the factors occurred in combination, their combined influence would have a greater influence on the relative favorability of a site than the sum of their individual weights.

\section{Response:}

The CRP agrees with the premise of this comment. However, at a regional scale of investigation, determining the impacts of interactions among variables (including whether such interactions represent a synergistic effect, linear effect, or counterbalancing effect) is not practical. These kinds of interactions will be addressed at subsequent phases of screening when site-and design-specific information are available. 
COMMENT LETTER REFERENCE: NC-B-7

\section{Comment:}

From the draft document it is not clear exactly how the scaling distances will be measured in every case. For example, if six miles is the most favorable distance from a given screening variable, does this six-mile measurement mark the closest possible edge of the repository shaft on the underground facility? It seems appropriate to use the boundary of the "accessible environment/controlled zone" as the closest point of any potential repository to the edge of scaling distance measurements. The Screening Methodology should specifically document and be adjusted to accommodate this concept as exp1icit in every case.

\section{Response:}

The screening variables which incorporate "proximity to" involve measurement of the distance from any grid cell to a given feature. The distance is measured from the center of the grid cell in question. No assumption is made as to whether a grid cell has any relation to the NRCdefined controlled area. However, those variables using a 10-kilometer (6mile) distance for the end point of the scale do reflect a consideration of the maximum distance to the accessible environment allowed by 10 CFR 60 (NRC, 1983a). As noted in Section 1.4, the size and orientation of the controlled area at a given site will be dependent upon ground-water flow and other characteristics. The controlled area (at a given site) will be finally established subsequent to site characterization to ensure that releases to the accessible environment will not exceed those permitted by EPA.

\section{COMMENT LETTER REFERENCE: VA-B-25}

\section{Comment:}

P. A-16, 2nd paragraph - The CRP should not rule out field work but should leave the matter open to consideration as circumstances warrant. 
Response:

The CRP believes that the region-to-area screening process can effectively and defensibly narrow the scope of the second repository search to identify 15 to 20 candidate areas without field work. However, should this belief not be realized upon implementation (e.g., 50 candidate areas result), additional mechanisms for narrowing the number of rock bodies under consideration will be examined. The specific nature and phasing of such mechanisms cannot be determined at this time, but one mechanism could include a firstlevel field reconnaissance of the remaining rock bodies. Whether such mechanisms would be employed before the end of the regional phase or as a point of departure for a subsequent area phase is an open question. Again, this is considered a low probability event given the confidence the CRP has in the region-to-area screening process to narrow down the existing number of rock bodies to the desired number of candidate areas. As previously mentioned in discussion with several states, the CRP has not developed any plans for performing a first-level field reconnaissance.

\section{COMMENT LETTER REFERENCE: VA-B-28}

\section{Comment:}

P. A-110 - "Response" - We doubt that "all possible geologic factors" have been considered.

\section{Response:}

To the extent practical, geologic factors have been considered consistent with provisions of the DOE Siting Guidelines and within the constraints of regional geologic data available through the literature. Of course, "all possible" geologic data cannot be fully evaluated let alone acquired until field and at-depth studies are performed. 
Comment:

The entire geologic portion of this document is geared to reducing sites from a regional to an area scale. The next logical step would be to proceed to a site-specific scale. Because of the great lack of data, can this present method be truly useful for a site-specific location, or must each rock body be individually investigated? If it cannot be used for specific site selection, what has been accomplished? After going through this exercise, must we then go back to start over again on an individual rock body by rock body study until we find one suitable for the repository?

\section{Response:}

The CRP believes that the output of the region-to-area screening process will be the identification of 15 to 20 candidate areas. The areas can represent either portions of or entire rock bodies. The rock bodies (or portions thereof) will subsequently be studied in detail in the area phase to identify sites for nomination and recommendation.

COMMENT LETTER REFERENCE: VA-B-32

\section{Comment:}

Geologic, hydrogeologic, etc., maps utilized in the weighting process should be the best available, including appropriate scale. The use of maps prepared by computer techniques for this process is not encouraged.

\section{Response:}

Development of favorability maps, composite maps, and summary composite maps is being accomplished through use of the computer. These maps will reflect the best available information applicable at a 17-state regional 
scale. For region-to-area screening purposes, the data from each source map are digitized utilizing thorough quality assurance/quality control procedures. This allows for the processing of these data at a common, regionally appropriate scale (e.g., 1:1,000,000), while maintaining accuracy from the original source maps. These techniques were carefully designed to maximize the defensibility of the product maps, and the computer cartographic techniques minimize human error in the numerous additional steps that would be required that would occur if this were done without such technology. 
SECTION AND TOPIC SPECIFIC

SECTION/TOPIC AREA 1.4 General Desciption of a Repository

COMMENT LETTER REFERENCE: MI-A-8, MI-A-9, and MI-A-10

\section{Comments:}

P. 4 - The screening document contains the first specific reference we have seen to transuranics as a separate category of high-level radiaoctive waste. Does this term refer to materials containing concentrations of alphaemitting transuranic nuclides greater than those in 10 CFR 61.55 (Table 1)? (MI-A-8)

Could the DOE reference some discussion on sources (other than spent fue 1 reprocessing or defense waste), form, characteristics, and estimated quantities of transuranic waste to be disposed of in a HLRW repository? (MI-A-9)

The document notes that "The wastes will be unloaded, inspected, sorted, and packaged at the surface facilities". Is the DOE no longer considering development of a combination transportation/disposal cask? (MI-A-10)

\section{Response:}

The crystalline repository design process is still in the preconceptual phase. As such, this section was intended to provide a general description of waste types and repository functions requiring consideration in the design process. The waste types that will be received and the actual methods of waste shipment, packaging, and emplacement in the host rock have not been finalized.

The waste types to be considered in the design process for receipt at the second repository are more fully described in the report Generic Requirements for a Mined Geologic Disposal System, (DOE 1984e). This document states that wastes to be received are spent fuel and, should the President decide, defense high-level waste. It further states that while design of the repository need 
not include specific provision for disposal of commercial high-level waste or commercial transuranic waste from reprocessing or any other source, it should not preclude a later decision to dispose of such waste. Commercial transuranic waste from sources other than reprocessing, pending identification of a firmly based inventory and characteristics of this waste type, is not included in the planning base. Nevertheless, the receipt and disposal of spent fuel will involve the generation of transuranic waste requiring disposal under present plans to consolidate spent fuel rods prior to packaging for disposal. The fuel assembly hardware, which would be packaged separately, as well as contaminated equipment and supplies resulting from the remote disassembly and packaging operations, would be classified for disposal as transuranic waste. These represent major sources of transuranic waste in the absence of spent fuel reprocessing. A general description of fuel assemblies and their associated hardware can be found in the report Proposed Rulemaking on the Storage and Disposal of Nuclear Waste, pp. IV-41 to -48 (DOE 1980).

Transuranic waste, as presently defined for disposal in the geologic disposal system, is waste measured or assumed to contain more than a specified concentration of alpha-emitting radionuclides (including uranium-233 and its daughter products) of long half-life and high specific radiotoxicity that requires isolation. In current usage, this concentration is defined as greater than 10 nanocuries per gram of waste. Thus, this definition extends to materials containing somewhat lower concentrations of alpha-emitting radionuclides than appears in 10 CFR 61.55 (Table 1) (NRC, 1983b). While spent fuel and high-level waste from reprocessing fall within the definition of transuranic wastes, by general usage, these waste types are not included in the transuranic waste category.

The combination transportation/disposal cask concept continues to be one of several system design concepts being evaluated by the Civilian Radioactive Waste Management Program both from the viewpoint of its impact on repository functions and of development by the DOE of an integrated waste management system. To date, this design concept has not been shown to provide any clear safety or cost advantages over the more conventional, independent waste shipment and disposal systems. 
Comment:

P. 5 - The top paragraph describes the designed retrievability of a repository up to 50 years unless a different period "is approved or specified by the NRC". Does this mean that DOE intends to request a different period of retrievability?

\section{Response:}

No, the DOE does not intend to request a different period of retrievability. The wording "...unless a different time period is approved or specified by the NRC" comes directly from 10 CFR 60.111. The CRP will fully comply with this licensing requirement. After a crystalline rock repository has been in operation for a sufficient time to collect data in the performance confirmation program to justify a different period of retrievability, the DOE could request the NRC to amend the license to begin final decommissioning activities at an earlier time. This decision would be made during the operations phase of the repository and would not offset the 50-year retrievability design criteria that will be used for the repository.

\section{COMMENT LETTER REFERENCE: MI-A-12}

\section{Comment:}

P. 5 - The third paragraph uses the terms "anticipated" and "expected" in the first two sentences, which imply uncertainty when regulatory restrictions (10 CFR 60 and proposed 40 CFR 191) are more clear. Such terms should be avoided unless uncertainty is unavoidable.

\section{Response:}

The usage of the verbs "anticipated" and "expected" is common terminolog for a project that is in the very early stages of conceptualization. The CRA 
is not expected to begin construction of a nuclear waste repository in crystalline rock for at least another 10 years. The design and safety analysis efforts are always conducted to meet the current regulatory guidelines.

\section{COMMENT LETTER REFERENCE: NY-21}

\section{Comment:}

P. 5 - The statement - "Favorable rock mass depth conditions can readily be met for the crystalline rocks because they are deep seated masses that generally extend downward for thousands of meters", is unfounded. It does not hold for the Adirondacks as the depth to which the rock mass extends has never been adequately measured and depth projections based on surface expression are rarely accurate in deformed rock bodies.

\section{Response:}

The reviewer is correct in that the depth of crystalline rocks in the Adirondacks and many other crystalline bodies has not been determined. This question has become particularly controversial with seismic reflection-based hypotheses that some eastern crystalline rocks have been cut by thrust faults, possibly superimposing crystalline rocks on sedimentary or metamorphic rocks (Cook et a1, 1979; Brown et al, 1983). However, the existence of such features does not preclude repository siting provided that a sufficient thickness of suitable rock exists. Boreholes in the Adirondacks have shown that crystalline rock extends to a depth of at least 600 meters (2,000 feet) (Isachsen and Fisher, 1970; Cook et al, 1983). Schematic projections show depths on the order of a few kilometers for the reflecting horizons that might be thrust faults. The statement in the draft SMD that crystalline rock masses "generally extend downward for thousands of meters" is correct. Clearly, boreholes will be drilled to confirm that the rock body has the required minimum thickness of 200 meters (656 feet) (see 10 CFR 960.4-2-5(d)). 
SECTION/TOPIC AREA: 2.1 National Survey

COMMENT LETTER REFERENCE: MI-A-13

Comment:

P. 9 - The fourth line from the top uses the term "and near surface" twice.

Response:

The correction has been made in the text.

COMMENT LETTER REFERENCE: NJ-9

Comment:

If a National Survey of Crystalline Rocks used erosion as a criterion, then what precludes the use from a regional survey?

\section{Response:}

The use of erosion as a criterion in the national screening was based, on a gross scale, on physiographic differences in landforms generated over geologic time through a variety of erosional processes. The amount and usefulness of available regional data on erosion is intermediate between that applicable at the national and area phases, but such data are not in a form which allows for application during Steps 1 and 2 of the region-to-area screening methodology without interpretation/evaluation. However, erosion is partly addressed in the Step 3 screening variable Thickness of Rock Mass. Specific data and analysis derived through more specific area-phase studies will result in data more suited to a meaningful evaluation of erosion for area-to-site screening. 
COMMENT LETTER REFERENCE: MI-A-14 and MN-C-3

Comments:

The document again states (on p. 9) the DOE's intention to identify 15 to 20 "candidate areas" containing potentially acceptable sites. Can this be viewed as a commitment by the DOE to do field work in approximately that number of areas, or will a significantly fewer (6 or 3?) number of areas be chosen for further study? We believe that there is a significant difference between a screening methodology designed to produce 20 areas and one designed to produce six. (MI-A-14)

The Region-to-Area screening methodology does not guarantee that 15-20 candidate areas will be identified. If the process yields too many, the CRP may have to revise the scales; if it yields inferior, heavily penalized areas, the credibility of the project will be in jeopardy. In either case, the CRP has not indicated what it will do. (MN-C-3)

\section{Response:}

The intent of the CRP at the end of the regional phase is to identify approximately 15 to 20 candidate areas that will be the subject of further study, including field investigations, in the area phase. The specific plans for area-phase field studies will be documented in the area characterization plan (ACP), a draft of which will be subject to state review and comment. The current CRP view is that there will be some level of field work done on each of these candidate areas.

The CRP believes that the proposed region-to-area screening methodology can effectively and defensibly narrow the geographic scope of the search for a second repository site to 15 to 20 candidate areas. Should this belief not be realized, additional mechanisms for further discrimination between rock bodies will be examined. Whether such mechanisms would be employed before the end of the regional phase or as a point of departure for the area phase is an open question. 
With respect to scale modification, the only plans for modifying scales is as part of Step 3 sensitivity analysis. In this step, selective variable scales will be modified to examine potential effects on the selection of candidate areas. As indicated in the main body of this document, the CRP will, as part of the Step 3 sensitivity analysis, modify scales for three variables - Proximity to Highly Populated Areas, Rock Mass Extent, and Seismicity. In addition, it should be noted that the methodology is designed to identify the most favorable areas defined in terms of the regional screening variables, in the aggregate.

COMMENT LETTER REFERENCE: NY-A-11

Comment:

pp. 9, Paragraphs 2 and 4 - It would be useful to have a rough idea of the size of the final 15 to 20 areas. Also, it is indicated that more than one potential site may be in each of the 15 to 20 areas. It is unclear when the number of sites per area will be designated - this should be clarified.

\section{Response:}

Given the land requirements for repository surface facilities ( 80 to 160 hectares or 200 to 400 acres), the underground facilities (approximately 810 hectares or 2,000 acres), and the controlled area which could extend to 10 kilometers ( 6 miles) in any direction from the underground operations area, the size of a candidate area could range from tens of square miles to thousands of square miles in areal extent. All other factors being equal, for regional-phase decisionmaking, larger areas may be more desirable than smaller ones because of the additional flexibility in siting within a large candidate area. For these larger areas, site-sized land units will be identified based upon subsequent area-phase investigations that will he:p determine the most suitable repository sites with in each candidate area. For smaller candidate areas identified at the end of the regional phase, problems that are identified in area-phase studies could not be mitigated as readily by simply moving to a more favorable portion of the area. 


\section{Comment:}

The report indicates that the data for the evaluation of each area is to be obtained from the states. What controls will be exercised to ascertain the equivalency and quality of this data?

\section{Response:}

The CRP has made every effort to develop a reasonably consistent data base across all 17 states for the region-to-area screening methodology. This has included a thorough search with substantial state input for data on variables under consideration. The disqualifying factors and regional screening variables applicable in the regional phase represent those conditions for which the CRP has been able to consistently define a data base that equitably covers a 1117 states. Some variables have been deferred to a subsequent screening phase where such a consistent data base could be developed.

The only exception to the above is the set of Step 3 variables. These geologic variables were suggested by state representatives as worthy of consideration in the regional phase even though there are only scattered data available across the 17 states. The Step 3 concept was adopted by the CRP in response to state requests to use health and safety-related geologic data, where available. This is done to ensure that DOE is using additional rock body-specific information in selecting the 15 to 20 candidate areas.

The reader is referred to the response to ME-12 in the section of this appendix entitled "General Methodology" (page A-28) for a discussion of quality of data. 
SECTION/TOPIC AREA: 2.3 Area Screening and Site Recommendation

COMMENT LETTER REFERENCE: NY-A-12

\section{Comment:}

P. 11 - the purpose of the ACP is to describe plans for data acquisition and we assume that data collection will be partially site specific. Therefore, it seems premature to release this report before the final ARR document. The report needs clarification of the relationship between the ARR and ACP documents.

\section{Response:}

The current CRP plans for release of the ACP include the submittal of preliminary draft sections of the ACP prior to the submittal of the draft ARR. Assuming this occurs, these sections will not and could not address plans for area-specific studies in the next phase. Instead, they will describe a set of geologic, environmental, socioeconomic, and engineering studies or techniques viewed as possible studies applicable to the further characterization of any candidate area in the area phase. This will be designed to elicit feedback from all 17 involved states on the desired elements of a good area-phase program.

The draft ACP, to be submitted for state review after the draft ARR is out for state review, will include the materials in the preliminary draft ACP (as modified by state inputs), as well as customized characterization plans for each of the 15 to 20 areas recommended for further study in the draft ARR. The draft ACP is scheduled to be submitted before the final ARR is issued on the assumption that there will be no changes in the recommended 15 to 20 areas between the draft and final documents. This is admittedly a risk-management decision on CRP's part, and it is recognized that should there be additions to the list of candidate areas between the draft and final ARR, additional areaspecific characterization plans would need to be developed. The CRP also recognizes that each of these plans should be subject to review in draft by appropriate state authorities. 
Comment:

Figure 3 is no longer valid, as Comment Response Document for RE/GCR's not released in September, 1984.

Response:

Figure 3 has been modified to reflect the current CRP schedule through the initiation of area-phase field work. 
SECTION/TOPIC AREA: 3.0 Regional Screening Methodology

COMMENT LETTER REFERENCE: MI-A-15

Comment:

The data base for the region-to-area screen will be the Regional Characterization Reports (RCR). In our comments on the initial drafts of these reports, we suggested that they were unsuitable for this purpose. Have extensive modifications been made to the RCRs as a result of the development of the Screening Methodology?

\section{Response:}

Extensive changes have been made to the revised draft RCR as a result of the development of the draft SMD. The RCR provide the data base (in descriptive, tabular, and map form) for application of each of the disqualifying conditions and regional screening variables (Steps 1 through 3 ). A significant portion of the (revised) data base was developed as a result of interactions between the CRP and the states. 
SECTION/TOPIC AREA: 3.1 Objectives

COMMENT LETTER REFERENCE: MI-A-16, SC-B-4, and SC-C-4

Comments:

P. 13 - Although Step 3 is described in greater detail later in the report, the reader is left, even after reading the entire report, with a concern over the equity of using data available for certain states but not others and how region-to-area screening will be affected vis-a-vis inclusion or exclusion of a given rock body or state due to this portion of Step 3. (MI-A-16)

If a variable (stress, overburden, ground-water salinity, etc.), cannot be applied to rock bodies with a fair degree of consistency, then the variable should only be applied at the site specific stage rather than at region-toarea screening. (SC-B-4 and SC-C-4)

\section{Response:}

The Step 3 variable concept was developed to incorporate additional rock body-specific geologic information after steps 1 and 2 have yielded an idea of where the most favorable rock bodies are located. The concept is responsive to previously expressed state concern that CRP should utilize geologic data where available, even if a consistent data base could not be developed for all 17 states (thus, it could not be employed as a Step 2 variable). The CRP continues to believe that the concept as described in Section 3.2.5.4, "Incorporating Step 3 Variables," is useful. It is recognized, however, that consistency in the application of these variables is important. The Step 3 variables which will be used in the region-to-area screening (as defined in Section 5.4) can be usefully and effectively applied.

The Step 3 concept was adopted by the CRP in response to state requests to use health and safety-related geologic data where available in the regional phase. This is done to help ensure that CRP is using important rock body- 
important to note that all 17 states have been solicited for data applicable to the conduct of the Step 3 evaluations.

COMMENT LETTER REFERENCE: MI-A-17

\section{Comment:}

P. 13 - The last paragraph, first sentence, should be rewritten as "Not all provisions ... are applicable." As written, the sentence implies that no such provisions are applicable.

\section{Response:}

The change has been made in the text.

\section{COMMENT LETTER REFERENCE: MN-C-4 and MN-C-5}

\section{Comments:}

P. 13 - We are concerned that the application of too many variables specified in the draft siting guidelines may have been postponed to later phases of the CRP. It is very possible that ignoring these variables at the Regional phase could ultimately yield a list of inferior sites. For example, transportation is not treated at the Region-to-Area phase, yet one of Minnesota's crystalline rock bodies in particular clearly lacks adequate transportation access. Located in Lake of the Woods, and known as the "Northwest Angle", it is accessible only by dirt road via Canada. If the same problem applies to other states (or with regard to any other variable, for that matter, a list of 15-20 areas for further study may include a good number which will have to be disqualified at the area (or site) phase. (MN-C-4)

Considering all the variables (including disqualifiers) postponed to later phases of the project, we can envision an area list with few or no 
potentially acceptable sites. If this comes to pass, we are afraid that the CRP will either tailor its site selection process to choose from a list of untenable sites, reevaluate previously rejected areas, or be forced to start the process over again. The CRP has not indicated what course of action it would follow in such an event. (MN-C-5)

\section{Response:}

The selection of variables applicable to regional-phase studies has been driven by the following considerations: (1) consistency with the DOE siting Guidelines, (2) the existence of a reasonably consistent data base (Step 1 disqualifying factors and Step 2 screening variables), (3) the ability to technically defend the variable as a reasonable measure of the desired phenomenon, (4) the feasibility of performing the data collection task for 17 states, and (5) the ability to resolve variability in the data bases of the involved states to equitably apply the data. As previously mentioned, Step 3 variables are being used to incorporate additional rock body-specific geologic information.

It is recognized that there are a host of other variables that clearly need to be applied in later phases of the CRP. It is also recognized that the constraints of regional-phase work will likely yield some candidate areas that, upon further analysis, are not totally viable for repository siting. In fact, that is one reason why the CRP wants to identify 15 to 20 candidate areas rather than a smaller number as a result of region-to-area screening. The CRP, however, is confident that the variables selected for region-to-area screening will help yield an informed and defensible set of area recommendations. In effect, these recommendations are investment decisions in that they will focus the CRP on smaller land areas where more detailed studies, including field work, can be performed. 
Comment:

Need more explanation concerning DOE's plans to modify factor scales in Step 3 (sensitivity analyses), as well as utilizing different sets of weights and incorporating other geologic factors. More thought and discussion on the use of Step 3 results is necessary.

\section{Response:}

The text of the final document has been modified to include an expanded discussion of the modification of variable scales, the use of weighting, and the use of Step 3 geologic variables. For example, variables for which scales will be modified are those believed to be the most controversial based upon CRP staff recommendations and upon state input. As noted in Section 3.2.5.1, CRP has determined that the scales for three Step 2 variables, Rock Mass Extent, Seismicity, and Proximity to Highly Populated Areas, should be modified as part of the Step 3 sensitivity analysis. As part of the weighting workshop, participants will be asked to assign weights to these three variables whose scales have been modified as part of the Step 3 sensitivity analysis. The plan is to modify the scales for all of these variables at one time, and to evaluate the results on the geographic distribution of the most favorable rock bodies. This input can be used by DOE to further discriminate between rock bodies in that areas of coincidence between the most favorable rocks with original and modified scales can be determined. 


\section{Comment:}

Application of the disqualifying factors is the simplest and most direct step in the screening process, and could be accomplished relatively quickly once the methodology and RCRs are finalized. We suggest that the DOE and its contractors perform the disqualifying factors screen, and present the states with the results, prior to proceeding with Steps 2 and 3 of the screening.

\section{Response:}

The CRP currently plans to furnish maps depicting application of the disqualifying factors to the states as part of the ARP. The CRP does not envision that application of the disqualifying factors will eliminate the need for Steps 2 and 3, nor will such maps necessarily provide a clear indication as to where the candidate areas are likely to be located.

COMMENT LETTER REFERENCE: MN-C-6, NJ-2, and GA-A-10

\section{Comments:}

P. 14 - Although the second paragraph states that six of the 10 disqualifiers will be used for the region-to-area phase, only five will actually be applied. It should be made clear that the sixth, dissolution, will not actually be used because it is not applicable to crystalline rocks. (MN-C-6)

The Screening Methodology Document, on p. 14, makes reference to six of the ten disqualifying conditions that are to be used in the region-to-area screening process. In review of the disqualifying conditions there are 5 of the 10 disqualifying conditions being considered, not six. They are: 
Natural Mineral Resources

Population Density and Distribution

Environmental Quality
10 CFR $960.4-2-8-1(d)(1)$

10 CFR $960.5-2-1(d)(1)$

10 CFR $960.5-2-1(d)(2)$

10 CFR $960.5-2-5(d)(2)$

10 CFR $960.5-2-5(d)(3) \quad(N J-2)$

P. 14 - "Six of the 10 disqualifying conditions will be used..." There are only five disqualifying conditions identified on Table 2 and on p. 47. (GA-A-10)

\section{Response:}

The CRP agrees. The text has been modified to reflect the comments.

COMMENT LETTER REFERENCE: MN-C-7

Comment:

P. 15 - CRP confidence in the weighting application, as a means of driving the selection of candidate areas away from land units with potentially adverse conditions, seems to be based on an assumption that a commonality of views exists regarding the relative importance of the different variables. Our experience as participants in the screening workshops has left us with an impression that there are some significant differences, particularly when comparing pre- and postclosure variables. For example, Minnesota has continually maintained that surface water bodies should be disqualified because of the necessity of siting 400 acres of surface facilities (see comment 25). There is no certainty, however, that the weight assigned this variable will be sufficient to steer selection of candidate areas away from surface water bodies; in fact, CRP has defended that decision not to disqualify surface water bodies by indicating that there may be technical solutions to repository/surface water body conf 1 icts. 
Response:

The CRP does not believe there is a single defensible view of the relative importance of the screening variables. Instead, the methodology has been purposefully designed to capture and utilize representative sets of weights that incorporate a broad range of views regarding the relative importance of these variables. Doing so enhances the CRP's ability to discriminate among the rock bodies in the regional phase, at the same time recognizing the legitimate differences in the way representative groups of individuals view the relative importance of the screening variables.

The weighting workshop process will afford Minnesota representatives a productively structured opportunity to influence peers regarding their position on the importance of surface water bodies in repository siting, as well as on their views of the remaining variables. The results of this process will be representative subgroup weights that can be utilized in the region-to-area screening process.

COMMENT LETTER REFERENCE: MN-C-8

Comment:

P. 15 - The statement regarding the 320 acre decision rule implies that features over 320 acres will be mapped and, where appropriate, disqualified. The Screening Methodology also discusses this decision rule in the context of features mapped as Step 2 variables. The Screening Methodology should note that this decision rule may fail to identify some areas over 320 acres, however, if those areas are distributed over two or more grid cells in a manner that precludes any one of the grid cells from having more than 320 acres of the total.

Is is possible, particularly in the case of the disqualifiers, to review the mapped features and add those that do not appear because of the situation described above? Perhaps the easiest way to accomplish this would be to assign the feature to the grid cell containing the greatest percentage of the urface feature's total. 
Response:

The text of the final SMD has been modified in a manner similar to the suggestion. Such anomalies will be handled in the region-to-area screening process by assigning the feature to that grid cell containing the centroid of the feature.

COMMENT LETTER REFERENCE: WI-3 and NJ-55

Comments:

P. 15 - Categorically disqualified areas should be disqualified as soon as identified rather than deferring smaller areas (less than 320 areas) to some later stage. (WI-3)

New Jersey has a concern over the reasoning and reluctance of the CRP to include various conditions as disqualifying factors. It is consistent with the screening process to disqualify unacceptable areas as early in the repository development process as possible. (NJ-55)

\section{Response:}

In Step 1 of the region-to-area screening methodology, the CRP has taken the following considerations into account in the identification of which disqualifying conditions in the DOE Siting Guidelines can be applied in Step 1 of the region-to-area screening methodology: (1) consistency with guideline provisions, (2) availability of a reasonably consistent regional data base from literature sources, (3) technical defensibility of disqualification determinations, and (4) equity in the application of disqualifying conditions. The CRP is applying all of the disqualifiers in the DOE Siting Guidelines judged to meet these basic criteria. It should be noted, however, that as part of the qualitative/descriptive literature review (see Section 3.3.1) the CRP will be attempting to determine if there is any evidence that a disqualifying condition actually exists within the candidate area. 
Furthermore, as the CRP moves into the area and site characterization phases, all of the other DOE Siting Guidelines disqualifiers will be carefully and consistently applied in making future siting, nomination, and recommendation decisions.

Disqualified features less than 130 hectares (320 acres) in size are not mapped during Step 1 of the region-to-area screening because of the 17-state scale at which the CRP is working. Using the chosen 1:1,000,000 scale, 1 square mile (260 hectares [640 acres]) is $1 / 16$ inch wide in this regional study. The CRP has always stated that the disqualified features, however smal1, will be consistently applied in later phases of the second repository selection process. It is simply more prudent and cost-effective to defer mapping of these small features. However, the CRP has decided that it will attempt to evaluate the impact of the Step 1 disqualified features which are less than 130 hectares (320 acres) in size as part of the qualitative/descriptive literature review.

COMMENT LETTER REFERENCE: NY-23

Comment:

P. 15 - It is indicated that the actual screening will be based on the data presented in the final regional characterization report scheduled for mid 1985. The screening method as detailed in this report does not require geological information. How is the RCR to be used?

\section{Response:}

The final RGCR and RECR will constitute the major portion of the data base to be used in the region-to-area screening process (See Section 3.3 for additional discussion). These reports will be developed in accordance with $t$ e final definitions of both the geologic and environmental factors and variables (Steps 1 through 3 ). The comment mistakenly states that the methodology does not require geological information. In fact, there is one eologic disqualifier (Deep Mines and Quarries) and several geologic Step 2 
and Step 3 variables. The final RGCR will reflect a data base capable of supporting each geologic factor and variable as an input to the region-to-area screening process.

COMMENT LETTER REFERENCE: NY-A-24, RI-3, GA-A-11, and NC-B-9

Comments:

P. 15 - The report states that the grid unit size is to be 320 acres. There is no explanation or qualification for this choice. (NY-A-24)

The decision to use a one-square-mile grid in region-to-area screening has caused some consternation among members of the Project Review Team who believe that many significant environmental features in Rhode Island will be overlooked as a result, only to force us to address them later. (RI-3)

P. 20 - "A 1-square-mile grid... has been judged by the CRP to strike an appropriate balance...". Because of the impact that the size of a sampling unit can have on the results of a study, we recommend that DOE document the statistical analysis that led to this decision. (GA-A-11)

P. 20 - The justification for the use of one square mile grid cel1 is too brief and deserves greater comparative discussion about the ramifications of its use on later analysis and decisions. (NC-B-9)

\section{Response:}

The grid cell size used by the CRP in the regional phase was largely determined by the geographic scale at which work is being undertaken. Because this phase involves 17 states, a $1: 1,000,000$ map scale is necessary to efficiently and effectively cover such an expanse of land. On this map scale, a square mile (260 hectares [640 acres]) grid is $1 / 16$ by $1 / 16$ inch. Consequent1y, it was determined that such a grid cell size was a reasonable choice to balance the needs to approximate actual feature boundaries; to 
discriminate degrees of favorability for each screening variable; and to do so without placing an unnecessary burden on the technical staff.

Because 1 square mile is equal to 260 hectares (640 acres), it was determined that it was reasonable to map features in the regional data base up to one-half a grid cell or 130 hectares (320 acres) in size. A discussion of disqualified Step 1 features less than 130 hectares ( 320 acres) in size is contained in CRP's response to WI-3 and NJ-55 (see page A-60 and A-61).

Given the fact that recommended candidate areas are expected to be from tens of square miles to thousands of square miles in extent, the square mile grid size provides an adequate level of detail for support of the decision process. The area-phase studies will be conducted in a more precise fashion because of the smaller geographic areas at which work will be undertaken.

COMMENT LETTER REFERENCE: NC-B-8

Comment:

P. 14 - Is there still sufficient data to support six disqualifying conditions or is the number fewer/larger?

\section{Response:}

The text has been modified to state that there are five disqualifying conditions that can be applied during Step 1 of the region-to-area screening methodology. The disqualifiers not used in Step 1 have data in a form which does not to allow their systematic use or are disqualifying conditions for which data cannot readily be collected during a regional literature investigation without interpretation/evaluation. As noted in Section 3.2.1, DOE recognizes that a finding must be made that the available evidence does not support disqualification for all 10 disqualifiers outlined in Appendix III of the DOE Siting Guidelines to identify potentially acceptable sites. 
COMMENT LETTER REFERENCE: SC-B-7 and SC-C-7

\section{Comments:}

Pp. 14-16 - In the discussion of the Disqualifying Factors Screen it is unclear exactly what is being eliminated. The text refers to the elimination of land units, rock bodies, and sites, but are not the $1 \mathrm{mi}^{2}$ cells the units being screened?

\section{Response:}

The text of the SMD has been modified to reflect that the part of the rock body containing a geologic disqualifier would be eliminated from consideration as a location for a repository (both surface and subsurface). This condition will eliminate the associated land surface from consideration as a location for a controlled area. Presence of the environmental disqualifying factors will eliminate the land surface coincident with these disqualifying factors from consideration as a location for the repository restricted area, repository support facilities, or surface facilities, but any portion of a rock body underlying this land surface would not be disqualified.

COMMENT LETTER REFERENCE: SC-B-8 and SC-C-8

\section{Comments:}

On p. 15 , the long paragraph concerning "inverse qualifying" is obtuse to the point of unintelligibility. This should be revised in plain English.

\section{Response:}

In finalizing the SMD this discussion has been deleted. 


\section{Comments:}

It is understandable that the scale of the composite maps reflect the degree of investigation possible for the regional activities (p. 15). It is advisable that in order to improve credibility of the maps among the public and improve the accuracy of the maps, that some symbol be devised to indicate grids that contain disqualifying features of less than 320 acres. (VA-A-2)

The last paragraph states that disqualified areas will only be charted on maps where that area exceeds 320 acres. Smaller acres must be identified on maps for the first screening either by blocking the entire square or by a partial block. This recognizes the existence of a disqualified area on the initial maps. Leaving out their smaller areas early will discredit the screening process when presented to the public. (VA-B-33)

\section{Response:}

The RECR list the Federal-protected lands disqualifiers that are less than 130 hectares ( 320 acres) (in Appendix A) and the state-protected 1ands disqualifiers that are less than 130 hectares (320 acres) (in Appendix B). A discussion of Step 1 disqualified features less than 130 hectares ( 320 acres) in size is contained in CRP's response to WI-3 and NJ-55 (see page A-60 and A61). 
SECTION/TOPIC AREA: 3.2.2 Step 2 - The Scaled Regional Variable Screen

COMMENT LETTER REFERENCE: MI-A-19 and NJ-38

\section{Comments:}

P. 22 - The last paragraph implies that each scale "number (1 through 5)" is assigned a shade of gray "for all variables". However, some variables are not scaled to 5-point scales, e.g., Rock and Mineral Resources and Suspected Quaternary Faulting. Although generically referenced in the preceding text on p. 22, the exceptions should be noted by revising the sentence of the last paragraph to remove inference of 5 shades of gray for all variables. (MI-A-19)

It is not clear as stated on page 22 where exactly fewer than five numbers are used in scaling. (NJ-38)

\section{Response:}

Chapter 5.0 includes discussions of variable scales for each of the Step 2 and Step 3 variables. Where fewer than 5 increments are used in scaling, an explanation or rationale is provided. The reviewer is referred to Sections $5.2,5.3$, and 5.4 of the text for details.

\section{COMMENT LETTER REFERENCE: MI-A-20}

Comment:

To be complete, the legend for each figure should include the physical measure corresponding to each scale value of 1-5.

\section{Response:}

The physical measures corresponding to each scale value on the figures have been added. 
COMMENT LETTER REFERENCE: MN-C-10, NY-A-4, and VA-B-13

Comments:

Pp. 24 and 25, Figures 8 and 9 - It appears that the shading on the hypothetical maps is incorrect because the grading is not darkest for the value "1". (MN-C-10)

The Draft Screening Methodology provides examples of "Favorability Maps" (pg. 24-26), a "Composite Favorability Map" (p. 39) and a "Summary Composite Favorability Map" (p. 42). The convention applied is that the darker the gray tone, the more adverse the condition that is being depicted. However, in reviewing the maps and the corresponding legends, that convention does not appear to have been strictly applied. The number 2 scale appears darker than the number 3 scale. Since the scales, as used in the draft, are discrete rather than continuous, the Department should consider using distinct color codes. (NY-A-4)

P. 24, Figure 8 - Why is shading for no. 2 darker than for no. 1 ? It would be logical for shading to become progressively lighter from no. 1 to no. 5. Also, it is difficult to distinguish in shading between "disqualified" and no. 2.

P. 25, Figure 9 - Corments same as for Figure 8. (VA-B-13)

\section{Response:}

The anomalies (on pp. 24 and 25 of the draft SMD) are an artifact of having to significantly reduce the original figures. At full scale, the graphics depict the shading becoming progressively lighter from a scale value of 1 to a scale value of 5 . The figures have been enlarged for inclusion in the final SMD. 
Comment:

P. 22 - In those cases where the "CRP's best technical judgment" is used, a clear explanation concerning the background of that judgment needs to be presented.

Response:

The CRP agrees and the final text has been revised to respond to the concern expressed in this comment. 
COMMENT LETTER REFERENCE: MI-A-2

Comment:

The proposed use of internal and external weighting groups, involving workshops and utilizing an iterative process to achieve consensus, may be an unwarranted and unproductive effort. We believe the provincial concerns of the participants in such an endeavor will prevent convergence of opinion toward consensus. We believe that the mandate of the Nuclear Waste Policy Act (NWPA) regarding consultation and cooperation with states and Indian tribes could be met if DOE were to take the lead by proposing a set of weighting coefficients, submitting the proposal to the states for comment, and incorporating state comments and concerns into a final Screening Methodology Document and associated set of weighting coefficients. However, if DOE chooses to hold one or more workshops as proposed in the draft screening methodology, Michigan will participate to the degree allowed...

P. 28 - We do not believe that "broadly representative" sets of weights are likely to evolve from the process described, nor are we sure of what "broadly representative" is intended to mean. No doubt the internal sets of weights can be derived through the process described in this document, but the DOE has not yet learned that consensus among the states is not possible. Even when the DOE states at the workshop that they no longer desire "closure" on an issue, the workshops, through polls, votes, and the direction of discussions, have always been directed to reaching agreement among the states. Michigan does not expect or intend to agree with every crystalline rock state on every issued related to repository siting. Furthermore, Michigan does not intend to allow consensus opinions to be characterized as Michigan's position. If an "external" weighting workshop is held, Michigan will send representatives, but we will make it clear the the work product of the workshop is not necessarily endorsed by or representative of Michigan's views. We suggest, as an alternative, that the DOE and its contractors develop a suggested weighting system and solicit the comments of each state on the system. 


\section{Response:}

The weighting workshop process described in the final SMD is designed to result in the development of representative sets of weights incorporating the views of CRP staff (the first workshop) and the 17 involved states (the second workshop). (Subgroup formation at both workshops is based upon similarity of views of the relative importance of the screening variables determined by statistical analysis of individual participant exercises.) The subgroups are, in turn, representative of a broad spectrum of largely different views on the relative importance of these variables.

It is recognized that the weights derived by each subgroup will not likely reflect an absolute agreement of the members of that subgroup. Discussion is designed to provide a structured opportunity for subgroup members to influence their peers' individual views of the variables. (This process is designed to continue until further discussion does not yield appreciable change in that subgroup's mean weights.) It is recognized by the CRP that there could be significant variance of views within the subgroup when this occurs, a circumstance that will be documented in subgroup statistics. Even so, by forming subgroups on the basis of a similarity of views, the CRP is generally minimizing the possibility of wide variance within a given subgroup. Thus, the process is more likely to yield convergence of views rather than "closure".

The CRP also recognizes that the results of such a process are not and should not be portrayed as a single state's set of weights. Consequently, the results of the second workshop will simply be portrayed as representative of the views of the 17 states as a whole without specific state identification.

COMMENT LETTER REFERENCE: MI-A-21

Comment:

P. 32 - Step B should emphasize that the weight allocation is for Step 2 variables only. 
Response:

The change has been made in the text.

COMMENT LETTER REFERENCE: MI-A-22

Comment:

P. 35 - The first paragraph is unclear concerning how to identify "subgroups with similar views" yet achieve subgroup formation "representative of the entire spectrum of views". These seem to be competitive processes.

\section{Response:}

The text of the final document has been modified to include a more specific description of the statistical technique to be utilized in forming subgroups at both the first and second weighting workshops. This cluster analysis technique is a widely accepted approach to performing such tasks, and the software for implementing the technique is part of the well-known Statistical Package for the Social Sciences (SPSS) system for statistical analys is (SPSS Inc., 1984).

The two workshops are structured so that participants will be representative cross sections of individuals with various technical, disciplinary, and policy backgrounds. Consequently, it is anticipated that there will be wide variation in individual views of the relative importance of the screening variables. When individuals are then clustered on the basis of similar views, the subgroups become representative of the whole spectrum of individual participants. These representative subgroups will be the focus of intensive interaction to derive weights that ultimately are likely to be indicative of a convergence of opinion within that subgroup on the relative importance of the screening variables. Consequently, the processes are complementary, not competitive, in the achievement of the CRP's region-to-area screening objectives. 
COMMENT LETTER REFERENCE: MI-A-23

Comment:

P. 25 - The fourth paragraph descries a "skilled individual" to facilitate subgroup discussion. How, among whom, and by whom will these individuals be chosen?

Response:

The facilitators selected to assist with the subgroup discussions during the weighting workshops are nationally recognized individuals that are skilled in facilitating structured group interaction. Criteria used in their selection included: (1) demonstrated experience with small-group facilitation, (2) experience in dealing with highly technical subject matter, (3) reputation for neutrality and objectivity on the high-level waste disposal issue, (4) availability to work at both workshops, and (5) willingness to accept the overall region-to-area screening methodology. The selection process included a review of each candidate's written credentials, a personal interview, and reference checks. The CRP contractor staff developed a list of potential candidates and CPO made final decisions on the selection of facilitators to be used in the workshops.

\section{COMMENT LETTER REFERENCE: MI-A-24}

\section{Comment:}

P. 36 - The prediction of success of the "iterative process" described in the first paragraph may be too optimistic.

\section{Response:}

The CRP defines "success" to be the completion of the process described in the text on weighting in a manner that gives each participant an 
opportunity to influence his/her peers in the subgroup through structured interaction. As mentioned previously, it is recognized that there will be varying degrees of consensus or closure reached in these iterative subgroup discussions. It is expected that convergence of views, evidenced in reduced statistical variances of subgroup weights, will in most cases result from these discussions. The variances will be recorded and will become part of the workshop documentation. It is also expected that the final subgroup weights will be representative of that subgroup's views of the relative importance of the screening variables.

\section{COMMENT LETTER REFERENCE: MI-A-25}

Comment:

P. 37 - It would help to add that, on the basis of the preceding discussion, a total of up to 12 sets of weights will be developed from the workshops.

\section{Response:}

A modification has been made to the text.

COMMENT LETTER REFERENCE: MN-C-9, NY-A-9, VT-5, VT-6, VA-A-4, VA-A-6, and VA-B-5

\section{Comments:}

P. 23 - CRP should conduct separate workshops for state participants and non-state participants, as we discussed at the October, 1984 Atlanta meeting. (MN-C-9)

If weighting workshops are conducted, states should have an individual workshop without outside people. This will allow adequate weight to be given specific state concerns. (NY-A-9) 
Weighting workshops should be as follows: one for the CRP group; one for the States; and one for non-State interests. These three would be preceded by an exercise that would result in a base case favorability map with all variables equally weighted. (VT-5)

P. 30 - DOE's ability "to reject remaining participants" in the States' workshop should be limited or eliminated. (VT-6)

The greater cause for alarm is the dilution of the states' role by the inclusion of other parties in the "external" (sic) group. With the mandate for state consultation, I would expect the Department to be more cautious in obscuring the states' positions on the relative importance of individual screening variables. (VA-A-4)

If states are merged with other interest group representatives, wi11 a11 participants have an equal vote when there is not a group consensus? (VA-A-6)

The process set for developing weighting for each variable fails to adequately involve all state representatives in a realistic and effective manner. The internal workshop weight by size will result in heavier weighting than for state representation. Under the system proposed, only 34 state representatives would participate, thus skewing the weighting process to the internal group. The external group should be expanded for greater state representation and used as the primary group for development of weighting factors. (VA-B-5)

\section{Response:}

Based upon state feedback at the October 1984, meeting in Atlanta, the CRP has decided to invite only involved-state participants to the second weighting workshop. The CRP does not plan to conduct a third workshop with non-state participants, primarily because the two workshops are deemed sufficient to develop the weighting inputs to be applied in the region-to-area screening process. 
The CRP is requesting that each state send three representatives to the second workshop: one representing geologic or waste-isolation expertise, one representing environmental/socioeconomic expertise, and one with a public policy background. This request is designed to help ensure a balanced crosssection of participants for the workshop. In addition, it is also desirable that the representatives have participated in previous methodology workshops.

\section{COMMENT LETTER REFERENCE: MN-C-12}

\section{Comment:}

P. 29 - The screening process will involve both geologists/engineers and environmental/socioeconomic specialists. We are concerned that having participants from one discipline weight variables from outside their discipline may be inappropriate. For example, socioeconomic specialists may not be comfortable arguing with geologists on the importance of post-emplacement faulting. Has CRP considered alternatives to this arrangement?

\section{Response:}

The assignment of weights is an admittedly complex process involving both technical knowledge and individual values. To deal with the first aspect, the CRP will prepare orientation material for workshop participants that highlight major technical issues related to each variable, and an introductory plenary session will be devoted to such discussion. In addition, technical resource personnel from the CRP will be made available for subgroups to call upon, if they so choose, to answer technical questions. Resource personnel will not express any opinions regarding their own views of the relative importance of variables. While these provisions will not bring all participants up to the same knowledge level for all variables, they will provide a fundamental technical understanding of technical issues in repository siting. The balance of the weighting process involves the application or expression of individual values in the assignment of weights, where each participant considers the tire list of variables. This is considered desirable by the CRP to capture epresentative views for screening. 
Alternatives to this arrangement were considered (e.g., a disciplinary segmentation of weights) but they were rejected in favor of the selected approach because of problems in defining the segmentation and in combining the segmented products into complete sets of weights for use in screening.

\section{COMMENT LETTER REFERENCE: MN-C-13}

\section{Comment:}

P. 30 - Materials provided to all workshop participants should reflect the concerns of the states. Information should not be limited to material prepared by DOE and its contractors.

\section{Response:}

Written orientation materials prepared by the CRP will reflect a wide range of technical issues and concerns related to the screening variables. These will include those expressed in the extensive interactions the CRP staff has had with the states in the regional phase to date. In addition, individual state representatives will be able to verbally express their views in both plenary and subgroup forums throughout the second workshop.

\section{COMMENT LETTER REFERENCE: MN-C-14}

\section{Comment:}

P. 31 - We are concerned that participants who are new to the screening process may not have sufficient time or familiarity with the program to digest the background materials, making them particularly susceptible to influence by the CRP. For this reason, we asked that information on the results of the internal workshop not be provided to participants in the non-state, external workshop. 


\section{Response:}

The CRP's position is that a third workshop for non-state participants is unnecessary, and thus the concern expressed in this comment is moot. In addition, the CRP has decided not to provide the results of the CRP workshop to the states until after the states' workshop.

COMMENT LETTER REFERENCE: MN-C-15, ME-10, GA-A-13, GA-A-14, GA-B-4, NC-B-10, VA-B-6, and VA-B-14

\section{Comments:}

P. 35 - The use of the mean value for weights within a subgroup is questionable without some regard for standard deviation. Some cutoff parameter could be employed to ensure that the mean value being used is not obtained from individual values that are too widely dispersed. (MN-C-15)

With respect to the weighting process, we feel that whatever process is used to develop suites of weights for use in the preparation of composite favorability maps, it should provide for the widest reasonable range of weights. There is some concern that the process described will, to some degree, reduce the range of weights by considering the mean weights of several groups of individuals. (ME-10)

Pp. 32-36, 41-43 - The procedure for the weighting workshops, as outlined in Section 3.2.3.4, has the effect of minimizing diversity of opinion and eliminating extreme variable weightings. Since the purpose of any sensitivity analys is is to examine the impact of a variable over its entire effective range, the proposed workshop procedure is counterproductive in that only the central portion of the range of values will be considered. For example, if participant $A$, in a weighting workshop subgroup, assigns a very high weight to the variable PROXIMITY TO STATE PROTECTED LANDS and a very low weight to PROXIMITY TO HIGHLY POPULATED AREAS, while participant $B$ assigns a reverse ighting to those two variables, then the proposed procedure would average 
the two individual weightings. This would result in assigning more or less equal weights to those two variables. It is our opinion that the average or consensus view may not be correct or prudent. (GA-A-13)

We recommend that the weighting workshops be conducted in such a fashion as to adequately address extreme views held by participants. Toward that end, we propose a modification of the workshop procedure that will address the effects of extreme views on the siting procedure, avoid peer group pressure on participants, and require less time than the currently proposed procedure. (GA-A-14)

Why group evaluators since divergent views are dampened due to averaging clusters? (GA-B-4)

Pp. 32-36 - The proposed weighting workshop process forces weights to the average. This does not seem appropriate for a process that is supposed to be seeking the most favorable site, rather than the best-average site. Computers should allow the use of individual weighting and the resulting large number of maps/variations. (NC-B-10)

P. 28 - The methodology proposes to consider views of subgroups rather than individuals after applying some unspecified statistical evaluation. Working from smaller groups to larger groups for discussion and consensus building is an appropriate group management technique. Scoring of factors, weighting of each and input into the statistical evaluation should be by the individual representatives. That scoring should not be masked within a group of 10 and translated to the total group decision. (VA-B-6)

Pp. 32-36 - We are concerned that the proposed workshop format will subordinate or nullify individual, technical expertise in the attempt to reach a consensus in diverse groups, some of whose members may have little experience or knowledge of a particular topic. Individual scientific expertise, as available, should be utilized to the fullest degree and not melted into a lowest common denominator. (VA-B-14) 
Response:

The weighting workshop process developed for the CRP's region-to-area screening methodology has been structured to yield representative sets of weights that capture a broad range of views of the relative importance of the screening variables. This is done through a combination of individual and subgroup exercises, with the final weight sets being the product of one or more repetitions of discussion during which individual participants attempt to persuade their peers on the merits of their individual weights. As noted previousiy, the subgroups are formed using a statistical cluster analysis technique that groups individual responses on the basis of similar views of the relative importance of the variables. Thus subgroup members share overall views of how weights should be assigned although individual assignments for given variables can vary significantly.

The CRP recognizes that individual participants' weights can be more extreme than subgroup weights and that subgroup discussion, and the sharing of knowledge within the subgroup, often leads to a degree of subgroup convergence on weight assignments. This is considered appropriate, however, because the subgroup discussions of ten shed new light on issues or perspectives that would have been otherwise overlooked by individual participants. The subgroups will be formed to be representative of a spectrum of views on weights, and even though the process does yield some buffering of individual views, it still leads to a series of weight sets that captures these diverse views.

It should be noted that basic descriptive statistical information will be calculated for each iteration of subgroup weights, including the final set of weights. In selecting which weight sets to use in screening, the CRP will look at both the standard deviation and variance figures to determine the degree of convergence of views achieved by each subgroup. This can help ensure that mean values used are not substantially distorted by extreme values of an individual subgroup participant.

Finally, the representative subgroup concept of weighting is preferable to the use of individual weight set because it is recognized that the weights of any given individual are no more "right" than those of any other individual. Rather, the CRP is committed to the use of broadly representative ybgroup weights as an indication of the spectrum of individual views of the 
relative importance of the screening variables. This also helps limit to a reasonable number (e.g., 5 or 6 ), the number of related composite maps used to be considered by DOE decisionmakers. Running a large number of individual weight sets to develop composite maps would yield no significant additional benefits to the selection of candidate areas as compared to the selected approach of comparing selected subgroup weights.

\section{COMMENT LETTER REFERENCE: WI-5}

\section{Comment:}

Pp. 23-27 - If OCRD then determines that weighting is necessary, the process must be changed to eliminate the constraints imposed (e.g., the proposed process only allows participants to assign weights to variables, not add or subtract variables). OCRD's proposed process - OCRD picks the non-state participants and facilitators, prepares the background materials, and controls the orientation activities - eliminates any pretense of objectivity.

\section{Response:}

The selected weighting process provides a systematic and consistent structure for the formulation of representative sets of weights. The constraints imposed upon state participants are limited to those that are necessary to derive such representative weights. For example, participants must utilize a common list of variables in weighting or the validity of the product can be compromised. These lists are a product of substantial state interaction over the last 2 years and are the CRP's best effort to balance all the considerations necessary to finalize them.

As outlined elsewhere, CRP has decided, per state request, to limit participation in the second workshop to representatives of the 17 crystalline states. The participants will be selected by those states and will be accepted by the CRP without reservation. The workshop orientation materials will be prepared by CRP staff, but the workshops will be structured to allow state participants to articulate their own views regarding the relative 
importance of variables in both plenary and subgroup sessions. Finally, the selection of facilitators is based solely on their ability to effectively function in the role conceived for them in an objective fashion, drawing out the views of participants and not expressing their own personal views. Consequently, every effort has been made by the CRP to help ensure that the second workshop captures representative views of the participants rather than some preconceived notion of what those views are.

\section{COMMENT LETTER REFERENCE: WI-6}

\section{Comment:}

Pp. 23-27 - To the extent that Delphi process techniques are statistically valid, they are valid as means of ranking individual preferences, not group preferences.

\section{Response:}

The CRP disagrees with the above comment and stands behind the selected approach to weighting as one that is both technically defensible and functional in support of the region-to-area screening process. Using individual preferences in screening would result in the CRP facing the almost insurmountable problem of which individual weights to use. The selected approach samples various relevant constituent and technical communities to develop representative weights that capture a broad spectrum of views while avoiding the problems of using individual weights.

\section{COMMENT LETTER REFERENCE: WI-7}

\section{Comment:}

Pp. 23-27 - This process is meaningless if DOE does not agree to be bound the weighting process results. 
Response:

The CRP is committed to the use of selective weight sets from the two suites of weights derived at the two workshops. The selection of sets to use will be based upon capturing the spectrum of subgroup weights, including extreme points and representative intermediate points. The selection will also consider supporting descriptive statistics (i.e., the standard deviation and variance) in selecting weight sets in order to utilize those weights where there was the most convergence of views within the subgroup.

It should be noted, however, that the use of these weights to develop composite and summary composite maps is designed to inform the DOE decisionmaker, not to mechanically make the decision. Other considerations such as regionality, hydrogeologic setting, and rock diversity may also play a role in the final area recommendation decision. The region-to-area screening process will be documented in the draft ARR which will be submitted to states and potentially affected Indian tribes for review and comment prior to finalization.

COMMENT LETTER REFERENCE: NJ-1

Comment:

A general comment on the report, as a whole, is that additional editing is needed to render this report lucid and readable. This document was extremely difficult to follow, especially concerning the weighting process, its implementation and use in determining aggregate favorability in conjunction with scales.

\section{Response:}

An effort has been made to improve the readability of the final report, particularly the section on the weighting process. 
Comments:

Consideration should be given to allowing an increased number of specialists to attend the workshop. (NJ-45)

Because of the variety of expertise needed to adequately discuss and determine their priorities in the weighting process, states should not be limited to two participants in the weighting workshops. While all CRP states should have an equal vote, the number of state representatives present and participating should not be limited. (VA-A-5)

Each crystalline rock state is limited to two representatives. This is inadequate as part of a meaningful state consultation process. State participation at this minimal level negates the "mutually beneficial and highly desirable" input by states. The external workshop should have no less than four representatives from each state so that a broader technical, environmental and policy base can be included...

With regard to the forthcoming workshop, ideally the most knowledgeable and experienced persons should participate. The arbitrary limit of two persons per state may exclude other well-qualified participants who could and might wish to make real contributions to the process. (VA-B-34)

\section{Response:}

With CRP's decision to limit participation at the second weighting workshop to only state participants from the 17 crystalline states, the number of participants per state has been increased to three. The CRP's preference is that each state send a representative with geologic or waste isolation expertise, one with environmental/socioeconomic expertise, and one with public policy experience. This would result in a total of 51 participants, if each state sends three representatives. This target number of approximately 50 people was arrived at by anticipating that five sets of weights could dequately capture alternate points of view, coupled with the fact that 
subgroup interactions tend to suffer in productivity as group size exceeds 10 in number.

The CRP believes that historical experience with the methodology development workshops has demonstrated that states can be adequately represented in technical discussions of the scope contemplated by the weighting workshops by three people.

\section{COMMENT LETTER REFERENCE: NY-A-5, VT-7, GA-A-12, and MD-2}

\section{Comments:}

The draft Screening Methodology, stipulates that the multiple sets of weights resulting from the internal CRP weighting workshop will be provided to the State as input to the state weighting workshop (p. 27). In our view, such action would prejudice the state weighting effort. The two weighting exercise should be totally independent. (NY-A-5)

The State of Vermont would want to have an opportunity to see in advance of the States' workshop the results of the application of the weights derived from the internal CRP weighting workshop. This information would help us prepare for the states-only weighting session, and provide a bas is for our participation. (VT-7)

P. 31 - Presentation of the internal CRP weights to the external weighting group, before, they have prepared their own weights, would prejudice the external group weightings. (GA-A-12)

We request justification for releasing the internal groups suite of weights to the external group prior to the latter groups discussion and development of their own suite of weights. (MD-2)

\section{Response:}

The CRP recognizes different points of view among the states involved on the desirability of seeing the results of the first weighting workshop prior 
to the states' workshop. Due to DOE's concern that the release of the suite of weights developed at the CRP workshop to the 17 crystalline states prior to their participation in the states' workshop could influence the suite of weights to be developed, DOE has determined that its previous decision to release CRP-selected weights in advance of the states' workshop for information purposes was inappropriate. States will be sent the results of the CRP workshop after the states' workshop has been conducted.

\section{COMMENT LETTER REFERENCE: GA-A-39}

\section{Comment:}

The first step in the current procedures for the weight ing workshop (subsequent to a review of procedures) is the completion of an individual weighting exercise. This exercise should be free from peer group pressure and will produce the most diverse set of weightings of the entire workshop. Because these weights are independent and cover the entire effective range of weights, they should form the basis of the sensitivity analysis. Using the 45 to 50 sets of individual weights, descriptive statistics (mean and standard deviation) can be calculated for the weights applied to each variable. Extreme values for each weighting can be defined as those weights that are either two or three standard deviations from the mean weight for each variable. Individual composite maps can be prepared by setting one variable at a time at an extreme value and assigning the other variables the mean value. A summary composite map can be prepared using all of these extreme value maps.

\section{Response:}

The CRP believes the selected approach to weighting is preferred over the one suggested by the comment for three major reasons. First, the anonymity associated with subgroupings is preferred to recording individual weights in the workshops. It is anticipated that many individuals would prefer to not have their names directly tied to a set of weights, as this may create roblems with others in their state who disagree with their views. Second, it 
is more likely that participants will listen to and act on the presentation of information by their peers in a subgroup context than in the suggested format. Finally, the suggested approach would complicate the screening process with an unnecessarily large number of weight sets, and reducing the number would be difficult.

\section{COMMENT LETTER REFERENCE: GA-B-1}

\section{Comment:}

My main concerns involve the general weighting method used in the draft which could be classified as a self-explicated weighting approach. An alternative direction which could be argued to be more appropriate on a conceptual basis would be an inferred weighting method.

The basic distinction between the two general approaches is that in the inferred method one can assess the relative importance a decision maker places on sets of variables based upon his actual choices or evaluations of alternatives. In other words, based upon the decision makers evaluations one can infer what the relative importances (weightings) are of a set of attributes rather than weighting the attributes and combining them to quantify the value of the alternative, which is the manner in which a self-explicited approach is implemented.

\section{Response:}

The CRP has evaluated the suggested "inferred weighting method" and has decided to retain the selected approach. This "self-explicated" approach can be successfully applied to the achievement of the primary objective, specifically to capture representative views of the relative importance of the screening variables. It has been effectively applied on numerous other siting studies, and is viewed in the technical community as a defensible approach to the derivation of weight sets. 
Comment:

Be specific in terms of how clusters are formed. Cluster analysis was not mentioned but is obvious for this use.

\section{Response:}

The CRP has, indeed, decided to use cluster analys is to form subgroups at the weighting workshops. The software used is part of the Statistical Package for the Social Sciences (SPSS) widely used in the United States (SPSS, Inc., 1984).

\section{COMMENT LETTER REFERENCE: GA-B-7}

Comment:

Maybe median rather than mean weights should be used if there are highly divergent weightings.

\section{Response:}

While the median is another measure of central tendency, the CRP prefers the use of the mean in this application. It should be noted that the variances will be provided to the facilitators for each weighting iteration. Experience in the CRP workshop suggests that subgroups tended to converge around the mean. Consequently, the CRP believes the mean is a more appropriate measure of central tendency. 
Comment:

How are they going to measure most extreme and intermediate sets of weights as per p. 37.

Perhaps suggest Euclidean or Mahalanobis $D^{2}$ distance metrics.

\section{Response:}

The CRP anticipates that there will be distinctive extreme sets of weights, roughly lining up on a split in emphasis between preclosure and postclosure considerations. In addition, various intermediate sets of weights will likely be determined quite readily by visual inspection. The final selection of weight sets to use in region-to-area screening will account for the standard deviation and variance for each weight set, and wi11 be designed to capture extreme and intermediate subgroup views. If it turns out that this cannot be done by inspection and review of limited statistical data, the CRP will consider use of the suggested approaches (Euclidean or Mahalanobis $D^{2}$ distance metrics).

\section{COMMENT LETTER REFERENCE： VA-A-3}

\section{Comment:}

The proposed design for the weighting process is particularly disconcerting. Indeed, the terms "internal" and "external" evoke suspicion of the acceptability of the states' weighting determinations to the "internal" group.

\section{Response:}

No such interpretation was intended. The final text calls the two workshops, the first or CRP and the second or states', with the second set of participants comprised of crystalline state representatives. Both 
workshops are designed to elicit sets of weights that will be used in the region-to-area screening methodology. It is recognized that neither of the two suites of weights is more appropriate for region-to-area screening.

\section{COMMENT LETTER REFERENCE: VA-A-7 and VA-B-9}

Comments:

The final document should be more specific on the types of statistical analyses that DOE intends to apply. (VA-A-7)

P. 35 - What specific statistical analysis does DOE intend for use in the workshops? There are candidate approaches listed but the methodology used must be pre-specified. If not, the result can be shopping for an analysis that gives the desired result. Further, the use of that specified statistical methodology should be spelled out within the methodology document. This same proposal would apply on page 40 when using alternative indices of aggregate favorability. The details of the statistical evaluation have to be selected up front, not after the process is started. (VA-B-9)

\section{Response:}

The revised text states that the approach selected for subgroup formation is cluster analysis. The revised text states that the alternate index of favorability that will be examined in Step 3 of the region-to-area screening process is the geometric mean.

\section{COMMENT LETTER REFERENCE: VA-B-7}

\section{Comment:}

P. 28 - The DOE confuses the issue of scaling workshop use by stating hat "base case" set of weights have been eliminated and replaced by DOE 
selecting broadly representative sets of weights from the two suites of weights. Since the internal workshop will have a greater-than-state role, the process does not represent objectivity. The expanded state workshop should provide DOE with the most effective weighting scales. By relying nore on the state developed weights, the inference that weight scales can only be developed where there are significant similarities between the two suites would be negated. The later inference seems to say that only external weights that agree with DOE will be used. I am sure this is not the intended method.

\section{Response:}

An equally weighted base case composite map will be developed and its use will be included as part of the draft ARR documentation. The reviewer is correct in saying that it is not the intention of the CRP to use only the second workshop weights that agree with the CRP weights. The intent is to use that combination of weights that best represents the broad spectrum of views of the relative importance of the screening variables, whether they be from the first or second workshop. In fact, where weight sets are similar, CRP's preference will be to use the set generated at the states' workshop.

Because the second workshop will now include only representatives from the 17 states, the first concern mentioned above is presumably moot.

\section{COMMENT LETTER REFERENCE: VA-B-8}

\section{Comment:}

P. 33 - After Step D, it is indicated that individuals will be formed into subgroups with individuals having similar views of the relative importance of the screening variables. This technique creates an obvious bias and prevents realistic dialogue in consensus building toward developing weighting factors. If more time is needed with a less biased grouping, why not expand beyond the two days. 
Response:

The CRP disagrees with the above observation. As discussed elsewhere in this Appendix, subgroup formation has been carefully designed to result in mean weights that are representative of a broad spectrum of views of the relative importance of the screening variables. Forming subgroups on the basis of similarity of views does not introduce bias but rather makes it easier and more productive for subgroups to discuss their remaining differences in weight assignment, thus leading to some degree of convergence of opinion as reflected in final mean weights for each subgroup.

COMMENT LETTER REFERENCE: VA-B-30

Comment:

With regard to the forthcoming workshop, it should be noted, also, that individual "experts" do not always agree among themselves. The level of knowledge and experience will probably vary widely among participants. Realistically, the most effective format would be one that would utilize fully and give appropriate weight to the expertise of the best-qualified members.

\section{Response:}

As mentioned in response to a related comment elsewhere, the assignment of individual weights is a combination of technical knowledge and personal values. In addition to different degrees of personal knowledge and experience, each participant will have received orientation materials prior to the workshop, will have an opportunity to interact with peers in plenary and subgroup discussions, and will be able to ask questions of knowledgeable CRP resource people. This does not eliminate the value judgement aspect of weighting, however, in comparing the significance of one variable to another. The approach takes into account both aspects of weighting and requires each participant to consider technical and value judgements in assigning weights. This is viewed by the CRP as the preferred approach. 
SECTION/TOPIC AREA: 3.2 .4 Composite Map Development

\section{COMMENT LETTER REFERENCE: MI-A-26}

Comment:

P. 37 - The term "weighted average" in the last paragraph should be classified as the weighted arithmetic average. In addition, nowhere in the text is the method for calculating the weighted arithmetic average given:

Weighted arithmetic average $=$

$$
\sum_{i=1}^{n} w_{i} s_{i} / \sum_{i=1}^{n} w_{i}
$$

where $n=$ number of variables $i$

$W_{j}=$ weighting coefficient for variable $i$

$S_{i}=$ scale value for variable $i$

\section{Response:}

A footnote has been added to the text indicating the method for calculating the weighted arithmetic average.

COMMENT LETTER REFERENCE: WI-8

Comment:

P. 38 - Nowhere is the single most critical disqualifying factor identified. The absence of crystalline rock is a disqualifying factor, and as such should be explicitly stated. On the favorability maps, those areas not underlain by the crystalline rock should be colored as disqualified. 
Response:

The reviewer's point is well taken. The CRP is looking to ultimately identify licensable sites in crystalline rock. Consequently, the geographic focus of the regional phase reflects those land areas in each of the 17 states that are underlain by crystalline rock. A broader definition of the region is applied in this phase because proximity of many other features (e.g., postemplacement faults and protected lands) is also relevant to the evaluation of the aggregate favorability for each rock body. The ARR will account for all the region-to-area screening variables in identifying those portions of crystalline rock bodies (candidate areas) that are recommended for further study in the area phase.

\section{COMMENT LETTER REFERENCE: NJ-49}

\section{Comment:}

Please clarify the development process of the composite maps. The screening methodology (August, 1984) states that the maps will be prepared by calculating the weighted average of all numerical entries in each grid cell. However, in the January 1984 document, it is stated that "differential weights" will be used, and in the October 1983 document that "equal weighting" will be used. Please compare and clarify how a weighted average differs from the "equal weighting" and "differential weighting" process as previously mentioned.

\section{Response:}

Composite maps will be developed using favorability maps for each screening variable and variable weights as inputs. For each grid cell on the composite favorability map, the composite favorability will be calculated (and shown) by summing, over all variables, the product of the scale value for a 
variable times the weight assigned to that variable divided by the sum of the weights. The mathematical expression for this is equivalent to:

$$
\sum_{i=1}^{n} w_{i} S_{j} / \sum_{i=1}^{n} w_{i}
$$

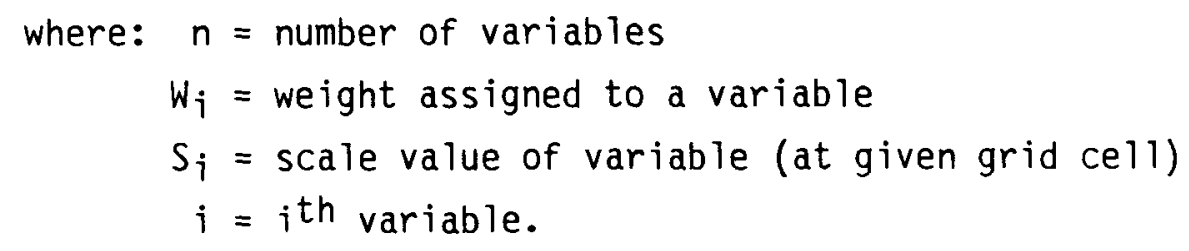

The CRP has modified appropriate sections of the text to make this discussion clearer. The CRP also plans to develop an equally weighted composite map. At this time, the CRP has not determined what equally weighted case means. For example, it could mean that each variable is equal in weight to every other variable or that the sum of all geologic variables is equal to the sum of a 11 environmental varibles. As discussed with representatives of the crystalline states in Albuquerque, New Mexico (February 1985), the CRP will seek state input on this issue.

COMMENT LETTER REFERENCE: GA-A-15

Comment:

P. 38 - We recommend that a large number of composite favorability maps be prepared. An adequate sensitivity analysis should consider the entire effective range of alternatives (see comment 4 ). Since the composite favorability maps are being produced by computer, DOE should be able to produce as many maps as are deemed technically necessary. 
Response:

The CRP will utilize as many composite and summary composite maps as necessary to provide map results that depict the most favored rock bodies (candidate areas) from a broad range of perspectives. The screening process will be structured to accomplish this with five or six sets of weights applied to: (1) the Step 2 variables, (2) the Step 2 and Step 3 variables, (3) the Step 2 variables with modified scales, (4) the Step 2 and Step 3 variables with modified scales, (5) the Step 2 variables with the geometric mean as the index of favorability, and (6) other scenarios, as appropriate. Care will be taken to organize this work to support an orderly and defensible decision process.

COMMENT LETTER REFERENCE: VA-B-15

Comment:

P. 39, Figure 11 - We assume that the grid-cells outlined by heavy lines are the rock bodies being considered. This should be so indicated in the legend.

\section{Response:}

The assumption is correct, and the use of these lines in previous figures as rock body boundaries is continued in Figures 11 and 12 .

COMMENT LETTER REFERENCE: VA-B-16

Comment:

P. 39, Figure 11 - Why are shadings for favorability shown far outside the rock-body boundaries? 
Response:

Figure 11 provides a simplified example of what a composite map may look like. The shadings are depicted in that manner to help orient the reader as to which features proximate to the rock body influence its favorability. It is recognized that only areas within a rock body boundary will be studied further as the location for a repository. It is CRP's current plan to depict only rock bodies on the composite maps. 


\section{SECTION/TOPIC AREA: 3.2 .5 Step 3 - Sensitivity Analysis}

\section{COMMENT LETTER REFERENCE: MI-A-27}

\section{Comment:}

It is not clear how equitably Step 3 analysis using new variables, for which only some states may have data, can be conducted. Upon redraft, the Screening Methodology should describe the process the DOE will use to incorporate the Step 3 variables in the area recommendations. For instance, how will the variables be used if there is not a consistent data base for favorable rock bodies that have been indicated after applying the Step 2 variables? Will the states be asked or expected to submit additional data or suggest additional variables for incorporation in Step 3? What process will be used to assign weights for these variables?

\section{Response:}

Step 3 variables, by definition, are those geologic variables which relate to potential health and safety issues for which only scattered data are available in the 17 states involved or for which the data collection effort for 17 states would be prohibitively expensive (i.e., ground-water resources). The concept was developed in response to state request to use such geologic data where available in region-to-area screening. Consequently, each state has been given the opportunity to supply such data to the CRP, but in some instances, a given state simply has no such data to provide.

Step 3 variables will be applied in screening only after the application of Steps 1 and 2. Where there are data for the Step 3 variables, the scaled information will be utilized to recompute the weighted average for each affected grid cel1. Where no Step 3 data exist, nothing will be assumed about the favorability of that grid cell for that Step 3 variable. Consequently, the weighted averages for grid cells with Step 3 data will be computed on the basis of a larger number of variables than for grid cells for which no Step 3 data are available. 
The Step 3 variables discussed in Section 5.4 of this document have been identified and defined with substantial State input. Only those variables will be utilized in Step 3 of the region-to-area screening methodology, and the CRP will not add any variables to this list. The weighting workshops will provide weights for the Step 2 variables and for a combined 1ist of Step 2 and 3 variables. This will allow the calculation of weighted averages to be done defensibly in both instances.

\section{COMMENT LETTER REFERENCE: MI-A-28}

\section{Comment:}

P. 41 - The second paragraph refers to four sets of weights. However, preceding discussion refers to up to six sets of weights from the external groups.

\section{Response:}

The number "four" was used as a hypothetical number in the discussion and relates to the generation of one summary compsite map. However, CRP anticipates that five or six sets of weights will actually be used in developing a single summary composite map.

\section{COMMENT LETTER REFERENCE: MI-A-29}

\section{Comment:}

P. 43 - The third paragraph does not indicate what will be done if "the addition of such data affects the aggregate favorability of these rocks significantly enough to displace them from the list ...". 


\section{Response:}

Given the CRP's intent to utilize available Steps 1 through 3 data in decisionmaking, the final recommendations of candidate areas will be based upon the incorporation of Step 3 data. Consequently, it is possible that the analysis of Step 3 variable information will result in a reordering of the most highly rated rock bodies resulting from the Step 2 results.

\section{COMMENT LETTER REFERENCE: MN-C-16}

\section{Comment:}

P. 40 - Minnesota endorses the concept of a sensitivity analysis using a geometric mean to provide a comparison with the arithmetic mean. Because we can not know in advance what the range and distribution of grid cell values will be, it is difficult to determine what the appropriate statistical measure should be. This sensitivity analysis will provide an opportunity to view how an alternative measure would affect those grid cell values and resultant area selection.

\section{Response:}

The CRP will investigate the use of the geometric mean as an alternate index of aggregate favorability in Step 3 of the region-to-area screening methodology. The results of this investigation may provide additional useful input to the area recommendation decision. If the geometric mean is chosen for application in the final decision-making process, its use and the results wil1 be documented in the draft ARR. 
COMMENT LETTER REFERENCE: ME-2, VT-8, and GA-A-17

Comments:

Modification of variable scale during the sensitivity analysis does not appear to be necessary or justified...

Within Step 3, the scales used for assigning the values 1-5 to the Step 2 variables should not be modified. The same effect can be produced by varying the weights of the variables (an integral part of the preparation of the aggregate favorability maps), and to consider the additional variable of scale change is not necessary and will make tracking the effects of the different suites of weights much more difficult. The scales as presented in the draft methodology document were developed by the DOE and Battelle personnel after extensive consultation with the States, and while no consensus exists on their adequacy, it is our opinion that they should not be modified during the sensitivity analysis. (ME-2)

The Step 3 Sensitivity analysis states that one of the four types of analyses which may be conducted is the "modifying (of) the scales of Step 2 variables" by the CRP technical staff. That selective modification is totally unacceptable if it is conducted internally. Why have the states participated in Step 2 activities when the first potential action in Step 3 is to modify previous scale work? (VT-8)

We strongly recommend that the scale modification be clearly defined before the weighting workshops and certainly before any analysis of the weighting workshop data. Testing should be conducted on a priori modifications rather than a posteriori modifications. (GA-A-17)

Response:

The CRP disagrees with Vermont's and Maine's position on the usefulness of scale modification, and will explore the implications of selectively modified scales on the selection of candidate areas. The reason that such sensitivity analysis is considered important is that, while substantial effort was 
expended in reaching agreement on variable scales, there are still selected variables that are subject to considerable differences of opinion among both State personnel and CRP staff. This portion of the sensitivity analysis is designed to examine what changes in screening would occur if these alternate scales were utilized. That is, would the most highly rated rock bodies change significantly? While the CRP does not believe that substantially different recommendations would result, it is important to demonstrate the effects as part of sensitivity analysis.

The CRP has identified three variables that will be subjected to scale modification, and their alternate scales have been identified (see Section $3.2 .5 .1)$.

COMMENT LETTER REFERENCE: NY-A-7

Comment:

P. 43 - The draft further discusses the incorporation of Step 3 variables. It is unclear from these discussions and statements if the states will be involved in weighting Step 3 variables. If it is DOE's intention to include states in that process, will a separate workshop be held for that purpose? The Screening Methodology should be revised to clarify this matter.

\section{Response:}

As part of the weighting workshop, participants will be asked to assign weights to the Step 2 variables and to the Step 2 and Step 3 variables (in combination). The text has been clarified in Section 3.2.3.4. 
COMMENT LETTER REFERENCE: NY-A-13

Comment:

P. 41 - It may be useful for the states to have specific summary composite maps prepared to facilitate their analysis of the ARR document. We would like this option included in the Final Report.

\section{Response:}

The screening process has been set up to incorporate state input into variable selection, into definition and scaling, and into weighting. The selection of composite maps that are run will be specifically designed to represent a broad range of views including the views of CRP staff and representatives of the 17 states (as reflected in subgroup weights). As previously stated, the documentation supporting the recommendation of candidate areas will be contained in the draft ARR. Accordingly, the CRP does not believe it is necessary to prepare specific summary composite maps requested by the states.

\section{COMMENT LETTER REFERENCE: VT-9}

\section{Comment:}

What is the role of OCRD's external Institutional/Environmental Peer Review Group? If there is relevant information or significant recommendations from them, we would like to be so advised.

\section{Response:}

The Office of Crystalline Repository Development (OCRD) Institutiona1/Environmental Peer Review Group is a group of nationally reputable and highly regarded individuals experienced in the scope of activities covered by OCRD's Environmental and Institutional Relations 
Jepartments. Their role as part of OCRD's peer review structure is to critically review the progress of the project with a special focus on the work of these two departments. They also recommend new approaches to the conduct of the work, or ways of improving the quality and defensibility of what OCRD does in these areas. They meet quarterly for 1 or 2 days. This peer review process is an internal (to OCRD) process.

COMMENT LETTER REFERENCE: GA-A-16, GA-B-3, and NC-B-11

\section{Comments:}

P. 38 - You state that "Four types of sensitivity analyses may be conducted..." (emphasis added). We recommend that DOE clearly define exactly what analyses will be performed. (GA-A-16)

How sensitivity analysis is to be done needs to be more specific, e.g., $a \pm X \%$ change in input parameters brings about a different evaluation of a site. (GA-B-3)

P. 38 - Rather than waiting, the DOE should set out specifically what types of sensitivity analys is and scale modifications will occur or be pursued. This will avoid the future appearance that the DOE is justifying prior decisions and provide an opportunity for meaningful discussion of such choices. (NC-B-11)

\section{Response:}

The final text is more definitive in the discussion of what will be included in sensitivity analysis; specifically, the modification of variable scales, the investigation of the use of the geometric mean as an alternate index of aggregate favorability, the incorporation of Step 3 variable data, and the development of summary composite maps are more completely described in this document. The level of specificity outlined in the second Georgia 
comment (GA-8-3) is not possible to provide in a document of this nature.

COMMENT LETTER REFERENCE: GA-A-18

Comment:

P. 43 - Weighting procedures for the additional Step 3 Geologic Variables should be more clearly defined.

\section{Response:}

The two weighting workshops will consider two lists of variables as described in detail in Section 3.2.3 of this document. The first list will include only the Step 2 variables. The results of this exercise will be used to support Step 2 of screening. The second list of variables will include both the Step 2 and Step 3 variables. Thus, the relative importance of the Step 3 variables will be examined by workshop participants in the context of all the variables, with weights assigned accordingly. The results of this exercise will be used to support Step 3 .

\section{COMMENT LETTER REFERENCE: MD-1}

\section{Comment:}

P. 40 - It is stated that the CRP believes the weighted average is a defensible index of aggregate favorability for each grid cell. We request the the CRP document this defense and compare the use of the weighted average to the use of the geometric mean and to alternate indices of favorability such as a composite rank score (see Eichbaum-to-Mann letter, 4/4/84). 


\section{Response:}

As noted in a prior response, the CRP will investigate the use of the geometric mean as an alternate index of aggregate favorability. The results of this analysis will be examined to determine if they provide additional useful input into the area recommendation decision process. If the geometric mean is chosen for application in the final decision-making process, this use and the results will be documented in the draft ARR.

\section{COMMENT LETTER REFERENCE: GA-B-6}

\section{Comment:}

As part of the "sensitivity analysis" in Step 3 perhaps weighting method should be varied to evaluate effects on results.

\section{Response:}

The weighting method is simply designed to capture reasonably representative sets of weights that reflect a broad spectrum of views of the region-toarea screening variables. The CRP is confident that the method described will do just that. Consequently, using another method to derive representative weights would be an unnecessary duplication of effort.

\section{COMMENT LETTER REFERENCE: SC-B-9 and SC-C-9}

\section{Comments:}

P. 41 - The development of summary composite maps will be central to the selection of areas for further examination. Therefore, the method of developing such summary maps will be of keen interest to the affected states. How will DOE keep the data processing and graphics development from becoming a "black box", within which the software, programming and manipulation will be a ystery to outsiders? 


\section{Response:}

The concept of a summary composite map is simply defined as a single map that graphically portrays the amount of coincidence between features on a number of related composite maps. Picking a given level of weighted average score, the summary composite map shows those portions of rock bodies with that weighted average or higher on all of the composite maps (say 4 for this example), on three of the four maps, on two of the four maps, on one of the four maps, and on none of the four maps. It is a way to structure the search for the highest-rated rock bodies or portions of rock bodies (candidate areas) that show up consistently on composite maps based upon widely varying sets of weights. The concept is important to understand, and the revised description in Section 3.2.5 should make it understandable.

Procedures used in developing the summary composite maps will be provided as part of the draft ARR documentation. 
SELECTION/TOPIC AREA: $\quad 3.2 .6$ Selecting Candidate Areas

COMMENT LETTER REFERENCE: MI-A-3, NY-B-2, SC-B-11, and SC-C-11

Comments:

We are concerned about reference in the draft document to "other factors" beyond the results of applying the Screening Methodology to the region-to-area screen. Our concern is heightened by recent remarks by DOE Secretary Hodel regarding the political considerations of siting a repository in Texas. The entire siting process, which has heretofore been conducted on what we believe to have been a good-faith basis, is compromised by incorporating political considerations. Siting must be on the basis of sound application of the criteria that are ultimately specified in the Siting Guidelines...

The unamplified statement that "The methodology is not the only input into the decision process, however," raises the possibility that the methodology will not even be a signifcant input. Recent remarks by Secretary Hodel regarding repository siting in Texas indicate that the DOE is neither hopeful of nor interested in finding a technically defensible and environmentally sound, permanent solution to the problem of high-level radioactive waste management. We are left with the distinct impression that states that have spent considerable time in technical and programatic review of such documents as this Screening Methodology have been wasting both time and money. In all this discussion of scaling, weighting, composite maps, regional variables, etc., there is no clear statement of how the sites will actually be selected. Upon redraft, the DOE should attempt to explain who will decide which sites are "potentially acceptable", if and how the Screening Methodology will affect the decision, and what other factors, including political factors, will influence the decision. (MI-A-3)

Our major concern stemming from the states meeting was the process by which your office will designate the 15 to 20 areas in the ARR document. Our understanding is that the screening variables will be applied, the implementation variables and qualitative literature will be considered and hen you will choose the final 15 to 20 areas. At the same time, the states 
will not have the opportunity to review the composite maps until the release of the ARR document. This will prevent the states from knowing the number, size, or location of potential areas that result from the screening process. In addition, the states will not be aware of the criteria, considerations, or other processes that result in the final selection of areas. This is totally unacceptable to New York State as it will reduce the at least quasi objective screening process to a "black box" process where various subjective, bureaucratic and political decisions will come into play. (NY-B-2)

P. 44 - In this section it is stated that--"the methodology is not the only input into the decision process". What are the other inputs, and at what point will states be able to scrutinize them? The decision process is critical, therefore the methodology should be more specific in planning for and outlining the components of its process. (SC-B-11 and SC-C-11)

\section{Response:}

The CRP intends to perform the region-to-area screen in accordance with the process described in this final document. Consequently, the results of the methodology, (Steps 1 through 3) will be very significant to the selection of candidate areas for further study in the area phase. The CRP recognizes and sincerely appreciates the substantial effort expended by the states in the development of this methodology, and feels comfortable that it represents a systematic and sound application of the regionally applicable provisions of the DOE Siting Guidelines.

Once the most favorable 15 to 20 areas are identified using the regionto-area screening methodology (Steps 1 through 3), the CRP will review any additional data in the data base or in the existing literature on these areas as part of the qualitative/descriptive literature review as described in Section 3.3.1. In addition, if it is determined that the intent of the DOE Siting Guidelines could be better met by considering regionality, diversity of rock type, and diversity of geohydrologic setting provisions, then the CRP would reexamine these areas to determine the trade-offs involved in substitiuting new areas. The states will be able to critically scrutinize this portion of the decision process as part of the documentation included the draft ARR. 
It must be noted that the process is not intended to be merely a mechanistic or "cook book" approach to the selection of candidate areas but requires additional judgments to be applied by DOE to fulfill its responsibility. The CRP recognizes the skepticism reflected in the above comments and has attempted in the revised SMD (Section 3.3) to clarify what additional siting provisions and considerations could influence the selection of candidate areas and how these might be assessed. This expanded section also summarizes how PAS may be identified.

COMMENT LETTER REFERENCE: MN-C-17, ME-6, MA-5, NH-7, VT-10, NC-B-4, SC-B-10, and $\mathrm{SC}-\mathrm{C}-10$

Comments:

P. 44 - "A review of qualitative/descriptive literature on the geology of the identified candidate area..." opens the door to the use of qualitative information to sidestep the results of the weighting process in the event that preferred rock bodies are not selected. CRP must assiduously avoid this if the program is to retain credibility. Any consideration of areas should follow issuance of draft Area Recommendation Report and external comment; it should not be done internally prior to issuance of those reports. (MN-C-17)

A review of "qualitative" information and use of implementation guidelines dealing with regionality, diversity or rock types, and diversity of geohydrologic setting could possibly negate the considerable time and effort that the DOE and the States have put into developing a quantitative screening methodology designed to identify suitable areas for additional characterization. (ME-6)

The intent to review qualitative/descriptive literature to possibly exclude candidate areas after they have been found favorable needs clarification. (MA-5) 
This paragraph can be interpreted to mean a number of things, including the elimination/addition of candidate areas. Exactly what is the purpose of this section? (NH-7)

More explanation on the review of "qualitative literature" and its application to the screening methodology is necessary. The way it is currently worded there will be too much discretion given to DOE. (VT-10)

The degree of discretion retained by the DOE through the Screening Methodology as discussed appears to be too great. There should be greater discussion of how qualitative and descriptive literature will be used during candidate area selection to assure the comparability of candidate sites. (NC-B-4)

Pg. 43-44 - Statements within this section indicate that DOE will have a great deal of latitude and discretion in decision making. The proposed undertaking on p. 44--"A review of qualitative descriptive literature on the identified candidate areas to help assure... that the candidate areas warrant further examination"--is an inappropriate basis for selecting candidate areas. This type of evaluation should have been initiated during the national survey. (SC-B-10 and SC-C-10)

\section{Response:}

The CRP's intent in reviewing additional qualitative/descriptive information is simply to determine, based upon the CRP data base reflected in the final RCR or the existing literature at that time, whether any applicable disqualifiers or potentially adverse conditions would substantially affect the recommendation decision. This is designed to be a confirmatory step prior to finalizing the list of areas recommended. The reader is referred to Section 3.3 of this document for a discription of this subject.

With regard to the Maine comment, it is noted that the considerations mentioned will be assessed, as appropriate, after the top 15 to 20 candidate areas have been identified. If it is determined that the intent of the DOE Siting Guidelines could be better met by considering regionality, diversity 
of rock type, and geohydrologic settings, then the CRP would reexamine these areas to determine the trade-offs involved in substituting new areas.

\section{COMMENT LETTER REFERENCE: ME-1}

Comment:

The role and relative importance of the screening exercise in the area selection process is a topic that must be more fully discussed.

We are concerned that only 1 page of the draft methodology document has been devoted to explaining the roles of the three elements involved in the actual area selection process.

We feel strongly that a more detailed disucssion of the area selection process be included in the final screening methodology document.

\section{Response:}

The CRP has attempted to be more definitive in the final SMD regarding those considerations that may influence the selection of candidate areas. It should be noted, however, that the decision process is not a mechanistic process, but rather one that is required to balance technical, regulatory, and other interests, the responsiblity for which rests with DOE. Consequently, the best that can be done is to describe the kinds of considerations that CRP may include in decisionmaking (e.g., geohydrologic setting, diversity of rock type, regionality) and the circumstances and manner in which such considerations may be used in selecting candidate areas. The ARR will fully document the way in which these decisions were made. The draft ARR will be subject to state review and comment. Identification of candidate areas occurs only when the ARR is issued as a final document. 
Comment:

Pg. 43-44 - In selecting candidate areas, state consultation is not envisioned until after completing a review of Screening Methodology, a literature review and review of implementing guidelines. Screening by this method could be completed in advance of a RCR being issued and thus not depend upon quantitative data that may exist. Then the only state consultation would be for review of the Draft Area Recommendation Report. Additional consultation is essential before an ARR is drafted and identified areas polarized against the process. The coming year will be crucial for DOE to build public confidence in the fairness of the process and it must be done in advance of drafting the ARR.

\section{Response:}

The CRP has structured a region-to-area screening process that includes state involvement at key points throughout. The states have been directly involved (through three workshops and review of the draft SMD) in methodology development, and also in the formulation and finalization of the screening data base (Steps 1 through 3) through their review and comment on the RCR. The states will be invited to assist with the development of representative sets of weights to use in screening through an additional workshop. Finally, the states will be given an opportunity to review and comment on the draft ARR before those decisions are finalized. The CRP agrees that state involvement is important in building public confidence, and believes that the process described above should effectively accomplish this objective. 
EECTION/TOPIC AREA: 4.1 Disqualifying Factors from the General Siting Guidelines

COMMENT LETTER REFERENCE: MI-A-30

Comment:

What is the rationale for limiting the consideration of "significant pathways" to those created by activities related to commercially important resources? Aren't significant pathways "pathways" regardless of the reason for which they were created? We suggest that the DOE provide more discussion on this factor in the final document, including any effect of limiting consideration to activities related to commerical exploration.

\section{Response:}

The rationale for limiting the disqualifying factor related to natural resources, for the purpose of region-to-area screening, to those of commercial importance is one of degree and magnitude. For purposes of region-to-area screening, test pits, drill holes, etc., are not considered "significant pathways". Only resources that are commercially important and have resulted in extraction operations are considered within this disqualifying factor (Deep Mines and Quarries) at this time. Extraction activities that require or have required dewatering would have significant effects on the local ground-water hydrology. Those mines and quarries of such magnitude that extraction has resulted in significant man-made pathways or has affected the geohydrology such that loss of isolation could result would be disqualified.

The text of the final SMD has been rewritten to clearly state the rationale for this disqualifying factor. 
COMMENT LETTER REFERENCE: MI-A-31, NJ-8, and NJ-10

Comments:

10 CFR 960-4-2-5(d) does not require, as suggested here, that the DOE evaluate potential erosional effects. The Siting Guidelines require that the DOE disqualify any rock body where conditions do not allow all portions of the underground facility to be situated at least 200 meters below the directly overlying ground surface. Since this is a disqualifying factor, the DOE should consider applying the proposed Step 2 variable, Thickness of Rock Mass, as a disqualifier wherever data are available. (MI-A-31)

If 10 CFR 960.4-2-5(b)(1), which states "Site Conditions that permit the emplacement of waste at a depth of at least 300 meters below the directly overlying ground surface", can be considered in region to-area screening, then it is not clear why 10 CFR 960.4-2-5(d) also cannot be considered. (NJ-8)

Also in the Screening Methodology on (p. 49) there is reference to "a depth limitation for the underground facility of at least 300 meters below the overlying ground surface..." It is our understanding from the guidelines that the "emplacement of waste" must be "at a depth of at least 300 meters below the directly overlying ground surface." (Presumably these are non-waste isolation portions of the facility.) Please clarify this and why a site may not be disqualified if found that the waste cannot be "isolated" at least 300 meters below the directly overlying surface or the underground facility at least 200 meters below the directly overlying surface if erosion processes will affect such depths. (NJ-10)

\section{Response:}

Appendix III of the DOE Siting Guidelines explains how the disqualifying conditions must be applied to determine if a site is potentially acceptable. The determination of potential acceptability is accomplished by evaluating the data available for the disqualifying conditions and assessing whether the available evidence does or does not support a finding that a site is 
disqualified. Section 4.1 summarizes the 17 disqualifying conditions from the DOE Siting Guidelines, and identifies the 10 for which a finding is required by Appendix III to determine if a site is potentially acceptable.

The following discussion specifically addresses the erosion disqualifier not used in Step 1 of the region-to-area screening methodology.

This postclosure disqualifying condition is related to the concern that if the underground facility were not situated at least 200 meters (656 feet) below the overlying ground surface, this might allow surficial erosional processes to affect the facility and induce unacceptable radionuclide releases. In the event CRP has data from which it can be determined that a rock body (or portion thereof) is less than 200 meters (656 feet) in depth, such areas will be disqualified.

The favorable condition for erosion from the DOE Siting Guidelines [ 10 CFR 960.4-2-5(b)(1)], is as follows: Site conditions that permit the emplacement of waste at a depth of at least 300 meters ( 984 feet) below the directly overlying ground surface. Accordingly, the DOE Siting Guidlines do not require disqualification if emplacement of wastes were to occur at depths between 200 and 300 meters (656 and 984 feet).

\section{COMMENT LETTER REFERENCE: NJ-11}

\section{Comment:}

It is the conclusion of the project review team based on experience of the Geological Survey, that in looking at certain mineralogical assemblages within the crystallines that dissolution does take place in crystalline rocks. There are specific well records that show that certain mineralogical occurences, such as a mixed gneiss sequence, will have yields of 100 to 500 gallons a minute. However the disqualifying condition should not be considered at the regional phase because of the lack of a consistent data base. The dissolution disqualifying condition should be considered at the area or site phase where sufficient data can be applied.

Please supply us with any data used to determine that dissolution does not occur in crystalline rock, since our geological staff believes that it bes occur under certain circumstances. 
Response:

The magnitudes and rates of dissolution are such that it is not a concern in the context of the application of this disqualifying condition for crystalline rock (Barnes, 1979). Accordingly, it is expected that no finding supporting disqualification will be made at any phase of the siting process.

\section{COMMENT LETTER REFERENCE: NJ-12}

\section{Comment:}

If seismicity, faulting, and "other tectonic processes", such as landslides, subsidence and earthquakes can be considered as Step 2 screening variables under 10 CFR 960.4-2-7(b and $c$ ) and 10 CFR 960.5-2-11(b and $c$ ), then it is not clear why such conditions cannot act as disqualifiers under 10 CFR 960.4-2-7(d) and 10 CFR 960.5-2-11(d). The DOE Siting Guidelines define tectonics as "the branch of geology dealing with the broad architecture of the outer part of the Earth, that is, the regional assembling of structural or deformational features and the study of their mutual relations, origin and historical evolution". This definition clearly points out that tectonic processes, as mentioned above, pertain to regional geologic structural features. It seems logical that such regional processes be reviewed at a regional phase.

\section{Response:}

The DOE Siting Guidelines include these two geologic disqualifying conditions. Appendix III of the DOE Siting Guidelines explains how these two disqualifying conditions must be applied to determine if a site is potentially acceptable. The determination of potential acceptability is accomplished by evaluating the data available for these and other disqualifying conditions and assessing whether the available evidence supports a finding that a site is disqualified. 
The CRP determined that 5 of the 10 disqualifying conditions (including the two tectonic conditions) could not be directly applied in Step 1 of the region-to-area screening methodology because sufficient regional data are not available in a form that allows their systematic application without evaluation/interpretation. Prior to identification of PAS, the CRP will be required to make a finding for these disqualifying conditions.

It should be noted that tectonism is addressed as a Step 2 variable in region-to-area screening in the Seismicity, Quaternary Faulting, and Postemplacement Faulting variables in Sections 5.2.4, 5.2.5, and 5.2.6, respectively, of this document. These three variables incorporate the favorable condition for tectonics from the DOE Siting Guidelines [10 CFR 960.4-2-7(b)], which states that it is considered favorable if the nature and rates of tectonic processes operating during the Quaternary Period would, if continued, have less than one chance in 10,000 of leading to release of radionuclides to the accessible environment during the first 10,000 years after closure. Similarly, the favorable condition for tectonics from the DOE Siting Guidelines [10 CFR 960.5-2-11(b)] states that it is considered favorable if the nature and rates of faulting within the geologic setting are such that the magnitude and intensity of the associated seismicity are significantly less, though generally allowable for construction and operation of nuclear facilities.

COMMENT LETTER REFERENCE: MI-A-32

\section{Comment:}

P. 50 - The DOE should examine the aspects of atomic energy defense that would justify treating those activities differently than civilian activities, which could also result in the need to evaluate or present the prospect of increased population dose. 
Response:

The citation on page 50 of the draft SMD is correct in terms of the language used in the disqualifier in the DOE Siting Guidelines (10 CFR 960.52-4(d)). Prior to identification of PAS, the CRP will be required to make a finding on this disqualifying condition. An evaluation of cumulative population dose from a proximate commerical reactor and from a repository (10 CFR 960.5-2-4(a)(2) and (c)(2)), respectively, requires site-specific information and cannot be addressed at the regional phase. There is a disqualifying condition related to evacuation (10 CFR 960.5-2-1(d)(3)). However, per Appendix III of the DOE Siting Guidelines, a Level 1 finding on this disqualifying condition does not have to be made prior to identification of PAS. As a result, this disqualifying condition is not mentioned in Section 4.1.

COMMENT LETTER REFERENCE: $N J-4$

\section{Comment:}

In Table 2 - Summary of Disqualifying Conditions (p. 46) there seems to be no indication as to whether or not these (ground-water travel time) data are available for region-to-area screening. If such data are not used in regional screening, such a disqualifying condition must be used in area screening because it is imperative to assure complete isolation of high level radioactive waste from groundwater and preclude any opportunity for groundwater contamination.

\section{Response:}

For those disqualifying conditions for which a finding is not required prior to identification of PAS (i.e., 10 CFR 960.4-2-1(d)), the assumption is that data necessary are not available at the regional scale. A finding relative to 10 CFR $960.4-2-1$ (d) is not required until nomination and recommendation. 
Comment:

P. 47, Table 2 - Sumary of disqualifying conditions; the regional screening will be based on

1. significant mining (deeper than $100 \mathrm{~m}$ )

2. population

3. national and/or state parks.

Are these factors sufficient to screen to the area level without having to use the additional factors which the DOE has admitted, in this report, as having insufficient data upon which to base the screen?

\section{Response:}

The disqualifiers noted in Table 3 (Table 2 in the draft SMD) plus the Steps 2 and 3 regional screening variables described in Sections 5.2, 5.3, and 5.4 , the application of weights, the qualitative/descriptive literature review, and the application of implementation guidelines (as appropriate) are considered to provide a sufficient basis to select candidate areas. 
SECTION/TOPIC AREA: 4.2 Implementation Guidelines

COMMENT LETTER REFERENCE: MN-C-18 and VT-12

Comments:

The discussion of regionality and its consideration in the screening methodology is still inadequate...

1. How might regionality be considered in the context of the region-toare a screening and the relationship of those areas selected to the first repository nominated sites?

2. Will regionality be considered in the context of area distribution among the three crystalline regions? (MN-C-18)

The regionality discussion ignores the NWPA section which states that several sites from the first repository selection process can be considered on the second repository process. (VT-12)

\section{Response:}

The text of the final SMD (specifically Section 3.3) has been modified to describe CRP's consideration of regionality.

The text of Section 4.2. has been changed to reflect the Vermont comment.

\section{COMMENT LETTER REFERENCE: $N J-44$}

\section{Comment:}

This, however, leaves several guidelines not referred to such as the Basis for Site Evaluation 960.3-1-5. This section states that "A site shall be disqualifed at any time during the siting process if the evidence supports findings by the DOE that (1) a disqualifying condition exists or (2) the qualifying condition of any system or technical guidelines cannot be met". To be consistent with the goals of elimination of inappropriate sites as early 
possible, this guideline should apply. However, this section, as with many others, is not referred to in the Screening Methodology for inclusion or exclusion in regional screening. There is a need for clarification on applicable guidelines.

\section{Response:}

Section 3.1 of the SMD does identify those implementation guidelines to be reviewed during selection of candidate areas. Included is 10 CFR 960.3-15, Basis for Site Evaluation. Section 4.2 has been revised to be consistent with Section 3.3.1.

COMMENT LETTER REFERENCE： VT-11

Comment:

What is the geohydrologic diversity in the three conterminous regions under consideration by the CRP?

\section{Response:}

Several possilbities exist for the definition of geohydrologic setting. For example, if geohydrologic diversity is considered to be related to the delineation of "major ground-water regions" as defined by the USGS (Heath, 1984), then there would be five geohydrologic settings occurring in the three crystalline regions. If geohydrologic diversity is considered to be related to the delination of "drainage basins" as described in the RGCR, then there would be significantly more geohydrologic settings occurring in the three crystalline regions. At this time, CRP has not determined the definition it will apply. 
Comments:

Remove reference to Mississippi River as east-west divider since it does not accurately distinguish the geographic location of the first repository study sites from the CRP regions; as presented (p. 53) one might interpret DOE to mean that one repository will be on each side of the Mississippi River. (VA-A-8)

Even though all previous discussions have said that crystalline rock would be considered along with certain Repository 1 candidate sites for Repository 2, this paragraph states clearly that a crystalline rock mass, east of the Mississippi River will be selected for the second repository. This question goes against all the consultation taking place up to this time and raises a question of objectivity for the methodology as we 11 as the entire siting process. (VA-B-11)

\section{Response:}

Reference to the Mississippi River has been removed and the text has been modified to reflect that sites for the second repository may come from sites being considered for the first repository program (except for those sites nominated but not recommended for site characterization) and from the CRP. 
COMMENT LETTER REFERENCE: VA-B-17

Comment:

"Presence of Ground Water Sources..." - This condition is site specific in crystalline rocks; how can it be screened in advance on a region-to-area basis?

Response:

In the Southeastern Region, these data cannot be applied on a region-toarea basis because the avaialable data would require interpretation to conform to the scale. In the area phase, well data for all regions using county-level information will be examined to determine if it can be applied. 
SECTION/TOPIC AREA: 4.4 Preclosure Guidelines

COMMENT LETTER REFERENCE: MI-A-34

Comment:

P. 58 - The choice of only critical habitat and wetlands to represent this siting guidelines factor is insufficient. The Siting Guidelines (as drafted) seem to clearly require identification of potential conflicts with state laws such as Michigan's Act 113, P. A. 1978, prohibiting disposal of radioactive waste, and other environmental laws, such as Michigan's Environmental Policy Act, granting standing to bring suit for actual or threatened damage to the environment.

No effort has been made by the DOE to identify potential conflicts with State or local laws. We suggest that, if this siting guideline is to be meaningfully considered, it must be addressed at the region-to-area phase.

\section{Response:}

The intent of Section 4.4 (and Section 4.3) is to identify the relationship between the specific provisions of the DOE Siting Guidelines and the disqualifying factors and screening variables used in the region-to-area screening methodology. It was not meant to imply that this was the only relationship possible.

The CRP agrees that state or local laws must be addressed in the siting process. A statutory review of state laws has been undertaken to determine comparable significance with statutes establishing the Federal Park System, Federal Wilderness Preservation System, Federal Wildlife System, and Federal Wild and Scenic Rivers System. Other state and local statutes (or 1aws) will be evaluated at the area and site phases as part of the assessment required by 10 CFR 960.5-2-5(c)(1). The sheer number of these and the difficulty in determining compliance (or noncompliance) at a regional phase prohibits their consideration in region-to-area screening. 
SECTION/TOPIC AREA: 5.1.1 Federal-Protected Lands

COMMENT LETTER REFERENCE: MI-A-35

Comment:

Under Natural Wildlife Refuge System, it is not clear what is meant by " 0 Protection for Species Threatened with Extinction".

\section{Response:}

The "o" was an editorial bullet and does not refer substantively to level of protection for species threatened with extinction. It has been removed from the final SMD.

COMMENT LETTER REFERENCE: MI-A-39

Comment:

...Why is the DOE unable to map... federal protected lands less than 320 acres in size?

\section{Response:}

As noted in an earlier response, the CRP has made a decision that at a 17-state scale, a 1-square-mile grid cell is an appropriate unit of measure. On a 1:1,000,000 map necessary to cover the 17 states, 1 -square mile is $1 / 16$ by $1 / 16$ inch. The RECR list the Federal-protected lands smaller than 130 hectares (320 acres) in Appendix A. For discussion of Step 1 disqualified features less than 320 acres in size, the reader is referred to CRP's response to WI-3 and $\mathrm{NJ}-55$ (see page A-60 and A-61). 
SECTION/TOPIC AREA: 5.1 .2 Components of National Forest System

COMMENT LETTER REFERENCE: WI-9 and NH-1

Comments:

Pp. 67-69 - The discussion here and subsequently on pg. 92 and 93 provide additional reasons for maintaining our original position that all national forest lands should be categorically excluded. It is unacceptable that special management areas for recreation are mentioned as areas which should not be disqualified in the region-to-area screening. (WI-9)

Treatment of National Forests, specifically the White Mountain National Forest. It should be disqualified.

New Hampshire's previous comments regarding the disqualification of the White National Forest are still valid. (NH-1)

Response:

The CRP continues to believe that only the presence of the restricted area or repository support facilities within the boundaries of research natural areas, primitive areas, and national recreation areas within the National Forest System would categorically represent an irreconcilable conflict of use and, hence, result in disqualification under 10 CFR 960.5-2$5(d)(3)$. At the regional phase of investigation, the CRP cannot make the determination that multiple-use components of the National Forest System represent an irreconcilable conflict of use with repository development. 


\section{COMMENT LETTER REFERENCE: NH-8}

Comment:

The discussion uses the term "primitive area" as components of the National Forest Lands. It is assumed that this term means the same as the "designated wilderness areas" and does not exclude the latter.

\section{Response:}

"Primitive areas" are administratively designated areas found only on National Forest Lands. "Wilderness areas" are congressionally designated areas that may occur on any of the major Federal land systems. 
SECTION/TOPIC AREA: 5.1 .3 State-Protected Lands

COMMENT LETTER REFERENCE: MI-A-39

Comment:

...Why is the DOE unable to map state... protected lands less than 320 acres in size?

Response:

As noted in an earlier response, the CRP has made a decision that, at a 17-state scale, a 1-square-mile grid cell is an appropriate unit of measure. On a 1:1,000,000 map necessary to cover the 17 states, 1-square mile is $1 / 16$ by $1 / 16$ inch. The RECR list the state-protected lands smaller than 130 hectares ( 320 acres) in Appendix B. For discussion of Step 1 disqualified features less than 130 hectares ( 320 acres) in size, the reader is referred to CRP's response to WI-3 and NJ-55 (see page A-60 and A-61).

COMMENT LETTER REFERENCE: WI-10

Comment:

As with national forest lands, the only way to avoid the arbitrary application of the comparable significance and irreconcilable conflict standards is to categorically exclude state protected resources.

\section{Response:}

The CRP has developed a region-to-area screening methodology which is based on application of the DOE Siting Guidelines. Application of 10 CFR 960.5-2-5(d)(3) limits disqualification of state lands to those that are comparably significant to either the National Park System, the National Wildlife Refuge System, the National Wilderness Preservation System, the 
National Wild and Scenic Rivers System, or National Forest Lands and that are dedicated to resource preservation and represent an irreconcliable conflict of use with the repository restricted areas and support facilities. Evaluation of all state-protected lands was determined not to be practical at the regional phase. The CRP is fully committed to evaluation of other stateprotected lands at the area and site phases, and the screening status such lands will receive will be based on an evaluation of pertinent provisions of the DOE Siting Guidelines and applicable Federal and state law.

COMMENT LETTER REFERENCE: NY-A-1, NY-A-2, and NY-A-3

Comments:

...It is unclear whether the 2.4 million acres of State Forest Preserve within the Adirondack Park, required by the Constitution of the State to be "forever kept as wild forest lands", inalienable, and from which the timber may not be sold, removed, or destroyed, has been considered a "wilderness area" or "park," thus disqualified, or a "State forest," thus only a Step 2 variable... (NY-A-1)

It should be noted that the entire Adirondack Forest Preserve in the National Register, and (if the Forest Preserve is not itself already disqualified) is entirely appropriate for use as a disqualifying factor in the region-to-area phase.

New York State considers that the State Forest Reserve's location within the Adirondack Park warrants its disqualification. (NY-A-2)

Following the Draft Screening Methodology's rationale for federal lands (p. 65), Class I status would disqualify the entire Adirondack Park. (NY-A-3)

\section{Response:}

The entire Adirondack State Park will be disqualified from consideration the location for the repository restricted area and support facilities. 
SECTION/TOPIC AREA: $\quad 5.1 .4$ Population Density and Distribution

COMMENT LETTER REFERENCE: MI-A-36, ME-11, and NJ-25

Comments:

P. 69 - The bottom 1 ine references the abbreviations "MCD" and "CCD", which are not defined but are presumed to mean "minor civil division" and "county census division", respectively. (MI-A-36)

The process used for calculation of mean population density was not described. We would like to see some elaboration of the method used for these calculations, especially in areas where minor civil divisions have been subdivided by the Bureau of the Census and contain census designated places (whether they have populations greater than 2,500 people or not). (ME-11)

Population density estimates should be based on minor civil divisions which are commercially available. (NJ-25)

\section{Response:}

The SMD text has been changed to identify minor civil divisions (MCD) and census county divisions (CCD).

Population for MCD and CCD are available in published form from the U.S. Bureau of the Census. The same information is available from the Census Bureau on tape (Master Area Reference File, or MARF). The MARF tapes were used to obtain the population numbers. Computer tapes containing digitized boundaries of MCD and CCD were purchased from a commercial source (Rand McNally Corporation). Files from the two tapes were merged to form a master tape. The population density of each MCD/CCD was calculated by dividing the number of persons by the area, resulting in persons per square mile. Population and area of incorporated places and census-designated places within $M C D / C C D$ are included in the calculations (except where the Census Bureau has treated census designated places as independent MCD). The application of the approach may result in an overestimation of the land area to be disqualified 
Comments:

The data base available from Rand McNally Corporation, while perhaps comnercially available, probably has been developed using census definitions. If so, this solution is unsatisfactory, as centers of population in New England will be treated differently from those in other areas within the 17 states. (NH-9)

Section 5.1.4, "Population nistribution and Density", should be considered together with Section 5.3.2, "Population Density" and 5.3.11, "Proximity to Higher Populated Areas". All three sections use the same threshold: 1,000 or more persons per square mile.

The methodology repeats an error made by the Bureau of the Census. Under the Census practices, cities in Rhode Island are recognized as incorporated places, but towns are not. There is, in fact, no difference in the incorporated status of cities and towns under Rhode Island law. The reference to "minor civil divisions" in all three sections should be interpreted as applying to both cities and towns. That interpretation should be made clear in the methodology. (RI-12)

\section{Response:}

The DOE Siting Guidelines (10 CFR 960.5-2-1(d)) state that a site shall be disqualified if:

(1) Any surface facility of a repository would be located in a highly populated area; or

(2) Any surface facility of a repository would be located adjacent to an area 1 mile by 1 mile having a population of not less than 1,000 persons as enumerated by the most recent United States census.

A highly populated area is defined in DOE's Siting Guidelines, as "any incorporated place (recognized by the decennial reports of the U.S. Bureau of the Census) of 2,500 or more persons or any census designated place (as defined and delineated by the Bureau) of 2,500 or more persons, unless it can 
be demonstrated that any such place has a lower population density than the mean value for the continental United States (which was 64 persons per square mile based on the 1980 census). Counties or county equivalents, whether incorporated or not, are specifically excluded from the definition of 'place' as used herein."

The CRP region-to-area screening methodology disqualifies highly populated areas as defined above and areas of 1,000 or more persons per 1-milesquare area as a possible location for a surface facility. Application of these disqualifying factors during the regional screen reflects the coincidence and adjacency conditions of Section 112(a) in the Nuclear Waste Policy Act of 1982 (42 USC 10101, 1983) and 10 CFR 960.5-2-1(d).

COMMENT LETTER REFERENCE: NJ-24 and GA-A-19

Comments:

The identification of highly populated areas should use 1980 census data. (NJ-24)

When DOE commences the region-to-area studies, census data will be five or more years old. DOE needs to document and identify how this issue is to be handled. (GA-A-19)

\section{Response:}

The population data base for the region-to-area screening is the United States 1980 census. Estimates of population between the decennial census periods involve projections, which will be made at the area and site phases of investigation. 
SECTION/TOPIC AREA: 5.1 .5 Hydrologically Significant Natural Resources 1

COMMENT LETTER REFERENCE: MI-A-37

Comment:

The factor seems to be intended to address both 1) areas where the integrity of the geologic deposit has been disrupted and 2) areas where disruption is likely to occur, but results in doing neither. As we suggested earlier disruption of the hydrologic regime is independent of the purpose for which the disruption occurred. How depth of a mineral deposit serves as a surrogate for existing disruptions is not entirely clear... How was the 100 meter depth limitation chosen?

\section{Response:}

The disqualifying factor has been redefined to address only active or inactive mines or quarries deeper than 100 meters (328 feet). One hundred meters (328 feet) is an appropriate measure for region-to-area screening of whether extraction of a resource was likely to affect the regional groundwater regime. The rationale for this depth is the fact that local ground-water flow in crystalline rock occurs in fractures common to depths of about 100 meters (328 feet) (see Section 5.1.5. of the SMD).

COMMENT LETTER REFERENCE: $M I-A-38$ and MI-A-40

\section{Comments:}

Also, does DOE intend to map such features as oil and gas wells to address this factor? (MI-A-38)

1 This section has been retitled "Deep Mines and Quarries" in the final SMD. 
...Must the mineral deposit be greater than 320 acres in extent to warrant consideration under this factor? (MI-A-40)

\section{Response:}

0il and gas wells will not be mapped during the regional phase. Deep mines and quarries were considered and mapped as point sources, regardless of size, for purposes of region-to-area screening. $0 i 1$ and gas wells, test bores and similar intrusions will be considered in subsequent screening phases.

\section{COMMENT LETTER REFERENCE: $M N-C-19$}

Comment:

The explanatory information on the hydrologically significant natural resource disqualifier is confusing because it does not differentiate between historical and future disturbance... The measure discussion appears to focus on future extraction risk that could be avoided by siting away from known deep resources. Do significant pathways need to already be present in order to apply the disqualifier, or can the disqualifier also be applied if a proven resource is present but lacks such pathways? If it is not possible to have a known or proven resource without such pathways, then the wording should be altered to more clearly reflect what the disqualifier applies to and what the definition of a proven resource is.

\section{Response:}

The disqualifier has been revised to consistently address only active or inactive mines or quarries deeper than 100 meters (328 feet). Proven but undeveloped resources are no longer considered in this disqualifying factor. For a rationale regarding the limitation of this disqualifying factor to deep mines and quarries and a discussion of the issue of significant pathways see Section 5.1 .5 of the SMD text. 
Comment:

"Hydrologically Significant Natural Resources" is too restricted based upon the definition and significance discussion. We consider in Vermont, where there are so many rural households where water is derived from fractured crystalline rocks, wells greater than $100 \mathrm{~m}$ to be of hydrologic significance equal to rock and mineral resources at the same depth.

\section{Response:}

The CRP recognizes that this disqualifying condition ultimately requires consideration of ground water as a natural resource. However, CRP has determined that for purposes of region-to-area screening, application of this disqualifying condition would be limited to deep mines and quarries and does not include ground-water resources. Furthermore, ground-water resources are included as a Step 3 variable.

COMMENT LETTER REFERENCE: NC-B-13, SC-B-12, and SC-C-12

Comments:

The DOE admittedly used 100 meters as a somewhat arbitrary measure for the disqualification of hydrologically significant natural resources. A strong case can be made for the use of 50 meters as the disqualification because of interconnections with the deep groundwater regime. This should be thoroughly evaluated on the basis of state experiences. (NC-B-13)

The $100 \mathrm{~m}$ depth for exclusion of a site is indeed "rather arbitrary" as the methodology discussion admits. Conceivably, excavations of half this depth could affect the deep groundwater regime. DOE should establish this disqualifying excavation depth at a maximum of $50 \mathrm{~m}$. (SC-B-12 and SC-C-12) 
Response:

The CRP does not disagree with the suggestion that 50-meter (164-foot) deep excavations could conceivably affect deep ground water. However, it is more likely that deeper excavations, on the order of 100 meters (164 feet) or more, would influence ground water at proposed repository depths. The 100meter (164 foot) depth is an appropriate value for regional-to-area screening (the rationale for this depth appears in Section 5.1.5 of the SMD). During the area and site phases, actual data will be collected and tests will be conducted to determine whether significant pathways exist between the repository and any nearby resources.

COMMENT LETTER REFERENCE: SC-B-13 and SC-C-13

Comments:

The DOE/OCRD definition of "Hydrologically Significant Natural Resources" should include groundwater resources, along with conventional rock and mineral resources, that potentially would be extracted. We suggest an addition to line 3 of the definition"... undeveloped resources, mineral fuels, and drill holes for water wells."

Response:

The CRP recognizes that this disqualifying condition ultimately requires consideration of ground water as a natural resource. The disqualifying factor has been limited to deep mines and quarries for purposes of Step 1 of the region-to-area screening methodology because CRP does not believe that water wells or drill holes represent the same potential for significant impacts on the hydrogeology of deep ground-water flow systems when compared to major dewatering of deep mines or excavations. Water well yields are considered under the Step 3 variable on ground-water resources in Section 5.4.4 of the final SMD. As previously noted, the CRP cannot apply this Step 3 variable to the Southeastern Region (see CRP response to VA-B-17 on page A-123). 
COMMENT LETTER REFERENCE: MI-B-1

Comment:

It is our belief that the presence of this system (U.S. Navy's extra low frequency communications system - Project ELF) renders the rock body designated $\# 9$ on the map provided by your office unsuitable for further consideration as a potential host for a high-level radioactive waste repository. We believe that it would be virtually impossible to assess the environmental, geologic, and socioeconomic effects or the strategic and tactical implications of estabiishing and operating a repository in close proximity to ELF Communication System.

\section{Response:}

An evaluation of the potential interactive effects between the ELF Communication System and a geologic repository will not be undertaken at the regional phase. This is because the relevant provisions of the DOE Siting Guidelines (10 CFR 960.5-2-4) require site-specific information, of not only the offsite installation but the geologic repository as well, in order to make the determinations required in 10 CFR $960.5-2-4(a)(1),(c)(1)$. It is CRP's position that if any of the candidate areas are coincident with or proximate to an atomic defense energy activity, a nuclear facility, or a potentially hazardous facility, then an assessment of potential interactive effects would occur as part of subsequent investigations. 
SECTION/TOPIC AREA: Other Disqualifying Factors (Ground-water Travel Time)

COMMENT LETTER REFERENCE: NJ-3

Comment:

Due to the present huge demand for water by industries, municipalities, and homeowners, there are no potential areas in New Jersey where groundwater travel time is more than 1,000 years. Therefore, areas in New Jersey being considered for repository development would be disqualified.

\section{Response:}

This may be true for shallow aquifers; however, at repository depths, travel times may be considerably longer than 1,000 years. Field hydrogeologic data need to be collected and evaluated before a determination can be made on disqualifying areas on the basis of ground-water travel times. 
SECTION/TOPIC AREA: Other Disqualifying Factors (Areas Designated by Federa) Statute)

COMMENT LETTER REFERENCE: RI-8, RI-9, and RI-10

Comments:

The definition of Federal protected lands should include... additional kinds of areas that apparently would slip through under the present wording:

- National Estuarine Sanctuaries. (RI-8)

- Areas designated for protection under the Coastal Barriers Resources Act (PL 97-348). (RI-9)

- The Narragansett Indian Land Claim Settlement Area (PL 95-395). This area is listed in Appendix B as one which has "...no comparable Federal land with screening status." This statement is obviously incorrect, since the area is established in Federal law and does not require identification of any "comparable" Federally designated areas. $(R I-10)$

Response:

The reviewer is correct that Federal statutes may grant protection to lands even though they may not be specifically referenced in the Nuclear Waste Policy Act or the DOE Siting Guidelines. In this regard, the reviewer is referred to 10 CFR 960.5-2-5(d)(1). In CRP's judgment, direct application of this condition during Step 1 of the region-to-area screening methodolgy was not appropriate. The CRP has, however, included Step 1 disqualifying factors and Step 2 screening variables for Federal-protected lands based on 10 CFR $960.5-2-5(d)(2)$ and $(d)(3)$ and 10 CFR $960.5-2-5(c)(3)$, respectively. During selection of candidate areas, the impact of the above legislation and its provisions will be considered. 
SECTION/TOPIC AREA: Other Disqualifying Factors (Proposed State-Protected Lands)

COMMENT LETTER REFERENCE: $\quad S C-B-39$ and SC-C-37

Comments:

The State Comprehensive Outdoor Recreation Plan is the state's official outdoor recreation plan. This plan includes areas that are now or are proposed to be designated as parks or recreational areas.

One of the areas of special concern and value to our state is the Mountain Bridge Wilderness Recreational Area in the Blue Ridge. A total of well over 10,000 acres will be included in this protected area... The State owned lands in this area are being managed by the South Carolina Department of Parks, Recreation and Tourism, and further evaluation will show this area is analogous to National Parks Units Management Plan... Therefore, state owned lands in this area should be disqualified just as all State Parks are disqualified from siting.

\section{Response:}

As described in Appendix A of the draft SMD, proposed State-protected lands were not used as a region-to-area screening variable for the following reasons:

- The CRP has decided to define the State-Protected Lands disqualifying condition within the administrative boundaries of such land features. Consequently, the most commonly articulated proposed land action, specifically consolidation of private in-holdings into public ownership, is taken care of by disqualification.

- As has been mentioned at the three methodology development workshops, it is extremely difficult to arrive at an equitable and defensible definition of proposed state-protected lands across 17 states with diverse statutes.

- Very few definitive new proposals for proposed state-protected lands have been identified in our extensive data collection efforts. 
In 10 CFR $960.5-2-5(d)(3)$, disqualification of state lands is limited to "any comparably significant state-protected resource... dedicated to resource preservation at the time of the enactment of the Act" (underline added). Futher, as noted in Appendix B, no statutory authority was available for wilderness areas in South Carolina and, therefore, such lands were determined to have no status at the regional phase. 
SECTION/TOPIC AREA: Other Disqualifying Factors (Significant Protected Private Lands)

COMMENT LETTER REFERENCE: $\quad S C-B-40$ and SC-C-38

Comments:

Lands owned by private non-profit organizations with a national perspective for the purpose of resource potential should be eliminated from site consideration at the Area Phase. Just as state and federally protected lands are disqualified, so should Nature Conservatory and National Trust for Historic Preservation properties be disqualified from consideration.

\section{Response:}

As noted in other responses, protected lands not considered at the regional phase of investigation will be addressed at the area and site phases. The CRP believes the only way significant protected private lands could be disqualified is through application of 10 CFR 960.5-2-5(d)(1) (Environmental Quality). Incorporation of this disqualifying condition requires sitespecific data and analysis, and hence, CRP has deferred treatment of this disqualifying condition until subsequent phases, as required. 
SECTION/TOPIC AREA: 5.2 Scaled Geologic Variables (Step 2)

COMMENT LETTER REFERENCE: NJ-21, SC-B-14, and SC-C-14

Comments:

On pg. 71 through 84 , scaled geologic variables to be considered on a regional basis are discussed in terms of their definition, significance, measure, data sources and comments. Tectonics (10 CFR 960.5-2-11(b)(c) is onitted from this discussion and is therefore impossible to comment on. Please provide us with any available tectonics information. (NJ-21)

"Tectonics" is listed as a Regional Screening Variable. However, no detailed discussion of tectonics is included in the screening methodology. (SC-B-14 and SC-C-14)

\section{Response:}

Tectonics as a screening variable was dropped because it was determined through discussion with state geologic personnel at the methodology workshops that an appropriate tectonics variable could not be defined. Unfortunately, all the related text was not eliminatated from the draft SMD. All references to tectonics as a screening variable were removed from the final SMD. Tectonic influence on rock masses is represented in the region-to-area screening by the variables dealing with seismicity and faulting (Postemplacement and Quaternary). Regional tectonic information for all regions is provided in the revised draft $R G C R$. 
SECTION/TOPIC AREA: 5.2 .1 Rock Mass Extent

COMMENT LETTER REFERENCE: MI-A-41

Comment:

A diagram or figure incorporating the Divisions discussed would be helpful.

Response:

A sketch is presented below that may clarify the application of the scale for this variable.

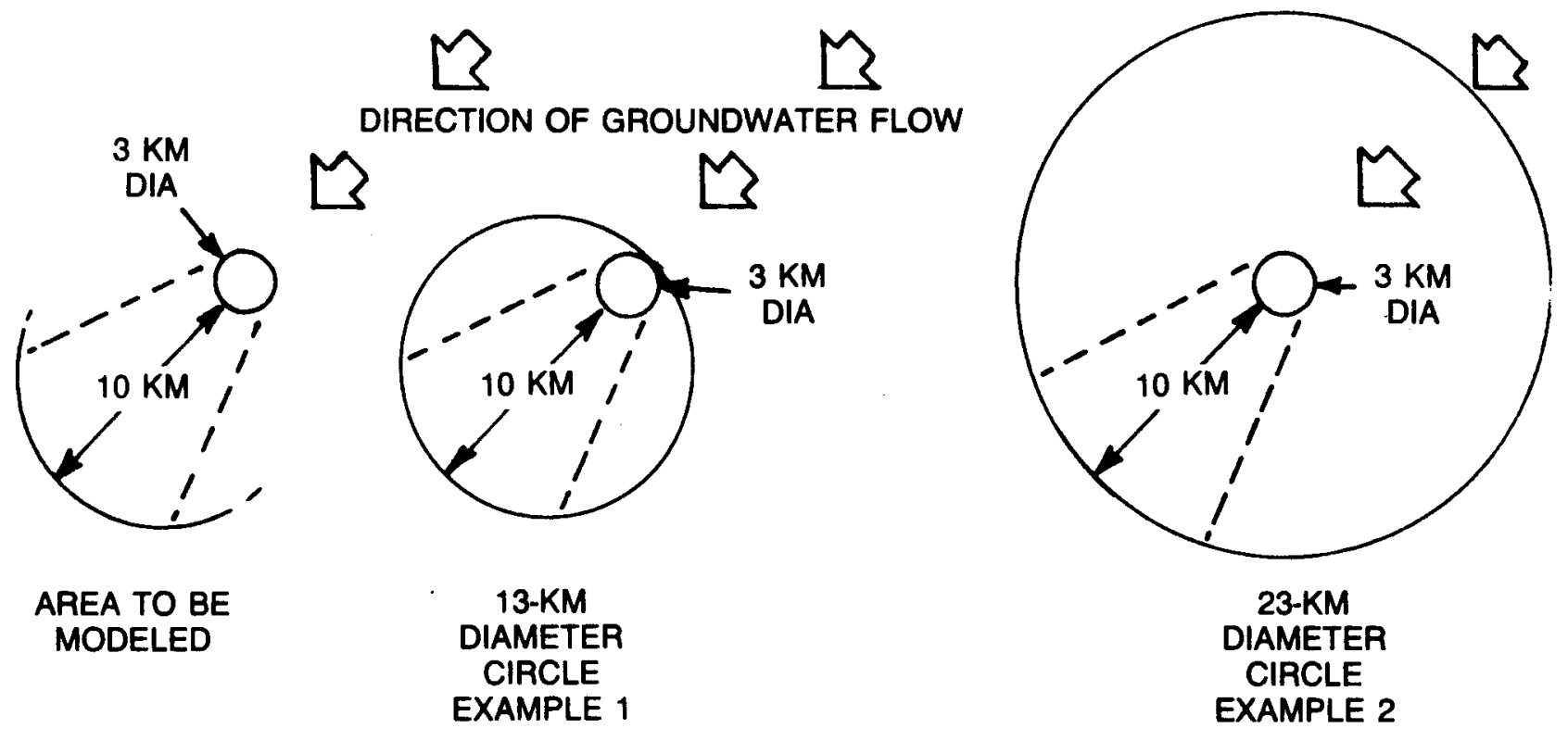

Example 1 Direction of ground-water flow well known; 13-km circle encompasses area to be modeled.

Example 2 Direction of ground-water flow unknown; it could move in any direction, so circle is expanded so that repository can be put in center and circle will encompass flow in any direction for $10-\mathrm{km}$ control zone. 
Comment:

P. 73 - The second bullet describes areal extent which should be defined.

\section{Response:}

The bulleted statement has been rewritten to read: "Included rocks must have a horizontal areal extent of a least 100 square kilometers (38 square miles), as shown on a bedrock map, irrespective of shape."

COMMENT LETTER REFERENCE: MI-A-43

Comment:

This is the first place since p. 22 that scaling is presented, it would be helpful to reiterate that the left end of the scale (1) is more adverse than the right end (5).

Response:

All scales have been annotated to indicate the more adverse and more favorable ends.

COMMENT LETTER REFERENCE: NY-A-27, NC-B-15, SC-B-15, and SC-C-15

\section{Comments:}

P. 74 - The definition for the inclusion of metamorphic rocks as "crystalline" is not sufficient or complete. (NY-A-27) 
While the definition of crystalline rock may be "central" to this guideline, the definition and its use is still being debated because the DOE definition is open to too much "professional judgment" on basic geologic issues. This definition must be tighter and made more universally acceptable/predictable if the siting process is to be effective in identifying the highest quality location for a repository. (NC-B-15)

Under Comments, the first "bullet" refers to the definition of "crystalline" rocks taken from OCRD-1. That definition is unacceptable because it is not rigorous and is not one used within the geologic profession. The definition listed in the Glossary of Geology (Bates and Jackson, 1980, American Geological Institute) is universally recognized, documented and serves as a defensible beginning for the OCRD working definition. (SC-B-15 and SC-C-15)

\section{Response:}

At the level of regional characterization, it is prudent to maintain flexibility in the selection process. Identification and characterization of a broad range of crystalline rock types will provide maximum flexibility to address the provisions of 10 CFR 960.3-1-2 which require consideration of a variety of geologic media so that recommended candidate sites have different types of host rock. The amplification of the "crystalline" rock definition provided in the bulleted portion of p. 73 and continued on p. 74 of the draft SMD (see Section 5.2.1 of the final SMD) provided adequate decision rules for the evaluation of rock bodies for inclusion.

COMMENT LETTER REFERENCE: GA-A-20, SC-B-18, and SC-C-18

Comment:

There is no relationship between the scale on $\mathrm{p} .75$ and the minimum rock body sizes as cited on pg. 72 and $75 .($ GA-A-20) 
The scale on $\mathrm{p} .75$ includes a variable value of 1 which represents a rock body which can include a circle with a diameter of less than or equal to 2 miles $(3 \mathrm{~km})$. This is contradictory with the statement on p. 72: "This minimum size is equal to a circle approximately 2 miles $(3 \mathrm{~km})$ in diameter." (That is the minimum subsurface area). Therefore, less than or equal to 2 miles $(3 \mathrm{~km})$ is an exclusionary value and should not be on the scales. (SC$\mathrm{B}-18$ and $\mathrm{SC}-\mathrm{C}-18)$

\section{Response:}

The scale value ( $\geq 2$ miles) on p. 75 of the draft SMD does not contradict the statement on p. 72 of the draft SMD. The 3-kilometer (2-mile) diameter minimum circle is considered by CRP as necessary to accomodate construction of a repository. Therefore, any rock body or portion of a rock body having a surface area equal to or less than this minimum is considered more adverse relative to rock bodies exhibiting larger surface areas. If the end point of the scale was 3 kilometers ( 2 miles), the only alternative would be to disqualify those surface areas of rock bodies that can not accomodate a circle of at least a 3-kilometer (2-mile) diameter. Because the DOE Siting Guidelines do not include a disqualifying condition on the basis of rock body surface area, the CRP could only consider rock bodies where surface areas are less than the 3-kilometer (2-mile) diameter minimum as an adverse condition.

\section{COMMENT LETTER REFERENCE: GA-A-21}

Comment:

P. 73 - "There is major compositional or structural change" (Emphasis added). Define "major"; the term is vague.

\section{Response:}

The intent in the use of the term "major" is clarified in the same sentence "(i.e., felsic to mafic composition; massive equigranular to gneissic exture, change in foliation...)". 
COMMENT LETTER REFERENCE: GA-A-22

Comment:

P. 73 - "Massive equigranular to gneissic texture." These are textural changes, not compositional or structural changes as stated on p. 73.

\section{Response:}

Textural changes would be implied in the structural change from intrusive granitic (equigranular) to metamorphic (gneissic) rock bodies.

COMMENT LETTER REFERENCE: NC-B-14, SC-B-16, and SC-C-16

Comments:

The use of surface data to measure rock mass extent is still considered questionable in its proposed use, and this calls for greater scaling distances to compensate for its weaknesses and inaccuracy. (NC-B-14)

This section (p. 72) assumes that rock bodies mapped on the surface have vertical continuity into the subsurface--at least--the depth at which a repository would be constructed... However, this assumption is very tenuous when applied to non-plutonic, high-grade metamorphic rocks which are characteristically tilted and folded into the surface. (SC-B-16 and SC-C-16)

\section{Response:}

Surface extent of crystalline rocks is used as a surrogate for actual extent at repository depth. These data are the best that can be collected and applied at the regional phase and are generally valid at a scale of $1: 1,000,000$. In some locales, rock mass extents may be greater than "actual" and, in other cases, less. The mapped extent of rock bodies was based on the best available published data. Many of the data sources used in the rock bodw 
map preparation were recommended as most appropriate by the respective state geological surveys. The predominant portion of the data sources were derived from state and USGS maps and reports. Standard geologic symbols were used to depict the level of reliability and confidence the original mapper indicated was warranted in the field data. Sufficient confidence exists at this regional level to maintain the present scaling distances.

Considering the typical areal extent (over hundreds of square kilometers), the generally thick geologic sections, and the steeply dipping to near vertical attitude of high-grade metamorphic rock bodies mapped in the Southeastern Region, assumptions applied to assess vertical continuity are valid. For later phases of characterization, information from specific field studies regarding the nature of contacts, attitude and orientation of the rock body and depth of extent will be considered.

\section{COMMENT LETTER REFERENCE: NC-B-16}

\section{Comment:}

The scaling measurements proposed would be suitable only if the repository were sited in the center of the measured circles of the scaling process, and the scale ran in four-mile increments from 8-24 over the five scaling values.

\section{Response:}

As the favorability scale progresses from less favorable to more favorable, the potential repository location becomes less constrained. This is explained in the Significance discussion under Rock Mass Extent. 
COMMENT LETTER REFERENCE: $S C-B-17$ and SC-C-17

Comments:

The SMD states that the, "included rocks must have an area extent of at least 100 square kilometers, irrespective of shape (p. 73). This concept has never been adequately explained. If the minimum subsurface area required for a repository is $27 \mathrm{~km}^{2}$ (area of circle with $3 \mathrm{~km}$ diameter), then why is a minimum surface area of $100 \mathrm{~km}^{2}$ required--particularly as the surface facilities will be encompassed within a smaller area than will be the subsurface facilities?

\section{Response:}

A value of 100 square kilometers ( 38 square miles) was used as a minimum size criterion for rock bodies to be included in the regional phase of screening. This was considered desirable since it provided an effective degree of conservatism by allowing for some uncertainity in subsurface dimensions and flexibility in adjusting the location of a candidate area within a given rock body's boundaries as a result of Steps 1 through 3 of the methodology. It should be noted that a candidate area does not have to be as large as 100 square kilometers ( 38 square miles).

\section{COMMENT LETTER REFERENCE: SC-B-36}

Comment:

Pp. A-141-142 - The response to a comment that thickness of rock mass should be a Step 2 variable was negative based on the problem of limited and very scattered data for the thickness of rock bodies. However, this is also true for the areal extent of rock bodies in the subsurface - especially for high-grade metamorphic rocks which dip in the subsurface. Therefore, if the respondent's logic is followed, then areal extent should be a Step 3 variable or thickness should be a Step 2 variable. 
Response:

The Thickness of Rock Mass variable information is very limited for the regional phase; thus, the variable is categorized as a Step 3 variable. This permits the few data points available to be considered on an individual basis for each rock body.

As noted previously, surface extent of crystalline rocks is used as a surrogate for actual extent at repository depth, and this assumption is believed valid at a regional phase. Rock mass extent is measured according to scaled diameters of inscribed circles within the rock body boundary.

COMMENT LETTER REFERENCE: SC-B-37

Comment:

If DOE intends to use either of these variables at Step 2, what assumptions will be used for numeration when data are not available--particularly for high-grade metamorphic rocks?

\section{Response:}

When data are not available for any Step 3 variable, the grid cell will not be scored in those cases (see Section 3.2.5). The assumption used regarding the Rock Mass Extent (Step 2) variable is noted in the preceeding response.

\section{COMMENT LETTER REFERENCE: VA-B-18}

Comment:

P. 75 - How can geologic age be used to delineate external limits of rock bodies? 
Response:

This criterion was used principally in the Northeastern Region. Geologic age data are used to differentiate rocks of dissimilar geologic systems which are adjacent and whose appearance is such that they would otherwise be indistinguishable.

COMMENT LETTER REFERENCE: VA-B-19

Comment:

P. 75 - "Consistency in using state geologic maps." Isn't this really saying that such maps are too generalized for area studies, much less sitespecific studies?

Response:

This will be true for some maps and states and not true for others. The state geologic maps vary depending on map scale, year of compilation, reliability of data sources, capability of the field mappers, etc. Data sources other than state geologic maps were used in the RGCR. Many were recommended by the states. The resulting compilation provides sufficient detail for regional characterization. 
Comment:

P. 75 - It is not clear that the list of areas to be delineated as potential groundwater discharge areas adequately address large fresh-water bodies. We suggest specific mention of the Great Lakes under (4) as follows: "(4) The ocean, the Great Lakes, and their embayments".

\section{Response:}

This section has been rewritten, and the discussion on areas to be delineated as potential ground-water discharge areas has been revised as suggested.

COMMENT LETTER REFERENCE: MI-A-45

Comment:

It is not clear to the uninformed reader what a "cut off point" is. Also, it would be helpful to label the "hinge line" on Figure 13.

\section{Response:}

This section has been rewritten, and the "cutoff point" is now explained. Figure 13 has been revised, and the "hinge line" is no longer used as part of the measure for the variable. 
Comment:

P. 77 - There is insufficient knowledge to state that "groundwater movement in crystalline rock is controlled primarily by topography and geology". We suggest removal of "primarily" from this statement.

Response:

This section has been rewritten and this sentence has been deleted.

COMMENT LETTER REFERENCE: MI-A-47

Comment:

P. 78 - Insert "repository level" between "of" and "groundwater flow" in both locations.

Response:

This section has been rewritten and Figure 14 has been deleted.

COMMENT LETTER REFERENCE: MI-A-48

Comment:

P. 79 - We suggest that addition of post-emplacenent dikes to "... faults, fractures, and foliations..." as a permeable zone in crystalline rocks. 
Response:

Postemplacement dikes have been added as suggested.

COMMENT LETTER REFERENCE: NH-11

Comment:

This discussion as a measure of ground water potential is difficult to understand, extremely weak as a surrogate and highly questionable.

Until it can be shown that this procedure provides the proper protection for ground water resources, New Hampshire withholds its final comments.

\section{Response:}

Major hydrologic recharge and discharge zones have been identified on Plate 4 in the revised draft RGCR. These features, based largely on topography and drainage information, were selected as a surrogate for hydrologic gradients because few data on hydrologic gradients at repository depths are currently available, as indicated in the SMD. These features are potentially connected to ground-water flow at repository depths. Ground-water resources, however, are further considered as a Step 3 variable.

\section{COMMENT LETTER REFERENCE: NJ-19}

Comment:

This criterion specifies that a favorable condition is to have the repository in the recharge zone. An unfavorable condition is to have a site in the discharge zone. As discussed previously such recharge areas have a primary significance in the management and development of water resources in New Jersey. Regulations Establishing Siting Criteria for New Major Commercial Hazardous Waste Facilities in New Jersey state that "New Commercial Hazardous 
Waste Facilities may only be sited in areas where prior to facility construction, the flow of groundwater in the uppermost saturated unit is predominately to or upwards toward the water table and the predominate groundwater flow direction is toward the nearest surface body without any intermediate withdrawals from the uppermost saturated zone for public or private water supply..." N.J.A.C. 7:1-9.8(a). This regulation is important to New Jersey because we cannot afford to have leaks from waste facilities go undetected until the effluent finally "surfaces" many miles from the site. The cleanup task is then magnified many times. Though this regulation does not specifically address radioactive waste, the concept is one we support and urge consideration of in this document.

\section{Response:}

This concept, is not applicable for repository facilities deeply buried at or near the limits of deep ground-water flow systems. In many places, the relationship between shallow and deep ground-water flow systems is not well understood and will require extensive field investigation and modeling to establish on a site specific basis.

COMMENT LETTER REFERENCE: VT-14, NC-B-17, SC-B-19, and SC-C-19

Comments:

The definition of Major Groundwater Discharge Zones is confusing, and its application to the region is questionable based upon the measure presented. The difference between "Major Stream" and "Eligible Stream" is not clear. It is also not clear how the lateral extent of the major discharge zone is to be determined where there is insufficient data to construct groundwater contours. What is the meaning of the cut-off point? Figure 13 appears to ignore it in delineating the discharge zone. This discussion of groundwater flow in crystalline rocks is naive and oversimplified, and thus meaningless for the screening process. (VT-14) 
The definition of major stream should be better defined as it is to be used in identifying major ground water discharge zones. Perhaps flow (intermittent or perennial) would be a more universally acceptable measure. It should also be noted that some major lakes are recharge rather than discharge areas. (NC-B-17)

The use of the point where only three tributaries enter the stream as the upstream "limit" or cutoff point of the discharge zone (stream) is unnecessarily arbitrary. A major stream should be defined by a certain minimum flow or stream order. (SC-B-19 and SC-C-19)

\section{Response:}

Data are insufficient to construct ground-water gradient maps in all of the regions. Thus, the method described in the SMD will be used to identify probable areas of deep ground-water discharge. It should be noted that this variable has been revised to address concerns raised by many of the states (see Section 5.2.2 of the SMD text). The CRP believes that the areas of ground-water discharge have been identified in a conservative manner and, therefore, exceed the area of actual deep-zone ground-water discharge.

The "cutoff" point represents the upstream limit of repository depth discharge to the major stream.

Hydrologic unit maps prepared by the USGS use flow and other discriminators as the basis for identification of major streams. The redefinition of major streams would require considerable additional data compilation and evaluation and would be beyond the scope of the region-to-area screening effort.

It is granted that some major lakes are recharge rather than discharge areas. To assume all major lakes are discharge areas may be overly conservative, but is in line with other conservative assumptions made in the regionto-area screening methodology. 
COMMENT LETTER REFERENCE: GA-A-23

Comment:

The entire variable needs to be reexamined.

The scale used for this variable is non-linear, with irregularly sized zones that will change from drainage basin to drainage basin. There are logical inconsistencies within the scale, and the scale values will not mean the same thing in small versus large basins.

\section{Response:}

The CRP agrees that the scale used for this variable was nonlinear and would produce irregularly sized zones. As a result of this and other comments, the scale for this variable has been revised (see Section 5.2.2 of the SMD text).

COMMENT LETTER REFERENCE: GA-A-38

Comment:

It needs to be recognized that, in glacial and saprolitic terraines, ground-water discharge zones may or may not have any relationship to the ground-water flow regime within the underlying crystalline rock body. He recommend that these relatively shallow flow regimes not be included in any region-to-area screening.

\section{Response:}

The concept of region-to-area screening and the nature of the regional data base precludes consideration or definition of smaller scale ground-water flow features or complexities. The basic assumption of ground-water flow from topographic highs to major basin-centered discharge areas indicates that localized shallow flow regimes will not be considered in the region-to-area screening. 
Comment:

It appears that the current definitions of groundwater discharge zones could, in narrow watersheds, provide for a six-mile Zone 2 which excludes one or both of Zones 3 and 4 (six-mile measurement crosses the "Hinge Line" as defined) but still having a Zone 4 and/or 5 . In spite of this complication that needs to be resolved, we support the concept of a minimum six-mile measurement from the discharge zone to the edge of underground facilities. Incorporating the regional groundwater discharge and six-mile measurement into Zone 1 may be a solution.

Response:

The measure for this variable has been revised and eliminates the complication noted in the comment (see Section 5.2.2 of the SMD text).

\section{COMMENT LETTER REFERENCE: $\quad S C-B-20$ and SC-C-20}

Comments:

Potential groundwater discharge areas are discussed and defined on p. 79; "surface water bodies along the primary stream". This definition should be altered to specifically exclude artificial water bodies, which are usually recharge areas.

Response:

The current definition provides for a more conservative approach which is considered valid at the regional scale where only limited data regarding these artifical water bodies are available (see Section 5.2.2 of the SMD text). 
COMMENT LETTER REFERENCE: SC-B-21 and SC-C-21

Comments:

The simplistic concept of lateral groundwater movement from a topographic high to a topographic low is unrealistic for an area of crystalline rocks. First, most precipitation in an area of crystalline rocks runs off as surface water because soils are thin-to-nonexistent and the rocks are impermeable. Some of the precipitation does become groundwater via fractures (faults, joints) in the rocks; however, the occurrence of fractures is not constrained by topographically high areas. Recharge zones can--and of ten do--occur downslope and downstream from topographic highs.

The SMD partially acknowledges the above considerations, but knowingly proceeds with an unsupportable position.

\section{Response:}

The assumed concept of ground-water movement is a generalization. An improved definition of the complexities of ground-water movement on a more localized scale requires a more detailed data base and more rigorous evaluation of those data. For regional characterization and screening purposes, the data base applied provides the most consistent and uniform level of information within the three regions under consideration.

COMMENT LETTER REFERENCE: SC-B-22 and SC-C-22

Comments:

An interesting note is that if "actual groundwater potentiometric data are available" (p. 77), these data will be used rather than the proposed scheme. This means some rock bodies could be evaluated unfairly if actual data are used to determine the scale value of some while an artificial scheme is used to calculate the scale value for others. 
Response:

The methodology utilizing topography was developed because of an observed lack of regional potentiometric data in the Northeastern and Southeastern Regions (as opposed to the North Central). As it would not be technically defensible to ignore actual data, though limited, it was envisioned that available data would be used in concert with topography to define recharge areas and discharge areas in these regions. This approach allows for a reasonable evaluation of potential ground-water discharge zones within all three regions for purposes of region-to-area screening.

\section{COMMENT LETTER REFERENCE: VA-B-20}

\section{Comment:}

Are crystalline rocks being treated in part as though they are a porous and permeable medium? Water migration through crystalline rocks is controlled by fractures. Migration through individual rock bodies would therefore have to be site specific to have true meaning. Known fracture zones in these rocks could be eliminated from consideration, but the large areas where data are lacking would overshadow the few known areas.

\section{Response:}

This judgement (regarding consideration of crystalline rocks as porous and permeable) is not made in the SMD. In the SMD, it is recognized that flow through crystalline rocks is controlled by fractures. In regional evaluations, a simplistic model (i.e., topographic control of recharge/discharge) is used to approximate ground-water flow. Detailed site studies will be performed during later characterization stages to provide input into sitespecific modeling approaches which incorporate specific fracture data. 
SECTION/TOPIC AREA: 5.2 .3 Rock and Mineral Resources

COMMENT LETTER REFERENCE: MI-A-49

Comment:

P. 80 - "...potential strategic or unique mineral resource..." must be defined. Present data are insufficient to address all "potential" resources, and significant mineral resources are known to occur in crystalline rock in some parts of the world.

Response:

"Potential" has been deleted. The variable does include proven but undeveloped resources.

COMMENT LETTER REFERENCE: MI-A-50

Comment:

Under "Scaling", it describes this variable as a step function. Technically all variables are scaled as step functions. This variable simply has fewer steps.

Response:

The CRP agrees, and the statement has been revised accordingly. 
COMMENT LETTER REFERENCE: $M N-C-20, N H-12, N J-40, N C-B-19, S C-B-23$, and $\mathrm{SC}-\mathrm{C}-23$

Comments:

The rock and mineral resources scales should be revised to allow for five-increment scale consistency with the other screening methodology scales (e.g., wetland or surface water body variables where the CRP has proposed a smaller distance limit). (MN-C-20)

The scale on the noted page does not make much sense. Why not show the Scale value as 1 if within the boundary and 5 if outside the boundary? This would be similar to the type of scale on p. 83. (NH-12)

For example the proposed scales for Rock and Mineral Resources (p. 81) ...do not have five clear ranges. ( $\mathrm{NJ}-40)$

Rather than the distances proposed, we would recommend using zero to two miles (approximate area of underground facilities) as scale value one, and two to eight miles (approximately controlled area and distance to the accessible environment) as scale value three. (NC-B-19)

Pg. 80-81 - "...either a deposit would be present within the site boundary or it would be outside. Additional distance is really not a consideration..." The scale, therefore, should have only two, not three, values. (SC-B-23 and SC-C-23)

\section{Response:}

The CRP scale for this variable was developed to provide a reasonable level of discrimination for the region-to-area screening relating to existing shallow rock and mineral resource extraction activities. The suggested scale revisions provide no advantages over the current scale. Expanding the scale by increasing the more favorable end point is not warranted as it would result possible denial of resources from use. 
Comment:

We recommend that any quarry, regardless of areal extent, be included within the region-to-area screening process.

\section{Response:}

The second sentence of the definition in Section 5.2.3 of the SMD states that "Active or inactive mines or quarries and proven but undeveloped resources would be included." Therefore, any quarry which contained (or contains) strategic or unique resources will be included in the process. No areal extent criteria were used in determining whether a quarry was included or excluded. All commercially significant operations are included.

COMMENT LETTER REFERENCE: VA-B-27

Comment:

P. A-43, "Response" - What is the definition of unique? From what point of view is the term applied; aesthetic, geologic, economic, etc.?

\section{Response:}

Unique is a term used by the Federal government in identifying mineral resources that are found in limited quantities within the boundaries of the United States. The term is applied from a viewpoint of the United States becoming totally self-sufficient for the resources in the event of economic constraints, boycotts, or aggression. 


\section{SECTION/TOPIC AREA: $\quad 5.2 .4$ Seismicity}

COMMENT LETTER REFERENCE: MI-A-51

Comment:

P. 81 - The second to last paragraph should include a statement that similar "additional design efforts" would be applied to repository construction.

\section{Response:}

The statement concerning design of nuclear reactor facilities has not been included in the revised paragraph. Therefore the suggested inclusion was not made.

\section{COMMENT LETTER REFERENCE: MI-A-52}

Comment:

The units for Maximum Probable Ground Acceleration are fractions of $\mathbf{g}$, not percent. Either the units should be changed, or the five scale indices should be changed to reflect percent $\mathrm{g}$.

\section{Response:}

The increment values on the scale have been changed from fractions of $\mathrm{g}$ to percent (\%) $\mathrm{g}$ to be in agreement with data in the revised draft RGCR.

COMMENT LETTER REFERENCE: ME-13, NY-A-28, RI-1, SC-B-25, and SC-C-25

\section{Comments:}

With respect to factors other than horizontal ground motion in assessing ismic risk, we have suggested a number of other variables that could also be used. 
The Algermissen (1982) 90\% probability map for horizontal acceleration is not acceptable for the State of New York. (NY-A-28)

Seismicity and seismic intensity maps have been generated by regional seismic networks and therefore should be considered at the region-to-area level. (RI-1)

In addition, measuring the seismic hazard by using Algermissen's 1982 map may not be appropriate since it has not been well accepted by his peer seismologists. The NRC and Electric Power Research Institute are currently completing methodologies independently for assessing the probability of ground accelerations and spectra for any location east of the Rocky Mountains. This is being done in order to assess the seismic risk at nuclear power plant sites in the eastern U.S. It may be more appropriate to use these assessments. (SC-B-25 and SC-C-25)

\section{Response:}

The Algermissen seismic risk map (Algermissen et al, 1982) has been selected for use in the region-to-area screening because it provides the most consistent data base for the three regions. Admittedly, this map does not consider many factors which are normally used to evaluate seismic risk, such as earthquake frequency and recurrence intervals; however, it is based on historical seismicity and is commonly used to make regional decisions on location of engineered structures. It is CRP's intention to utilize available information on seismic intensity, magnitude, recurrence interval, or ground acceleration during subsequent phases of evaluation. It is beyond the scope of the regional phase, however, to reduce and analyze raw data or to obtain new field data.

To properly evaluate the seismic risk of a specific rock body or a specific location of an engineered structure, one must know such things as previous recorded events in the immediate vicinity, distance to known epicenters, type of materials (rock, soil, etc.) underlying or composing the proposed site or rock body, or level of ground shaking recorded (Richter Magnitude) or felt (Mercalli Intensity) in the vicinity previously. This typ 
of seismic evaluation is more appropriate to selected areas or sites which involve discrete rock bodies or portions of rock bodies rather than regions containing crystalline rock bodies.

At the present time, this map represents a consistent and uniform data base adequate for regional characterization and screening. Even though the position papers currently under development by the NRC and the Electric Power Research Institute will require years of field testing and refinement before a satisfactory acceptable working model is produced, these assessments will be considered, and included as appropriate, as part of the data base to be used in the area characterization phase.

\section{COMMENT LETTER REFERENCE: SC-B-24 and SC-C-24}

\section{Comment:}

P. 81 - The seismicity variable should be defined and measured according to some spectra and duration, and not just $g$ values alone. Some very small earthquakes have produced very high peak $g$ values at high frequencies and short duration. These events have very little energy and thus will not cause structural damage. The spectra may be defined in the NRC 10 CFR 60.12 or DOE 10 CFR 960.4-2-7.

\section{Response:}

As noted, the design of a nuclear waste repository will be developed to meet both the requirements for the technical guidelines in 10 CFR 960 and the technical criteria in 10 CFR 60 (NRC, 1983a). "The tectonic history of a site will be considered" in establishing design parameters for both surface and underground facilities. However, the expected duration and spectra of any probable event for a particular location is indeterminate until a site has been selected as the design tectonic event is dependent on various factors including propagation path geology, source mechanism, local site conditions, and repository layout. For region-to-area screening purposes, the probability the g-value is taken as a representative guide to areas of high seismic 


\section{A-168}

risk. The proposed measure allows a consistent application of data across the three regions; no other existing data base could be so compared. Utilization of earthquake response spectra and duration are not warranted at the regional scale. Application of more detailed earthquake parameters will be considered during later phases as more data become available. 
COMMENT LETTER REFERENCE: MI-A-53, NJ-41, and NJ-42

Comments:

It is not clear why scaling cannot incorporate use of intermediate scale values, e.g.,

\begin{tabular}{ccccc}
$<-5$ & $5-6$ & $6-7$ & $7-8$ & $>8$ \\
\hline 1 & 2 & 3 & 4 & 5
\end{tabular}

For example the proposed scales for ... suspected Quaternary Faulting P. 83 do not have five clear ranges. (NJ-41)

On the proposed scale for Suspected Quaternary Faulting, 4.9 miles is most adverse while 5.1 miles is most favorable. With this scale there are no gray areas - just black and white. (NJ-42)

\section{Response:}

The scale has not been changed. For region-to-are screening, the CRP prefers to use a distance criterion that has been accepted in the past for siting other nuclear facilities.

COMMENT LETTER REFERENCE: MN-C-21

Comment:

Suspected quaternary faulting should be a Step 3 variable due to a lack of data. The reference cited in this section for the five mile maximum (10 CFR 60.122) could not be found in the latest version of 10 CFR 60, June 21, 1983. Even if a reference could be found which states that a distance of five miles is more favorable than distances within five miles, the CRP choice of scales is not supported. There is no reason that scales for 
quarternary faulting should be different than post emplacement faulting in the screening methodology. Therefore, for consistency, the scale for post emplacement faulting should be adopted for quaternary faulting, and the quaternary faulting variable should then be moved to Step 3.

\section{Response:}

Suspected Quarternary Faulting will remain as a Step 2 variable because there are sufficient data to indicate that there are very few suspected Quarternary faults in the three regions. The reference cited in the SMD on the 8-kilometer (5-mile) distance is incorrect and has been deleted. As noted in the previous response, the scale is not being revised.

\section{COMMENT LETTER REFERENCE: NY-A-29}

\section{Comment:}

Post-Quaternary faults pose no greater threat than pre-Quaternary as a function of only their relative age.

\section{Response:}

The CRP agrees in principle. However, questions remain regarding seismic potential of faults in the upper crust. The NRC has continued to support research on this topic, and seismic monitoring of suspected "capable" faults is ongoing. The CRP believes that it has taken a conservative approach.

\section{COMMENT LETTER REFERENCE: NC-B-20, SC-B-26, and SC-C-26}

Comments:

Surface data are not sufficient to identify faults that dip. Therefore, the proposed scaling should be greater than the five miles cited in 10 CFR 60.122 to allow for potential inexactness. (NC-B-20) 
P. 83 - The 5-mile distance measured on the surface is meaningless if the fault plane dips into the subsurface and intersects the repository area. (SC-B-26 and SC-C-26)

\section{Response:}

The near field for earthquake faults is considered by seismologists to be 5 kilometers ( 3 miles). Thus, the use of 8 kilometers ( 5 miles) for scaling is considered to be conservative for suspected Quaternary faults and already allows for considerable inexactness in the location of the surface trace of the fault. In the Southeastern Region, specific data regarding the dip on faults is very limited. Use of the surface trace for regional characterization and screening provides a reasonably consistent methodology.

This variable emphasizes avoidance of zones along which surface rupture or significant fracturing of the rock might occur as the result of an earthquake associated with the fault. To intersect the repository would require a fault plane dip of less than 10 degrees. This is not considered likely for faults more than 8 kilometers ( 5 miles) distant from the controlled area. 
SECTION/TOPIC AREA: $\quad$ 5.2.6 Postemplacement Faulting

COMMENT LETTER REFERENCE: MI-A-54

Comment:

Establishing a minimum length criterion of 15 miles seems to be too restrictive. It is not clear why a much shorter length, say 1 mile, is not used. As presented, a grid cell within 2 miles of a 14-mile fault would be scaled as 5 . If there is a sound geologic reason, it should be explained.

\section{Response:}

The definition has been revised to read: "All faults, shear zones, and zones of brittle deformation of any age, having a length of greater than about 24 kilometers ( 15 miles) or that are shown on small-scale bedrock maps considered accurate by the state geological surveys".

COMMENT LETTER REFERENCE: MN-C-22, NH-13, VT-15, GA-A-2, GA-A-25, and NC-B-21

\section{Comments:}

The supportive reasoning for the new scale divisions for post emplacement faulting should be explained. Why are the distances in unequal increments? What data verify this type of distribution? (MN-C-22)

Scale is not linear. Why is this scale provided in this form? (NH-13)

Distance from fault scale is not internally consistent, and it should be... Distance should be given a three dimensional consideration, not just a two dimensional map plan. (VT-15) 
Section 5.2.6 Post Emplacement Faulting: DOE's proposed scale is as follows:

\begin{tabular}{ccccc}
$0-2$ & $>2-3 \mathrm{mi}$. & $>3-5 \mathrm{mi}$. & $>5-6 \mathrm{mi}$. & $>6 \mathrm{mi}$. \\
\hline 1 & 2 & 3 & 4 & 5
\end{tabular}

For the $\# 1$ (worst case) and $\$ 3$ (median values), the geographic spacing is up to two miles; whereas for the other geographic spacings a one mile interval was chosen. Such a variance in spacings is not logical and can only be considered as arbitrary. (GA-A-2)

This scale is non-linear, illogical, and arbitrary. DOE should not have one set of distance increments for geologic variables and another set for environmental variables... We recommend that DOE use the following scale:

\section{Distance From Facility (Miles)}

\begin{tabular}{ccccc}
$0-2$ & $>2-4 \mathrm{mi}$. & $>4-6 \mathrm{mi}$. & $>6-8 \mathrm{mi}$. & $>8 \mathrm{mi}$. \\
\hline 1 & 2 & 3 & 4 & 5
\end{tabular}

$(G A-A-25)$

The proposed scale for Post-emplacement Faulting is nonlinear. A two mile increment is recommended for each scale value. (NC-B-21)

\section{Reponse:}

The scale has been revised as shown below to penalize areas closer to faults and to make the scale more linear and consistent with other scales in the SMD.

\begin{tabular}{rrrrc}
$0-3$ & $>3-4$ & $>4-5$ & $>5-6$ & $>6 \mathrm{mi}$. \\
\hline 1 & 2 & 3 & 4 & 5
\end{tabular}


Comment:

The definition of fault is insufficient, as many lines of unknown origin are included on various maps, and some geologic maps omit faults unless specifically defined.

Reponse:

With regard to the definition of a fault, as stated in the revised draft RGCR, a conservative approach was taken. If a line shown on the state geologic map was indicated as a feature of uncertain origin but possibly a fault, the assumption was made that it was a fault. Therefore, the screening result based on this variable will be conservative by penalizing areas close to assumed faults.

COMMENT LETTER REFERENCE: GA-A-4

Comment:

We also find it ironic that DOE used a two mile spacing for postemplacement faulting, which is a safety related issue (i.e., brittle structures such as faulting provide pathways for ground-water flow), and a three mile spacing for proximity to federally protected lands, which is really no more than an issue of aesthetics. It seems, on the basis of these two scales, that DOE considers aesthetics issues to be paramount over safety related issues.

\section{Response:}

The scale for the Postemplacement Faulting variable has been changed to be similar to that for Proximity to Proposed Federal-Protected Lands by expanding the more adverse end point and reducing the spacing to 1-mile increments. 
Comments:

Why is it assumed that all crystalline rock bodies are faulted to some extent?

Reponse:

This assumption appears to be valid for crystalline rock bodies because of their geologic age, genesis, and mode of emplacement. Most crystalline rocks have been subjected to high stress fields and thus have experienced brittle and/or ductile deformation simply because they are much older geologically than other types of rocks and may have been subject to multiple tectonic events.

COMMENT LETTER REFERENCE: SC-B-28 and SC-C-28

Comments:

The distance measured on the surface is meaningless (p. 84) if the fault plane dips into the subsurface and intersects the repository area.

\section{Response:}

The use of distance for scaling is considered to be appropriate and conservative in that it allows for considerable inexactness in the location of the surface trace of faults. Specific data regarding the dip on faults are very limited. Use of a zone on either side of the surface trace for regional characterization and screening provides a reasonably conservative buffer. 
COMMENT LETTER REFERENCE: VA-B-21

Comment:

State geologic maps and other small-scale maps may not most accurately represent structural geology, depending upon date of map, level of knowledge at time of map preparation, work subsequent to map publication, interpretational differences, and similar factors.

\section{Response:}

This is true for some maps. Many data sources were consulted to provide information on structural geology in the Southeastern Region. The final maps are believed to represent the current state of knowledge as determined through consultation with the involved states. 
SECTION/TOPIC AREA: Other Geologic Variables (Uplift and Subsidence)

COMMENT LETTER REFERENCE: MI-A-67

Comment:

Previously considered as variables for the region-to-area screen were "Uplift and Subsidence"... Please explain the reasons for el iminating (this) variable.

Uplift and Subsidence was eliminated as a region-to-area screening variable because the low rates of uplift and subsidence in the three regions of interest is not significant for repository performance in that most of the movement is epeirogenic. Epeirogenic movements affect very broad areas in a nearly uniform way (in contrast to orogenic activity which gives rise to localized disturbances and mountain building). Thus, epeirogenic movements do not, in general, produce the stresses typical of regions of active faulting and seismicity. Uplift and subsidence, where they do occur, extend over very broad areas and produce only very gradual changes in hydraulic gradients. Similarly, because changes in elevation affect such broad areas, these changes are not likely to localize erosion in such a way that pathways are significantly shortened or that a repository might be exhumed.

In the North Central and Northeastern Regions, uplift has been occurring as a result of isostatic rebound (accompanied in some places by subsidence perhaps due to collapse of a peripheral bulge) after the last deglaciaton. Although these effects have produced relatively large changes in level over the last 10,000 to 20,000 years, the rates of uplift have decayed to a small fraction of the initial rates which produced most of the observed changes in level. The decay in uplift rates has been noted for many regions where rebound is known to have occurred.

Gable and Hatton (1983) provides the most current synthesis of available information on deleveling in the coterminous United States over the last 10 million years and in post-glacial times. Figures in this publication show the effects of epeirogenic and isostatic processes in the regions of interest. They also show that there are a number of widely scattered measurements or 
observations of deleveling that do not fit into any obvious regional patterns but might, if supplemented with additional data, indicate relative instability of particular structures. For this reason a careful examination of uplift and subsidence resulting from any mechanism will be made at the area phase of site characterization. During this phase, consistent data sets can be developed for specific areas which will permit meaningful comparison of results within the three regions and from one site to another. 
SECTION/TOPIC AREA: Other Geologic Variables (Climate Change)

COMMENT LETTER REFERENCE: ME-14 and ME-15

Comments:

Comments made in our letters of 9 January 1984 (ME-2) and 3 April 1984 (ME-3) were misrepresented to imply that potential glacial erosion was the only factor we favored for inclusion in the screening methodology. In fact, we argued that climatic change is a factor that is explicitly cited for consideration in the General Study Guidelines, and given the extremely regional character of climate and climatic variations, should be considered in the region-to-area screen. (ME-14)

We also suggested several alternate variables that could be considered in either Step 2 or Step 3 of the screening process. None of these comments were addressed in the comment and response document (Appendix A of draft SMD). (ME-15)

Response:

In the letter of April 3, 1984, Maine proposed two possible variables to represent climatic change: (1) the limit of the Pleistocene ice sheets and (2) the maximum anticipated sea level rise. Maine has interpreted the DOE Siting Guidelines as requiring consideration of climatic change in the regionto-area screening process. Technical reasons for eliminating potential glacial erosion as a region-to-area screening variable were addressed in the draft SMD (p. A-130). The decision to not include climatic change as a region-to-area screening variable was an earlier CRP programmatic decision and was based on the knowledge that the data consistency criteria could not be met for applications to all three regions being investigated. This applies as well to the two variables proposed by Maine to represent climatic change. Generally, reported values of maximum amounts of glacial erosion are below a threshold that would be considered as potentially adverse. The absence of an adverse condition precludes the use of climate change as a variable for gion-to-area screening. This factor will be considered in subsequent phases. 
SECTION/TOPIC AREA: Other Geologic Variables (Enhanced Natural Radiation) COMMENT LETTER REFERENCE: ME-16

\section{Comment:}

The variable for enhanced natural radiation has been removed from the screening process with no explanation given.

\section{Response:}

This screening variable will not be included in the region-to-area screening methodology. The existing data base was determined to be inconsistent from one quadrangle to the next and, due to the methods utilized for data collection, it is difficult to determine the actual source of elevated radiation. Consideration of enhanced natural radiation will be reexamined in subsequent phases of the project. The rationale for this was discussed in a response on p. A-136 of the draft SMD. 
SECTION/TOPIC AREA: Other Geologic Variables (Peat Lands)

COMMENT LETTER REFERENCE: MA-6

Comment:

Finally, since sand and gravel are not considered as an important resource for Massachusetts, we would like to take this opportunity to submit our list of 180 peat lands, which are one (1) mile-square or greater; and submit our definition of the relation of peat and ground water.

\section{Reponse:}

The CRP appreciates receiving the information on peat lands in Massachusetts. This listing will be added to CRP's data base. However, peat lands are not considered in the definition of rock and mineral resources nor are they considered appropriate for inclusion as a separate Step 2 variable for the purpose of region-to-area screening. The data on peat lands may become valuable during the area-phase screening when fewer areas (and of smaller size) are considered in detail. 
SECTION/TOPIC AREA: 5.3 .1 Proposed Federal-Protected Lands

COMMENT LETTER REFERENCE: MI-A-55

Comment:

Under Scaling, " $>6$ " should be " $<6 "$.

Response:

The scale value should read " $>6, "$ not " $>6$ " as in the draft SMD.

COMMENT LETTER REFERENCE: NH-14

Comment:

Once again these scales (Proposed Federal Protected Lands, Proximity to Federal Protected Lands, Proximity to State Protected Lands, and National Forest Lands) are non-linear and appear to be inconsistent. It would seem that distances from boundaries should be based on similar principals.

\section{Response:}

Two of the variables in question, Proposed Federal-Protected Lands and National Forest Lands, are not derived from disqualifiers. Therefore the first scale value must (at least) include the feature (i.e., inside boundary). This also occurs for all other environmental variables that are not derived from disqualifiers (i.e., State Forest Lands, Designated Critical Habitat for Threatened and Endangered Species, Wetlands, Surface Water Bodies). The two environmental variables that are derived from disqualifiers and are not related to population (i.e., Proximity to Federal-Protected Lands and Proximity to State-Protected Lands) are scaled similarly. For these, the first scale value is 0 to 5 kilometers ( 0 to 3 miles) to conservatively estimate a zone around each protected land that would be most vulnerable to adverse 
direct and indirect environmental impacts. This allocation of the 10kilometer $(6-m i l e)$ zone across the five scale values represents a conservative approach to region-to-area screening.

COMMENT LETTER REFERENCE: GA-A-26

Comment:

P. 87, Paragraph 6 - Change the first sentence to read, "Administrative boundaries of proposed Federal-protected lands..."

Response:

The change has been made in the text.

COMMENT LETTER REFERENCE: NC-B-23

Comment:

The discussion of Proposed Federal Protected Lands would be improved if the "Comments" section addressed how the DOE planned to handle areas designated on the National Register. We agree that these sites are best addressed the first time at the area phase, but a reference to this process would be advantageous.

Response:

The CRP recognizes the importance of these sites, and a reference to treatment of the areas at subsequent phases continues to appear in Appendix B, decision rule \#7. 
COMMENT LETTER REFERENCE: SC-B-29 and SC-C-29

Comments:

The list which specifies "National Historical Sites" should be designated "National Historic Landmarks".

\section{Response:}

The term "National Historic Sites" is correct, and "Sites" should not be replaced with "Landmarks". "National Historic Site" is the title most commonly applied to historical features that are components of the National Park System. "National Historic Landmark" is a term applied to properties on the National Register of Historic Places.

COMMENT LETTER REFERENCE: SC-B-32 and SC-C-32

Comments:

The terminology used in discussion of proposed wilderness areas is confusing. On p. 86, areas "which have actually been proposed for wilderness designation" are discussed, but p. 88 refers to them as "lands recommended by the U.S. Forest Service for wilderness designation". The former implies inclusion in a wilderness bill, while the latter may not. The language used in $\$ 3$, p. 86 and $\$ 2$, p. 88 should be the same, preferably the language found on p. 88.

\section{Response:}

The text has been revised as suggested. The language on p. 86 of the draft SMD has been modified to be consistent with the language on $p .88$ of the draft. 
COMMENT LETTER REFERENCE: WI-11

Comment:

The scale proposed on p. 90 is questionable. This variable is improved by the decision to map the population density according to census enumeration districts rather than the centroids. Under the proposed scale, any area with less than 200 persons per square mile is considered highily favorable. The mean value for the continental United States in 1980 is 64 persons per square mile. If the objective is to locate the repository away from highly populated areas, we recommend the scale which we proposed to OCRD in our April 18, 1984 submittal of comments on the screening methodology.

\section{Response:}

The population density scale in Section 5.3.2 of the final SMD remains the same as in the draft SMD. Accordingly, areas below 200 persons per square mile will be considered as more favorable in the region-to-area screen. However, population is also considered in the context of a second variable, Proximity to Highly Populated Areas. When the Population Density variable is combined with the Proximity to Highly Populated Areas variable (Section 5.3.10 of the final SMD), region-to-area screening will be driven toward the most remote and least populated areas of the CRP regions (assuming other factors are equal).

The population density scale reflects consideration of the 1,000 persons per square mile disqualifying consideration (on the most adverse end of the scale) and is equally incremented because of the regional scale assumption that population density impacts are linear. While the mean value of population density for the continental United States is 64 persons per square mile, the mean values for the three regions are:

North Central - 58 persons per square mile

Northeastern - 288 persons per square mile

Southeastern - 160 persons per square mile. 
COMMENT LETTER REFERENCE: NJ-22

Comment:

If understood correctly, the scales on pg. 90 and 102, would indicate that the most favorable site for a repository would be greater than 48 miles from an area that has a population of 1,000 persons per square mile. As already pointed out, New Jersey feels this is a relatively high population density for the United States.

\section{Response:}

The scale for the Proxmity to Highly Populated Areas variable reflects that there is no perceived difference in favorability if a repository is $48 \mathrm{miles}$ ( $77 \mathrm{kilometers)} \mathrm{from} \mathrm{either} \mathrm{a} \mathrm{highly} \mathrm{populated} \mathrm{area} \mathrm{or} \mathrm{an} \mathrm{area} \mathrm{of}$ 1,000 people per square mile. A highly populated area is defined as any incorporated place of 2,500 or more persons or any census-designated place of 2,500 or more persons unless it can be demonstrated that such a place has a lower population density than the mean value of the United States (i.e., 64 persons per square mile in 1980).

The scale for the Population Density variable reflects a difference in favorability for lower population densities versus higher population densities. The fact that this scale is equally incremented (i.e., 200 persons per square mile increments) reflects the regional scale assumption that population density-related impacts are linear. The CRP realizes that 1,000 persons per 1-mile-square area is highly dense, and that is why greater distances from these population concentrations are scaled more favorably.

\section{COMMENT LETTER REFERENCE: MD-3}

Comment:

We request clarification of the relation between the controlled area as defined under NRC regulation (10 CFR 60.2) and the regional screening factor 
...population density... We are uncertain of the restrictions being placed on the controlled area with regard to land use.

\section{Reponse:}

In 10 CFR 60.2 (NRC, 1983a), the NRC defines controlled area as "a surface location, to be marked by suitable monuments, extending horizontally no more than 10 kilometers ( 6 miles) in any direction from the outer boundary of the underground facility, and the underlying subsurface, which area has been committed to use as a geologic repository and from which incompatible activities would be restricted following permanent closure." Neither deep well drilling nor deep excavations will be allowed in the controlled area. No assumption is made in region-to-area screening (in the Step 2 variable, Population Density) as to whether a grid cell has any relationship to the NRCdefined controlled area. 
SECTION/TOPIC AREA: 5.3 .3 Proximity to Federal-Protected Lands

COMMENT LETTER REFERENCE: MI-A-57

Comment:

Under Comments, the last two sentences should be combined to clarify what 3 miles is the "largest" of (e.g., the wording on p. 92 is better). A figure would be helpful.

Response:

The wording under the Comments discussion has been changed to be consistent with what appears under Section 5.3.4.

COMMENT LETTER REFERENCE: NH-14, GA-A-3, GA-A-27, and NC-B-26

Comments:

Once again these scales (Proposed Federal Protected Lands, Proximity to Federal Protected Lands, Proximity to State Protected Lands, and National Forest Lands) are non-linear and appear to be inconsistent. It would seem that distances from boundaries should be based on similar principals. (NH-14)

DOE's proposed scale is as follows:

\begin{tabular}{ccccc}
$0-3$ & $>3-4 \mathrm{mi}$. & $>4-5 \mathrm{mi}$. & $>5-6 \mathrm{mi}$. & $>6 \mathrm{mi}$. \\
\hline 1 & 2 & 3 & 4 & 5
\end{tabular}

Here the \#1 (worst case) value has a geographic spacing of up to three miles; whereas for all other values, a one mile spacing was chosen. (GA-A-3)

This scale is non-linear, illogical, and arbitrary. DOE should not have one set of distance increments for geologic variables and another set for environmental variables... We recommend that DOE use the following scale: 
Distance From Facility (Miles)

\begin{tabular}{ccccc}
$0-2$ & $>2-4 \mathrm{mi}$. & $>4-6 \mathrm{mi}$. & $>6-8 \mathrm{mi}$. & $>8 \mathrm{mi}$. \\
\hline 1 & 2 & 3 & 4 & 5
\end{tabular}

$(G A-A-27)$

The scale for Proximity to Existing Federal Protected Lands is not linear. We recommend two mile intervals for the five units of scale value. (NC-B-26)

Response:

Two of the variables in question, Proposed Federal-Protected Lands and National Forest Lands, are not derived from disqualifiers and, hence, the first scale value must (at least) include the feature (i.e., inside boundary). This also occurs for all other environmental variables that are not derived from disqualifiers (i.e., State Forest Lands, Designated Critical Habitat for Threatened and Endangered Species, Wetlands, Surface Water Bodies). The two environmental variables that are derived from disqualifiers, and are not related to population (i.e., Proximity to Federal-Protected Lands and Proximity to State-Protected Lands) are scaled similarly. The first scale value is 0 to $5 \mathrm{kilometers} \mathrm{(} 0$ to 3 miles) to conservatively estimate a zone around each protected land that would be most vulnerable to adverse direct and indirect environmental impacts. This allocation of the 10-kilometer (6-mile) zone across the five scale values represents a conservative approach to region-to-area screening.

COMMENT LETTER REFERENCE: NY-A-15 and MD-5

Comments:

Pg. 90-91 - Proximity of existing Federal Protected Lands and Proximity of State Protected lands. As indicated on p. 5 of this report, a controlled a will extend out in all directions from the boundary of the underground 
facility. The radius of this area will be determined during the site characterization phase and could be as much as 6.2 miles. It will be very difficult to assess for example, the visual impact of the disposal sites surface facility on a state park if the distance from the structures to the controlled area boundary is not known. We recommend a specific distance be agreed upon early in the impact analysis. (NY-A-15)

We request clarification of the relation between the controlled area as defined under NRC regulation (10 CFR 60.2) and the regional screening factor ...Federal... protected lands... We are uncertain of the restrictions being placed on the controlled areas with regard to land use. (MD-5)

\section{Response:}

As noted in Section 1.4 of the SMD, the size and orientation of the controlled area at a given site will be dependent upon ground-water flow and other characteristics. The controlled area (at a given site) will be established subsequent to site characterization studies.

In 10 CFR 60.2 (NRC, 1983a), the NRC defines controlled area as "a surface location, to be marked by suitable movements, extended horizontally no more than 10 kilometers ( 6 miles) in any direction from the outer boundary of the underground facility, and the underlying subsurface, which area has been committed to use as a geologic repository and from which incompatible activities would be restricted following permanent closure." The CRP agrees that analysis of visual impacts requires site-specific information (e.g., identification of restricted area, controlled area). Visual impacts will be considered in subsequent phases of screening.

The regional screening variables which incorporate proximity are a measure of distance from the centroid of a grid cell to some feature such as a Federal- or State-protected land. Neither deep well drilling nor deep excavations will be allowed in the controlled area. No assumption is made in region-to-area screening (in the Step 2 variable, Proximity to FederalProtected Lands) as to whether a grid cell has any relation to the NRC-defined controlled area. However, the $10 \mathrm{kilometer}(6-\mathrm{mile})$ zone for this variable is derived from the definition of accessible environment in proposed 40 CFR 191 (EPA, 1982). 
Comment:

We also find it ironic that DOE used a two mile spacing for postemplacement faulting, which is a safety related issue (i.e., brittle structures such as faulting provide pathways for ground-water flow), and a three mile spacing for proximity to federally protected lands, which is really no more than an issue of aesthetics. It seems on the basis of these two scales that DOE considers aesthetics issues to be paramount over safety related issues.

\section{Response:}

The scale for the Postemplacement Faulting variable has been changed to be similar to that for Proximity to Federal-Protected Lands.

The purpose of the weighting workshop exercise is to allow participants to make judgments regarding the relative importance of screening variables. 
SECTION/TOPIC AREA: 5.3.4 Proximity to State-Protected Lands

COMMENT LETTER REFERENCE: MI-A-58

Comment:

Under Scaling, ">6" should be " $<6$ ".

\section{Response:}

The scale value should read " $>6$," not " $>6$ " as in the draft SMD.

COMMENT LETTER REFERENCE: NH-14, GA-A-28, and NC-B-27

Comments:

Once again these scales (Proposed Federal Protected Lands, Proximity to Federal Protected Lands, Proximity to State Protected Lands, and National Forest Lands) are non-linear and appear to be inconsistent. It would seem that distances from boundaries should be based on similar principals. (NH-14)

This scale is non-linear, illogical, and arbitrary. Refer to our earlier comments regarding Proximity to Existing Federal Protected Lands. (GA-A-28)

The scale for Proximity to State Protected Lands is not linear. We recommend two mile intervals for the five units of scale value. (NC-B-27)

\section{Response:}

Two of the variables in question, Proposed Federal-Protected Lands and National Forest Lands, are not derived from disqualifiers and, hence, the first scale value must (at least) include the feature (i.e., inside boundary). This also occurs for all other environmental variables that are not derived from disqualifiers (i.e., State Forest Lands, Designated Critical Habitat for 
Threatened and Endangered Species, Wetlands, Surface Water Bodies). The two environmental variables that are derived from disqualifiers and are not related to population (i.e., Proximity to Federal-Protected Lands and Proximity to State-Protected Lands) are scaled similarly, the first scale value being 0 to 5 kilometers ( 0 to 3 miles) to conservatively estimate a zone around each protected land that would be most vulnerable to adverse direct and indirect environmental impacts. This allocation of the 10-kilometer (6-mile) zone across the five scale values represents a conservative approach to region-to-area screening.

\section{COMMENT LETTER REFERENCE: NY-A-15 and MD-6}

\section{Comment:}

Pp. 90-91 - Proximity of existing Federal Protected Lands and Proximity of State Protected Lands. As indicated on p. 5 of this report, a controlled area will extend out in all directions from the boundary of the underground facility. The radius of this area will be determined during the site characterization phase and could be as much as 6.2 miles. It will be very difficult to assess for example, the visual impact of the disposal sites surface facility on a state park if the distance from the structures to the controlled area boundary is not known. We recommend a specific distance be agreed upon early in the impact analysis. (NY-A-15)

We request classification of the relation between the controlled area as defined under NRC regulation (10 CFR 60.2) and the regional screening factor ...State protected lands. We are uncertain of the restrictions being placed on the controlled areas with regard to land use. (MD-6)

\section{Response:}

As noted in Section 1.4 of the SMD, the size and orientation of the controlled area at a given site will be dependent upon ground-water flow and other characteristics. The controlled area (at a given site) will be

tablished subsequent to site characterization studies. 
In 10 CFR 60.2 (NRC, 1983a), the NRC defines controlled area as "a surface location, to be marked by suitable movements, extended horizontally no more than 10 kilometers ( 6 miles) in any direction from the outer boundary of the underground facility, and the underlying subsurface, which area has been committed to use as a geologic repository and from which incompatible activities would be restricted following permanent closure." The CRP agrees that analysis of visual impacts requires site-specific information (e.g., identification of restricted area, controlled area). Visual impacts will be considered in subsequent phases of screening.

The regional screening variables which incorporate proximity are a measure of distance from the centroid of a grid cell to some feature such as a Federal- or state-protected land. Neither deep well drilling nor deep excavations will be allowed in the controlled areas. No assumption is made in region-to-area screening (in the Step 2 variable, Proximity to State-Protected Lands) as to whether a grid cell has any relation to the NRC-defined control area. However, the 10 kilometer (6-mile) zone for this variable is derived from the definition of accessible environment in 40 CFR 191 (EPA, 1982). 
COMMENT LETTER REFERENCE: NH-14

Comment:

Once again these scales (Proposed Federal Protected Lands, Proximity to Federal Protected Lands, Proximity to State protected Lands, and National Forest Lands) are non-linear and appear to be inconsistent. It would seem that distances from boundaries should be based on similar principals. (NH-14)

\section{Response:}

Two of the variables in question, Proposed Federal-Protected Lands and National Forest Lands, are not derived from disqualifiers and, hence, the first scale value must (at least) include the feature (i.e., inside boundary). This also occurs for all other environmental variables that are not derived from disqualifiers, and are not related to population (i.e., State forest Lands, Designated Critical Habitat for Threatened and Endangered Species, Wetlands, Surface Water Bodies). The two environmental variables that are derived from disqualifiers (i.e., Proximity to Federal-Protected Lands and Proximity to State-Protected Lands) are scaled similarly. The first scale value 0 to 5 kilometers is ( 0 to 3 miles) to conservatively estimate a zone around each protected land that would be most vulnerable to adverse direct and indirect environmental impacts. This allocation of the 10-kilometer (6-mile) zone across the five scale values represents a conservative approach to region-to-area screening.

COMMENT LETTER REFERENCE: NC-B-22

Comment:

Components of National Forest Lands should also include disqualification for special-interest recreational, scenic, scientific, educational, 
conservation, and historical uses as designated in approved forest management plans. All of these areas give special consideration to a specific use to the exclusion or limitation of other uses, and a repository would conflict with each.

\section{Response:}

The CRP does not consider it prudent at the regional phase of investigation to evaluate specific forest management plans to determine whether special or exclusionary uses of forest lands are in effect and whether a repository would conflict irreconcilably with such uses of forest lands. These types of considerations will be addressed at the area or site characterization phase. 
COMMENT LETTER REFERENCE: MN-A-1, MN-C-23, MN-D-1, DOI-1, NJ-13, NY-A-14, $S C-B-33$, and $S C-C-33$

Comments:

...Minnesota "State Wildlife Management Areas" should be included as areas automatically disqualified for inclusion as potential sites. (MN-A-1)

We wish to note, in particular, our comments on the treatment of state protected lands. We strongly disagree with the position your office has taken, and we request that you reconsider that position based on the material we have provided and the DOE guidelines that you must comply with.

...Minnesota strongly opposes the decision to postpone disqualification consideration of state wildlife lands until the area phase of the siting process. We are particularly concerned because it is our understanding, based on conversations with CRP staff, that this decision was due more to political than technical grounds...

Contrary to CRP staff statements that there are no criteria for the "irreconcilable conflict" determination, DOE has clearly adopted a criterion which CRP has failed to apply. We suggest that CRP review again the wildlife lands information and materials collected from the states, using the "resource preservation" criteria that were not used previously. If CRP is still unable to disqualify these lands, we request an explanation, not in a categorical sense, but in a Minnesota specific sense, of how Minnesota's concept of resource preservation differs with regard to the state parks, wild and scenic rivers, and wilderness areas that were disqualified, and the wildlife lands

1 Incorporated into Section 5.1.3, State-Protected Lands, in final SMD. 
that were not. This is the crux of our disagreement with this process, and if CRP cannot satisfactorily address this question, we will continue to forcefully pursue a remedy to this arbitrary action. (MN-C-23)

It is our understanding that your office is now reevaluating the status of state-protected wildlife lands. We welcome your willingness to reconsider the treatment of these at the regional phase, and we hope your staff proposal to use ownership as the basis for disqualification will be adopted. Ownership data should be readily available as part of the state material collected by DOE contractors. (MN-D-1)

I am pleased that the U.S. Fish and Wildlife Service (FWS) Wildlife Management areas are excluded from consideration as potential sites. I recommend and urge similar status for the State of Minnesota, Department of Natural Resources, Wildlife Management Areas. (DOI-1)

The CRP has determined that state wildlife lands do not "categorically" represent an "irreconcilable conflict" of use and are therefore treated as Step 2 screening variables. What exactly does this mean? New Jersey deems wildlife management areas to be of tremendous value. If state wildlife lands are 'comparably significant' to Federal wildlife lands, then how does one represent an "irreconcilable conflict" of use and the other does not? (NJ-13)

CRP has lumped all state wildlife management areas into a Step 2 variable. It is our feeling that these areas should be included in the "StateProtected Lands" disqualifying variable. These areas will be exempted at some point in the siting process and we see no reason to delay the disqualification of these areas as potential disposal sites. (NY-A-14)

South Carolina's experience with Battelle's subcontractors indicates that adequate information has been gathered to make a determination regarding state wildlife refuges which are analogous in purpose to the National System. DOE and Battelle should make that determination and disqualify lands where warranted. (SC-B-33 and SC-C-33) 
Response:

As a result of further evaluation by CRP staff and a great deal of input from many of the states, CRP has determined that a change in the treatment of State Wildlife Lands is warranted. All categories of wildlife lands that are comparable in statute to the National Wildlife Refuge System and whose primary form of ownership is state ownership-in-fee will be disqualified at the regional phase. Other categories of State Wildlife Lands noted in the RECR data base and in the draft SMD will receive no screening status at the regional phase. Appendix $B$ of this report provides a state by state description of the treatment of state-protected lands.

COMMENT LETTER REFERENCE: NH-15 and RI-11

Comments:

Wildlife protection has been afforded under two federal grant programs. Specifically there are the Pittman-Robertson and Dingell-Johnson programs. It is assumed that land purchased under the requirements of these programs will be disqualified as a potential site. (NH-15)

There should be a relationship drawn between the areas covered by the definition and Pittman-Robertson and Dingell-Johnson funding. All properties funded from these sources should receive the same protection as other Federal and State park areas. (RI-11)

\section{Response:}

It is expected that the decision to disqualify State Wildlife Lands (see previous response for details) should largely address these comments in that lands covered by these Federal grant programs would be eliminated from consideration. 
SECTION/TOPIC AREA: $\quad$ 5.3.8 Designated Critical Habitat for Threatened and Endangered Species

COMMENT LETTER REFERENCE: NY-A-17

Comment:

The state federally funded endangered species units are another important source of information that should be contacted.

Response:

As noted on p. A-78 of Appendix A of the draft SMD, because state criteria for designation of threatened and endangered species vary widely, it has been determined that consideration of threatened and endangered species, defined by states, would be deferred until the area or site phases. It should be noted, however, that the RECR identify the number of state-protected threatened and endangered species and the status of state protection.

COMMENT LETTER REFERENCE: NH-18, NJ-32, and VA-B-22

Comments:

We recommend that the state designated critical habitat be considered at least as a Step 2 variable if not in Step 1. (NH-18)

To maintain ecological diversity and balance, state designated critical habitats should be considered in the screening process. (NJ-32)

Even though a threat to a species habitat in a state may not seem significant "when viewed in a national context", this is a real concern to the state involved and should be treated accordingly. (VA-B-22) 
Response:

The CRP agrees that threatened and endangered species, defined by states, require consideration in the site-screening process, although not at the regional phase. The CRP recognizes that any conflicts or inconsistencies between state criteria for designation would have to be resolved at whatever point in the process state-designated critical habitats are evaluated. However, the number and magnitude of the conflicts or inconsistencies would (likely) be less at the area or site phases of investigation.

COMMENT LETTER REFERENCE: NY-A-16

Comment:

Formally designated critical habitat along with important habitat for endangered and threatened species should be considered a Step 1 disqualifying variable.

Response:

The provisions in the DOE Siting Guidelines associated with critical habitats for threatened and endangered species (10 CFR 960.5-2-5(c)(6)) are a potentially adverse condition and not a disqualifying condition. The CRP does not believe that there are any disqualifying conditions related to critical habitats for threatened and endangered species that could be applied at the regional phase. However, the CRP will evaluate the provisions of 10 CFR 960 . 5-2-5(d)(1) (Environmental Quality) at subsequent phases of screening. 
SECTION/TOPIC AREA: $\quad 5.3 .9$ Wetlands

COMMENT LETTER REFERENCE: $M N-C-24$ and GA-A-29

Comments:

Minnesota can find no justification for the reduced distance limit for wetlands and surface water bodies. The explanation on p. 98 does not address why the direct and indirect adverse impacts are not as extensive in geographic scope for these variables as the impacts associated with the other "proximity to" variables. He would like to have CRP explain the distinction between the wetlands and surface water body impacts and those impacts associated with federal and state forest lands or protected lands. Specifically, why are they geographically less? (MN-C-24)

We recommend the following scale:

Distance from Wetlands (Miles)

Inside

\begin{tabular}{ccccc} 
Boundary & $<2$ & $>2-4$ & $>4-6$ & $>6$ \\
\hline 1 & 2 & 3 & 4 & 5
\end{tabular}

$(G A-A-29)$

Response:

It is CRP's judgement that the kinds and level of impacts a repository would likely have on a wetland or surface water body (i.e., water quality, ecological, water usage, noise) would not extend beyond a 3-mile (5-kilometer) distance. These kinds of impacts, to a large degree, are mitigable with proper planning, engineering, and design measures.

Federal- and state-protected lands are believed to represent dedicated areas set aside for preservation, protection, and public enjoyment of national (or state) resources. By their very nature, these lands are in pristine areas and generally not located near either population centers or industrial 
developments. In addition, many Federal lands are coincident with Class I Air Quality Areas. As a result, it is CRP's view that the radius of impact associated with a geologic repository would be greater for Federal- or stateprotected lands than for wetlands or surface water bodies.

COMMENT LETTER REFERENCE: NY-A-19 and NY-B-1

Comment:

We feel that wetlands should be considered a Step 1 disqualifying variable especially since only very large or large concentrations of wetlands will be identified in the region-to-area phase.

(NY-A-19) I will take this opportunity to again state New York State's position that the large $(320 \mathrm{ac}+) .$. wetlands mapped during this regional phase should be given the Step 1 disqualifier status. (NY-B-1)

\section{Response:}

The provisions in 10 CFR 960 used to support incorporation of wetlands into the region-to-area screening methodology (10 CFR 960.5-2-5(c)(1) and (c)(2)) are potentially adverse and not disqualifying conditions. The CRP does not believe that there are any disqualifying conditions related to wetlands that could be applied at the regional phase. In addition, wetlands as small as 130 hectares ( 320 acres) or concentrations of wetlands within a given grid cell that, in the aggregate, are 130 hectares (320 acres) or larger are being considered in the region-to-area screening process.

COMMENT LETTER REFERENCE: VA-B-3

\section{Comment:}

The incorporation of wetlands at this step is weak since selection of thlands for screening seems limited to what shows up on a very small scale map. 


\section{Response:}

The CRP believes that the inclusion of wetlands in the region-to-area screening process is supported by provisions of the DOE Siting Guidelines (10 CFR 960.5-2-5(c)(1) and (c)(2)). The 1-square-mile grid cell constraint affects application of all screening variables. As noted in the previous response, concentrations of wetlands within a given grid cell that are greater than 130 hectares ( 320 acres) are being considered at the regional phase. 
SECTION/TOPIC AREA: 5.3 .10 Surface Water Bodies

COMMENT LETTER REFERENCE: MI-A-59

Comment:

Under Significance, third line, add "and subsurface" after "surface".

Response:

The first sentence under Significance addresses 10 CFR 960.5-2-8(c) which is the potentially adverse condition related to flooding under Surface Characteristics. The issue of subsurface flooding is addressed in the following sentence and refers to 10 CFR $960.5-2-10(b)(2)$. It is believed that the discussion in Section 5.3.9 of the final SMD accurately reflects the respective DOE Siting Guideline provisions.

COMMENT LETTER REFERENCE: MI-A-60

Comment:

Under Comments, it would be helpful to clarify the wording to ensure that within a grid cell the aggregate area of small surface water bodies exceeding 320 acres will meet the minimum criterion for representation of that grid cell.

Response:

The wording in the final SMD has been modified to reflect the suggestion made in this comment. 
COMMENT LETTER REFERENCE: $M N-C-24$ and GA-A-30

Comments:

Minnesota can find no justification for the reduced distance limit for wetlands and surface water bodies. The explanation on p. 98 does not address why the direct and indirect adverse impacts are not as extensive in geographic scope for these variables as the impacts associated with the other "proximity to" variables. We would like to have CRP explain the distinction between the wetlands and surface water body impacts and those impacts associated with federal and state forest lands or protected lands. Specifically, why are they geographically less? (MN-C-24)

Our comments regarding scale variables for Hetlands... also would be appropriate to Surface Water Bodies. (GA-A-30)

\section{Response:}

It is CRP's judgment that the kinds and level of impacts a repository would likely have on a wetland or surface water body (i.e., water quality, ecological, water usage, noise) would not extend beyond a 3-mile (5-kilometer) distance. These kinds of impacts, to a large degree, are mitigable with proper planning, engineering, and design measures.

Federal- and state-protected lands are believed to represent dedicated areas set aside for preservation, protection, and public enjoyment of national (or state) resources. By their very nature, these lands are in pristine areas and generally not located near either population centers or industrial developments. In addition, many Federal lands are coincident with Class I Air Quality Areas. As a result, it is CRP's view that the distance to which the impacts associated with a geologic repository would extend would be greater for Federal- or state-protected lands than for wetlands or surface water bodies. 
COMMENT LETTER REFERENCE: MN-C-25, GA-A-31, and NC-B-28

Comments:

The definition fails to indicate how major rivers would be identified. What will be the criteria for classifying rivers as "major" and mapping them as a surface water feature? (MN-C-25)

Define "major rivers". The term "major" is vague. (GA-A-31)

No discussion is presented to explain how "major rivers" are to be distinguished from other rivers. Is the process different from that of designating major streams? (NC-B-28)

Response:

All rivers shown on USGS Map.3-A, (USGS, 1965) are considered "major rivers" for the purposes of this screening variable.

COMMENT LETTER REFERENCE: MN-C-26, MN-D-2, NH-3, NH-20, NJ-56, and NY-B-1

Comments:

Minnesota continues to maintain that surface water bodies should be disqualified for the numerous reasons offered in earlier reviews (December 12 , 1983, March 20, 1984, and April 19, 1984). (MN-C-26)

Minnesota remains opposed to the SMD classification of surface water bodies as regional screening variables rather than as features that should be disqualified. Like the Wildlife Management Areas, surface water bodies have already been identified and mapped by DOE contractors, and a satisfactory decision rule can be established at the region-to-area phase to remove from further consideration large bodies of water that are obviously unsuitable for repository siting. He believe that this position is consistent with the aidelines for the following reasons: 
a. The guidelines are clearly intended to concentrate siting efforts where suitability for disposal is greatest...

b. The guidelines also recognize the dichotomy between surficial and geologic suitability by providing for postclosure and preclosure guidelines...

c. In past comments, Minnesota has referred to the provisions of 10 CFR $960.5-2-8$ as the basis for disqualification of surface water bodies...

Recognizing that large surface water bodies are permanently flooded, it seems only logical that they would be inappropriate locations for repository surface facilities. (MN-D-2)

Surface water bodies should be disqualified from consideration. It is illogical to say that factors which impede surface construction such as water are adverse. In fact water is a condition that precludes surface construction and should be disqualified. (NH-3)

It has been New Hampshire's position that the presence of surface water bodies should be a disqualifying condition. These water bodies are managed resources and the potential siting of a HLW facility would create irreconcilable conflicts. (NH-20)

Surface water bodies should be included as a disqualifying condition in region-to-area screening to exclude appropriately sized lakes, reservoirs, artificial impoundments, rivers, swamps, ocean bays and estuaries from further consideration in the repository development process. Such disqualification should be based on the need for approximately 400 acres of land required for a repository. (NJ-56)

I will take this opportunity to again state New York State's position that the large ( 320 acres) waterbodies...mapped during this regional phase should be given the Step 1 disqualifier status. (NY-B-1) 
Response:

The CRP continues to believe that there is no provision in the DOE Siting Guidelines that would support categorical disqualification of surface water bodies at the regional phase of screening. A major point raised in one of the Minnesota letters is that inability to meet the qualifying condition 10 CFR 960.5-2-8(a) could be used as a basis for disqualification of surface water bodies. The region-to-area screening methodology has not incorporated qualifying conditions in the development of disqualifying factors or screening variables. This is because it is difficult to demonstrate categorical noncompliance with constraints or conditions for region-to-area screening. The CRP recognizes that construction of all surface facilities in a surface water body is highly unlikely. However, this neither precludes presence of surface water on portions of the restricted area nor prevents filling in of such features. To identify a cut-off or threshold level for surface water bodies above which disqualification would occur would introduce a decision rule for one feature that would not be applied to any other feature. The CRP has addressed surface water bodies in the regional phase to the extent appropriate through their status as a screening variable. The weighting workshop will enable participants to evaluate the relative importance of surface water bodies and other screening variables. The CRP is committed to further evaluation of surface water features at the area and site phases.

COMMENT LETTER REFERENCE: MN-C-27 and MN-D-4

Comments:

For the sake of consistency, we wish to know why CRP has excluded from further repository siting consideration the following lakes that are underlain by granite but left off the Minnesota rock body map: Lake of the Woods (307,010 acres), Red Lake (288,800 acres), Mille Lacs Lake (132,510 acres), and the Minnesota portions of Lake Superior? (MN-C-27) 
We have noted in the past that some of the largest Minnesota lakes have al ready been "disqualified" by virtue of the size and appearance on the USGS map that served as the basis for crystalline rock bodies in the North Central Region (Lake of the Woods, Upper and Lower Red Lakes, and Lake Mille Lacs and Lake Superior). (MN-D-4)

\section{Response:}

The index map for Minnesota in the revised draft regional geologic and environmental characterization reports reflects information on rock bodies supplied to CRP by the Minnesota Geologic Survey. The information provided by Minnesota did not show rock bodies underlying the lakes in question, and CRP did not make any further intrepretation of the data. It should be noted, however, that the lakes in question are shown on Plate $1 A$ of the revised draft RECR for the North Central Region as well as on Plate 6A of revised draft RGCR for the North Central Region. These surface water bodies will be considered in the region-to-area screening methodology under the surface water body screening and major ground-water discharge zones variable.

COMMENT LETTER REFERENCE: NH-2

Comment:

Treatment of water bodies, specifically Great Ponds/Lakes in New Hampshire are owned and managed by the State. They should be disqualified.

Great Ponds (i.e., water bodies over 10 acres) in New Hampshire are owned and managed by the State. They in fact are resources managed for recreation and wildlife purposes. The "comparably significant" argument should be applied to these State-protected resources as though they were State Parks. The location of a HLW facility in or adjacent to such body of water would result in an irreconcilable conflict of use. 
Response:

State-protected lands or resources receiving disqualification status at the regional phase are those lands (or resources) for which there is statutory comparability with either the National Park System, National Wilderness Preservation System, National Wildlife System, or National Wild and Scenic Rivers System. It is CRP's view that Great Ponds do not exhibit statutory comparability and, therefore, at the regional phase, would not be treated as a screening variable. However, any Great Pond that is within the boundaries of a disqualified state-protected land would also be disqualified. The CRP is committed to further examination of surface water features at the area and site phases of investigation.

COMMENT LETTER REFERENCE: MN-D-3, NH-21, NH-22, NJ-16, and NJ-17

Comments:

Minnesota has also previously noted that surface water bodies are of ten sources of drinking water and serve a variety of recreational and environmental uses. Rivers, lakes, and shores in Minnesota and many other states are heavily regulated through a wide variety of federal and state legislation that prohibits or discourages drainage or filling, shoreline alteration, or development in close proximity to lakeshore. (MN-D-3)

An important additional consideration is the use of surface water in New Hampshire for water supplies. These water supplies are not only managed as Great Ponds but also have more restrictive use limitations placed on them due to their status as public water supplies. (NH-21)

A separate and particularly important concern is the lack of treatment of Class $A$ watersheds and water bodies which are managed as public water supplies. (NH-22) 
New Jersey's reliance on surface water bodies as water supply supports the need for a surface water body disqualifying condition under 10 CFR 960.5-2-8. (NJ-16)

New Jersey Water Supply Master Plan allows for both use and development of surface and groundwater to maintain water quality and supply. It would be sensible and consistent with the DOE repository development process to disqualify such water supplies, surface and subsurface, as early as possible to eliminate unnecessary review and evaluation of unusable sites later in the planning process. The DOE Siting Guidelines provide a disqualifying factor for "offsite supplies presently suitable for human consumption" under 10 CFR 960.5-2-6(d); however, this is not to be considered a disqualifying condition. (NJ-17)

\section{Response:}

As noted in Appendix A of the draft SMD (p. A-87), the CRP believes that there is too much variability in the surface drinking water supply data base across the 17 crystalline states for it to be applied as a region-to-area screening variable. In addition, making a determination of disqualification on the basis of 10 CFR 960.5-2-6(d) would require site-specific information on water quality and water usage as well as repository design information. The CRP is fully committed to addressing surface water quality and water usage at the area and site phases of investigation.

\section{COMMENT LETTER REFERENCE: NJ-18}

Comment:

It is important to consider both existing water quality and any additional degradation that may occur due to siting, construction and operation, especially short and long term heat production at the repository and the effects on surrounding rocks and water by chemical decomposition and behavior of the waste. 


\section{Response:}

The CRP agrees with the comment. However, addressing these considerations is not feasable at the regional phase. The impacts of waste emplacement, including near- and far-field heat effects and potential releases can only be assessed with design-specific and site-specific information and the use of appropriate models. These kinds of assessments will begin to be conducted at the area phase and will continue through site characterzation.

COMMENT LETTER REFERENCE: RI-13

Comment:

At the very least, the fourth sentence in the definition should be reworded to state, "Major rivers are included in this category but may be a misleading and inaccurate surrogate measure of flood potential". We are not satisfied with the use of such a surrogate.

\section{Response:}

The fourth sentence under Definition has been modified.

\section{COMMENT LETTER REFERENCE: RI-14}

Comment:

No mention is made of coastal flooding which simply cannot be handled by the scale on p. 101. Some mention should be made of the impact of sea-level rise. 
Response:

The scale for surface water bodies will be applied along coastal regions as well as along rivers adjacent to the Great Lakes and around interior water bodies. The provisions of 10 CFR 960 that are used to support inclusion of surface water bodies in region-to-area screening are preclosure-related (10 CFR $960.5-2-5(c)(2), 5-2-8(c), 5-2-10(b)(2))$. It is not believed that significant changes in the coastline resulting from sea level rise would constitute a major consideration during the repository preclosure period because major variations in sealevel would not be expected to occur. 
COMMENT LETTER REFERENCE: NH-16, NJ-22, and MD-7

Comments:

The value of this variable as presented is questionable. The distribution of populated areas is such that the sensitivity of the variable is minimized. In other words, most areas in the Northeast will have the same scale; therefore, there will be little differentiation. 'As a result other variables will have a relatively greater importance. (NH-16)

If understood correctly, the scales on $\mathrm{pg} .90$ and 102, would indicate that the most favorable site for a repository would be greater than 48 miles from an area that has a population of 1,000 persons per square mile. As already pointed out, New Jersey feels this is a relatively high population density for the United States. (NJ-22)

We suggest the investigation of a nonlinear scale for the proximity to populated areas variable. We feel that the risk to the population per unit distance from a repository site may not be a constant (as implied by the linear scale) over the range of distances considered on the scale. The decrease in risk per unit increase in distance from a repository site may be small within a certain radius of the site relative to that outside this radius. (MD-7)

\section{Response:}

Remoteness of a site from highly populated areas is a favorable condition in the DOE Siting Guidelines (10 CFR 960.5-2-1(b)(2)). The scale of distance with intervals up to and beyond 48 miles ( 77 kilometers), as was discussed with the representatives of the states at the February 1984 screening workshop in Atlanta, will tend to drive the siting focus to the more remote and less populated areas of the CRP regions. This will meet the widely accepted intent to locate a repository away from population concentrations. 
The scale of proximity to highly populated areas reflects that there is no perceived measured difference in favorability if a repository is 48 miles (77 kilometers) from either a highly populated area or an area of 1,000 people per square mile than if a repository is a greater distance from the same. A highly populated area is defined as any incorporated place of 2,500 or more persons or any census designated place of 2,500 or more persons unless it can be demonstrated that such a place has a lower population density than the mean value of the United States (i.e., 64 persons per square mile in 1980).

The scale for this variable is one of three whose scales will be modified as part of the Step 3 sensitivity analysis. The CRP believes this modification, in part, addresses New Hampshire's concern.

The scale for the Population Density variable reflects a difference in favorability for lower population densities versus higher population densities. The fact that this scale is equally incremented (i.e., 200-persons-persquare-mile increments) reflects the assumption being used for region-to-area screening that population density-related impacts are linear.

\section{COMMENT LETTER REFERENCE: MD-4}

Comment:

We request clarification of the relation between the controlled area as defined under NRC regulation (10 CFR 60.2) and the regional screening factor ...proximity to populated areas. We are uncertain of the restrictions being placed on the controlled area with regard to land use.

\section{Response:}

In 10 CFR 60.2 (NRC, 1983a), the NRC defines controlled area as "a surface location, to be marked by suitable monuments, extending horizontally no more than 10 kilometers ( 6 miles) in any direction from the outer boundary of the underground facility, and the underlying subsurface, which area has been committed to use as a geologic repository and from which incompatible activities would be restricted following permanent closure." The regional 
screening variables which incorporate proximity are measures of distance from the centroid of a grid cell to some feature such as a highly populated area. Neither deep well drilling nor deep excavations will be allowed in the controlled area. No assumption is made in the region-to-area (in the Step 2 variable, Proximity to Highly Populated Areas) screening as to whether a grid cell has any relationship to the NRC-defined controlled area. 
SECTION/TOPIC AREA: Other Environmental Variables (Proposed State-Protected Lands)

\section{COMMENT LETTER REFERENCE: MI-A-67 and NJ-30}

Comments:

Previously considered as variables for the region-to-area screen were... "Proposed State Protected Lands". Please explain the reasons for eliminating (this) variable. (MI-A-67)

New Jersey also strongly opposes the omission of proposed state protected lands as a regional screening variable. It is understood that both Federal and state protected lands are to be given "parallel treatment" in regional to area screening. However, the omission of proposed state protected lands as a Step 2 variable is not consistent with this goal. In order to give proposed state lands "parallel treatment", they should be screened on a regional basis as are the proposed federal protected lands. (NJ-30)

\section{Response:}

As described in Appendix A of the draft SMD, Proposed State-Protected Lands will not be used as a region-to-area screening variable for the following reasons:

- The CRP has decided to define the State-Protected Lands disqualifying condition within the administrative boundaries of such land features. Consequently, the most commonly articulated proposed land action, specifically consolidation of private in-holdings into public ownership, is taken care of by disqualification.

- As has been mentioned at the three methodology development workshops, it is extremely difficult to arrive at an equitable and defensible definition of proposed state-protected lands across 17 states with diverse statutes.

- Very few definitive new proposals for proposed state-protected lands have been identified in our data collection efforts. 
Further, in 10 CFR $960.5-2-5(d)(3)$ disqualification of state-protected lands is 1 imited to "any comparably significant state-protected resource... dedicated to resource preservation at the time of the enactment of the Act" (underline added). 
SECTION/TOPIC AREA: Other Environmental Variables (Transportation)

COMMENT LETTER REFERENCE: MN-C-30, WI-13, ME-3, ME-9, MA-1, NH-17, NJ-28,

$$
\begin{aligned}
& \mathrm{NJ}-29, \mathrm{NJ}-34, \mathrm{NY}-\mathrm{A}-10, \mathrm{RI}-2, \mathrm{VT}-16, \mathrm{GA}-\mathrm{A}-6 \text {, } \\
& \mathrm{NC}-\mathrm{B}-32, \mathrm{SC}-\mathrm{B}-42, \mathrm{SC}-\mathrm{C}-40 \text {, and } \mathrm{VA}-\mathrm{B}-4
\end{aligned}
$$

\section{Comments:}

We agree with Wisconsin that a transportation variable can and should be applied at the Region phase to eliminate or penalize those areas which are highly unfavorable from a transportation standpoint. (MN-C-30)

Transportation of spent nuclear fuel and high level waste is one of the key human environmental, social and economic issues facing the siting of a nuclear waste repository. We recommend that DOE include the transportation infrastructure, for example, the proximity of interstate highways or actively used railroad lines, in both steps 2 and 3 of the methodology. If this is not acceptable, we recomnend that the fourth objective of step 3 be expanded to include human, environmental, social, and economic factors such as the transportation infrastructure be incorporated in conjunction with the geologic factors. (WI-13)

A consideration of proximity to and quality of the regional transportation network should be included in step 3 of the screening process... The rationale for not considering transportation provided on p. A-97 is inadequate. Many of the variables used in step 2 and step 3 involve simplifications of the physical process (as in the case of regional ground water discharge areas) or data sets that are far more inconsistent from State to State than information on the transportation network is liable to be. At one time DOE suggested several variables to measure transportation access to potential areas. We suggested that it be applied to the more reasonable number of candidate areas remaining in the step 3 sensitivity analysis. (ME-3)

The limited number of candidate areas derived from the summary composite maps could be examined from the standpoint of suitability of the existing 
transportation network and cost of constructing new transportation links. (ME-9)

The transportation variable has been dropped from immediate consideration in the process. We feel that transportation in terms of site accessibility must be included. It is clear that the most desirable of repository sites is of little use if it is distant from rail and truck routes. (MA-1)

This concern has rot been addressed in the methodology. It is critical that a measure of this factor be included in the review process. The information relating to rail and highway conditions is available in some detail through rail and highway plans. Factors such as condition, relative proximity, capacity, and safety should provide the basis for review. The routing of HL wastes through or adjacent to a highly populated area should be an adverse if not disqualifying condition. (NH-17)

As Superfund monies become available, the hazardous material will be removed from these sites and transported to facilities for treatment and disposal. The transportation of such toxic and hazardous materials coupled with the transportation of high level radioactive wastes greatly magnifies the potential risk. Both the existing sites and potential transportation routes of both types of wastes must be reviewed carefully. (NJ-28)

New Jersey is in the process of siting one or more Major Hazardous Waste Facilities for treatment and disposal of hazardous materials. Such siting plans and potential transportation routes need to be identified and screened on a regional basis. (NJ-29)

Since protection of public health and safety is the top priority we urge that potential corridors be identified and that population densities along such corridors be measured and used as a screening variable in addition to variables measuring the proximity of major rail lines and major highway routes to the site boundary. If such corridors require transportation through densely populated areas for any prolonged distance, the screening methodology must recognize this as a potentially adverse or disqualifing condition. 
Under Step 2 screening variables, the screening methodology should include a screening measure for transportation. There is a need to identify existing railways, highways and waterways which could provide access for the transportation of spent fuel. It is important to point out that the transportation of high level radioactive waste will be new to our transportation modes for the majority of this waste has never before been transported. (NJ-34)

Impacts such as transportation routes through cities are an important concern. Further, sites with excellent transportation routes which do not require movement through populated areas may be ranked higher. (NY-A-10)

In the Northeast, especially, transportation is a regional concern because of the size of the states and our interdependence on a common transportation network. (RI-2)

Transportation should be included as a Step 2 variable, divided into a variable for highway concerns, and into a variable for rail concerns. (VT-16)

While transportation of radioactive wastes is an important consideration in siting any repository, data available at a regional scale are inadequate for any meaningful decision-making process. (GA-A-6)

Thus, we are recommending no specific transportation scaling variable, but we would not be opposed to such a scale being developed. (NC-B-32)

South Carolina concurs with DOE's decision to defer... transportation from regional screening to a later stage in the site selection process. (SC-B-42 and SC-C-40)

Other factors such as transportation should not be considered at this stage. Transportation issues are extremely important but should receive initial consideration when evaluating recommended study areas. (VA-B-4) 
Response:

As noted in Appendix A of the draft SMD, the four potentially adverse conditions related to transportation require assessment of "local" transportation (10 CFR 960.5-2-7(c)(1) through (c)(4)) conditions and knowledge of siting options. In addition, the subject of transportation requires an evaluation of numerous concepts and variables (e.g., volume/capacity parameters, distance, topography, demography, road/rail condition, shipping rates, and origin of wastes). Given the need for site-specific information and the complexity associated with evaluating the transportation concepts listed above, it remains the CRP's position that no adequate variable can be defined to measure transportation considerations realistically at the regional phase.

With regard to the comment from Maine, the Step 3 variable concept was designed to be responsive to State concerns that health and safety-related geological considerations should be incorporated into the screening process, where practicable. "Practicable" was defined in terms of the CRP's ability to develop a defensible scale for each variable and of the availability of some regional data to implement that scale. The scope was limited to geologic variables because of a concern that the regional scale tended to favor the use of nongeologic variables, and that special effort should be made to incorporate rock body-specific, geologic data. The CRP is retaining the original concept of Step 3 variables for these reasons.

The CRP plans to evaluate transportation at the area and site phases and as part of selection of candidate areas (see Section 3.3.1). The CRP will be reviewing the data in the CRP data base and in the existing literature to determine if there is any evidence that a potentially adverse or favorable condition (that has not been addressed at the regional phase) exists within an identified candidate area. CRP also plans to review on a non-risk-related basis the existing highway networks (interstate, state, and local) and rail networks to evaluate the favorable and potentially adverse conditions of 10 CFR 960.5-2-7. 
SECTION/TOPIC AREA: Other Environmental Variables (Prime Agricultural Land)

COMMENT LETTER REFERENCE: $M N-B-1$ and MN-B-2

Comments:

Prime agricultural land is a diminishing resource in this country, and when lost, is difficult to replace. It would seem appropriate to me to include prime agricultural land as a screening factor in Step 2 of the screening methodology... However, soil maps of some level should exist or could quickly be obtained for most areas of the country. In short, some type of procedure for identifying prime agricultural land should exist for virtually any area to be considered. (MN-B-1)

The statement on p. A-100 of the draft screening methodology that says the CRP will address agricultural land preservation "as appropriate, in subsequent phases" seems too vague to at least meet the intent of federal policies directing that federal agencies avoid impacting prime agricultural land whenever possible. (MN-B-2)

\section{Response:}

The CRP still believes that, at a regional phase of investigation, there is no equitable way to address prime agricultural land (for reasons of inconsistently applied mapping criteria and incomplete mapping efforts). The CRP agrees that after candidate areas are identified in the final ARR, it would be appropriate to obtain the type of information Minnesota suggests.

The statement on $p . A-100$ of the draft SMD was not intended to be vague, but to reflect that it is uncertain at this point the location and extent of prime agricultural land that will occur within the candidate areas. The CRP fully intends to comply with applicable Federal law and policy regarding prime agricultural land. 
SECTION/TOPIC AREA: Other Environmental Variables (Defense Facilities)

COMMENT LETTER REFERENCE: WI-14

Comment:

Recognition of federal facilities seems to be limited to nuclear installations and hazardous facilities (if in fact they are hazardous. OSHA should investigate, unless the author means to write facilities handling hazardous materials). A possibility exists for the U.S. Department of Defense to construct a major naval communication system. The construction and operation of a repository may be limited by the limitations placed on activities adjacent to such DOD installation.

\section{Response:}

The CRP agrees that the wording "hazardous facilities" was probably inappropriate on p. A-103 of the draft SMD. If the U.S. Department of Defense (DOD) installation referred to in the Wisconsin letter were to be constructed and if this facility were in the vicinity of a potential repository site, then an evaluation of potential interactive effects would be undertaken consistent with the provisions of 10 CFR 960.5-2-4, Offsite Installations and Operations. In any event, the CRP does not judge that such an evaluation is appropriate at the regional phase. 
SECTION/TOPIC AREA: Other Environmental Variables (Hazardous Facilities)

COMMENT LETTER REFERENCE: NJ-27 and NJ-29

Comments:

Also, in reference to $960.5-2-4(c)(1)$, New Jersey is greatly concerned with hazardous and solid waste facilities and operations. New Jersey contains 95 hazardous waste sites on the National Priority List that are eligible for Superfund monies for cleanup. This does not include the hundreds of other sites not included on this list, estimates from 1,700 to 2,000 in New Jersey alone. Such hazardous installations in operation could adversely affect repository siting, construction operation or closure. Such hazardous waste sites in addition to solid waste facilities which accept municipal refuse, can and should be considered as a screening variable. It is important to locate these hazardous facilities at this point in the screening process in relation to the waste funnel. (NJ-27)

In addition, New Jersey is in the process of siting one or more Major Hazardous Waste Facilities for treatment and disposal of hazardous materials. Such siting plans and potential transportation routes need to be identified and screened on a regional basis. (NJ-29)

Response:

Evaluation of potential interactive effects between existing hazardous waste facilities and a high-level nuclear waste repository (10 CFR 960.5-2$4(c)(1)$ ) will depend on local environmental conditions, proximity of the two facilities, the specific materials handling procedures and processes utilized at the hazardous waste facility, and site and design parameters of the geologic repository. Adequate information to provide an accurate characterization of the issue of repository siting near hazardous facilities is not available at the regional phase of screening. Accordingly, evaluation has been deferred to the area or site characterization phases where the number of potential facilities which must be considered (if any) is reduced, and the site and design features associated with a geologic repository will be more fully developed. 
SECTION/TOPIC AREA: Other Environmental Variables (Nuclear Facilities)

COMMENT LETTER REFERENCE: NJ-26, SC-B-41, and SC-C-39

Comments:

New Jersey strongly objects to the omission, of the consideration of Offsite Installations and Operations 960.5-2-4. The location of nuclear power plants is well known and accessible and can be applied on a regional-to-area screening basis. Under Section 960.3-1-2, Regionality the siting of the repository "shall take into account the proximity of sites to locations at which waste is generated or temporarily stored..." This should be interpreted to include spent fuel at nuclear power plants, hazardous and solid waste facilities, and any large generators of low level radioactive waste or storage facilities for low level radioactive waste. (NJ-26)

South Carolina continues to be concerned that this issue affects emergency response capabilities and unknown health effects and believes it should be considered at the area phase. (SC-B-41 and SC-C-39)

\section{Response:}

The CRP agrees that the location of nuclear power plants is we11. known and documented. The CRP maintains that a determination under the provisions of 10 CFR 960.5-2-4 requires more than knowledge of location. Specifically it requires a judgment as to whether there is "(c)(2) Presence of other nuclear installations and operations, subject to the requirements of 40 CFR 190 (EPA, 1977) or 40 CFR 191, Subpart A (EPA, 1982), with actual or projected releases near the maximum value permissible under those standards."

Analysis of the dose and cumulative release standards of 40 CFR 190 and 40 CFR 191 requires detailed site-specific information on meteorology, hydrology, geology, radionuclide transport mechanisms, and design parameters for both the repository and other proximate nuclear facilities as well as determinations of cumulative dose effects. Data adequate to evaluate all these parameters do not exist at the regional phase of repository siting, and aluation has been deferred to the area or site characterization phases. 
As noted in Section 3.3.1 of the SMD, the provisions of 10 CFR 960.3-1-2 will be considered during selection of candidate areas.

Consideration of atomic energy defense activities (under 10 CFR 960.5-2$4(d)$ ) requires a determination of irreconcilable conflict of use between the activity at the defense facility and the (potential) repository construction, operation, closure, and decommissioning activities. Prior to identification of PAS, the DOE will have to make a finding with respect to this disqualifying condition. 
SECTION/TOPIC AREA: Other Environmental Variables (Appalachian Trail)

COMMENT LETTER REFERENCE: ME-17, NJ-31, NC-B-31, and VA-B-26

Comments:

With respect to the inclusion of the Appalachian Trail as an adverse factor in Step 2, the DOE responded that it should not be treated as an adverse factor because any effects are likely to be mitigable. There was no rationale provided for this assumption. The Appalachian Trail in Maine has a significance comparable to many state parks, and as there are presently federal initiatives for inclusion of the Trail in the National Trail System, we still feel it should be considered as a Step 2 screening variable. (ME-17)

New Jersey believes that the Appalachian Trail and any other National Trails should be recognized as a Step 2 screening variable and be screened for on a regional basis. (NJ-31)

The Appalachian Trail should be given Region-to-Area screening status as a disqualifier. Such inclusion would provide the comparable Federal land screening status necessary to guide a reasoned decision on whether to treat state trails at the area or site phases. (NC-B-31)

The Applachian Trail is an interstate entity of national significance, and should not be threatened because of overly rigid disqualification requirements. (VA-B-26)

\section{Response:}

As noted in the SMD, unless a land system is either a component of one of the four federal-protected land systems noted in 10 CFR 960.5-2-5(d)(2) (i.e., National Park System, National Wildlife Refuge System, National Wilderness Preservation System, National Wild and Scenic Rivers System) or is a comparable state-protected land, then the land system in question will be neither disqualified nor treated as a screening variable (in terms of proximity to) at 
the regional phase. The statement on mitigation of impacts was based on the judgment that the limited areal extent of a trail within a given geographic area and the nature of impacts that would be incurred (principally aesthetic or cultural) would be such that the impacts could be alleviated or avoided. The reader is referred to Section 5.1 .1 for a list of those components treated in the regional phase. 
SECTION/TOPIC AREA: Other Environmental Variables (Seasonal Population and Population Projections)

COMMENT LETTER REFERENCE: MI-A-56, NH-5, NJ-23, NC-B-25, NC-B-33, SC-B-38, and $\mathrm{SC}-\mathrm{C}-36$

Comments:

None of the population density related variables reflect seasonal variations in population density. Is this variation ignored? (MI-A-56)

Populations, specifically seasonal and future, should be addressed. (NH-5)

Consideration should also be given to specifying minimum distances to highly developed urban areas to avoid population encroachment to the repository from the predictable expansion of urban areas and to reduce the transport of high level waste through densely populated areas. To do this, consideration must be given to population projections as well as the most recent census. (NJ-23)

While we are encouraged by the Population Density Comments, we would like a little more discussion on how these more refined/detailed studies are to be performed, included in the Area-to-Site Screening Methodology, and reviewed by interested States. (NC-B-25)

Again, the methodology must indicate that population projections will be used (at least as a Step 3 variable) in the near term, and that population updates will be made at 1,990 and 2,000 with appropriate disqualifications. (NC-B-33)

From 1970 to 1980 South Carolina's total population increased 20.5 percent. A 25 percent increase in total population is projected from 1980 to 2000. Pickens County in South Carolina (approximately one third of its total area is underlain by a CRP rock body) increased 35 percent in population from 
1970 to 1980 . An additional 34 percent increase is projected by the year 1990. The CRP Screening Methodology in no way accounts for these increases in population. Groundbreaking for the construction of a crystalline repository will not begin for another 10 to 20 years. Population projects should be considered during the regional screening phase to account for the significant changes in population that are expected to occur in CRP affected areas over the next two decades. (SC-B-38 and SC-B-36)

\section{Response:}

Two aspects of population identified by reviewers are seasonal variations and projections. In order to estimate the seasonal variation of population, information on the size and duration of the variation must be obtained. Few states or counties compile such data. For the data to be used in the regionto-area screening, the data collected by each state must be consistent, and such consistency does not exist (for seasonal variations). Hence, seasonal population will be addressed in later screening or site characterization phases where there are smaller land units and where data consistency can be achieved.

Population projections provide estimates of future population trends in an area. There are many projections available, few of which are prepared for the same reason. Because there is no standard method of preparing such projections, the projections may vary widely for a given area. Regional population projections are generally useful only at the state level. Projections for smaller areas are tailored to the economic and demographic characteristics of the area. As a consequence, population projections are best applied at the area or site level of analysis.

If it is found, at some future point, that a disqualifying condition exists at a site, even if that condition does not now exist, that site would be disqualified. Further amplification of issues associated with seasonal population and projections of population is in Section 4.4 of the revised draft RECR. 
SECTION/TOPIC AREA: Other Environmental Variables (Green Acres Land)

COMMENT LETTER REFERENCE: NJ-15

Comment:

Green Acres deserve protection as state-protected lands and proposed state protected lands. A specific list of Green Acres land(s) are available.

Reponse:

Those lands that have been purchased under the Green Acres Program, subsequently turned over to a state agency for administration, and are statutorily comparable to federal lands are considered under the StateProtected Lands disqualifier and under the Proximity to State-Protected Lands screening variable. 
SECTION/TOPIC AREA: Other Environmental Variables (Meteorology)

COMMENT LETTER REFERENCE: NJ-20

Comment:

New Jersey agrees with the argument presented by Minnesota that climatic data is available on a regional scale for treatment of meteorological conditions as a Step 2 variable. Under both Sections 960.4-2-4 and 960.5-2-7(b)(9), meteorological conditions can be considered using data available from the National Weather Service.

\section{Response:}

In 10 CFR 960.4-2-4, climatic changes are to be viewed from the standpoint of their effect or influence on the isolation capabilities of the repository and the likelihood that such climatic changes will lead to releases in excess of 40 CFR 191 (EPA, 1982). In CRP's judgment, repository design information and data on the hydrology and geology of the potential repository site are necessary in order to make a determination based on 10 CFR 960.4-2-4.

In order to address 10 CFR $960.5-2-7(b)(9)$, information is necessary regarding not only regional meteorology but transportation aspects as well. The CRP position is that transportation will not be considered as a screening variable during region-to-area screening but will be considered as part of the qualitative/descriptive literature review (see response on page A-224 and Section 3.3.1 of the text).

In subsequent phases of screening, the CRP will apply 10 CFR 960.5-27 (b) (9) which requires consideration of the mode(s) of shipment, likely shipping routes, shipping frequencies, and timing of shipments throughout the year. 
SECTION/TOPIC AREA: Other Environmental Variables (Socioeconomic Factors)

COMMENT LETTER REFERENCE: NJ-35

Comment:

If Step 2 is to consider socioeconomic variables, it should consist of those conditions outlined in the DOE Siting Guidelines (10 CFR 960.5-2-6) such as projected population changes, availability of affected labor force in relation to locating a repository in a low population area, housing supply and demand, purchase of water rights, economic effects such as changes in property values, community infrastructure and existing facilities, existing and future demands on public services and the sense of the community.

Response:

The DOE Siting Guidelines specify four potentially adverse and one disqualifying condition concerning socioeconomic impacts (10 CFR 960.5-2-6). Detailed characterization of social and economic conditions such as that required by the DOE Siting Guidelines is beyond the scope of work conducted at the regional phase. Community studies will, therefore, be deferred to the area and site characterization phases, when more detailed studies will be appropriate. 
SECTION/TOPIC AREA: Other Environmental Variables (Cultural, Archaeological, and Historic Resources)

COMMENT LETTER REFERENCE: NC-A-1 and NC-B-24

Comments:

We note in the project report that consideration of sites involving properties listed in the National Register of Historic Places and state historic sites will not be treated at the regional phase of screening, but will be considered in subsequent phases of screening. It is the hope of this office that such properties will be given the utmost consideration given their significance to the historical, archaeological and architectural character of their localities and state. He will be happy to provide information once the sites to be considered are selected. (NC-A-1)

Because of the lack of cultural resource inventories in some areas, it is al so recommended that area phase grants cover the cost of carrying out such inventories; and that any sites eligible for designation be disqualified at the site phase of the process, regardless of whether the designation process is completed. (NC-B-24)

\section{Reponse:}

The first comment from North Carolina is correct in that properties listed in the National Register of Historic Places and State Historic Sites will be treated at the area and site phases. The CRP will work with state officials responsible for historic preservation in identifying these features.

It is yet to be determined whether eligible but not yet designated sites would be considered during area or site phase investigations. Regarding grants for cultural resource inventories, it is expected that DOE will have the necessary work performed and thus grants to states will not cover such activity. 
SECTION/TOPIC AREA: Other Environmental Variables (Native American Resources)

COMMENT LETTER REFERENCE: NJ-33 and WI-12

Comments:

There is also objection to the omission of $960.5-2-5(c)(5)$. In addition to $1,2,3,4$, and 6 , the proximity to, and projected significant adverse environmental impacts of the repository and its support facilities on, a significant Native American resource, such as a major Indian religious site, or other sites of unique cultural interest should be reviewed as a Step 2 variable. The regional consideration of such sites would be consistent with the Nuclear Waste Policy Act and the DOE Siting Guidelines. (NJ-33)

Our position remains that reservation lands, Indian-owned nonreservation lands, and lands to which Indian tribes hold special treaty rights should be disqualified. At the very least these lands should be treated as a Step 2 or Step 3 variable, given the recognition as a potentially adverse condition in the siting guidelines. (WI-12)

\section{Response:}

The CRP continues to believe that consideration of Native American Resources under 10 CFR $960.5-2-5(c)(5)$ is not achievable at the regional phase. The evaluation of 10 CFR $960.5-2-5(c)(5)$ is complex and requires consideration of land ownership, administrative boundaries, legal jurisdictions, and acknowledged (reservation and off-reservation) rights. It is CRP's position that the Nuclear Waste Policy Act does not mandate evaluation of Native American Resources at the regional phase of investigation. A discussion of Native American Lands and identification of Federal and State Indian reservations appears in Section 3.4 of the RECR. Should a candidate area impinge on Native American Resources, then an evaluation of the impacts would occur as part of the area and site phase investigations. 
SECTION/TOPIC AREA: 5.4 Other Factors (Step 3)

COMMENT LETTER REFERENCE: NY-A-31

Comment:

How does no data effect a site's evaluation as related to positive/negative data?

Response:

No judgment is made regarding a grid cell's favorability if that grid cell does not contain data for a Step 3 variable. 


\section{SECTION/TOPIC AREA: 5.4 .1 Thickness of Rock Mass}

COMMENT LETTER REFERENCE: MI-A-61

Comment:

The proposed measurement for this variable from ground surface credits the thickness of the overburden to the rock body. Since thick overburden is considered an adverse factor, we suggest that when information is available, the depth of overburden be subtracted before the variable is scaled.

\section{Response:}

The distances to the bottom of the rock body used in the scale are considerably greater than overburden thickness in the three regions, which comprises only a small fraction of the overall distance. Overburden thickness, therefore, is not considered significant enough to be subtracted from the total distance. Areas with thick overburden are already penalized by the thickness of overburden variable.

\section{COMMENT LETTER REFERENCE: MI-A-62}

Comment:

Under Measure, the nature of this measurement is not clear for oddly shaped rocks. A generic figure showing how this dimension is measured would be helpful.

\section{Response:}

Thickness of rock mass data (obtained from drill holes and geophysical surveys) will be measured by means of a contour (isopach) map showing lines of equal thickness in the same manner as overburden thickness. 
COMMENT LETTER REFERENCE: GA-A-32

Comment:

This scale is nonlinear, illogical and arbitrary. Since DOE has defined the reference repository depth to be 1,500 feet, then a worst case situation would be where the distance to the bottom of the rock body was less than this value. We recommend the following scale:

Distance to Bottom of Rock Body (feèt)

\begin{tabular}{ccccc}
$\leq 1500$ & $>1500-3000$ & $>3000-4500$ & $>4500-6000$ & $>6000$ \\
\hline 1 & 2 & 3 & 4 & 5
\end{tabular}

Response:

The scale adopted by the CRP and described in Section 5.4.1 of the SMD, al though not entirely linear is logical, as the first increment is based on a multiple of twice the depth of a reference repository (465 meters $[1,500 \mathrm{ft}]$ ). The only real difference between the reviewer's scale and the one chosen by CRP is the establishment of the most adverse end point at a depth which is twice the reference repository depth.

COMMENT LETTER REFERENCE: SC-B-36

Comment:

Pp. A-141-142 - The response to a comment that thickness of rock mass should be a Step 2 variable was negative based on the problem of limited and very scattered data for the thicknesses of rock bodies. However, this is also true for the areal extent of rock bodies in the subsurface - especially for high-grade metamorphic rocks which dip in the subsurface. Therefore, if the respondent's logic is followed, then areal extent should be a Step 3 variable or thickness should be a Step 2 variable. If DOE intends to use either of 
these variables at Step 2, what assumptions will be used for numeration when data are not available--particularly for high-grade metamorphic rocks?

\section{Response:}

Thickness of rock mass information is very 1 imited for the regional phase. Thus, the variable is categorized as a Step 3 variable. This permits the few data points that are available to be considered on an individual bas is for each rock body.

As noted previously, surface extent of crystalline rocks is used as a surrogate for actual extent at repository depth, and this assumption is believed valid at a regional phase. Rock mass extent is measureed according to scaled diameters of inscribed cirlces within the rock body boundary. 
SECTION/TOPIC AREA: 5.4 .2 Thickness of Overburden

COMMENT LETTER REFERENCE: GA-A-33

Comment:

This scale is nonlinear, illogical and arbitrary. DOE's scale does not appear to be based on any quantitative engineering data.

Thickness of Overburden (feet)

\begin{tabular}{ccccc}
$\geq 200$ & $>150-200$ & $>100-150$ & $>50-100$ & $>0-50$ \\
\hline 1 & 2 & 3 & 4 & 5
\end{tabular}

\section{Response:}

The scale for thickness of overburden has been modified to make it more linear and to better fit the data available. The result is more like the scale proposed by Georgia.

COMMENT LETTER REFERENCE: VA-B-23

Comment:

We doubt that data on thickness of overburden on a regional scale are available in sufficient amount to be useful in region-to-area screening. Overburden thickness should be an onsite, not region-to-area determination.

\section{Response:}

Step 3 variables, by definition, are those geologic variables which relate to potential health and safety issues for which only scattered data are available in the 17 crystalline states or for which the data collection effort for 17 states would be prohibitively expensive (ground-water resources). The 
concept was developed in response to State requests to use such geologic data Where it was available in region-to-area screening. In the Southeastern Region, very few of these data are available. 
SECTION/TOPIC AREA: 5.4 .3 State-of-Stress

COMMENT LETTER REFERENCE: SC-B-34 and SC-C-34

Comments:

Is the scale for Maximum Stress Difference (p. 106) (MPA) applicable, if the rock body being considered (1) is not a granitic body or (2) is a granitic gneiss?

Response:

The state-of-stress criterion is applicable to all crystalline rock, as defined in Section 5.2.1. The term "granitic" under Scaling has been replaced by the term "crystalline". 
SECTION/TOPIC AREA: 5.4.4 Ground-Water Salinity

COMMENT LETTER REFERENCE: MI-A-33, MI-A-63, MN-C-28, NJ-36, GA-A-34, GA-A-35, and NC-B-29

Comments:

Should the ground-water salinity variable be addressed differently for rock bodies near the seaboard? (MI-A-33)

Under Comments, "Fewer data" than what? (MI-A-63)

The ground-water salinity variable requires rescaling to be consistent with other scales. The size of each category spans an order of magnitude, and there is room for adjustment by making two categories out of any one of the four recognized categories. (MN-C-28)

On page 102 the reference to the DOE Siting Guidelines for Ground-water Salinity is 10 CFR $960.4-2-1(b)$. This section in the most recent draft of the DOE siting guidelines (May 14, 1984) is quite extensive, however does not deal with ground-water salinity as discussed on pages 106 and 107 of the screening methodology. On p. 54 (Section 4.3.1 Postclosure Guidelines Feasible for Regional Screening) there is a section pertaining to Ground Water with $10,000 \mathrm{ppm}$ or More Total Dissolved Solids. This section cites (10 CFR 960.4-2-1(b)(7)) of the DOE Siting Guidelines, however in the most recent draft of the DOE siting guidelines, this section has been deleted. Please clarify the use of the ground-water salinity condition and whether all of 10 CFR 960.4-2-1(b) will be used in Step 3 screening. (NJ-36)

P. 107 - The greater density of high-salinity water will not prevent convection. Thermal loading by the repository will tend to increase the mixing of saline and surface water. (GA-A-34)

This scale is nonlinear, illogical, and arbitrary. The $\$ 3$ and $\# 4$ values appear to represent the same thing or something is missing. The scale needs values not 4 . We recommend the following scale: 
Content of TDS in Ground-Water (ppm)

Drinking

\begin{tabular}{|c|c|c|c|c|}
\hline $\begin{array}{l}\text { ter } \\
500\end{array}$ & $\begin{array}{r}\text { Fresh } \\
>500-1000\end{array}$ & $\begin{array}{c}\text { Brackish } \\
>1000-10,000\end{array}$ & $\begin{array}{c}\text { Salty } \\
>10,000-100,000\end{array}$ & $\begin{aligned} & \text { Brine } \\
> & 100,000\end{aligned}$ \\
\hline
\end{tabular}

1

2

3

4

5

While nonlinear, the scale, nevertheless, would be based on ground-water salinity classifications in relatively common use. (GA-A-35)

The effect of thermal loading on saline water is not considered in the discussion of Ground-Water Salinity, and this could affect the significance of this variable's performance. (NC-B-29)

Response:

The comment that the greater density of high-salinity water will not prevent convection is correct. However, the need to prevent convection is alleviated by the absence of connecting pathways, as evidenced by the difference in salinity between the saline ground waters and surface waters. This variable has been dropped from the region-to-area screening based on indications that much of the available data are more directly related to seawater encroachment rather than paleo-salinity. 
SECTION/TOPIC AREA: 5.4 .5 Ground-Water Resources

COMMENT LETTER REFERENCE: MI-A-64

Comment:

P. 108 - Under Comments, third to last line, change "is" to "are".

Response:

The change has been made.

COMMENT LETTER REFERENCE: NH-6

Comment:

Ground water concerns are not adequately addressed given the surrogate being used to measure availability.

\section{Response:}

The CRP believes ground-water concerns are being appropriately addressed for region-to-area screening. Availability, reliability, and utility of data on this factor vary widely between and within the states. In some states, all wells are recorded and reported on a form which requests information on gallons per minute pumped and drawdown, thus giving information on specific capacity. More commonly, however, data are not available for areas remote from population centers, are not uniform in quality and quantity, and of ten exist as hundreds or thousands of records that are inconsistent in quality and never have been evaluated by professional hydrogeologists familiar with local ground-water resources. These concerns will be considered and evaluated in greater detail in subsequent characterization phases. 
Comments:

Section 5.4.5 on ground-water resources may not give adequate consideration to the stratified drift aquifers that are the primary source of groundwater for about 30 percent of the population of Rhode Island. The groundwater yield used in this scale seems extremely high and the scale itself is nonlinear. (RI-15)

Definition of the term "significant potable ground-water resource suitable for development as water supplies" varies from region to region depending upon the availability of ground water. In Vermont crystalline bedrock aquifers capable of yielding $10 \mathrm{gpm}$ are "significant" in terms of the State's needs and usage. The scaling displayed on page 108 is therefore inappropriate for Vermont and is not a valid factor to assure protection of our ground-water resources. (VT-17)

\section{Response:}

Potential ground-water resources of unconsolidated aquifers along major streams in Rhode Island and Vermont are presented on Plate 5 of the revised draft RGCR (DOE, 1984d). Relative differences of resource significance are discussed in the RGCR and pertain to commercial or industrial-capacity wells and not to supplies for individual low-volume users. The scale has been modified to be more conservative and somewhat more linear.

\section{COMMENT LETTER REFERENCE: GA-A-36}

Comment:

P. 107, paragraph 7 - Define the term significant in the phrase "...as significant potable ground-water resources...". 
Response:

In the context of the paragraph defining Ground-Water Resources, the modifier "significant" refers to resources that would be able to provide quantities of potable water which would be adequate for commercial or light industrial uses.

\section{COMMENT LETTER REFERENCE: GA-A-37}

Comment:

This variable is measuring individual pump capacity of a given well rather than the resource availability for the well. The scaled values cover the range of present demands for water of major users, not projected future demands.

\section{Response:}

This variable is scaled using yield in units of gallons per minute. The mapped data are potential well yields represented by contours. Essentially, this is an evaluation of presently mapped availability of the resource. Knowledge of the current availability and demand provides an indication of the reserve ground-water resources available to meet potential additional future demands.

COMMENT LETTER REFERENCE: NC-B-30

\section{Comment:}

The scale for Ground-Water Resources is not linear. He recommend using 50-gallon increments ranging from 0-250 over the five units of scaling value. The DOE's 500 gallon/minute standard for measurement is not consistent with Morth Carolina's growth patterns, physical conditions, and potential for pendence on ground water in the future. 
Response:

The Ground-Water Resource variable scale has been changed to more closely reflect the data mapped in the only region which has directly mappable information (the North Central Region). Information in the Northeastern and Southeastern Regions is not in a form suitable for mapping and implementing this variable, because in the Northeastern Region interpretations would be required while in the Southeastern Region both collection of additional data and interpretations of the data would be required. For application of Step 2 and Step 3 variables, the CRP is consistently avoiding interpretation of both environmental and geologic data to prevent misrepresentation.

\section{COMMENT LETTER REFERENCE: SC-B-35 and SC-C-35}

Comments:

The scale of average ground-water yield used for this variable does not accurately reflect water wells in crystalline rock. Yields indicated at 1 and 2 on the scale are quite rare. Average yields would be closer to $10-50 \mathrm{gpm}$, 4 on the scale. This scale should be changed from an exponential to a linear scale, which should range from 250 to $0 \mathrm{gpm}$ in $50 \mathrm{gpm}$ increments.

Response:

To more accurately evaluate Ground-Water Resource potential, the scale of this variable has been changed to range from $\leq 20$ to $>500 \mathrm{gpm}$ ( $\leq 76$ to $>1,9001 \mathrm{pm})$. The scale is still nonlinear to permit encompassing the total range of well yields for which data are available. To truncate the scale at $250 \mathrm{gpm}(950 \mathrm{lpm})$ would not permit an adverse scaling assignment to areas of greater potential yield; therefore, the upper limit of $>500 \mathrm{gpm}(>1,900 \mathrm{lpm})$ was retained. 


\section{Comment:}

Major fractures can produce significant quantities of water in crystalline rock... If a crystalline rock body does contain a highly productive shear zone, the portion of the body not affected by the zone could remain as a potential site because of the lack of porosity and permeability in that unaffected portion. A method should be devised so that weighting under the program format does not eliminate the unaffected portion of the body.

\section{Response:}

The hydrologic significance of major shear zones is represented in the Postemplacement Faulting variable. A rock body would be considered more favorable at greater distances from these features. Thus, the unaffected rock would remain available for siting a repository. 
SECTION/TOPIC AREA: Other Step 3 Variables (Host Rock Thermal Properties)

COMMENT LETTER REFERENCE: VA-B-29

Comment:

P. A-153, "Response" - Are there not some circumstances under which thermal data would be critical to repository performance?

\section{Response:}

No, thermal conductivity and thermal expansion, al though highly variable for different rock types, are not so great that they cannot be accomodated by specific parameters of design on a site specific basis (Tammenagi and Chieslar, 1985). 
SECTION/TOPIC AREA: 7.0 Statutes And Regulations

COMMENT LETTER REFERENCE: VA-B-12

Comment:

Those regulations for 10 CFR 960 and 40 CFR 191 should be final before proceeding with the screening process.

\section{Response:}

The final DOE Siting Guidelines (DOE, 1984c) were codified prior to finalization of the SMD. As noted in a previous response, an additional 30day period was allotted for states to perform a subsequent review of the draft SMD based on the final DOE Siting Guidelines. It is not expected that 40 CFR 191 (EPA, 1982) will be published as a final rule prior to preceding with the region-to-area screening process. However, there are no provisions of proposed 40 CFR 191 as currently written that would invalidate the region-toarea screening process. 
SECTION/TOPIC AREA: Appendix B: Summaries of State-Protected Lands

COMMENT LETTER REFERENCE: MI-A-66

Comment:

State recreation areas administered by the Parks Division of the Michigan Department of Natural Resources and Wild Life Research Areas in Michigan should be disqualified.

Response:

Data obtained from the Michigan Department of Natural Resources indicated that all state park system units in the Upper Peninsula are state parks, and none are termed recreation areas. State recreation areas were, therefore, not identified as disqualified state park system components.

COMMENT LETTER REFERENCE: ME-18

Comment:

...The status of Critical Areas as defined by the State Planning Office. We would appreciate a clarification of the status of these lands in the region-to-area screening process and in subsequent phases of screening.

\section{Response}

As noted in Appendix $B$, these lands are being disqualified. 
Comments:

... No mention is made of Class $A$ rivers as defined in recent Maine legislation. At one time it was our understanding that Class $A$ rivers were granted disqualification status (letter 6 April 1984 from Ben Maiden to Walter Anderson). (ME-19)

We also requested that other rivers be considered to be of statewide or local significance be considered as adverse factors (letter of 7 May 1984 from Walter Anderson to Tom Anderson). (ME-20)

Response:

Class A rivers will be disqualified. The disqualified rivers are listed in the revised draft RECR.

Any surface water body that meets the definition of surface water bodies used in the SMD (see Section 5.3.9) will be treated as a regional screening variable.

COMMENT LETTER REFERENCE: NJ-14

Comment:

In addition, the New Jersey State Wildlife Management Area list (NJ-3) is incomplete. It should include the Musconetcong Wildlife Management Area and the Round Valley Reservoir Wildlife Management Area.

Response:

The Round Valley Reservoir Wildlife Management Area is listed in Appendix $B$ of the Northeastern RECR. The CRP has received conflicting information from New Jersey regarding the status of the Musconetcong Wildlife hagement Area. 
Comment:

In Appendix B, page 10, the disqualified land category listed for New Jersey is termed 'Natural Area Preserves'. For clarification purposes, New Jersey does not refer to lands designated under the Natural Areas Systems Act N.J.S.A. 13:1B-15.12a et seq. as preserves but simply as Natural Areas.

\section{Response:}

The change has been made in Appendix $B$ in the final SMD.

\section{COMMENT LETTER REFERENCE: NJ-51}

Comment:

Please be advised that portions of the following areas have been added to the Register of Natural Areas: Johnsonburg, Freling Luysen and Green Townships, located in Warren and Sussex Counties.

Response:

If these areas were established prior to passage of the Nuclear Waste Policy Act of 1982, then they will be added to the RECR data base. If these areas were established after passage, then consistent with 10 CFR $960.5-2-5(d)(3)$, these areas would not be disqualified.

\section{COMMENT LETTER REFERENCE: NJ-52}

\section{Comment:}

Please forward to us your list of New Jersey State Natural Areas. 
Response:

The New Jersey State Natural Areas are listed in the revised draft RECR (DOE, 1984f).

\section{COMMENT LETTER REFERENCE: NJ-53}

Comment:

As previously mentioned we disagree with decision rule \#4 on p. B-8 and we also feel that decision rule \#7 is inconsistent with the DOE Siting Guidelines to eliminate sites as early in the screening process as possible. If CRP recognizes that certain National and State Historic Sites "will ultimately" ... "be disqualified" then why not disqualify them in the regional screening process. If variability in State Statutes is recognized and known, any and all disqualified sites should be eliminated.

\section{Response:}

It is CRP's view that the elements of decision rule \#4 are consistent with provisions of the DOE Siting Guidelines (10 CFR 960.5-2-5 (d)(2) and (d)(3)). Regarding decision rule \#7, the CRP neither has within its data base a complete list of National and State Historic Sites nor believes that resolution of the variability in state statutes (which would be required to determine screening status) is practical or necessary at the regional phase.

COMMENT LETTER REFERENCE: NY-A-34

Comment:

P. B-9 - It should be made clear that the Adirondacks are exempted as a state park. 


\section{Response:}

The Adirondack State Park will be disqualified from consideration as the location for the repository support facilities or for the restricted area.

COMMENT LETTER REFERENCE: $S C-B-30$ and SC-C-30

Comments:

The proper terminology on page $\mathrm{B}-8(7)$ is National Register of Historic Places.

Response:

The change has been made as suggested.

COMMENT LETTER REFERENCE: SC-B-31 and SC-C-31

Comments:

Discussion on p. B-8, number 7 , concerns National Register and state historic sites and recognition that these will be considered in repository siting. This section should be revised to make clear that properties found to be eligible for inclusion in the Register should receive consideration equal to properties listed in the National Register. This is very important because most significant archeological sites in this region have not been listed nor have many eligible structures. Furthermore, only with the consideration of eligible properties will the CRP be in compliance with Section 106 and 36 CFR Part 800 . 


\section{Response:}

The discussion in Appendix $B$ has been expanded to note that sites eligible for inclusion in the National Register and archaeological sites will be considered in subsequent phases of screening.

COMMENT LETTER REFERENCE: VA-A-9

Comment:

Sites certified as historic districts and Virginia Historic Landmarks pursuant to Title 10, Chapter 11 of the Code of Virginia are irreconcilably conflicting with repository siting and should be listed as a disqualifying land use (Appendix B, p. B-11).

\section{Response:}

During region-to-area screening, the CRP is considering only Federal or State historic sites and landmarks during Step 1 if they are contained within the administrative boundary of a component of either Federal or Stateprotected lands. Both Federal and State historic sites and landmarks will be considered in the area phase. 
SECTION/TOPIC AREA: Editorial

COMMENT LETTER REFERENCE: SC-B-6 and SC-C-6

Comments:

There is inconsistent use of metric and English units throughout this document, making evaluation and understanding of the text difficult and awkward in many places.

Responses:

In the sections of the final SMD related to scaling, English units are used because mapping of features is performed using a 1-square-mile grid cell unit of measure. In other parts of the final SMD, metric units are shown as the preferred unit of measurement with English units following in parentheses. 


\section{REFERENCES}

Algermissen, S. T., O. M. Perkins, P. C. Thenhaus, S. L. Hauson, and B. L. Bender, 1982. Probabilistic Estimates of Maximum Acceleration and Velocity in Rock in the Contiguous United States, Open-File Report 82-1033, U.S. Geological Survey, U.S. Department of Interior, Washington, DC.

American National Standards Institute/American Society of Mechanical Engineers, 1983. Quality Assurance Program Requirements for Nuclear Facilities, NQA-1, New York, NY.

ANSI/ASME, see American National Standards Institute/American Society of Mechanical Engineers.

Barnes, H. L., 1979. Geochemistry of Hydrothermal Ore Deposits, John Wiley \& Sons, Inc., New York, NY, p. 466.

Brown, L., C. Ando, S. Klemperer, J. Oliver, S. Kaufman, B. Czuchea, J. Walsh, and Y. Isachsen, 1983. "Adirondack-Appalachians Crustal Structure: The COCORP Northeast Traverse", Geologic Society of America, Bulletin, V. 94, pp. 1173-1184.

Cook, F., D. Albaugh, L. Brown, S. Kaufman, J. Oliver, and R. Hatcher, 1979. "Thick Skinned Tectonics in the Crystalline Southern Appalachians: COCORP Seismic Reflecting Profiling in the Blue Ridge and Piedmont", Geology, V. 7, pp. 503-507.

DOE, see U.S. Department of Energy.

EPA, see U.S. Enviromental Protection Agency.

Gable, D. J., and T. Hatton, 1983. Maps of Vertical Crustal Movements in the Conterminous United States Over the Last 10 Million Years, USGS Miscellaneous Investigations Series Map I-1315, map scale 1:5,000,000-1:10,000,000, U.S. Department of the Interior, Washington, DC. 
Heath, R. C., 1984. Ground-Water Regions of the United States, USGS Water Supply Paper 2242, U.S. Department of the Interior, Washington, DC.

Isachsen, Y., and D. Fisher, 1970. Geologic Map of New York, Adirondack Sheet, New York State Museum and Science Service Map and Short Series \#15.

NRC, see U.S. Nuclear Regulatory Commission.

OCRD, see Office of Crystalline Repository Development.

Office of Crystalline Repository Development, 1983. A National Survey of Crystalline Rock and Recommendations of Regions to be Explored for High-Level Radioactive Waste Repository Sites, BMI/OCRD-1, Battelle Memorial Institute, Columbus, OH.

SPSS Inc., 1984. Statistical Package for the Social Sciences, Statistical Analysis Sytem for the IBM PC/XT, Version 1, Chicago, IL.

Tammenagi, H. V., and J. D. Chieslar, 1985. Interim Rock Mass Properties and Conditions for Analyses of a Repository in Crystalline Rock, BMI/OCRD-18, prepared by RE/SPEC Inc for the Office of Crystalline Repository Development, Columbus, $\mathrm{OH}$.

U.S. Department of Energy, 1980. Proposed Rulemaking on the Storage and Disposal of Nuclear Waste, DOE/NE-007, Washington, DC.

U.S. Department of Energy, 1984a. Region-to-Area Screening Methodology for Crystalline Repository Project, DOE/CH/10139-1 (Draft) prepared for the Crystalline Repository Project Office. Office of Civilian Radioactive Waste Management, Battelle Memorial Institute, Columbus, 00.

U.S. Department of Energy, 1984b. "General Guidelines for the Recommendation of Sites for the Nuclear Waste Repositories", July, with concurrence by the U.S. Nuclear Regulatory Commission June 22, to be codified. 
U.S. Department of Energy, 1984c. "General Guidelines for the Recommendation of Sites for the Nuclear Waste Repositories", Final Rule, Federal Register, Vol. 49, No. 236, pp. 47714-47770, Washington, DC, December.

U.S. Department of Energy, 1984d. Revised Draft Northeastern Regional Geologic Characterization Report, Vols. 1 and 2, DOE/CH-7, prepared for the Crystalline Repository Project Office by the Office of Crystalline Repository Development, Battelle Project Management Division, Argonne, IL.

U.S. Department of Energy, 1984e. Generic Requirements for a Mined Geologic Disposal System, DOE/NE/44301-1, Washington, DC.

U.S. Department of Energy, 1984f. Revised Draft Northeastern Regional Environmental Characterization Report, Vols. 1 and 2, DOE/CH-4, prepared for the Crystalline Repository Project Office by the Office of Crystalline Repository Development, Battelle Project Management Division, Argonne, IL.

U.S. Environmental Protection Agency, 1982. "Environmental Standards for the Management and Disposal of Spent Nuclear, High-Level and Transuranic Radioactive Wastes", Proposed Rule Federal Register, Vo1. 47, No. 250, pp. 58196-59206, Washington, DC, December.

U.S. Geological Survey, 1965. A Base Map of the United States, Map 3-A.

USGS, see U.S. Geological Survey.

U.S. Nuclear Regulatory Commission, 1983a. Disposal of High-Level Radioactive Wastes in Geologic Repositories: Licensing Procedures, Technical Rule, 10 CFR 60, Code of Federal Regulations, Washington, DC, June.

U.S. Nuclear Regulatory Commission, 1983b. Licensing Requirements for Land Disposal of Radioactive Waste, 10 CFR 61, Code of Federal Regulations, Washington, DC, January. 
APPENDIX B

SUMMARIES

OF

STATE-PROTECTED LANDS 
In development of the region-to-area screening methodology, certain state-protected lands were determined to warrant status as a disqualifying condition or a potentially adverse condition or were recommended to have no screening status at the regional phase. The DOE Siting Guidelines provide the basis for consideration of state-protected lands in the region-to-area screening methodology in Section 960.5-2-5(d)(2) and (3) as follows:

"Any of the following conditions shall disqualify a site:

(2) Any part of the restricted area or repository support facilities would be located within the boundaries of a component of the National Park System, the National Wildlife Refuge System, the National Wilderness Preservation System, or the National Wild and Scenic Rivers System.

(3) The presence of the restricted area or the repository support facilities would conflict irreconcilably with the previously designated resource-preservation use of a component of the National Park System, the National Wildlife Refuge System, the National Wilderness Preservation System, the National Wild and Scenic Rivers System, or National Forest Lands, or any comparably significant state-protected resource that was dedicated to resource preservation at the time of the enactment of the Act."

The application of (d)(2) has been detailed in Chapter 5.0 of this methodology document and includes a listing of the "components" of the four Federal systems as defined by U.S. Code and having disqualifying status in the region-to-area screening methodology.

The disqualified Federal components under (d)(3) are essentially those land units discussed in (d)(2) with the addition of three types of National Forest Lands: research natural areas, primitive areas ${ }^{1}$, and national recreation areas. It has been determined by the CRP that the presence of the restricted area or the repository support facilities within the boundaries of these three National Forest Lands types would categorically represent an irreconcilable conflict of use, since they are typically dedicated to a single-resource preservation use. 
They therefore merit disqualification under (d)(3) of the DOE Siting Guidelines. The remaining National Forest Lands, predominantly multiple-use National Forests, do not categorically represent irreconcilable conflict-ofuse and are thus being treated as Step 2 variables in the region-to-area screening.

The assignment of screening status for state-protected lands under (d)(3) requires a determination of comparable significance between the disqualified Federal components and state-protected lands, and requires a determination of irreconcilable conflict-of-use between the state component and the presence of a restricted area or repository support facilities. The CRP has based a determination of comparable significance on a comparison of state laws and regulations, which establish the purpose of various state-protected land categories, with the legal authority in the U.S. Code and Code of Federal Regulations, which establish the purpose of the Federal components. The determination of whether an irreconcilable conflict-of-use exists for purposes of the region-to-area screen is a CRP decision that has been made for each state-protected land category using the following conservative assumption: the restricted area or the repository support facilities are assumed to be located within the administrative boundaries of the state-protected resource.

Further details of the decision rules utilized in these determinations are discussed later in this appendix. For the region-to-area screening methodology, only land units in excess of 130 hectares ( 320 acres) in size are being mapped. Units smaller than 130 hectares ( 320 acres) will be afforded at least similar status and considered in subsequent phases of screening and CRP will evaluate the impact of Step 1 disqualifying features which are less than 130 hectares ( 320 acres) in selecting candidate areas.

\section{PROCESS}

To determine how the various state-protected lands would be treated in region-to-area screening, it was announced at the third workshop in Atlanta in February 1984, that the CRP would undertake a statutory review of legislation establishing Federal-protected lands and related state-protected lands to evaluate comparable significance. A complete listing of state-protected land categories was compiled which included the names of the units known by the CRP to exist in each category. These categories were reviewed and statutory ar 
regulatory needs identified. This information was combined into statespecific packages and mailed to the respective states in March and April 1984. The CRP request accompanying this information asked for additional state input including: (1) copies of relevant statutory and/or regulatory information, (2) state review of the land categories and unit names for completeness and accuracy, and (3) formal opportunity for the states to submit additional state-protected land categories, with supporting statutory and or regulatory rationale, which a state considered to deserve region-to-area screening status. Limited follow-up by the CRP was conducted for clarification or to acquire additional data. As information was received, applicable state statutory authority was reviewed for each land category, by state, and compared to the language of the statutory authority for the Federal components.

The purpose set forth in the U.S. Code and Code of Federal Regulations for the five Federal systems identified in the DOE Siting Guidelines, $960.5-2-5(d)(2)$ and (d)(3) is as follows:

National Park System - 16 USC \$1C defines the "National Park System" to "include any area of land and water now or hereafter administered by the Secretary of the Interior through the National Park Service for park, monument, historic, parkway, recreational or other purposes." 16 USC \$1 states the fundamental purpose of parks and monuments is to "conserve the scenery and the natural and historic objects and the wildlife therein and to provide for the enjoyment of the same in such manner and by such means as will leave them unimpaired for the enjoyment of future generations." National Wildlife Refuge System - 16 USC \$668dd establishes "for the purpose of consolidating the authorities relating to the various categories of areas that are administered by the Secretary of the Interior for the conservation of fish and wildlife, including species that are threatened with extinction, all lands, waters, and interests therein administered by the Secretary as wildlife refuges, areas for the protection and conservation of fish and wildlife that are threatened with extinction, wildlife ranges, game ranges, wildlife management areas, or waterfowl production areas are hereby designated as the "National Wildlife Refuge System." 
National Wilderness Preservation System - 16 USC $\$ 1131$ states "there is hereby established a National Wilderness Preservation System to be composed of federally owned areas designated by Congress as 'wilderness areas', and these shall be administered for the use and enjoyment of the American people in such manner as will leave them unimpaired for future use and enjoyment as wilderness, and so as to provide for the protection of these areas, the preservation of their wilderness character, and for the gathering and dissemination of information regarding their use and enjoyment as wilderness."

National Wild and Scenic Rivers System - The policy and criteria for designation pursuant to the Wild and Scenic Rivers Act as stated in 16 USC $\$ 1271$ is that certain rivers posses outstandingly remarkable scenic, recreational, geologic, fish and wildlife, historic, cultural, or similar values, and shall be preserved in free-flowing condition and protected for the benefit and enjoyment of present and future generations.

National Forest Lands - Congressional declaration of purpose is set forth in 16 USC $\$ 528$. "It is the policy of Congress that national forests are established and shall be administered for outdoor recreation, ranges, timber, watershed, and wildlife and fish purposes." Pursuant to 16 USC $\$ 529$ "The Secretary of Agriculture is authorized and directed to develop and administer the renewable surface resources of the national forests for multiple use and sustained yield of the several products and services obtained therefrom. In the administration of the national forests due consideration shall be given to the relative values of the various resources in particular areas. The establishment and maintenance of areas of wilderness are consistent with the purpose and provisions of this Act." The importance of National Forest System research natural areas is established in 36 CFR $\$ 251.23$ "when appropriate the Chief (of the Forest Service) shall establish a series of research natural areas, sufficient in number and size to illustrate adequately or typify for research or educational purposes, the important forest and range types in each forest region, as well as other plant communities that have special or unique characteristics of scientific interest and importance. Research natural areas will be retained in a virgin or unmodified 
condition except where measures are required to maintain a plant community which the area is intended to represent." Primitive areas are afforded a similar degree of importance within National Forest Lands; however, none occur in the 17 crystalline states under study. National recreation areas are established by Congress for public recreational use and protection of related resource values. There are two national recreation areas in the 17 crystalline states. 
DECISION RULES

The determination of whether a given state-protected land would be a disqualifying condition, a Step 2 regional screening variable, or not considered in the region-to-area screening methodology was guided principally by a series of decision rules.

1. Those state-protected land categories determined to (1) be comparable to a disqualified component of one of the Federal systems and (2) categorically represent an irreconcilable conflict-of-use and be assigned "disqualification" status as the recommended screening status. As a result, such land categories as wilderness areas, parks, wild and scenic rivers, wildlife lands, and natural areas would be disqualified.

2. All categories of state-protected wildlife lands that are comparable in statute to the National Wildlife Refuge System and whose primary form of ownership is state ownership-in-fee were assigned "disqualification" status. It could not be determined categorically whether non-state-owned wildlife lands were dedicated to resource (i.e., habitat) preservation. Therefore, non-state-owned wildlife lands were given "no status" in region-to-area screening because it could not be categorically determined that an irreconcilable conflict-of-use would exist.

3. Those state-protected land categories determined to have a primary purpose of timber production, conservation, or management which may include other uses received a recommendation of "Step 2 variable" status consistent with the treatment of analogous units of national forests. As a result such land categories as state forests were assigned a "Step 2 variable" status.

4. Land categories were recommended to have "no status" for region-to-area screening if any of the following apply: (1) comparability to a Federal component addressed in the guidelines could not be established (2) enabling legislation was passed after the passage of the Nuclear Waste Policy Act of 1982, or (3) no state statutes exist authorizing the 
designation of a land category. As a result, land categories such as fish hatcheries were recommended to have "no status".

5. Land title helped categorize the units within each state but was not a basis on which screening status was determined.

6. Current management practice was not a basis on which screening status was determined. Considerable variation between states and among similar units within a state precluded the consistent use of management practice as a regional decision rule.

7. Historic sites that are components of the National Parks System (i.e., national military parks, national monuments, national historic sites, national memorials, national historical parks, national battlefields, national battlefield sites, and national battlefield parks) and are greater than 130 hectares ( 320 acres) will receive a "disqualification" status (under 10 CFR 960.5.2.5d(2)). It is a CRP decision that the National Register of Historic Places and State Historic Sites will not be treated at the regional phase of screening and, hence, are designated as "no status". The CRP recognizes that these features and other historic sites of potential significance (i.e., sites eligible for inclusion in the National Register or archaeological sites), need to be considered in repository siting. The determination to defer was made on the basis of considerable variability in state statutes, the extremely large number of such sites, and their generally small size (i.e., less than 130 hectares [320 acres]). Even so, a number of State Historic Sites are expected to be disqualified in the region-to-area screening because they are located within the administrative boundaries of disqualified state parks, or within disqualified populated places.

Those land units receiving a recommendation of "Step 2 variable" status may, at subsequent phases, warrant a "disqualification" status. Those land units receiving a recommendation of "no status" may, at subsequent phases, receive a recommendation of a "Step 2 variable" or a "disqualification" status. 
DISQUAL IFIED

The review of statutes applicable to state parks supported a determination of comparability to the National Park System and were determined by the Crystalline Project Office (CPO) to represent an irreconcilable conflict of use with the presence of the restricted area or repository support facility. Therefore, in all 17 states, parks will be disqualified (this will also include recreation areas covered under state park statutes in North Carolina, Connecticut, New Jersey, Massachusetts, New York, Minnesota, and Wisconsin).

Review of applicable statutes for state wild, scenic, and recreational rivers also supports comparability with the Federal system and were determined by CPO to represent an irreconcilable conflict-of-use with the presence of the restricted area or the repository support facilities. Therefore, such rivers will be disqualified in all 17 states.

Review of applicable state statutes established comparability with the disqualified Federal Wilderness Preservation System and Research Natural Areas of the National Forest System, components of the National Wildlife Reguge System, and similar areas in the 17 states. These lands were determined by CPO to represent an irreconcilable conflict-of-use with the presence of the restricted area or repository support facilities, and therefore, these lands will be disqualified. A listing of the disqualified state-land categories comparable to Federal wilderness areas, research natural areas, and wildlife lands is provided for each state below.

\section{North Central}

Michigan
- wilderness areas
- wild areas
- natural areas
- research natural areas
- waterfowl management areas

Minnesota

- wilderness areas 
- scientific and natural areas

- wildlife management areas

Wiscons in

- scientific and natural areas

- wildlife areas

Northeast

Connecticut

- natural areas

- Fish and Wildlife Areas

- sanctuaries

- fish and wildlife management areas

Maine

- critical areas

- wildlife management areas

- game management areas

Massachusetts

- wildlife sanctuaries

- wildlife management lands

New Hampshire

- wildlife management areas

New Jersey

- natural areas

- wildlife management areas

New York

- preserves and unique areas

- wildlife management areas

Pennsylvania

- natural areas

- game lands

Rhode Is land

- none

Vermont

- fragile areas 
- wildlife management areas

- waterfowl management areas

- natural areas (established prior to NWPA)

Southeast

Georgia

- natural areas

- wildlife management areas (state-owned only)

Maryland

- wildlands

- wildlife management areas

North Carolina

- natural areas

- natural heritage areas

- gamelands (state-owned only)

South Carolina

- heritage areas

- game management areas (state-owned only)

Virginia

- natural areas

- wildlife management areas

ENVIRONMENTAL SCREENING VARIABLE (STEP 2)

Statutory review of state forest language established comparability in all 17 states with the nondisqualified components of the National Forests Lands. However, irreconcilable conflict-of-use could not be determined for purposes of region-to-area screening. As such, state forests will be treated like the national forests as a Step 2 screening variable in all 17 states.

NO REGION-TO-AREA SCREENING STATUS

Certain state-protected land categories proposed by various states are not be if given region-to-area screening status. This determination was made on the basis that (1) there was no comparably significant Federal land category, 
no state statutory authority was available to establish comparable significance, or (3) based on available statutory authority determinations of comparable significance or irreconcilable conflict could not be made at this time. Therefore, the following categories are being deferred from region-to-area screening and are being given no status in the methodology at this time.

North Central

Michigan

- water access sites

- wildlife sanctuaries

Minnesota

- fisheries lands

- trails

- department of military affairs lands

- game refuges

Wiscons in

- trails

- boat access sites

- fishery areas

- watersheds

- game farms

- fish hatcheries

- Department of Military Affairs lands

- wildlife/game refuges

- trust lands

- gift lands

- youth camps

No statutory authority available for determination

- wilderness areas

- wild areas

- wilderness lakes

- wild lakes

- rights-of-way

- habitat preservation 
- extensive wildlife habitat management and remnant fishery areas

- public use natural areas

Northeast

Connecticut

- indian lands

- miscellaneous wildlife areas

Massachusetts

- watersheds

- conservation lands

- junior conservation camps

- game farms

- fish hatcheries

Maine

- fish hatcheries

New Hampshire

- flood control areas

New Jersey

- natural land trust

Rhode Island

- fish hatcheries

- Narragansett Indian Land Management Corporation Areas

- other state-controlled land (e.g., colleges)

- groves/picnic areas

- public fishing/boat access areas

Vermont

- natural areas - established after enactment of NWPA

Southeast

Georgia

- public fishing areas

- public hunting areas - no statutory authority available for determination

- wildlife management areas (non-state-owned) 
Maryland

- heritage areas - no statutory authority available for determination

North Carolina

- trails

- game lands (non-state-owned)

South Carolina

- fishing lands

- wilderness areas - no statutory authority available for determination

- game management areas (non-state-owned).

As stated previously, these land categories, as well as numerous others, will be considered in later phases of the CRP screening, where the detailed analysis necessary to determine their effect on repository siting on these land categories, is more appropriately conducted. 